\title{
Constructing and Unsettling Utopia: The Hundertwasser-Haus, Vienna and Nant-y-Cwm Steiner School, Pembrokeshire
}

\author{
Kraftl, Peter
}

How to cite:

Kraftl, Peter (2005) Constructing and Unsettling Utopia: The Hundertwasser-Haus, Vienna and Nant-y-Cwm Steiner School, Pembrokeshire. Doctoral thesis, Swansea University.

http://cronfa.swan.ac.uk/Record/cronfa50753

Use policy:

This item is brought to you by Swansea University. Any person downloading material is agreeing to abide by the terms of the repository licence: copies of full text items may be used or reproduced in any format or medium, without prior permission for personal research or study, educational or non-commercial purposes only. The copyright for any work remains with the original author unless otherwise specified. The full-text must not be sold in any format or medium without the formal permission of the copyright holder. Permission for multiple reproductions should be obtained from the original author.

Authors are personally responsible for adhering to copyright and publisher restrictions when uploading content to the repository.

Please link to the metadata record in the Swansea University repository, Cronfa (link given in the citation reference above.)

http://www.swansea.ac.uk/library/researchsupport/ris-support/ 
Constructing and Unsettling Utopia: The Hundertwasser-Haus, Vienna and Nant-y-Cwm Steiner School, Pembrokeshire

\section{Peter Kraftl}

Submitted to the University of Wales in fulfillment of the requirements for the degree of Doctor of Philosophy

University of Wales Swansea 


\section{Summary}

The thesis draws on a range of theoretical and methodological approaches to interrogate some of the ways in which the idea of 'utopia' is relevant to contemporary socio-spatial practices. It does this in two, inter-linked ways. Firstly, the notion of utopia is retheorised following a re-reading of utopian literature through certain 'nonrepresentational' and post-structural theories (performativity, Actor Network Theory). Secondly, the thesis explores the complex relationship between architecture and utopia. I promote a number of new ways in which studies of architecture and utopia can be related. Crucially, I do this through a 'critical geography' of two ecological buildings: The Hundertwasser-Haus, Vienna, and Nant-y-Cwm Steiner School, West Wales. This meant examining - through mixed, ethnographic methods - the complicated 'performative' meanings that builders and users constructed. This is particularly important because these two examples, and ecological architecture in general, can be associated with various utopian features, but have not yet been explored through a more 'critical' approach. The research drew together these strands to provide a number of often surprising conclusions. The most important was that in addition to (re)presenting visions of comfort, order or political critique, much of the effect and attraction of utopias is that they can in many ways be fundamentally unsettling, discomforting and un-homely. Focussing on three specific themes - difference, the homely and community - the thesis demonstrates this empirically by arguing that utopias are contingent, painful, embodied, anxiety-inducing, momentary, co-relationally produced with non-human actants (including ruination!), and require a tremendous amount of work, whether euphoric experiences of 'escape' or ethical versions of the 'good'. It highlights important ways in which critical geographies of architecture can collect and disperse a variety of emotional, ethical and material concerns (such as utopia or community), and are hence well-suited to the complex demands of contemporary theories and everyday lives. 


\section{DECLARATION}

This work has not been previously accepted in substance for any degree and is not being concurrently submitted in candidature for any degree.

Signed. (candidate)

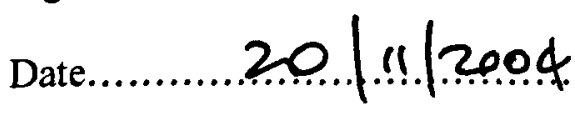

\section{STATEMENT 1}

This thesis is the result of my own investigation, except where otherwise stated.

Other sources are acknowledged by references contained in the text and footnotes, both giving explicit references. A bibliography is appended.

Signed........................................... (candidate)

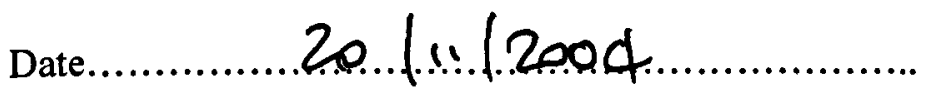

\section{STATEMENT 2}

I hereby give consent for my thesis, if accepted, to be available for photocopying and for inter-library loan, and for the title and summary to be made available to outside organisations.

Signed.

(candidate)

Date................. $20 / 1012004$ 


\section{Contents}

Summary

Declaration and statements

Contents

List of figures and plates

Acknowledgments

1. Introduction

1.1 This thesis: context

1.2 Case studies

1.3 Aims and structure

2. 'Traditional' utopias, and difference, the homely and community

2.1 Introduction

2.2 Utopia and function

2.3 The political function of utopias

2.4 Other functions of utopias

2.5 Form/content: space, architecture and utopia

2.6 The form of fiction

2.7 Architecture and planning: the spatial form of utopia

2.8 The problem of (urban) space

2.9 Conclusion

3. The utopian unsettling

3.1 Introduction

3.2 Revolution

3.3 Work and community

3.4 The un/homely: Freud and Heidegger

3.5 Ruin(ation) and the agency of 'nature'

3.6 Sacrifice, terror, euphoria

3.7 Romanticism and the flâneur

3.8 Risking 'public space' and 'community'

3.9 Performativity, ANT, difference and the utopian unsettling

3.9.1 Difference/différance

3.9.2 Performativity, ANT and an unsettling utopian ethics

3.10 Conclusion

4. Critical geographies of architecture: collecting/dispersing buildings

4.1 Introduction 
4.2 'Reading' architecture

4.3 'Critical geographies of architecture'

4.4 Gieryn's 'moments' and other approaches

4.5 Actor Network Theory

4.6 Performativity (and non-representational theory)

4.7 Collecting/dispersing buildings: translation

4.7.1 Collecting and dispersing the Hundertwasser-Haus and Nant-y-Cwm: texts

4.7.2 Practices

4.7.3 Summary: what about utopia?

4.8 Conclusion

5. Methodology

5.1 Introduction

5.2 A note on collecting/dispersing and material-semiotic methods

5.3 The Hundertwasser-Haus

5.3.1 Texts

5.3.2 Ethnographic methods

5.3.3 Interpreting ethnographic material

5.3.4 Problems

5.4 Nant-y-Cwm School

5.4.1 Texts

5.4.2 Ethnographic methods

5.4.3 Interpreting ethnographic material

5.4.4 Problems

5.5 Conclusion

6. Introducing the Hundertwasser-Haus and Nant-y-Cwm: constructing 129 'different' buildings

6.1 Introduction

6.2 The Hundertwasser-Haus

6.2.1 The house

6.2.2 Context and influences

6.2.3 Movement and the Hamburg Line

6.2.4 Nature and artistic creativity

6.2.5 Hundertwasser's other built projects

6.2.6 The Hundertwasser-Haus in the context of Viennese architectural history

6.2.7 Press responses to the Hundertwasser-Haus: difference

6.3 Nant-y-Cwm Steiner School

6.3.1 The school

6.3.2 Rudolf Steiner and anthroposphy

6.3.3 Influences and Day's written work

6.3.4 Work, health and process-based design

6.3.5 Parents and the local area

6.3.6 Day's other projects 
6.3.7 Press attention and difference

6.4 Conclusion

7. Living with difference: The Hundertwasser-Haus

188

7.1 Introduction to chapters $7 \& 8$

7.2 Introduction: Hundertwasser-Haus

7.3 Living with an artwork

7.4 Living with the press and tourists

7.4.1 The press at the house

7.4.2 Tourists at the house

7.5 Conclusion: Hundertwasser-Haus

8. Living with difference: Nant-y-Cwm School

8.1 Introduction: contextualizing the difference of Nant-y-Cwm

8.2 The buildings

8.3 A general 'culture' of difference at Nant-y-Cwm

8.4 'Right' difference, a 'right education' and a 'fitting' time

8.5 Conclusion: Nant-y-Cwm

8.6 General conclusion to chapters $7 \& 8$

9. Constructing home: The Hundertwasser-Haus

9.1 General introduction to chapters $9 \& 10$

9.2 The Hundertwasser-Haus: Introduction

9.3 Home and identity

9.4 Practical considerations

9.5 Everyday moments or utopian escape?

9.6 Conclusion

10. Constructing home: Nant-y-Cwm

10.1 Introduction: Nant-y-Cwm

10.2 Constructing and compromising a homely school

10.3 Performing a 'homely' school: Structuring the day

10.4 Children's use of the school

10.5 From constructions of an ideal to ideal constructions: utopian moments

10.6 Conclusion

10.7 General conclusion to chapters $9 \& 10$

11. Constructing community spaces: The Hundertwasser-Haus

11.1 Introduction to chapters $11 \& 12$

11.2 Introduction: Hundertwasser-Haus 
11.3 The original community

11.4 The house's openness

11.5 Personal friendships

11.6 Conclusion

12. Constructing community spaces: Nant-y-Cwm School

12.1 Introduction

$12.2 \mathrm{~A}$ 'pioneering spirit'

12.3 Community today

12.4 The future of the school (community)

12.5 Conclusion: Nant-y-Cwm

12.6 General conclusion to chapters $11 \& 12$

13. Conclusion

13.1 Unsettling utopia

13.2 A critical geography of architecture

13.3 The Hundertwasser-Haus and Nant-y-Cwm

13.4 Future work and closing comments

Appendices

Appendix 1 Interview schedule for the Hundertwasser-Haus Appendix 2 Interview schedule for Nant-y-Cwm Steiner School Appendix 3 List of interviews at the Hundertwasser-Haus Appendix 4 List of interviews at Nant-y-Cwm

Bibliography 


\section{List of figures and plates}

$\begin{array}{ll}\text { List of figures } & \text { Page }\end{array}$

Figure 6.1 The Hundertwasser-Haus: location and local sketch map 131

Figure 6.2 Nant-y-Cwm School: location and local sketch map 162

\section{List of plates}

Plate 1.1 The Hundertwasser-Haus

Plate 1.2 Nant-y-Cwm Steiner School

Plate 6.1 The Wintergarden, Hundertwasser-Haus 134

Plate 6.2 Corridor, Hundertwasser-Haus $\quad 135$

Plate 6.3 Loewengasse façade, Hundertwasser-Haus $\quad \mathbf{1 3 6}$

Plate 6.4 Kegelgasse façade, Hundertwasser-Haus $\quad 137$

Plate 6.5 Kegelgasse, cafes and surrounding buildings, Hundertwasser-Haus 138

Plate 6.6 Shopping village opposite Hundertwasser-Haus 139

Plate 6.7 Kegelgasse, pedestrianised area, Hundertwasser-Haus $\quad 139$

Plate 6.8 Tourists outside the Hundertwasser-Haus $\quad \mathbf{1 4 0}$

Plate 6.9 KunstHausWien, near the Hundertwasser-Haus

Plate 6.10 Main school, classroom, Nant-y-Cwm School $\quad 164$

Plate 6.11 Main school, entrance, Nant-y-Cwm School 164

Plate 6.12 Kindergarten, interior close-up, Nant-y-Cwm School 165

Plate 6.13 Kindergarten, exterior, Nant-y-Cwm School 167

Plate 6.14 Kindergarten, interior, Nant-y-Cwm School $\quad 167$

Plate 6.15 Playground, Nant-y-Cwm School $\quad 168$

Plate 6.16 Ffald-y-Brenin retreat centre, Pembrokeshire 182

Plate 10.1 Daniel's sketch of the school $\quad \mathbf{2 7 0}$

Plate 10.2 Joanna's drawing of the woodland area $\quad \mathbf{2 7 3}$

Plate 10.3 A painting of the Kindergarten $\quad 274$ 


\section{Acknowledgments}

Firstly, I would like to sincerely thank my joint supervisors, Pyrs Gruffudd and Marcus Doel for their help, interest and stimulating discussions with regards to the thesis and all aspects of academic life. Thanks also to Loretta Lees and Keith Halfacree for their insightful comments on the thesis, and the opportunity to explore the different themes it covers.

Secondly, I gratefully acknowledge all the help and kindness my family have shown me, and the interest they have all taken in my work. My many thanks to Mum and Dad for their support, continued interest and encouragement. Huge thanks to my fiancée, Juliet, for her enduring and optimistic encouragement, and helping me through the (few) stressful times, particularly in the months writing up. Thanks also to my brother Martin, Grantie, Lyn, Claire and Neil.

Thirdly, thanks to all those at the Department of Geography in Swansea whose friendship and varied insights have all benefited my work greatly, and made my time in Swansea hugely enjoyable! Thanks to Dave "Beano Boy" Matthews for putting up with me in the same office for three years, humourous support, and numerous new and challenging office sports! Thanks also to the other members of the office, Chris Anderton, Huw Jones and Larch Juckes-Maxey for many 'stimulating' discussions. I would also like to thank Aimée Sayer, Kath Hawkes, Andy Tallon, Pete Mackie, Rosemary Bromley, Vaughan Robinson, Keith Halfacree (again!), Phil Metcalfe, Rob Stacey and Mark Llewellyn. For their help with various aspects of my thesis and teaching, many thanks to Alan, Yvonne, Gill, Anna, Nicola and Ellis. Outside Swansea, thanks to Keith, Andy, Vicky, Steve and Amelia.

Finally, I wish to wholeheartedly acknowledge the friendly and interested support of all those who agreed to take part in, and help me organize, my research at the Hundertwasser-Haus and Nant-y-Cwm Steiner School. In Vienna, thanks to Andrea Fuerst and Joram Harel at Buero Harel, Pfarrer Zeck in Baernbach, the residents of the Hundertwasser-Haus, and those who took part in E-Mail discussions. In Pembrokeshire, particular thanks to Phil Forder for helping to organize interviews and research time at the school, but to all the other teachers, founders, ex-pupils, parents and pupils who took part in the research, as well as to Christopher Day for an invaluable initial interview. 


\section{Chapter 1 Introduction}

\subsection{This thesis: context}

This thesis explores the notion of utopia at both a broad, historical and conceptual scale, and through empirical work at two buildings. Those buildings are the HundertwasserHaus in Vienna, and Nant-y-Cwm Steiner School in Pembrokeshire, Wales. Both are examples of 'ecological' or green architecture. Utopia - the term coined by Thomas More in 1516 (1988) to describe the imagination of perfect yet unattainable places became an unpopular term during the twentieth century due to associations with totalitarian regimes, and its perceived irrelevancy. However, the term has enjoyed a resurgence in recent academic debate, and for many commentators utopias are found in more diverse forms than ever before (Geografiska Annaler, 2003; History of the Human Sciences, 2003; Kumar, 2003; Parker 2002a). Following pioneering work that engaged with post-structuralist and feminist theory (Levitas, 1990; Sargisson, 1996; Sandercock, 1998), academics from architecture, geography, literature studies, organization studies, philosophy, planning and sociology, have stressed with increasing force that utopias still have a part to play in debates ranging from ethics, to politics, to the consumer society, to urban planning (Lees, 1997; Law and Mol, 2002; Baeten, 2002b; Yacobi, 2002). The problematic role of space in utopian visions has provided one of the most interesting debates of late (Harvey, 2000; Bauman, 2003). Moreover, for many, "Architecture has been the most utopian of all the arts" (Kumar, 1991: 14); and ecological architecture in particular has a distinct utopian edge (Edwards, 2001). Two recent initiatives, the RIBA's (Royal Institute of British Architects) 'Building Futures'1 website, and the 'Latent Utopias'2 exhibition in Graz, Austria, are contemporary illustrations of this observation. This double acknowledgment of the importance of space has encouraged me to re-visit the relevance of space to the often intangible concept of utopia - and

\footnotetext{
${ }^{1}$ The name of a recent initiative by RIBA. See www.riba.org.

2 The exhibition, which I attended, ran from 01/2003-03/2003. Many popular architects exhibited, including Greg Lynn, Co-op Himmelb(l)au and Zaha Hadid.
} 
particularly that most concrete of arts, architecture - in light of various developments in especially geographical thought.

With geographers' enduring interest in architecture, and people's everyday use of spaces, have come calls for a 'critical geography' of architecture (Lees, 2001). Using two buildings that are surrounded by utopian debate (see below), I attempted to explore how critical geographies of these buildings - and hence critical geographies of utopian themes - might help us construct many and varying ideas about contemporary experiences of utopia. This is reflected in my largely ethnographic methodological approach (Chapter 5). Lees' geography draws on a number of recent academic debates, which I attempt to re-configure in this thesis. First, Lees retains an interest in the symbolism of architectural design, and the power relations which lead to the emergence of a building in space (see also Dovey, 1999). Second, however, Lees, focuses on the non-representational practices of everyday life - performances, mundane routines - that go on at buildings, and from which meanings are made (also Thrift and Dewsbury, 2000). Third, others (especially Gieryn, 2002) highlight the importance of materiality to research on buildings - the place of non-human actors such as bricks and mortar, or even buildings themselves as agents in a non-hierarchical, Actor-Network Theory (ANT) sense (Law, 2002). In particular, I argue that these debates can be re-read, and connected, to highlight how the contingency of architectural use - symbolic, performative and material in a conjoined way - can provide radical new insights into the various ways that utopias are constructed and experienced in the context of people's lives at buildings.

As well as these general contexts, I am also concerned with particular themes that straddle work on utopia, space and architecture: those of difference, the homely and community. These emerged as key elements of people's experience of the Hundertwasser-Haus and Nant-y-Cwm, and are consistent in debates on utopia since the nineteenth century at least, although, as I show, they require re-thinking in light of insights from 'non-representational' theory (Thrift, 2000a). The context for this thesis is thus very broad, and touches on the political, ethical, emotional and practical 
implications of utopia which emerge from these three themes. Debates about difference are still current in geography (Harvey, 1996), as are those on community (D.M. Smith, 1999). The notion of 'home' is perhaps less fashionable (but see Bachelard, 1994 [1967] for an earlier example, or the themed issue of Antipode, 2003, 35[3]), and requires most re-thinking in connection with non-representational theory. Nevertheless, I argue that all three are inter-related strands that contribute to the central conceptual argument of the thesis, which appears in Chapter 3. In that chapter, I argue that utopias, as much as being comforting, homely, escapist, perfect fantasies, can also be unsettling, dis-comforting and un-homely - often in an architectural sense - if we follow how they are experienced and lived. In general, as well as non-representational theory, the thesis draws on Nietszche, Heidegger and Freud amongst other theorists, illustrating the breadth (and depth) of contemporary utopianism, and the inter-disciplinary nature of my arguments. Overall, the thesis emerges from a need within the literature to engage more fully with the performativity of utopia (drawing on Grosz, 2001 and Pinder, 2002), to interrogate the interaction between (ecological) architecture, its use, and utopia, and to develop critical geographies of architecture in new directions. This will begin to extend and give consistency to an important yet poorly understood element of utopias: the utopian unsettling.

\subsection{Case studies}

My two case study buildings are the Hundertwasser-Haus in central Vienna, Austria, and Nant-y-Cwm Steiner School in Pembrokeshire, West Wales. More detail on the buildings and their architects can be found in Chapter 6. However, I will briefly introduce them here. The former building was designed by the Austrian artist-architect, Friedensreich Hundertwasser (1928-2000). He was an ardent critic of 'Modernist' architecture, for him characterized by Loos, Le Corbusier and the many copies of their work found in box-like social housing projects all over the world. He sought the virtual banishment of the straight line, to be replaced with colourful, plant-covered designs where residents were free to express themselves by decorating walls however they wished (including outside). Although an artist, he was commissioned in the 1970s to 
'heal' various Modern structures with his now familiar, colourful style. With this background, the Vienna Gemeinde (Council) asked Hundertwasser to re-design a social housing block on the corner of Loewengasse and Kegelgasse in Vienna's 3. Bezirk (district). Situated about fifteen minutes' walk from the city centre, it has become an icon of Vienna's late twentieth-century architectural history. The house has a total of 52 flats, each of which is different, with wavy walls, terraces at all levels, and trees planted on roofs and in inset external wall cavities (Plate 1.1). Perhaps one of the house's greatest effects on residents' lives is the mass of tourists who flock to the house each year.

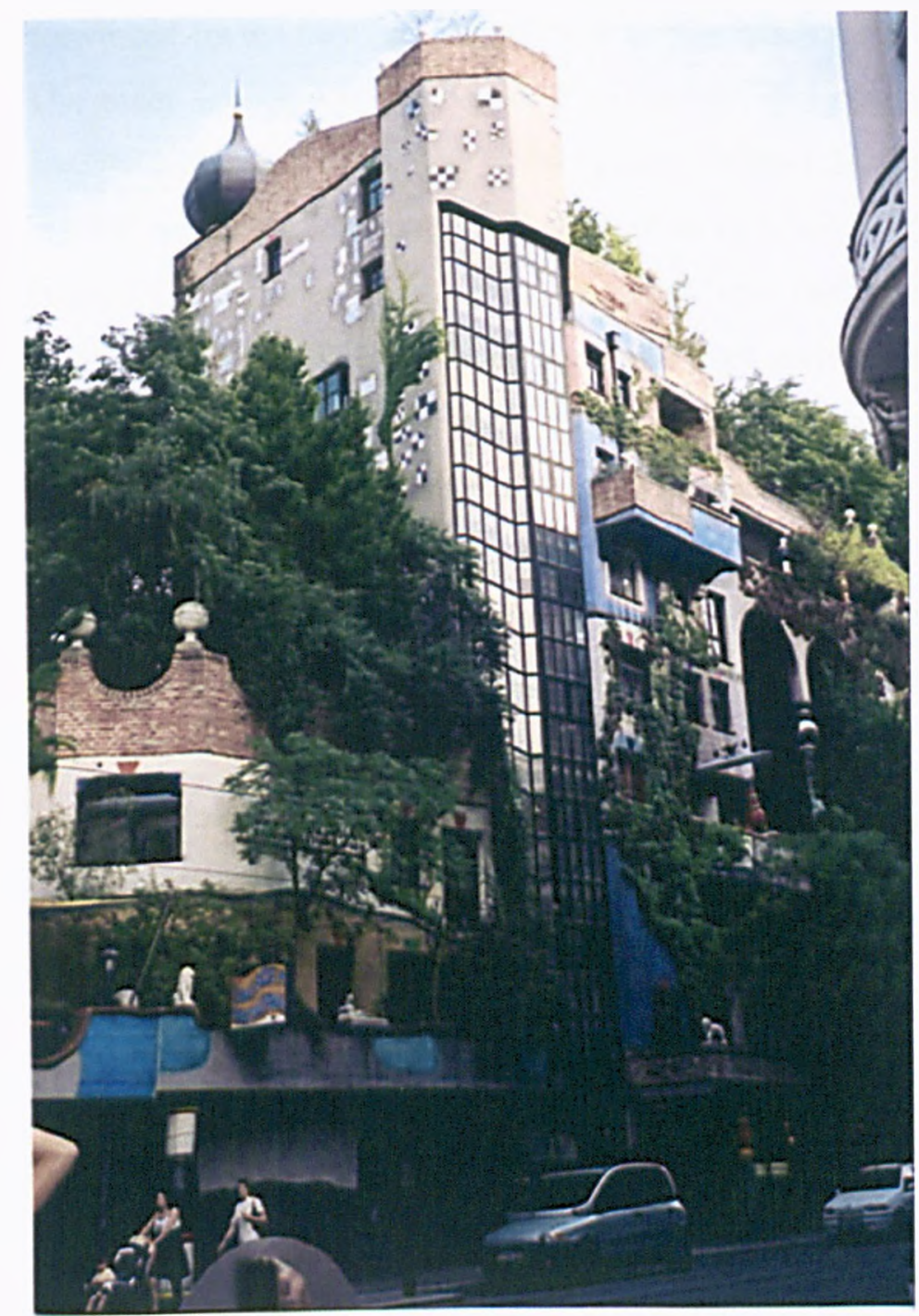

Plate 1.1 The Hundertwasser-Haus, Vienna, Loewengasse façade. Author's photograph. 
Nant-y-Cwm Steiner School was begun in 1979, when a group of parents who were seeking alternatives to mainstream schools forged an interest group geared around the writings of anthroposophist Rudolf Steiner (1909: see chapter 6 for more). Steiner education provides a holistic teaching curriculum, based around the stages of a child's physiological and psychological development, and is taught using art- and movementbased methods. This became the chosen curriculum. Christopher Day, the architect, was also one of the founding parents. His design philosophy is again broadly ecological, but also based in Steiner's recommendations for architectural design, and specifically schools. He too is critical of Modern architecture and the straight line, and again convinced by the healing properties of a fully environmentally harmonious architecture. The main school was renovated from an old Victorian Schoolhouse, largely through parents' volunteer work. The Kindergarten (Plate 1.2), a new-build structure, was built in 1990 as the school's pupil body expanded to around 100 (there were roughly 50 as of 2004). The Kindergarten, with its grass roof and circular, enclosing, soft, pink classrooms is best known, receiving visits from architectural students as an example of ecological architecture. In sum, the buildings, education, and community should be conceived holistically in order to provide a 'correct' version of childhood and education.

I chose these two buildings for many reasons. First, various brands of ecological architecture in general are doubly 'utopian', as indicated above. The discourses and designs of these two contemporary ecological architects, and their shared critiques of Modern (utopian) architecture in themselves provide fascinating insights into contemporary constructions of utopia in ecological design. Each of them, and particularly Hundertwasser, makes particular comments about utopia and paradise which are folded into many of the meanings and practices at the two buildings. 


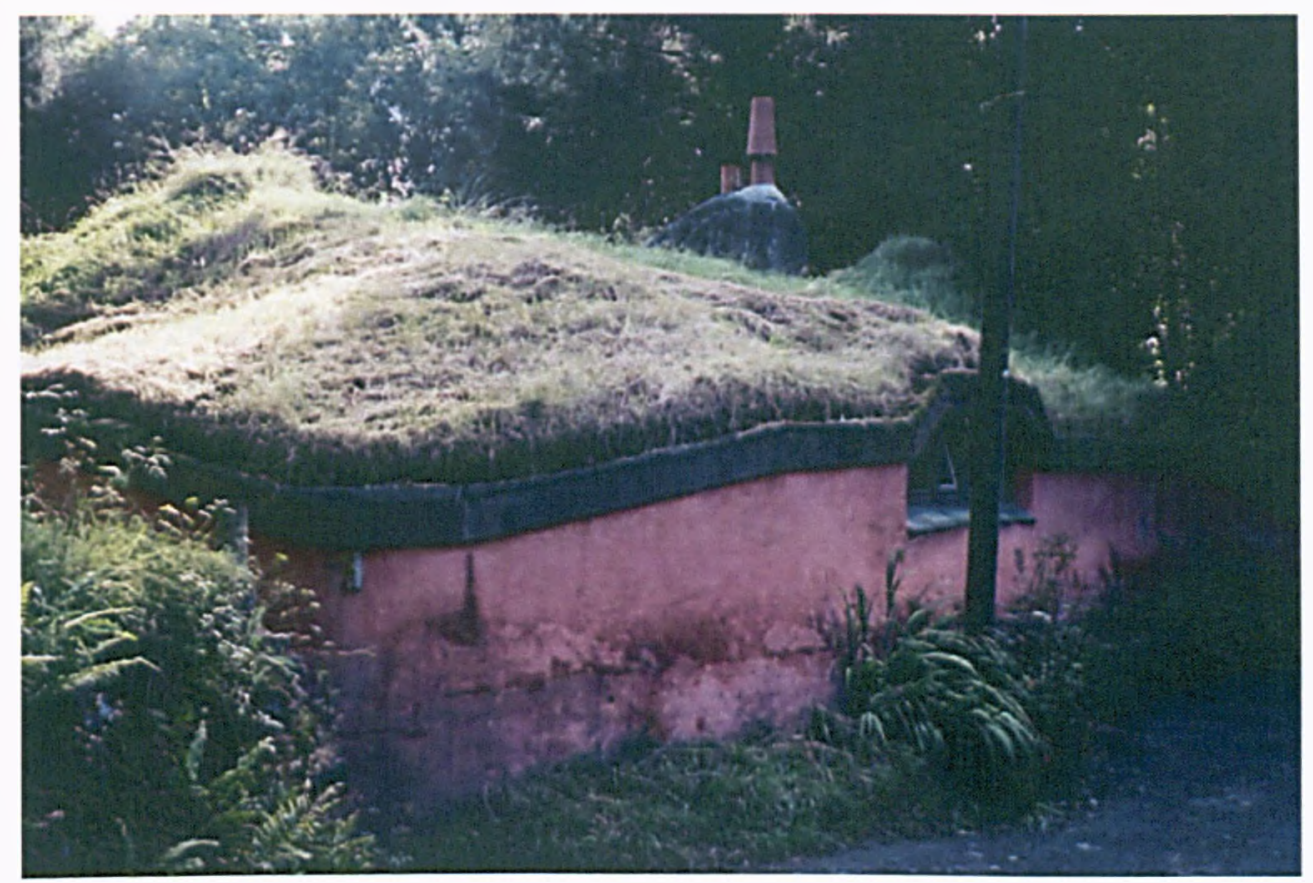

Plate 1.2 Nant-y-Cwm Steiner School, Pembrokeshire: Kindergarten. Author's photograph.

Second, there are some striking similarities in the ways that space and the architectural process are conceived, from the idea of the 'Third Skin', to the 'healing' and creative properties architecture can hold (Chapter 6). Third, the processual conception of architectural design these two architects promote, although not always explicitly utopian, moves from purely spatial, static conceptions of buildings (or ideal places) to more dynamic and thus inclusive versions favoured by feminist and post-structuralist commentators in very recent writings on utopias. Fourth, this processual notion means that for each architect that a building is never finished, even after it has been 'built': only then do the users begin to imbue it with meaning, whether material, performative or emotional. This enticed me to follow aspects of the lives of these particular buildings, and, with them, to construct critical geographies at these new sites. Fifth, each of these buildings has been conceived as 'different' in a variety of ways. For example the 'processual' idea of buildings' lives (in fact inherent to life at any building) is reinforced by the ongoing construction of home-like spaces there - whether house or school. Morever, each has been identified with strong communities through those constructions (my three key themes). 
There are also a couple of useful disparities between the buildings. One is in an 'urban' location, the other 'rural'. The prospects for ecological architecture, utopia and related concepts like community in these different sites thus make interesting comparisons, as ethnographers seek to understand the emergence of similar concepts and themes at two or more very different sites (Katz, 1994). Another disparity is the context in which the buildings were constructed. Although freedom was given to the labourers on site, the prospective inhabitants of the Hundertwasser-Haus were not involved in its construction. The school (also a much smaller-scale building) was built by the community there, on its own initiative. At both, however, it is now interesting how the 'original' community and some of the cultures they tried to instill at each building have 'left' (not always literally). Moreover, those feelings are now becoming contested in many, similar ways - often through the buildings, despite their short histories (both are around 20 years old).

At times, my discussion of the two buildings does not bear much resemblance to that on utopia, as I attempt to do justice to the complexities of life at the two buildings - the fruits of my critical geographies. There are distinct points at which various versions of utopia emerge - in the architects' texts, in interview material, and in observations. Yet I attempt to highlight how these are folded into each other, in chains or collections of heterogeneous elements. Sometimes, when people collect these together, they might provide an economic history of the school, far removed from utopia. Some elements I describe are more 'practical': perhaps they say more about architecture, perhaps they are stimulated by debates on architecture that take us far away from the buildings. At other times, these elements come to be defined as utopian, paradisiacal, 'good' or ideal - and it is the appearance and experience of those instances in which I am interested. I demonstrate how these utopian moments and discourses emerge in context, and sometimes, when followed carefully, how seemingly 'non'-utopian moments actually feed into utopian experiences at later (or earlier) points. I try to flag up these connections throughout the thesis, through my persistent consideration of difference, the homely and community, through my use of utopia as a background to these buildings (or a mid-point at which they are encountered: see Deleuze and Guattari, 1983), and in the concluding chapter. Yet sometimes, and this is the point, it can be hard, if not impossible, to make 
sense of these messy geographies (Harrison, 2000, 2002; Lees, 2001)! This might render discussion a little complicated at times, although I hope that the conclusion to each chapter clarifies my arguments without over-simplifying the inter-connections that run throughout my argument.

I should add one other important note: although both buildings were examples of ecological architecture, and I asked users about this theme, ecology and environment were rarely as important as the three themes I do focus on. I did try to discuss this in interviews, yet it was the themes of difference, the homely and community that were of most interest and relevance to our discussions. I am aware that ecology is an important element of both buildings' difference, and the notion of home: but in remaining as 'faithful' as possible to interview and observational material, and hence for reasons of space and coherence, I feel it is suitable to keep discussion concerning ecology to a minimum.

\subsection{Aims and structure}

This thesis has three aims, which attempt to interrogate the notion of utopia through contemporary utopian and architectural theory, and through these two buildings in particular. I have already etched out some of the main arenas and themes I intend to cover, and the main 'gaps' I intend to consider, and summarise these as follows. My first aim is to undertake a re-reading and re-construction of the notion of utopia. As I have already mentioned, post-structuralists and non-representational theorists have begun to do this, yet I argue that this requires further work, in particular to expand both the historical, and contemporary, importance of utopia. A key element of this aim is to demonstrate theoretically and empirically that utopias and dystopias, and utopias and reality, may not be opposed or disconnected - as some authors have begun to suggest (Baeten, 2002b). I therefore begin to think about the ways in which purportedly discomforting or unhomely experiences or desires might in fact be utopian in both emotional and ethical terms, in order to expand the ways we think about utopias. My second aim is to undertake this by thinking about utopia through architecture, both 
conceptually and empirically. I watch where and how the idea of utopia emerges in (a spatial) context, not merely as a finished, separate form. This involves an ethnographic, critical geography of architecture, following through the insights of non-representational theory in theory and research practice, to construct a sense of the meanings and uses people make of buildings which are in many senses seen as ideal or utopian. Hence I ask: what utopian (or non-utopian) situations, meanings, emotions and ethics emerge, and how are these related to those 'texts' that originally surrounded the buildings' designs? I therefore also attempt to add to and refine Lees' arguments for a critical geography of architecture. My third aim is to contribute to those 'geographical' and nongeographical literatures on which I draw (performativity, ANT, deconstruction) to stress the importance of a re-formulated notion of utopia to those literatures. I also aim to begin an 'ethical' critique of these literatures through retaining a focus on the emergence of ideas about the utopian 'good'.

The thesis begins in Chapter 2 with a review of recent work on utopia from geography, and a variety of other disciplines. There I explore what I term for simplicity 'traditional' concerns of utopias, through definitions of their form, content and function. I discuss the fundamental importance of space and architecture to utopia, broadly reviewing conceptual approaches to utopia which focus on urban space in particular, and providing a brief review of twentieth-century utopian architectural trends. In Chapter 3, I detail the main conceptual arguments of my thesis, drawing on the gaps identified in Chapter 2, arguing for the various ways in which utopias can be unsettling, through a disparate band of theorists ranging from Nietszche to 'performative' geographers. Chapter 4 depicts my interpretation of a critical geography of architecture, in particular through a re-reading of ANT and performativity begun in Chapter 3. Through the notion of collecting/dispersing, I demonstrate how a translation of emergent ideas or emotions (such as utopia) can come about through critical geographies which engage with changing mixtures of texts, materials and practices, sensitive to the particular buildings in question. The various methods I employed to achieve this are discussed in Chapter 5 , which is followed by seven largely empirical chapters based around my key themes of difference, the homely and community. These interpret the geographies of the 
Hundertwaser-Haus and Nant-y-Cwm in the context of my key themes and debates. In chapter 6, I provide more background on the physical construction of both buildings, in the context of their architects' work and the trends in which they can be placed. I begin to explore the theme of difference here, following how the buildings are embroiled in quite simplistic aesthetic debates about originality and art, drawing largely on press material. The following two chapters complicate the notion of difference through observational and largely in-depth interview material at each building. Chapters 9 and 10 deal with the importance of 'homeliness' or making home at each building in the face of such difference, and in the face of the school's obvious position as not-a-home, and the house as a tourist attraction. Chapters 11 and 12 explore the importance of community, although are weighted towards the school where that theme was far more prevalent. As I mentioned above, each of these chapters is inter-related, and only at times deals with the thesis' main aim. Moreover, I have separated each theme into couplets dealing with each building (for instance, Chapters 9 and 10 explore 'home' at the house, then the school). I separated these discussions in order to clarify the points that concern each building, but I hope this renders a comparison of the similarities and differences between them easier to follow. However, as I attempt to show in the final chapter, the notion of utopia emerges in complex chains or collections of events at both of these buildings, in ways which allow more general conclusions to be drawn. These exemplify, inform and extend still further many of my major arguments in Chapter 3, and provide indications as to the usefulness of conceiving utopia in the ways that I highlight in this thesis. 


\subsection{Introduction}

The main aim of this thesis is to construct a new sense of utopia, through a critical geography of architecture, and of two buildings. This chapter reviews what I term the major 'traditional' concerns of utopias - perfection, impossibility, comfort and the 'good' life. These often rely heavily upon spatial formations such as architecture and planning, hence the rationale for joining utopia with architecture in this thesis, and (in the case of Modernist architecture) with many themes of which Hundertwasser, Day and people at their buildings are well aware. I also pick on three themes that I argue are conspicuous in many versions of utopia - themes that also helped both respondents and myself understand everyday processes at the Hundertwasser-Haus and Nant-y-Cwm. These are difference, the homely, and community. In the next chapter, I then re-read these themes to highlight various versions of the utopian that I argue are fundamentally unsettling. However, I demonstrate here and in later chapters how notions of difference, the homely and community are particularly important to more strongly identifiable, traditional utopias. They are then re-worked in the performative, contingent, material versions I present and contextualise in Chapter 3 onwards.

Utopianism - imagining future, better or perfect worlds - has in its long history seen a mixture of desire, hope, and usually disappointment. Whether pure flights of fancy, or explicit criticisms of the 'status quo', such imaginings emerge from particular historicogeographical contexts, and are often constrained by discourses contemporaneous to those contexts. For Levitas (2003: 3), "They are intrinsically linked to the concerns and assumptions of modernity." In late- or post-modernity, however, the context has apparently changed. In particular, the fragmentation (Saurup, 1993) and dis-location (Olalquiaga, 1992) that are felt to characterise postmodernity have signalled to some extent the demise of totalising visions of the future, better society, rooted in a stable, bounded community space or ideal city. But what is utopia? 
Most texts on utopia are concerned with its fundamental nature - its definition - and in some ways, this thesis is little different. However, in seeking to explore the relevance of utopia to contemporary practices, I am less concerned with a definition. Instead, I seek to uncover how the idea of utopia - not necessarily called such - and emotions and practices related to the construction of happy, perfect and/or euphoric event-spaces, are all evoked. The difficulty of identifying what is utopian is ever-present when evading definition, or leaving it open-ended as do most contemporary commentators (Levitas, 1990; Sargisson, 1996; Sandercock, 1998). A similar difficulty befalls Freud (see below) when he attempts to depict the unheimliche (uncanny). Almost all social theorists encounter this problem when attempting to find a general explanation or theory for an emotion or phenomenon. This of course leads to the caveat that any attempt to represent - to name a form or process 'utopia' - is at best bewildering, at worst futile (Thrift and Dewsbury, 2000). Thus I do not seek any particular definition of utopia (even an openended one, although this is the best we have). Instead, I am concerned with what utopias can $d o$, and with how ideas related to the utopian (perfection, comfort, homeliness, revolution) are contingent and emergent. I attempt to follow how the word utopia becomes imbued with event-specific qualities, and how the world or certain assemblages therein might become utopian.

Nevertheless, this act requires some definition(s), particularly where the idea of a utopian 'tradition', involving certain actions or emotions, is perhaps the only way in which any (and this) text on utopia can forge a semblance of coherence. Most texts define utopia in terms of its content, form and/or function, although many cite the latter as its crucial characteristic (Levitas, 1990). Almost all commentators begin with the root of the word - St. Thomas More's 'Utopia' (More, 1988 [1516]). This combines the eutopian (perfect place) with the outopian (unattainable place - nowhere) (Olin, 1989; Carey, 1999). Although a satire, ridiculing Renaissance religious-scientific visions of the future, the word has since been used to define "... literary fictions, satire, fantasy, science fiction, religious or secular paradises, political theories, political programmes and manifestos, small-scale attempts to create ideal communities and nationwide attempts to 
create the good society..." (Levitas, 1990). Some of these, particularly spatial forms such as ideal cities or buildings, have been inspired by More's utopia, although there is an identifiable more general tradition and development of the term along with the history of modernity (Bauman, 2003). Here the 'real world' and utopia are often conceived dialectically (Mannheim, 1960). In these terms, utopias are opposed to 'reality', defined by what is not (yet), in a similar way that the imagination has been (Kearney, 1998). Yet many argue - still evoking a degree of separation - that utopias also help us to define our social realities, needed for the endurance and 'progress' of society (Rabkin, 1999). I examine the definition and importance of utopias through their function, then form and content in light of this general definition, although the three aspects are well-integrated in most accounts and visions. I advance the case that - even when used for political critique - there are identifiable similarities in terms of perfection, stability, spatiality, comfort, euphoria and art in the following texts. Difference, the homely and community run throughout this discussion, as I explain the 'traditional' importance of these themes.

\subsection{Utopia and function}

Utopias have many functions. Most popularly, they may be used for political critique (Harvey, 2000 does this to some extent), or, almost as much, as escapism into lands of plenty and comfort (like the popular 'Land of Cockaygne: Ward, 1974). They may also be an outlet for worry, anxiety about the present or future, either presented positively in a comforting, often conservative vision. Conversely, they may be constructed negatively, in a nightmarish vision, as the diametrical opposite of utopias: dystopias (Kumar, 1991; see Orwell, 1964, 1990 and Huxley, 1994 for well-known examples). The division between utopias and dystopias is questioned later, however it is worth noting that the latter (and anti-utopianism in general) have dominated the twentiethcentury imagination. Therefore, many argue that utopianism today - and hence its definition - is irrelevant, escapist and dangerous (Kolnai, 1995; Jacoby, 1999; Baeten, 2002a; Levitas, 2003). 
True or not (Kumar, 2003 argues there were more utopias than ever in the 1990s), utopias/dystopias are intimately linked to the social realities they deride or transcend. Thus for Bauman (2003: 12), the over-riding function of utopia has always been to measure life as it is, by life as it should be. For him, this is a defining feature of humanity where the "urge to transcend is a nearest to universal" (Bauman, 2003: 12). This can of course be a positive turned into a negative (life as it should not be), but the power of utopias seems to emerge from the simple difference between life as it is and should be. The seeming necessity of utopias and this difference - the desire to imagine a better life - is implied throughout human history (Holloway, 1984). This may be overtly religious, in terms of Millennialism (Harrison, 1984), or political (Sorel, 1969). This necessity may in many ways be a call to revolutionary action or social change (Marx, 1977), or, in a contemporary context, a covert method for justifying a particular, dominant ideology (Jacques, 2002). I do not cover religious utopias here - largely as these have been subsumed by political utopias and fantasies of abundance and euphoria today. Instead, I explore a selection of these specific functional definitions of both textual and practical, experimental utopias. Here, we see how, folded into notions of escape, desire and luxury, are the inter-related themes of inclusiveness (of difference), hence of social relations and community, and hence of belonging and home. This demonstrates that these three themes are in fact inherent elements of all but a few utopias.

\subsection{The political function of utopias}

The political function of utopias is perhaps the most popular in academic discussion. Some definitions present very closed, often highly exclusionary frameworks. For instance, Davis (1984) argues quite pragmatically that the problem with most discussions of utopia (he picks out Manuel and Manuel, 1979) is that they are too broad and ambiguous to allow discussion of their histories or social value. He focuses on utopias' political function, arguing that only those that aim at the abolition of politics, producing a static state, are true utopias. The Manuels' supposedly ambiguous definition is still relatively closed in that it argues that one particular characteristic of utopias - 
apart from their overtly political nature - is their clarity (Manuel, 1966: 2). This clarity is both found in these rational, ideal social spaces themselves, and in their more efficacious function as critical mirrors to society (Manuel, 1966: 3; but see Foucault, 1986: 24). They thus question and harbour potentials for a different future than that assumed. Yet again this notion is partial as they focus on French utopias (also Crossley, 1999). Practically, one must focus on particular examples and theorise relevant definitions from these. However, it is in these more generalising statements that the exclusionary nature of such definitions and histories is to be found, along with an often static political notion of utopia, which has itself informed exclusionary, often totalitarian visions (Levitas, 1990; Kolnai, 1995).

Many others also focus on the overtly political function of utopias. With less closed definitions, I think that in order to assert the 'practical' value of utopia, many authors focus on particularly Marxist-inspired utopias and theorists and the general political function utopia might have today (Marcuse, 1968; Grey and Garston, 2002; Fournier, 2002; Lassman, 2003; Osborne, 2003). Turner (2003), for example, focuses on the potential of Mannheim's (1960) 'chiliastic utopias' in relation to contemporary sensibilities of fragmentation, insecurity and risk (see also Ackroyd, 2002). Here, we might see an egalitarian individuality where "democracy has the potential to become the basis...for ecstasy as a 'universally shared form of experience"' (Ackroyd, 2002: 41). Much work, particularly feminist-inspired, has attempted to take on the political significance of post-structuralist theory (especially Derrida, Irigary, and Cixous). This work argues that utopias, and definitions thereof, should be more inclusive of difference and open-ended (Levitas, 1990; Young, 1990; Sargisson, 1996; Sandercock, 1998). I explore this next.

Socio-cultural difference, and its difficult incorporation into communities, has become an important element of political utopian and non-utopian contemporary thought. Geographers, for example, have become interested in how spatial practices and imaginations produce and justify various spatial exclusions based along lines of class, race or gender (Gregory, 2000). They attempt to 'deconstruct' the oppressive nature of 
such dualistic divisions, towards a (sometimes abstract) goal of 'social justice' (Pratt, 1992; Rose, 1993; Pratt and Hanson, 1994; Harvey, 1996; also Young, 1990). This often involves a discussion of how such re-theorised social relations might play out in space, and, most tellingly, public and community spaces. These authors debate as to which configurations might best allow more open, inclusive, responsive and liberated social interaction to occur (Mitchell, 1995; D.M. Smith, 1999; Popke, 2003). I would not risk branding all of these texts utopian. Yet in celebrating difference, and with such goals in mind, as well as more enlarged versions of social justice, elements of a concern with the 'good life' (or at least ironic versions thereof) are apparent in many of these texts (Smith, 1997). Writers on utopia, often following Derrida and Cixous, have similarly attempted to de-naturalise Western concepts of difference and 'otherness' in their discussions of utopias' function (Sargisson, 1996). In particular, they argue that more 'homely' versions of community, and rural and urban idylls can in fact be the most divisive and least inclusive, in particular when manifested spatially (Sibley, 1995; Ellin, 2001). Thus, when the homely is tied to community, dystopian and anti-utopian visions which stress inclusiveness and diversity attempt in many ways to evade those notions of home and community. When they do (carefully) construct visions of utopia, these are far from perfection and boundedness, drawing on various post-structuralist 'stars' (Derrida, Deleuze, etc.) to promote utopias as processes in which the good life is perpetually under construction, new spaces always opened up for human interaction (Sargisson, 1996), often in participatory planning processes (Sandercock, 1998). Through the idea of the un/homely, and through my empirical and conceptual experience of the contingent and material performance of architectural spaces, I later attempt to connect ideas of difference, the homely and community into notions of utopia that are often unsettling. There, I show how the idea of difference - or différance - fits into the utopian unsettling, and provide another way to think about the political and affectual implications of utopia.

A key group whose concerns and voices remain excluded is children (Daniel and Ivatts, 1998; Matthews, 2002, 2003). Themselves a diverse group, children's needs often remain ignored in terms of decisions made regarding housing, community regeneration 
and even education and playgrounds (McKendrick, 1999). One concern of this thesis will be to explore children's use of the school in particular, and the extent to which their needs are taken into account. One particular (policy) debate that connects with the school and wider utopian discussion comes through the notions of 'childhood' and 'play' (Garvey, 1977; Lubelska, 1993). Children are an often emotive and symbolic issue, often viewed as the 'future' (of the nation, for instance), rather than social agents in their own right (Daniel and Ivatts, 1998). Various versions of 'the good' can thus be attached to education, as well as play. Children at play - through 'free', organic, imaginative (idealised) activity - test out those skills they learn in school, as well as other 'life skills', relating to ([crypto-]utopian) themes such as inclusiveness, difference, community and communication with others (Bruce, 2003). This has led to policy and academic debates over the correct provision of facilities for play (Department for Education and Skills [DfES], 2003; Maxey, 1999). This is rooted in often nostalgic, yet ostensibly more emancipated forms of play that are 'free' of constraints from adults, 'stranger danger' and passing cars, yet encapsulate an element of risk $^{l}$ (as for Steiner education). This is a utopian vision of childhood and play that seems to have no extrinsic value to adults and yet contributes to more vibrant, healthy communities where children are a crucial, valued element. This utopianism has both negative and positive strains, as it used to legitimise particular positions or funding decisions. It can be reactionary and unhelpful in terms of a backward-looking connection with the 'rural idyll', for instance, which although comforting for parents, does not represent the diversity of children's contemporary needs in a variety of settings (Valentine and McKendrick, 1997; Matthews et al., 2000; Smith and Barker, 2001). It can also repeat a pigeon-holing of children which views them as social actors, but only at play, rather than work. In a positive sense, however, it points to the variety of settings and ways in which children play, and hence the ways that architectural (for example, playground) design could 'catch up' with children's rights and demands, and the ways in which children appropriate and 'produce' their own spaces - and perhaps utopias. It is against this background of 'childhood' and 'play', and the various utopian elements associated with

\footnotetext{
${ }^{1}$ See chapter 3 , on risk and the utopian unsettling.
} 
it, that I explore the construction of an 'ideal' and specifically child-centred education at the school.

A current of thought from the Surrealists through Débord (1967), de Certeau (1984) and Lefebvre (1991) is also concerned with difference. However, this follows the production and resistance of power relations in space through often romantic notions of oppressed people's embodied usage of (urban) places (Thrift, 2000c). These political notions (and their Marxist-ludic-subversive matrices) are popular amongst geographers (Stewart, 1995; Molotch, 1993; Blum and Nast, 1996; Soja, 2000), and often identifiably utopian. However, the power dualisms they invoke are critiqued by many (Thrift, 2000b; Hinchliffe, 2000; Massey, 2000). Some of these critics provide more relational conceptions of power which I think could provide new insights for utopias and definitions of utopian action. Similar to the discussion of difference, the politico-utopian potential of Deleuze and Guattari's smooth and striated spaces (which does conceive of power more relationally), and their actual/virtual following Bergson, has influenced utopian theory (Halfacree, 1996 on the rural idyll; Grosz, 2001). Again, the playful aspects of Deleuze and Guattari's account compare with various versions and definitions of the utopian which follow the political, ludic and subversive potentialities open-ended utopias of 'difference' might proffer (see Knight, 1997, for examples from Barthes) . These aspects place the function of utopias firmly into the contexts and 'goals' of contemporary theory. Moreover, part of the utopian unsettling I offer later draws on the unsettling tendencies such ideas of subversion (even if potentially mis-placed) and play might have. All of these utopias, and the definitions which incorporate them, stress the political function of utopias. Moreover, we begin to move from visions of comfort, homeliness and excess - and stable, static visions such as those Davis (1984) advocates - to those which leave political acts open-ended and within notions of everyday difference in a Foucauldian (1986) sense. I link these together with post-structural renderings of utopia with performative and Actor-Network versions later on.

In many ways, from Manuel's (1966) critical mirrors, through Foucault's (1986) heterotopian spaces which are a mythic and real contestation of everyday spaces, to 
Grosz' (2001) use of Deleuze, it is the functional relationship between reality and utopia that is under question. Very often, this is dialectical, whether (political) utopias are meant to reinforce (Jacques, 2002) or shatter an existing reality (Mannheim, 1960), predicated on a degree of stability from and against which utopias can be constructed. Much of this, it must be stressed, is influenced at some stage by the emancipatory political thought of Karl Marx. Marx himself (1977) in fact argued that the function of utopia was quite limited, and that social change should be rooted in material transformation (also Bataille, 1985). Harvey (2000) notes how for Marx, the visions of the utopian socialists (Fourier, Owen: see Ward, 1974; Levitas, 1990) were futile fantasies, although he did concede that in times of social unrest, they might contain the first seeds of revolution. However, the revolution, and thus wholesale political change to another stable (static again) order became a function of utopias, a goal in itself, both ideally and materially (in the Eastern Bloc) (Mannheim, 1960; Sorel, 1969). For this reason, as well as the resolution of class differences that Marx anticipated through revolution and a change in economic organisation, Marxism and socialism have been strongly identified with definitions of the utopian, and political definitions in particular. Nevertheless the divisive, totalitarian elements of these utopias have led to the strongest critique.

Moreover, socialist versions of politics and utopia are geared around socio-spatial organisations - local or national communities - often represented in concrete design (Margolin, 1997). More generally, architecture and utopia have been jointly implicated in the search for ideal political socio-spatial orderings, from the Renaissance to Modern architecture (Howard, 1965; Le Corbusier, 1971; Fishman, 1984, 1999; Hall and Ward, 1998; Barricelli, 1999; Worpole, 2000). I discuss the place of such forms in the search for political utopias (and more generally) in section 2.7 .

\subsection{Other functions of utopias}

Mumford argues that utopias should offer people a fuller intensity of life through the complete integration of artistic endeavour into everyday life (cf. Hundertwasser, 1997). 
He asks whether "If the arts are not to disintegrate utterly, must they not focus more and more upon eutopia?" (Mumford, 1959 [1922]: 297). The issue of partiality and a personal politics is again raised here - is Mumford trying to save the arts or argue that utopia is a more artistic social space? Although again closed, Mumford's definition of utopias through their artistic function relates to the importance of creativity to the imagining of utopias, and the importance of leisure, play and creative work within utopias (Marcuse, 1968; Bataille, 1985 on the surrealists; Knight, 1997; Borden and McCreevy, 2001; Lightfoot and Lilley, 2002). For many, such as the Situationists, it was the crossing of art and everyday life that again held political potential. Interestingly, much of this was to be found in the realms of urban life and architectural form-making (Debord, 1967; Bonnett, 1992; Loewy, 1998; Pinder, 2001). For others, the psychological benefits of free, craft-based work were again the bases for many, often community-based, often rural endeavours (Hardy, 2000). 'Work' was also a key element of utopian images justifying (the future) of whole nations, such as the blood-and-soil National Socialism of inter-war Germany (Bramwell, 1985). Although these images of art and work were often quite comforting, and rooted to notions of home or home-land (Heimat: Kockel, 2001), I discuss the unsettling, unhomely elements of these ideas later on. I would also highlight here the importance of artistic creativity to both Day and Hundertwasser (Chapters 6, 7 and 8).

The relationship between rurality, nature, art and utopia (also below) is interesting in two further ways. Firstly, this linkage is found for example in visions of the North American wilderness as a site for colonial expansion (often utopian itself), where technology, landscape, Edenic new versions of rurality and new orderings of that society (Thomas Jefferson's 'yeoman capitalism' and, again, community) combined to produce a utopian edge to nineteenth century Westward expansionism and exceptionalism (Marx, 1964; Cosgrove, 1998; Cronon, 1991; Allen, 1992; Baudrillard, 1988, 1998 on Americaas-utopia-achieved; Verstraeten, 2002; Jacques, 2002 on exceptionalism and cryptoutopias - see below). Secondly, I argue that the artistic representation of the American landscape in these various - often incoherent - guises, and of utopias as a whole through painting, fiction, poetry and architecture/planning, is a crucial element of their 
contemporaneous experience and past and present dissemination, impacts or functions (Walther, 1981; McGreevy, 1987; Baker-Smith and Barfoot, 1987; Robinson, 1988; Daniels, 1993; Keohane, 2002). I pick up on one of these - architecture - in this thesis, although go on to argue that 'representation' should be thought with materiality and performance too.

The notion of the homely also relates to conditions of comfort, and luxuriant excess. Many 'personal', community and National utopias would comprise these features. Indeed, many fairy stories (Hansel and Gretel), popular myths (The Land of Cockaygne) and religious visions (The Garden of Eden), whilst not all strictly utopias, represent (in)formal versions of endless food, drink, play and usually sex. These are forms of 'spatial play' (Marin, 1984, cited in Harvey, 2000) that were and are translated into desires of transcendence and luxury orientated around treasure or pleasure islands (Boesky, 1999; also any television holiday programme), (post)modern consumption patterns (Harvey, 1989; Jameson, 1991; Bauman, 1992; Goss, 1993; Hannigan, 1998), and the internet (Mitchell, 1996; Porush, 1999).

Less spectacular versions are orientated around the comforts of the modern home, as a driving force behind 'ordinary modernities' (Taylor, 1999a, 1999b; also Rybcinski, 1987). Similarly, Baudrillard (1996) shows how 'systems of objects' in (bourgeois) homes came to represent their owners' identities, often through the construction of the house as a homely place of opulent consumption. More broadly, the home(ly) acquires a distinct utopian edge in the work of phenomenologists such as Bachelard (1994) and in Heidegger (1962). There, specific, often vernacular versions of the hearth, of one's childhood (also Matthews et al., 2000), the safety of community (Till, 1993; Ellin, 2001) and again nation (Heimat) evoke largely nostalgic visions of a golden time-place. Images such as the English rural idyll (Murdoch and Marsden, 1994; Halfacree, 1996; Holloway, 2003) are equally implicated in notions of home, and of utopia. Moreover, home as comfort or haven, surrounded by familiarity (systems of objects, landscapes, people), is very prevalent in the construction and maintenance of rose-tinted images of traditional, safe localities (McDowell, 2002). Safety and comfort are hence key elements 
and objects/states of desire for many people. They are linked to often personal, embodied notions of health and the body, through a variety of practices both 'traditional' and '(post)modern', as explained by very recent geographical work (Coyle, 2004; also Fannin, 2003; Hyams, 2003).

These nostalgic yearnings for comfort and luxury are also often politicised forms of utopia - of legitimation and celebration. As nearly all of the above authors attest, there are inherent problems with all of these comforting utopian images, in particular that they exclude certain groups, may in fact incite institutionalised hatred (cf. Heidegger), and are often (thus) inherently conservative, (bourgeois) middle-class, and racialised (white) (for example, Murdoch and Marsden, 1994; Millbourne, 1997). An especially stinging critique of bourgeois conservative consumption is found in Bataille (1985), and his visions of excess (Botting and Wilson, 1997) and creative consumption which oppose that. Various others - perhaps inspired by Nietzsche's (1976) violent attack on bourgeois decadence - such as the Surrealists and the architectural Expressionists, also wanted to excite those classes out of decadence and cosiness (Frampton, 2000). And it is the utopianism therein that I discuss, through specifically architectural versions of the unhomely, in Chapter 3. I would also note that in that chapter, as in Chapter 9, I attempt to pick apart the construction of notions of home and haven (for the school especially), through the often unhomely, unfamiliar and contingent ways in which those notions are performed and justified. Thus I discuss the 'projects' of Modernity as a drive to discomfort as much as comfortable perfection.

Eco-topias lead on from materialistic, community and homely concerns, where 'green' ideas become a crucial function for utopias. In general, environmentalism cannot be classed as a coherent movement. However, certain of its more conservative versions, which advocate a return to small-scale production, community life and comforting, often ruralised images of even urban spaces, are often aligned with utopianism (Pepper, 1991; 1996; Morris, 1993). Callenbach's (1990) Ecotopia, whilst incorporating futuristic technologies, is one such essentially conservative vision of San Francisco. Another example is Huxley's (1967) Island, an initially pristine landscape populated by beautiful 
people - relating back to the lure of islands noted above. Again, the homely draw of the community, as a symbolic, political and economic way of solving society's ills - at whose heart lies degradation of the environment - is central to these fictional utopias, and practical attempts to realise utopian communities (Hardy, 1979, 2000; Kumar, 1987; Forsey, 1989; Pepper, 1991; Martell, 1994; Dobson, 1995; Diggers and Dreamers, 2003).

The importance of alternative spatial orderings is as important to notions of comfort and more radical ecological critiques as to the utopian socialists and almost all revolutionaries (Hetherington, 1997). This often cites the oft-problematised concept of community and, interestingly, the symbolic-material promise of ecological architecture (Papanek, 1995; Wines, 2000; Ole-Jensen, 2001). Once again, ecological architects sometimes effect an almost triple utopianism - through architecture (see below), phenomenology (see Relph, 1976; Norberg-Schulz, 1985; Mugerauer, 1994), and environmentalism. For these reasons, as well as their being omitted from critical geographies of architecture thus far, green buildings provide a fascinating and complex site (in an ANT sense) for the study of utopia. Moreover, we can simultaneously explore the interplay of difference, the homely and community as aspects of these utopias.

Naturally, we see cross-overs between the political-, artistic-, work-, comfort- and environment-related aspects of utopias. This is to be expected where most visions, and thus definitions which generalise and compartmentalise these, are complicated by the ironically simple fact that nearly all utopias aim for perfection, or at least the 'good life' (eutopia) - and hence must be stable and 'cover all bases' with a degree of universality. This latter point, with connotations of impossibility, totalitarianism and hence exclusions has clearly been rendered problematic by anti-utopians (Kolnai, 1995) and poststructuralist theorists (Sargisson, 1996; Baudrillard, 2001), and I draw out these themes later. This is an essentially political point, such that the political function of utopias stands out here, making use of images of specific versions of comfort and ecology, for example, to make a particular argument. Moreover, there is a difficult tension, which I think has still not been overcome, between utopias as open-ended, and the ethical, 
grounded insights utopias can give if they are (as it seems most authors want) to remain politically relevant. There is also a tension between individual utopias and group utopias (Bauman, 2003; compare Anderson, 2002 with Fournier, 2002), wherein the former, drawing on Bloch (1995) are seen to be relevant to the perceived splintering of societies (Saurup, 1996), and incommensurate with the co-operative visions many desire (for a good discussion, see Sennett, 1996). I discuss ethics at the end of the next chapter.

A final element of utopias, which takes on such political, homely, luxuriant, artistic and community-related functions, is that of euphoria, an important element of later discussion. This also signals a partial move from the stasis and separation of eu-topia to more performative (yet still spatialised) events. Often, the function of utopia might relate to those above, yet it is the emotive, and - I argue along with post-structural thought 'embodied' experience of utopia as and in happy, nostalgic or euphoric moments which are important to utopias' goals and to the utopian experience, whether in writing, reading, building or living utopias. This entails a joint discussion of how utopian representations are 'read' - the affect they might create - and of the imaginationexperience of utopias within 'everyday' life. In fact, for the Surrealists, Lefebvre, Marcuse and the Situationists for example, it was the ludic and often sexual euphoria that their political visions and actions incorporated, that opened a fuller space for desire. Desire and euphoria can in fact be related back into the political function of many utopias (Cockaygne, Marx, Morris), and many technological and science fiction utopias (W. Mitchell, 1995; Frayling, 1995; Porush, 1999). Yet it is not merely the intense pleasure that such utopias promise, or that escapist moment achieved upon reading them, which is the affectual import of utopianism. Others argue, largely through Bloch's (1995) 'not-yet', that utopia is to be found within latent conditions in the present, in 'embodied' moments of hope, desire and euphoria, a kind "of affective hope...enabling the configuration of traces of how 'something better' might feel" (Anderson, 2003: 224). Many theorists, although not necessarily drawing on Bloch, highlight how 'an immanent utopianism', is "concerned with the pragmatic articulation, and cultivation thereafter, of specific existing potentialities and possibilities, rather than the production of fully worked out theoretical or political programmes or statements" (Anderson, 2003: 225). 
Similarities can be found in the work of Grosz (especially 2001), Sargisson (1996) and Pinder (2002), who all argue - through Deleuze and Derrida for Grosz and Sargisson respectively - that the relationship between everyday life and utopia is sustained and emergent through immanence, virtuality and open-endedness. We thus evade a dialectical relationship between utopia and reality found in Mannheim and other socialists. Although there is a degree of separation, this is a creative tension between what exists and what is immanent within that existence. Here, however, I would highlight the relationship between Bloch, desire, euphoria and these emergent versions of utopia, and the desire in such post-structural accounts "to resist the closure that is evoked by approaches to utopia as perfect..." (although in places I do wonder what the place of euphoria might be) (Sargisson, 1996:226). Later, I draw out the coherency in all of these debates - and the inconsistencies - in order to stress the continued importance of such open-ended political-and-everyday utopias, and of desire, whilst drawing these into a discussion of the utopian unsettling.

\subsection{Form/content: space, architecture and utopia}

There is also debate regarding the form and content that utopias should take. These are necessarily related to their function, and I return to function various times here. The form that utopias take (narrowly, whether literary fiction, or architectural plan), and their content (who or what is in them, and where) are so strongly inter-twined that I do not attempt to separate them. I briefly mention literary utopias which, although important, are not the explicit concern of the empirics of this thesis. I then move onto architectural and urban utopias that highlight the explicit importance of space, and the importance of utopia to those fields. I do not focus on 'intentional communities' here as I want to focus on architecture, however a summary of work on communities and utopia can be found in Chapter 11. Of course, it is again hard to divide between 'real' architectural or community visions/practices and 'fictional' utopias bearing in mind the above discussion. Still, I attempt to focus on more 'practical' attempts where possible. More importantly, elements of the homely and of community appear in various guises - in particular where, as Baydar (2003) usefully suggests, architects have deliberated over 
the literal and metaphoric relationship between city and home, between macro- and micro-scale communities, the body at large and the body-at-home (also Grosz, 1992).

\subsection{The form of fiction}

There are many encyclopaedic collections of utopias, most of which focus on literary texts as the key utopian form (Manuel and Manuel, 1966; Neville-Sington and Sington, 1993; Kumar, 1987; Carey, 1999). Kumar argues that, in fact, "Utopia is first and foremost a work of imaginative fiction in which, unlike other such works, the central subject is the good society" (Kumar, 2003: 64). He, and many others, thus recount a raft of well-known utopias (from More to Bellamy, Campanella to Morris) and dystopias (Huxley, Orwell, Zamyatin, Koestler), so that form and function are entwined in a definition which allows the collection of specific (often the same, and often politicized) utopias in a literary format, which allow a differentiation between utopias and 'other such works' (for example Kumar, 1987). Even Sargisson (1996) and Levitas (1990), with their more open-ended definitions, often focus on literary and theoretical utopias, although drawing on more diverse sources (in particular feminists, such as Irigary, Cixous or Atwood).

Many of the texts they describe have had important effects, and are often concerned with real world events, spaces, and critiques thereof - and in particular the socio-spatial organization that utopian societies might take. In fact: "Architecture has been the most utopian of all the arts" (Kumar, 1991: 14). This grates somewhat with Kumar's definition above, although we realise the importance of the spatial imagination (of different worlds, cities, homes, communities, colonies) to that of utopia. However, in all, many such collections do not account for more design-orientated - or 'real world' experiments whose forms have been just as influential in the history of utopia, or the meanings that users have made of them. There is, however, a raft of definitions which do focus on more 'real world' attempts, outside fiction. I have discussed some of these in relation to function (for example, on work and community), but continue in a moment. 
There is, however, an inherent spatiality in the form and content of almost all utopias, and thus how people define their form - beginning with the root of the word, 'topos' or place (Bauman, 2003). As Baeten (2002b: 143) notes: "Ironically, imagined space has always been at the very heart of the utopian project." There is, in fact, no clear distinction between those texts and definitions that deal with purely literary, 'a-spatial' utopias and those that do not. This lack of distinction comes in particular as space is implicit in many visions, and even explicit in certain of those that are included (for example, Morris, Campanella, Huxley and Orwell). I return to spatiality below, after a discussion of the importance of architecture and planning to utopias.

\subsection{Architecture and planning: the spatial form of utopia, Modern and Post- Modern architecture}

Here I focus on those collections that are organised more around the spatial forms that utopias have taken, in particular through (urban) plans and 'real world' experiments (Fishman, 1984; 1999; Hardy, 2000; Coates, 2003). Space/spacing is not necessarily the function of these utopias, although it is a function of the ideas they (re)present and attempt to enliven. Moreover, a concern with space and spacing is very much apparent in recent geographical (Harvey, 2000; Geografiska Annaler, 2002) and non-geographical (Parker, 2002a; History of the Human Sciences, 2003) offerings on utopia. Here, then, I highlight the importance of architecture, planning and space to utopia, whilst providing a background to the (perhaps ironic) contingency and fluidity of the utopian unsettling thought through architecture and spacing.

Architecture, as Kumar notes above, has been inherently linked to utopianism (Fishman, 1998; Crouch, 1999). In many ways, since the Renaissance and before, architects sought to reflect, house and even determine the ideal society and body through seeking perfect, concrete solutions to particular engineering problems (Grosz, 1992, 1995; Gold, 1997; Worpole, 2000; Imrie, 2003; also Day, 1990a; Hundertwasser, 1997). Thus as a search for static perfection, a concrete version, container and determinant of the good, architects have been involved in the literal construction of the 'good society' whose 
functions we discussed above. For example, architecture as art has been entailed in the representation of power relations (Dovey, 1999), but more broadly in those struggles for power which require the solidity of bricks and mortar for justification. This can be found in various contexts, such as the expansion of the USA and Chicago as the new 'Rome' (Cronon, 1991). Other examples are Hitler's construction and use of motorways, vernacular architecture ${ }^{2}$ and spectacular neo-classical edifices created by his architect Albert Speer (Shand, 1984; Lane, 1985; Golomshtock, 1990; Rollins, 1995).

Moreover, the relationship between architecture, space and utopia is entailed in utopian visions, plans and experiments. These sought not merely to represent, but act as material determinants and 'actors' within social discourse and change. This is a materialsemiotic version of architecture and landscape, promoted by Nash (2000) and Don Mitchell (2000), which can equally be applied to the effects that such designs (should) have. In fact, the power of buildings and designs to act within and structure utopias runs from More's (1988) utopian island, through the settlements of Fourier, Owen, Cadbury and other (philanthropic) utopian socialists, to that inherent in one of the RIBA's recent initiatives - 'Building Futures' ${ }^{3}$. I focus here, however, on the spatiality and utopianism in constructions of Twentieth-Century architecture and community construction: from the Modern architects and expressionists, to postmodern urban design. I pick out the implications of these trends for notions of ecology, sociality health, comfort and order, for the critiques that Hundertwasser and Day effect, and in preparation for following chapters.

Modernism in architecture has been strongly linked with utopianism. In particular, Modernism is associated with the trend to 'avant-garde' design (for example, Expressionism), and a desire to overcome the chaos, dirt and (moral) disintegration of the Nineteenth-Century industrial city (Williams, 1973; Crouch, 1999). As Le Corbusier noted, contemporary technological, social and aesthetic change heralded a new time:

\footnotetext{
${ }^{2}$ This insight was gained on a tour of the Eagle's nest and surrounding mountainside near Berchtesgaden in July 2003, where the changes in size and function of Hitler's house and command centre there were hidden by the house's name: Berghof ('Hof meaning farm in this instance).
}

(accessed 29/06/2004) 
"Geometry is the means, created by ourselves, whereby we perceive the external world and express the world within us. Geometry is the foundation. ...Machinery is the result of geometry. ... The dwelling again puts before us the architectural problem in the demand for totally new methods of building...the problem of an aesthetic in harmony with the new spirit. The moment comes when a widespread enthusiasm is capable of revolutionizing an epoch" (Le Corbusier, 1971 [1929]: 1-2, original emphasis).

Le Corbusier is related to a string of Modern architects, but Fishman (1999) relates the significance of utopia to Le Corbusier to Frank Lloyd Wright (also Pfeiffer, 1997) and Ebenezer Howard (Howard, 1965; Hall and Ward, 1998). He argues that these three "...[R]esponded to social conditions...by detaching themselves from immediate action to devote thousands of hours to their urban utopias. But detachment is not necessarily escapism; for the three planners believed that before they could take effective action they had to stage a strategic withdrawal into their own minds" (Fishman, 1999: ix-x).

I would express four points regarding these architects, and Fishman's point in particular. Firstly, that although there is no coherent 'trend' or aesthetic that incorporates all Modern architects (Gold, 1997), there are similarities in a desire to break with the past, and produce a Modernist aesthetic in various ways. Modernist architecture stereotypically revolves around the work of Le Corbusier, Gropius, van der Rohe and Loos, in particular the gleaming and simple, clean lines of their work (Worpole, 1999) as can be found at the Weissenhofsiedlung in Stuttgart. The Bauhaus argued that the future was turned towards industry and mass production rather than individual craftsmanship, and thus attempted a modern synthesis of many fine and applied arts, as disinterested, rational architects (Bayer, Gropius and Gropius, 1959). In Austria, Adolf Loos was critical of the 'Potemkin City' (in Schorske, 1998: 158) that early-Twentieth Century Vienna had become with its show of false bourgeois power, concealed ostentatiously by masks of the past. He hence sought to break from such fake aesthetics. For him, ornament was a crime, and even the Jugendstil of Otto Wagner was too much of a contradiction between style and utility, where a more modern utility was required (Schorske, 1998: 158; see also Hundertwasser, 1997 [1968]). Meanwhile, Ludwig Wittgenstein's attempt from 1926 to build a house for his sister in Vienna was typified 
by an intense, restless, detailed attempt at the cubic forms Loos had advocated, yet with a unique (but austere) interior (Leitner, 1976). The future-orientated, often nationalistic elements of such discourses were not always utopian but did, as Fishman suggests above, often entail a detachment, through various institutes such as the Bauhaus, before more 'practical' suggestions could be made. Interestingly, although Le Corbusier and others were often seen as madcaps by their contemporaries (Fishman, 1999), their radical utopias - like those of Owen and Marx before them - became crucial elements of twentieth century UK and global landscapes, in the forms of tower blocks, suburbs and British Town Planning.

Secondly, the utopias produced by these architects point to a more general relationship between modernity and utopia. In this relationship, "They [utopias] are intrinsically linked to the concerns and assumptions of modernity" (Levitas, 2003: 3; Kumar, 1991, makes the same point). Bauman (2003) argues that as those assumptions have changed in 'liquid modernity', so too have utopias and their relationship with modernity. However what also concerns me here, and what has gone unnoticed by many, is that the joint history of modernity and utopia has been accompanied by the rise of the modern expert. Indeed, Bauman himself $(1987,1992)$, discusses the rise of the expert, such as the architect, planner, dietician or lifestyle guru. In addition, I think that the rise of the expert has allowed the production of specific utopias, with specific forms, contents and functions, which legitimate or critique current practices, and envision new, utopian ways of doing. As Fishman points out above, a great deal of work, but also withdrawal, went into the construction of utopias such as Howard's: yet he, as an 'expert', was in a position to produce these visions, and indeed become revered as one of the founding fathers of British (expert) town planning. Critiques of such top-down visions are familiar (Sandercock, 1998 on planning), as is the utopianism inherent in contemporary planning (below) and politics (Jacques, 2002), as well as in Hundertwasser's and Day's attempts to involve (communities of) future users in architectural design. I look at the implications of this in terms of utopia and critical geographies of architecture later in the thesis. 
Thirdly, architecture and design are more broadly implicated in the material-semiotic production of nationalisms, particularly during the inter-war period, as I mentioned above. In a socialist context (post-revolutionary Russia), the position of avant-garde artists and architects was there for the taking: "[Artists] wanted those forms to become signifiers of a new spirit. ... They wanted to effect a "double revolution" by redefining revolutionary art practice so that it became revolutionary social practice as well" (Margolin, 1997: 3). In Britain, a tension between progress and tradition led (again) to the importance of order as an aesthetic and social determinant of national identity, through technology, planning, rurality and its depiction in art (Sheail, 1975; Wright, 1985; Jeans, 1990; Matless, 1990, 1998; Lowenthal, 1991). As mentioned earlier, the importance of nationhood, nostalgia, and comforting, homely emotions attached to more orderly imaginings of national landscapes, are paramount to the effect such designs and representations provoked. Moreover, in general, art, architecture, planning and orderly spatiality were key to these images, whether revolutionary or comforting. But, I argue, what about, dis-order, and dis-comfort, the pain of nostalgia, and the unsettling, unhomely elements entailed in the construction of such orders through often emergent ethics?

Finally, all of these images, and particularly those of Modern architecture, imply a degree of perfection. There is a yearning for order and a healthiness and education of body and mind, determined by the clean lines and clear organisation of cities and landscapes (Worpole, 1998). As Matless (1998) shows, such imagery was also designed to order bodily behaviour, linked to an ethics which constrained the ways people acted in the countryside, in order to produce a healthy, ordered nation. The importance of education to utopia - or at least orderly practices - is wrapped up in discourses about health and sociality, however certain commentators add that the importance of education to and in utopia, and the forms it takes, should be a key consideration (Chapter 9; Cooper, 2004; Sargent, 2004). I also deal with education elsewhere in relation to the school (Kraftl, forthcoming). The inter-relationship between nationality, cities, domesticity, health, sociality and education is played out in many utopian designs through the manipulation of space and spatial practices. This can be seen, as 
Hetherington (1997) argues, the modes of ordering that characterise different phases and spacings of Modernity.

Hence space in general, from the nation, to colonial expansion, to the home, to the city, to the community and public space, is implicated in the envisioning of utopias, and in particular Modernist architecture and what followed. If we skip towards postmodern planning and design, we see that utopian considerations have changed in some ways, but remained constant in others. Certainly, the utopianism, luxury and euphoria contained within images of the desert island and internet I mentioned earlier are important. Yet we see in the playfulness, irony and excess of the 'key' sites of postmodernity - such as Las Vegas - a utopianism based around some of the features of 'liquid' modernity: consumption, fantasy, ephemerality and the necessary exclusions for these to operate (Venturi et al., 1977; Davis, 1990; Jameson, 1991; Hannigan, 1998). Moreover, in those exclusions, we see how the excesses of such leisure spaces are translated into comfortable-yet-divisive versions of community, and static architectural expressions of middle-class utopia which require aesthetic and moral control (Till, 1993; Fyfe and Bannister, 1996; Frantz and Collins, 1999; Soja, 2000; Ellin, 2001). These have come to be known as 'revanchist utopias' (Baeten, 2002a; from N. Smith, 1996). The (dystopian) implications of such communities are well known, and have added weight to critiques of totalitarianism and irrelevancy aimed at utopias. Still, Richard Rogers and various task forces in the UK persist with design-led utopian visions of future urban community life (Botto, 2004).

In Chapter 3, then, I explore 'solutions' to spatial exclusions often created as a result of such homely, bounded spaces (whose problems extend to space-times previous to postmodernity), based around 'inclusive' visions of public space and community which often border on the utopian (compare Young, 1990, with Sargisson, 1996) and aspects of the unsettling (Sennett, 1996). Nevertheless, I do not discount all malls, airports, casinos and gated communities as necessarily divisive or 'place-less'. I suggest, in fact, that they are entailed in broader global-local spacings, embroiled in the 'crypto-utopias' of global capitalism and neo-liberal ideology (Jacques, 2002). Moreover, such places and flows 
resonate with some of the (seemingly) more positive aspects of traditional utopias. We should not thus discount the ways that these places are consumed and reproduced, interpreted and re-imagined, through their creative re-appropriation - as perhaps very different, (post)modern utopias. This re-connects with the performative, contingent approach I take to buildings, in particular that comfort can be contingent (and unsettling) as much as dis-comfort!

\subsection{The problem of (urban) space}

As I mentioned, it is partially the exclusions inherent in both historical utopias, and postmodern (urban) offerings that have driven theorists of various persuasions to imagine theoretical (and often utopian) alternatives. At the heart of the debate, I believe, is not just the image of perfection, or the universalising and impossible tendency to seek global happiness, but the problematic figure of space. Part of the problem, lies in conceptions of space which view it as pre-given, determining, Euclidean, and static (where actions take place upon or in it, and time occurs separately). I attempt to overcome this difficulty later on. Moreover, another (although lesser) problem has been the tendency to focus on urban spaces (Baeten, 2002b; Pinder, 2002; MacLeod and Ward, 2002; Yacobi, 2002) in very recent work. This is perhaps surprising, given (in the UK at least), a pervading interest in rural traditions, landscapes and communities, thought through images such as those of the inter-war period, and in particular the importance of the comforting 'rural idyll' (Halfacree, 1996; Matthews et al., 2000). This is one reason for my choice of Nant-y-Cwm School. Moreover, $I$ would not wish to conflate the utopian unsettling with urban landscapes, however much these figure in Chapter 3. The point is that notions of rurality and urbanity are co-constructed with (and without) utopian elements and images, and that in many instances, from gated communities to green communities, notions of home and comfort persevere.

Returning to the more pervasive problem of spatiality, it is the static bounded-ness that space implies - and that visions of utopia conjure - that are at the heart of many negative critiques, especially those where architecture is involved. Harvey (2000: 173) argues that 
the dominance of space in Western thought and utopianism has lead to the impossibility and inherent exclusions associated with particularly architectural utopias. Harvey argues for 'spatio-temporal' utopias, rooted in the temporal processes of social struggle (Harvey, 2000: 189). Such a 'utopian dialectics' would "operate in relation to both space and time," (Harvey, 2000: 196), and provide in many ways open-ended utopias, similar to those of Sargisson and others. Harvey does attend to the problem of space well, and its enaction, yet through his (post-)Marxist framework is unable to properly account for the contingency, and emergent spatiality that geographers have recently discussed (for now, see Thrift, 2000a). Moreover, in his own (comforting) vision, he is unable to escape a dialectical (either/or) conception of space and the ontological problems associated with it (Doel, 1992).

Zygmunt Bauman approaches the problem of space and utopia from an almost opposing angle, arguing that utopianism and utopias have become disconneceted from space and place, in global, floating, privatized images and imaginations (Bauman, 2003: 23). He argues that "In the transgressive imagination of liquid modernity the 'place'... has been replaced by the unending sequence of new beginnings, inconsequentiality of deeds has replaced fixity of order, the desire of a better today has elbowed out concerns with a better tomorrow" (Bauman, 2003: 24). Nevertheless, for Harvey and Bauman, then, space has lost, or should lose, its hegemony in utopia. For the former at least, space should be integrated into processual versions of sociality (and spatiality) in postmodernity. I argue later that Harvey does not go far enough in his assertion, and that a fuller - and more unsettling - rethinking of stability/flux in late-modernity is warranted and, indeed, partially attainable.

Other contemporary work on utopia focuses largely on urban space, and perhaps this results from the dominance of the city in utopian thought, and its prevalence in geographical research. Much is evocative of Jacques' (2002) argument that current neoliberal, free-market policies are not merely utopian (and that part of their potency is in hiding that utopianism whilst deriding other visions and practice as utopian), but that this merely reinforces the inequalities of the existing urban order (Baeten, 2002b). 
Similarly, MacLeod and Ward (2002:154) argue that utopian planning has inspired much of the 'real' contemporary city, as "an intensely uneven patchwork of utopian and dystopian spaces", found in edge cities and the new urbanism, for instance (Ellin, 2001). Such a visioning is also apparent in the production of (spatial) historical order, in order to legitimise and naturalise certain versions of the past - as Yacobi (2002) notes for the city of Lod, Israel (also above on inter-war Britain). A degree of temporality is again apparent here - in the historicity of such political attempts as Yacobi depicts, and the aesthetic historicity of festival market-places (Hannigan, 1998). This is implicated in the 'patchworks' produced in urban spaces.

Encouragingly, all these authors (as does Pinder, 2002), focusing on urban spaces, note the positive effects that a re-vitalised and re-defined utopianism might have through various versions of open-ended, processual utopias of difference. Some are similar to Harvey's, some (like Pinder's), quite different as they resist the closure that even Harvey suggests (and drawing on Levitas, Sargisson and Sandercock). Moreover, these authors begin to move towards a deconstruction of utopia/dystopia, and to more painful notions of public space (Baeten, 2002b, following Sennett, 1996). Additionally, they all stress that critical utopian visions are necessary in order to challenge the political impotence and mediocrity Baeten identifies in urban research, bringing us to the integration of utopian function with form and content, and the co-relational production of space (and hence spatial utopias) as a dynamic process. Whether or not this mediocrity is evident, Pinder (2002: 239) argues that such utopianism should (again) move away from representations of the 'perfect' city: "Rather, it may be re-thought in terms of addressing what is possible, and of seeking out the prospects within present conditions for different and more just processes of urbanisation", thus emphasising utopias' potentially disruptive qualities.

I would make three points here. Firstly, that I do agree with much of this, and similar work (Sandercock, 1998; Parker, 2002b; Bann, 2003), and with a focus on both urban space and space-time in general. Second, however, although a more focused (urban) utopianism is useful, I wonder at both the micro-scale politics, and the broader-scale 
implications of such utopias. For which parts, of which cities, at what scale, and even for whom, are such open-ended, urban utopian discourses relevant? Moreover, what of those places 'outside' (or held in relation to), urban areas - a utopian suburbanism, ruralism - or even a more general utopia(nism)? Third, where Pinder (2002) talks of 'possibilities', I wonder to what extent he means 'virtualities' (cf. Grosz, 2001). With his emphasis on Bloch, the not-yet, and the everyday, I would suggest that this is potentially a difference in nomenclature. Yet I attempt, in the next section, to broaden and focus the notion of utopia, perhaps beyond (urban, spatial) definitions, but at least encompassing their undoubted worth to some extent. In particular, I address these last two points through an emphasis on more general (and rural) utopianisms, as well as a deeper (or at least, different) discussion of contingency, the performative, and the non-human in the construction of utopia(nism)s.

\subsection{Conclusion}

Thus the form, content and function of utopia in relation to spatiality can be re-thought in light of contemporary work on spacing. Hence, the definition of utopia (or lack thereof) can also be re-thought. I therefore suggest that a re-theorisation of utopia through space and architecture would aid a more general re-conceptualisation of utopia, its contemporary relevance, and historical impacts. In this chapter, I have discussed, broadly through moves to define utopia, the varied concerns of utopian visionaries and theorists: politics, comfort, euphoria, luxury, consumption, ecology, politics, perfection/stability, space, urbanism and process. The form, content and function of utopias are thus mutually implicated, and at many instances, it is difficult (if not undesirable) to separate these out, as these many concerns themselves are coconstructed. I showed in particular that our key themes of difference, home and community are constantly apparent in discussions of utopia, but that they need to be reworked somewhat, along with the concept of utopia, in order to take account of various historical and contemporary insights. I sketch these out in the next chapter, where I do not altogether evade definition, or form, content and function. There, I draw on much of the above work to suggest that the idea of the utopian unsettling might enable new, 
creative interpretations and interventions into both the historical and contemporary spatial construction of utopias. Much of the preceding work opens up gaps to enable this, or leans in a similar direction, but I begin to read various post-structural concerns with community and difference through a more general notion of the utopian unhomely and unsettling. 


\section{Chapter 3}

\section{The utopian unsettling}

\subsection{Introduction}

I do not intend the utopian unsettling to replace any previous versions of utopia, as the problem of defining exactly what utopias are and do, would render this highly questionable. However, I argue that - through my work at the Hundertwasser-Haus and Nant-y-Cwm School - utopias can be anxiety-inducing, dis-comforting and even implicated in ruin - and moreover that these facets might actually be desired as elements of ideal visions. I fuse work particularly from post-structuralist theory (and its heritage in Nietzsche, Heidegger and Freud), and utopian studies, geography and architecture. I argue that the utopian unsettling is not merely relevant to a 'contemporary condition' (of 'liquid modernity') but to a raft of utopias and theories throughout history.

I present versions of the utopian unsettling that remain under-explored in past and contemporary theory in discrete sections. These include: revolution; difference; ruination; the un/homely; the contingent; euphoria/nostalgia; work and community. I argue that all of these inter-relating elements are crucial, in particular to the impact of utopias, even where utopias are 'traditionally' comforting and settling, and even where that perfection should provide critique or revolutionary change. Some of these elements first became apparent in my empirical work at the Hundertwasser-Haus and Nant-yCwm School, in particular how utopias are contingently constructed. Yet l never argue that all of these elements are present at the house and school. Rather, I present a broader discussion of many examples that back up my claim that utopias can be unsettling, and provide a general background for later discussion. For, only at times are certain of these ideas emergent from the Hundertwasser-Haus and Nant-y-Cwm. Thus, I investigate some of the more general historical and contemporary impacts that utopias can have, through various - perhaps surprising - notions that are the seeming obverse of comfort, perfection and the good. This thesis is also then, I hope, relatively unsettling and perhaps deconstructive itself. However I also show how, crucially, notions of homely comfort, community and so forth should not be discarded. I instead merely demonstrate how the 
construction and experience of such (emotive) terms are implicated within actions that are fundamentally unsettling or unsettled - and this is where my work at the house and school helps illustrate these points empirically. Thus, the three themes that emerged as of over-riding importance and structure the 'empirical chapters' (difference, the homely and community) have already emerged as key 'traditional' elements of utopia, but also crucially infect the arguments in this chapter and my reading of certain utopian texts. I also promote the place of non-human actors (in an Actor-Network Theory sense), such as buildings, to utopias with/in the everyday - and the need for 'critical geographies' of architecture to enable me to do this.

\subsection{Revolution}

I begin with a very simple version of the unsettling, whose power and relevance to utopia has already been discussed. For Marxists (if not Marx himself), the utopian dream lay in the material transformation of social relations, in what Harvey terms a processual utopianism where revolution became intimately linked with the promise of the good society (Harvey, 2000). Plainly, revolution is (or should be) pretty unsettling for those involved. Moreover, through revolutions, and their incitement by utopian visions, utopias are (pre-)figured, by Marxists, as explosive and even violent. Mannheim defines only those practices "as utopian which, when they pass over into conduct, tend to shatter, either partially or wholly, the order of things prevailing at the time" (Mannheim, 1960: 173). Similarly, Sorel proclaims that "what is necessary is an energetic war...and finally, when there is no way to do anything else, silence" (Sorel, 1969: 214). I discuss the Nietzschean element of this a little later. However, the idea that utopias - even in the form of visions of perfection, stability and comfort - are in themselves able to produce tremors within the social status quo, to incite revolution, and war, and a shattering of order through revolution, is a fascinating one. Indeed, in a somewhat different sense, this relates to the disruption I described in Pinder (2002) above, and that is found in urges to Derrida-inspired utopian discourse in, for example, Young (1990). This is also attached to the more abiding, but perhaps less violent, notion of utopia as a political critique of the present, even where the 'original' utopia was in fact a critique of what came to be 
termed utopianism (More, 1516)! Thus utopia, and crucially even images of perfection, are imbued with transformative, disruptive and unsettling power.

However, I argue that there is a second element of utopianism present within the idea of revolution. I think that for many revolutionaries, the event and the experience of revolution is itself a utopian dream. Where enlivened, this dream can provoke a dionysiac jouissance and euphoria found in many more traditionally-defined utopias. Part of this, I suggest, comes from a similar condition to the so-called 'Stockholm Syndrome' - where a hostage becomes so attached to their captor that they fall in love with them. The energy with which Marxists and other revolutionaries discuss the power of revolution, and the enjoyment derived from (quasi-)revolutionary activities such as those of the Situationists, display a similar if bizarre attachment to the rupturing, anxiety and unsettling that revolution promises. The actions of the latter, although not always specified as revolutionary (although present in the events of May 1968 in Paris), were essentially concerned with the disruptive power of play. The potency of Homo Ludens (Nieuwenhuys, 2001) to "maintain a creative game within current conditions in order to figure alternatives" (Pinder, 2001: 19) created provocations that were concerned with urgent questions of emancipation, and the incitement of socio-spatial change, but also the sheer enjoyment and even luxurious freedoms experienced in and through those changes (Pinder, 2001.; Bonnett, 1992). I relate this to the concept of work in the next section. On another tack, I think of the nostalgia, communal camaraderie, and often comforting simplicity evoked in depictions of war-time or revolutionary action in people's own stories of those events. Finally, the obvious promise of revolution - the latent creativity and excessive virtuality and difference from the status quo with which revolution could be imbued - meant that the ongoing construction of revolution-inprogress was an opportunity for (utopian) practices themselves, as Margolin (1997: 3) suggests in terms of the 'double revolutionary' social and artistic creations of Rodchenko, Lissitzky and Moholy-Nagy.

One must be more than a little careful in suggesting an unproblematic relationship between war (cf. Sorel), revolution and utopia, and I move towards a performative ethics 
of utopia through this chapter. Both war and revolution imply more than discomfort, of course, and in particular the creation of oppositions and antagonisms only resolved through violence, destruction and pain. I suggest in subsequent sections that even elements of these are evident in certain versions of utopia. However for now, I would like to be a little less assertive in suggesting that utopian elements are apparent in certain violent circumstances, and that violence, revolution and the unsettling are entailed in the construction, experience and impact of many utopias. This is only partially explained in the 'disruptive' potential of utopias, where I argue that many comforting, homely utopias - can be disruptive for various reasons, often in the willful production and experience of anxiety.

\subsection{Work and community}

Where utopias are often concerned with comfort, community and leisure (even the Situationists mention the latter), it might seem rather strange to discuss 'work'. Yet work is important to utopia in three, inter-related ways. Firstly, an emancipated, artistic workforce is far more likely to be productive, and to gain pleasure from work, if organised along more democratic lines. An example would be a socialist society, often organised into distinct, tight-knit communities or guilds but with a responsibility to the greater 'good' (Marx, 1977; Hardy, 2000; also the appendix of Harvey, 2000). Similar yet distinct from the Situationists, it is such artistic, free work which produces a happier, more fulfilled workforce. The distinction between work and leisure is thus lost, as work becomes enjoyable and the need for 'free time' recedes, as all time is 'free'. Hundertwasser in fact evades an economic notion of work altogether where he describes the artistic creation of 'beautiful paths' (Hundertwasser, 1983), each of which should always be different and new, rather than following an old (or commodified) route. Hence he argues that the future tenant of a building should also be its architect, engaged in a healthier relationship with architecture. For him, this can lead to a Blochian sense of paradise as not-quite graspable, yet attainable through such liberated artistic effort (Hundertwasser, 1997; also Wilson, 1979; Ward, 1995 on Walter Segal's self-build projects). 
The second version of work in utopia is related to the first. I argue that it is the work entailed in materialising an 'end' goal - in particular for our purposes, a building - that is utopian, even an end in itself. This feeds very much into the importance of a relational conception of utopia-as-work, where a community of humans and non-humans work and are worked together to construct a certain artifact-idea. Indeed, the 'end' goal may not be clear, and the utopianism may instead lie wholly within this process. In many ways, this relates to Hundertwasser's sense of paradise, beset by the virtualities of the presentfuture (see below). Yet this is distinct from other examples of the first version as it happens not so much in a utopia already achieved, but one ongoing, before a goal (or no goal) is reached. Moreover, a utopia is then only apparent as an emergent, ethical decision to name that work 'utopian' - at certain instances therein (Chapter 12).

One example of this is the health-giving and socialising power of voluntary and community work. Where building towards a goal, Wates and Knevitt (1987: 119) argue that evolutionary architecture, geared to "the environmental needs of individuals and communities," can overcome the problems of pre-planned settlements, ascribing a (utopian) sense of ownership, home and community. I argue it is ongoing and evolutionary work that creates these senses, even though they may be contingent and ephemeral properties rather than the comforting stabilities Wates and Knevitt suggest. However, the promise of community work, rooted in the materiality of the everyday, is a key facet of many texts depicting alternative ways of building communities (Hughes and Sadler, 2000).

Likewise, Christopher Day stresses the psychological and physiological benefits of hard work, in relation to sociality and the performances involved in constructing buildings (especially 1990b). The basic premise of Day's argument is that the process of work itself - especially gift work - is where euphoria, senses of belonging and of achievement lie. This, of course, leads to the end goal of 'a building'. However it is the process often contingent, and a collection of various energies - of the combined hard work of communities of various human and non-human actors, ideas and emotions that is crucial 
(Day, 1990). It is in these performative moments that the utopian is found within the everyday, as work, not as necessarily a result thereof.

Finally, and strongly related again, is the willful disruption of (bourgeois) constructions of comfortable homeliness, and the oppositional utopianism inherent therein. This draws largely on angry polemics against the decadence of bourgeois attitudes. For example, in the utopianism of Expressionist architecture (Sharp, 1966), such a disruption is notable: "New social welfare organizations, hospitals...these will not bring a new culture - but glass architecture will... . Therefore the European is right when he fears that glass architecture might become uncomfortable. ...For first of all the European must be wrenched out of his [sic.] cosiness" (Behne, 1918, cited in Frampton, 2000: 117). This statement is in many ways evocative of Loos' arguments in relation to the Viennese Ringstrasse (Chapter 6), and, ironically, Hundertwasser's later attraction to ruination. In all these instances, a critical part of this utopianism lies in creating discomfort through largely aesthetic, deterministic means. This will to disruption, to shake from comfortable decadence, is a significant energy in Nietzsche (1976: 572): "It is my contention that all the values in which mankind now sums up its supreme desiderata are decadencevalues." He continues: "Life itself is to my mind the instinct for growth, for durability, for an accumulation of forces, for power: where the will to power is lacking there is decline. It is my contention that all the supreme values of mankind lack this will - that the values which are symptomatic of decline, nihilistic values, are lording it under the holiest names" (Nietzsche, 1976: 572). Apart from Nietzsche's (the alleged nihilist) critique of nihilistic values, what interests me is a critique of decadence, and the 'supreme values' - perhaps utopian - which are implicated therein. Nietzsche affirms the supremacy of a will to power - dionysiac, hard work - wherein decadence is equated with decay, a lack of thought - "the realm of no risk (no life). And life is quite literally tension, that is, the apperception of risk, which makes subjective living an essentially anxious activity" (R. Smith, 1999: 174). This evokes the arguments of Heidegger and Freud, and the elements of risk discussed below. I must note of course that neither Nietzsche nor Smith note utopia in the context of these quotations. However, I would suggest that, when set into the rest of my argument, and when taken as over-riding tenets 
by which life might or should be lived (cf. Bauman, 2003), Nietzsche's ideas at least (in particular 'growth', above, and the Uebermensch) are commensurate with more idealistic visions (see also Bataille, 1985 on Nietzsche, especially 36-39). The critical point is that these versions of work and the 'good' can be related to other versions of the utopianism of work. Additionally, they unsettle the hegemony of 'perfection' through specific practices, rather than valorising mere abstract 'open-endedness', and exposing the work that is desired as utopian. This last point, of course, relates to the previous section on revolution.

\subsection{The un/homely: Freud and Heidegger}

A key element of utopias past and present is the importance of comfort and the homely, expressed through, for example, 'the rural idyll'. A similar tone, often bordering on the nostalgic utopian, can also be found in traditional readings of Heidegger, and humanist (architectural) geographies (Tuan, 1974; Relph, 1976; Norberg-Schulz, 1985). In this section, I add weight to my argument by unsettling this comforting heritage.

Freud's concept of the uncanny (unheimlich) has been interpreted in various ways, and is in fact one among various popular and academic usages of the term (Masschelein, 2002: 54). Heidegger too mentions the term several times in Being and Time (Heidegger, 1962: 320-322) ${ }^{1}$. Freud's basic argument, drawing on literary and medical cases, is that "The subject of the uncanny...is undoubtedly related to what is frightening - to what arouses dread and horror" (Freud, 1955: 219). From uncanny repetition, to a loss of orientation, from what had been repressed, to hidden or subverted returning to (haunt) one, and even déjà $v u$ - what had seemed in particular homely can gradually become unhomely. Through some etymological gymnastics (Freud, 1955: 220-226) and through examples from fiction, he shows how the homely and unhomely are mutually implicated in another in conditions of uncertainty and anxiety where once there was (or should have

\footnotetext{
${ }^{1}$ Page numbers refer to those from the earlier versions of the text, as found at the top of the pages of Heidegger (1962).
} 
been) comfort. For Freud, a key site of this is the haunted house/home in stories that create an uncanny tingle, dis-orientation or sense of anxiety (Freud, 1955: 227)

Heidegger performs a similar blurring of homely and unhomely, this time in relation to 'death [as] a possibility-of-being', something 'distinctively impending' (Heidegger, 1962: 294). Thus the homely, or phenomenological security with which Heidegger's work has been associated, is conditioned by "a more primordial and impressive manner in that state-of-mind which we have called "anxiety"' (Heidegger, 1962: 295). He continues: '[T]his anxiety is not an accidental or random mood of 'weakness' in some individual; but... a basic state of mind of Dasein... . Uncanniness is the basic state of Being-in-the-world, even though in an everyday way it has been covered up" (Heidegger, 1962: $294 \&$ 322). There are disparities in these understandings of unheimlich, however what is clear is not merely an emphasis on what is discomforting, but also the blurring of homely and unhomely this entails.

The unheimlich has been specifically related to architecture in a number of ways, for example by Krell (1997), who illustrates his argument at times with examples of ruins (Krell, 1997: 59, 67; section 3.5). He shows how both Freud's and Heidegger's unheimlich relate to a condition of [B]eing which is anxious, specifically in relation to particular architectural examples and architecture in general. Like Krell, Vidler (1992) relates the unhomely to architecture (the birthplace of the homely), and in particular haunted houses and ruins. These, whilst they should be homely, they become the opposite (Vidler, 1992: 32). Yet this is not a merely Romantic or aesthetic version of architectural ruination or haunting:

"[T]he contemporary place of the uncanny...places it centrally among the categories that might be adduced to interpret modernity and especially its conditions of spatiality, architectural and urban. As a frame of reference [it] confronts the desire for a home and the struggle for domestic security with its apparent opposite, intellectual and actual homelessness, at the same time as revealing the fundamental complicity between the two... . [It provides] a way of understanding an aspect of modernity that has given new meaning to the traditional Homeric notion of "homesickeness"' (Vidler, 1992: 12, my emphases). 
Both Vidler and Krell seek ways to account for the uncanny in poststructural readings of architectural practice. Yet I argue that, in relation to this and the example of ruin below, the $u n /$ heimlich (fused together) present/s a crucial version of utopia - that is unsettling - and connects with above depictions thereof in four ways. Firstly, as my emphases in Vidler's quotation highlight, the unhomely can be at the root of a lack (cf. Bloch) or desire (and work) for a home, for comfort and security. If, as Heidegger suggests, our essential condition is one 'not-at-home', then at the heart of many of our desires is a yearning - which is very often utopian - to be comfortable and at home (whether a house, city or nation/Heimat). Although one should be careful not to universalise such a condition, the place of the $u n / h e i m l i c h$ within, and as, a condition for utopias should not be ignored.

Second, where the homely and unhomely are so closely allied, we might undertake a wholesale deconstruction of the duality to argue that each is fully implicated in the other. Hence I suggest that where utopia is often aligned with the homely, and dystopia with the unhomely - and the transcendence of the unhomely everyday pre-figures the homely, non-everyday utopian - all of these oppositions (homely/unhomely; utopia/dystopia; utopia/everyday) are together exploded. As I have already illustrated, the unsettling can be utopian in various ways, but to those we can add the unhomely, as it both predicates and is contained within the homely - in contingency, euphoria and excitement which leads to the joint production of the un/heimlich. Thus more than the deconstruction of un/heimlich might logically imply a deconstruction of utopia/dystopia, this is already apparent in practices of revolution, and in the euphoria of hard work - as well, perhaps, as in the uncanny excitement and risk a haunted house might evoke.

Third, aspects of the seemingly homely utopian - I think of nostalgia as a yearning, almost paranoid and painful desire for the homeland - can be powerfully anxietyinducing and unsettling. The draw of one's home, a yearning for rootedness, is present here (although Vidler deconstructs this through literal homelessness), whilst the draw of a locale - not necessarily a home, although it might be homely, can be both euphoric and painful. Fourth, this leads to our discussion of ruins, as sites where the unsettling and 
utopian meet and are fully implicated yet again. We see examples of how the sense of difference and lack that physical ruins and 'nature's' action at buildings engender may drive a yearning for the homely, the (national) past and future. Moreover, we also understand how ruins, and a more general notion of ruination, can be perhaps shockingly re-theorised to provide new aesthetic, creative and ethical versions of utopia.

\subsection{Ruin(ation) and the agency of 'nature'}

We have been concerned with emotional responses to certain situations, where the agency of 'nature' and various non-human actors has been assumed. Yet I argue that one of the key features of the utopian unsettling - and of an expanded Freudian uncanny - is the unsettling and perhaps uncontrollable effect that non-human actors might have, be granted, or be desired to enact. Here, I present various versions of the utopianism of ruination, and (begin) a tentative ruination of utopianism. Simultaneously, I use this to exemplify the importance of ANT to utopia. I take ruin quite widely, involving humaninduced and 'natural' 2 processes of decay, crumbling, wild vegetation and even less visible actions like bio-invasion. These have often provided imagery for dystopian visions, but I show again how we overcome the dualism utopia/dystopia in asserting the positive role that 'non-human' ruination might have.

Morris' influential News from Nowhere is an effective starting point. His vision presents an ecological, socialist utopia, in which London has become a series of self-contained but inter-connected communities. Morris depicts the Houses of Parliament as a manurestorage facility, and the city and its other landmarks are greened over with fields. 'Nature', through trees, wild and controlled growth, has 'taken back' the city to provide an often comforting image which draws together many familiar utopian themes, from work to social ordering (for example Morris, 1993: 60, 64; see above). A similar effect can be found in Callenbach's (1990) Ecotopia, for San Francisco, and the terrible beauty

\footnotetext{
${ }^{2}$ I do not discuss the false dualism culture-nature here, nor the ways in which human and non-human merge, save to say that $I$ avoid such a dualism, instead viewing each effect of ruination as a mutating combination of actors changing in response to their contingent collection, dispersal and circulation. For more on the dualism see Macnaghten and Urry (1998); Szerszynski et al. (2003).
} 
of Ballard's (1999) The Drowned World (although the latter is perhaps less avowedly utopian and comforting, but usefully ambiguous). Marx commented (above) on the effects that such utopias might have during unsettled times. Yet I think this power comes from the unsettling effect that Morris engenders through gradually revealing London's familiar landmarks through these pastoral and ecological 'layers'. We are led around London, and feel a tingle every time we recognise a feature of its landscape which is now almost unrecognisable. This might stir up various unsettling emotions, but reminds us of two of Freud's. First, the return of what has become hidden (not repressed, in this case). Second, the dis-orientation of an unfamiliar place yet which is - and this is the point - also familiar: an uncanny form of non-identical repetition. Such familiarity within unfamiliarity (the un/heimlich) is, I argue a key narrative effect of Morris' utopia - and of various aspects of life at 'different-yet-everyday' buildings such as the house and school.

Hundertwasser himself promotes the action of ruin as part of a 'harmonious', healthy, 'anti-modern' architecture that attends to the creative needs of humans and non-humans. "When rust sets in on a razor blade, when moss grows in a corner of a room...we should be glad because...life is moving into the house. ...In order to rescue functional architecture from its moral ruin, a decomposing solution should be poured over all those glass walls...so the moulding process can set in" (Hundertwasser, 1997: 48). Hundertwasser has a double notion of ruination: decomposition/rust/mould and, later (Hundertwasser, 1997: 84), 'ruin' itself is juxtaposed with the moral ruin that he argues functional architecture enacts. This is, then, a manifesto for an ethically specific, creative type of ruin - a quite aesthetic, Romantic one - which is opposed to the 'evils' of modern architecture. In Concrete Utopias for the Green City (Hundertwasser, 1997: 68-70), Hundertwasser treads a similar path to Morris, wherein the city should be 'returned' to nature, through individuals' creative appropriation of natural processes within and outside themselves. He argues for beauty barriers consisting of such intermingled, artistic acts:

"[W]hat we urgently need are barriers of beauty. These barriers consist of nonregulated irregularities. And these non-regulated irregularities consist either of 
spontaneous vegetation or of the creativity of the individual. Both are mutually complementary creations. ...Paradises can only be made by the individual, with his creativity, in harmony with the free creativity of nature" (Hundertwasser, 1997: 70).

Whilst this is an aesthetic, individual notion, it compares with Morris' eco-topia, Bloch's everyday utopias, and provides the material basis for Hundertwasser's architectural practice - $\mathrm{a}$ utopian architectural manifesto for mould and ruin.

Furthermore, the integrative but often uncontrollable effects of nature are crucial to the imagination and construction of some of the key spaces of modernity. In particular, during phases of colonialism, plants and animals from the 'West' spread faster than people. In fact, virulent diseases aided the passage and success of crusaders (Clark, 2002: 111-113). This is not necessarily utopian in itself, yet Clark highlights the unacknowledged importance of 'bioinvaders' in the construction of modernity and modern urban spaces. One could, I suggest, equally extend this into the utopian characteristics of 'settling' (also unsettling itself!), pioneering, colonising, and also the construction of Modern, comfortable gardens (the spread of the exotic) and cities in 'home' countries.

Similar to Hundertwasser and such modernities, a fascination for ruin and the action of nature upon and as ecological architecture is also incorporated into many built and designed (future) projects of 'green' architects (Wines, 2000: 13, 69-77; Jodidio, 2001: 205-207; Edwards and du Plessis, 2001). Although we must acknowledge the many ecological buildings that use technology and social practice as a structure for design, the place of material objects is always crucial, as are the multifarious ways they 'perform' (Day, 1990; Ole-Jensen, 2002). Thus, as both utopian and 'practical', ruination conceived positively - is a more than peripheral concern.

As utopias can be presented through ruin, so can ruins be interpreted as utopian. This can be allied with the uncanniness they present, particularly in terms of Freud's un/homely. They often do this through lack. Utopias too, are often predicated on a sense of loss or longing for the not-yet. Although one must be careful in asserting that ruins 
are utopian for this reason (not necessarily 'lacking' at all, and perhaps indicating a terrible loss), the conversation they incite, a "[D]ialogue between incompleteness and the imagination" (Woodward, 2002: 15) can, at times, be considered utopian: "[W]hen we contemplate ruins, we contemplate our own future" (Woodward, 2002: 2). This connection of past and present may provoke various futures, but the utopian cannot be ruled out. This may manifest in various versions of home (a ruined house), or painful nostalgia for the homeland as the events of a nation are literally suspended, as, for example, a "holy shrine of the revolution" (Woodward, 2002: 205). Again, one must be careful not to overdo this, although certainly the various versions of lack - whether Romantic or more material and socially contextual - can be specifically related to the utopian unsettling.

Moreover, the general draw of ruins has been apparent from the picturesque movement (Hussey, 1967) to neo-Romanticism (for example, Piper, 1940, on Hafod House). Piper (on Pleasing Decay, 1947: 85) presents tones of Hundertwasser: "A consistent plan will not spring from his [the planner's, sic.] consistent loyalty to modern architecture, because the world is not consistent. Expediency suggests a visual theory which reconciles inconsistencies rather than rolls them out - i.e., the democratic approach". He continues, "[F]or the good town planner decay - present decay, as well as possible future decay - should be one of the tricks in his box", but, "Pleasing decay is to be found everywhere, but not all decay in buildings is pleasing. What Ruskin would have called the "moral" aspect may override the aesthetic aspect" (Piper, 1947: 85 \& 87). Finally, Piper concludes by saying that "Abroad, a building of the eighth or tenth century stands ruinous in the open street; the children play around it, the peasants heap their corn on it... . No one wonders at it, or thinks of it as separate, or of another time... antiquity is not a dream; it is rather the children playing about the old stones that are the dream" (Piper, 1947: 94). The (aesthetic) valorisation of ruins exemplifies the effect with which Woodward imbues them. Yet Piper especially makes some interesting points (on 'consistency'), which can be related in particular to Hundertwasser's critique of Modern architecture and love of irregularities. Moreover, I do not take all ruin, war or unsettling to be utopian ('good': section 3.9). Rather, an emergent morality attaches utopianism to 
ruins in spatial co-relation with other actors and priorities, and Piper hints that we require such. Yet, as I have discussed, ruins can be utopian, and utopia can include ruin. Piper's final point feeds into section 3.9 - a dream-like materiality (utopianism, perhaps) which is rooted in the imaginative capacity of ruins (cf. Woodward), but one emergent from the material context of the ruin, and even the everyday performance thereof.

Roland Barthes develops a sense of lack and performance in various utopian themes such as (socialist) struggle, and the importance of desire (Knight, 1997: 20-43). However, Barthes was also fascinated by the spatiality of potential after the 1955 Paris floods: here was the anxious excitement of the de-familiarising of cars and buildings, the release of potential, the uncanny questioning of our perception of context and referent, where for once all hung in the balance (Knight, 1997). The utopianism is clear: "[P]ictures of the floods also provoke the euphoric pleasure of restructuring the space in the imagination..." (Knight, 1997: 38). Here again, the interpretation of 'natural' incidents - even the disaster of flood - is imbued with utopian fantasy and many of the positive elements of revolution and even war (solidarity, new beginnings). Crucially, it is from within the experience and representation of the flood that such euphoric pleasure overflows, and is connected with these other versions of the utopian unsettling.

\subsection{Sacrifice, terror, euphoria}

I do not wish to make over-much of a link between Georges Bataille's writings on excess and sacrifice, and the orgiastic euphoria of certain notions of utopia (for example, Marcuse, 1968; Barthes in Knight, 1997). Bataille's writings do, however, provide a (sometimes Nietzschean) qualification to notions of utopia based around both egalitarian access to goods (and the 'good'), and to those in luxuriant decadence. They also prove quite unsettling themselves. Bataille argues that "humanity recognizes the right to acquire, to conserve and to consume rationally, but it excludes in principle nonproductive expenditure" (Bataille, 1985: 117). Through various examples, in particular war (cf. Sorel and above), potlatch and Aztec sacrifice (Bataille, 1988), he provides visions of creative wastage, the violent, seemingly useless consumption as a 
critique of such conservatism, and as an often (deliberately) shocking depiction of the experience of religious euphoria and ecstatic energy. I would not push the point too far and mis-represent Bataille's argument, but there are at least connections here which can be made with the disruptive and orgiastic elements of revolution, and the unsettling of ideals (even the 'sacred' ideal of abundance for all) that my version of the utopian unsettling suggests (Vidler, 1992, for example, discusses the disruption and excess of Mediaeval festivals).

The work of Barthes again provides a linkage between this point and previous sections. Barthes attempted to de-naturalise the spaces of alienation where stasis had become naturalised, with indirect, creative and un-graspable approaches to writing (Knight, 1997). His critique of bourgeois (cf. Bataille and Nietzsche) theatre led him to an interest with the Theatre National Populaire. There, open to the night air, the usually mystified stage was overturned. It became an un-decidable space, threatening and terrorising, without scenery, without a known future, and pregnant with extreme performative possibilities (Knight, 1997). The excessive virtuality of these situations evokes more recent readings of Bloch (Anderson, 2002), and still more performative accounts of daily life, whether utopian or not (Harrison, 2000). I discuss these later, however here it is the connection between this and the literally terrifying that most interests me. For, rather than being merely unfamiliar or unsettling, now utopia is imbued with the prospect of becoming fully horrific - both aesthetically and affectually - through the critique effected by sacrificial and performative excess in both Bataille and Barthes. A flow is thus apparent through various tremorous versions of utopia, from revolution to the unhomely, whose (excessive) extreme opens out into the terrifying, dizzying utopic presented here. This might lead to an unapologetic and quite paradoxical utopian nihilism, but at least demonstrates the various ways in which the utopia/dystopia distinction can be at least blurred.

Surely, however, some care is necessary for this version of utopianism not to eradicate any idea of the 'good'. We must also question whether this advocates (and hence runs the risk of devaluing) potentially, relationally 'unethical' actions as utopian, or allows 
the utopian unsettling to run so far that it appears ridiculous and contrived. I debate this - overtly ethical point - later on, but would stress again for now the intimate relationship between the various elements of utopia I have characterised so far, and those of Chapter 2.

\subsection{Romanticism and the flâneur}

Rudolf Steiner's philosophies (hence the Stockmeyer Curriculum, and Day's philosophies) were influenced by the German Romantic Goethe. My argument here does not warrant detailed discussion of Goethe's writings, however I would note the (tangential) relationship between this Romantic version of the utopian unsettling and the homely, enclosing 'truths' of Steiner education at the school-haven, and the processes of building-work Day advocates. I develop two versions of Nineteenth-century 'Romantic' depictions of landscape that are uncanny, potentially terrifying, and utopian.

First, Romantic poets (such as Wordsworth) and landscape painters (like Turner) were taken in by the awe-inspiring, terror-inducing effects of sublime landscapes like the Alps (Honour, 1981; Gage, 1987). The relationship between religion - the terror of God's power (for example, in the paintings of Caspar David Friedrich) and such landscapes displays utopian tendencies apart from the moral utopianism of the Victorian Romantic, Ruskin (Cosgrove, 1982; Cosgrove and Thornes, 1982). The awe of God's power can, for example, be related to the contemporaneous concern with utopian millenarianism the promise of Christ's second coming at/after the (unsettling) apocalypse and various communities set up around that (Harrison, 1984; Pitzer, 1984). Moreover, the desire for such landscapes, the intensity of religious and psychological feeling that they engendered in artists such as Ruskin, Wordsworth and Turner, display a euphoria (and paranoia), as well as a nostalgia for certain aesthetic and moral purities which neatly connects with the versions of the utopian unsettling I have discussed so far. The sublime power of 'wilderness', apart from any rural idyll, has remained a crucial magnet for visits/pilgrimages to National Parks, and the Romantic euphoria they instill in those who choose to enact them in that way (Shoard, 1999). Similarities between traditional and 
unsettling versions of utopia hence become clear in the intensity with which such spaces are enacted and represented. Moreover, this is an example of a move away from utopian urbanism, as 'rural' or 'wild' spaces are as much an element of the utopian unsettling. Moreover, the uncontrollability of nature - the contingencies it might enact through ruin, growth and flood - was not lost on aesthetes of the picturesque or Romantic, and, more importantly, re-iterates the importance of non-human agencies discussed earlier (Howard, 1985; Lucas, 1988; also Hundertwasser, 1997).

Second, the stereotypical nineteenth-century city displays elements of the utopian unsettling. Once again, as contradictory, fast-changing and indeterminate spaces, these comprised sites pregnant with possibilities, excitement and danger. Stallybrass and White (1986) describe how cities in Victorian London were experienced by upper class men as landscapes of simultaneous desire and disgust, each implicated in the experience of the other (also Walkowitz, 1992; Howell, 2000). Thus for the flâneur - the explorer of such dangerous landscapes, which were full of exotic/erotic potential - each journey was unknowable, whether through Paris arcades, or London slums (Wilson, 1995; Caygill, 1998; Hundertwasser's 1997 valorisation of slums). The city became, through a consumption of goods, sex and gazes, a site for exploration, whilst dangerous, uncomfortable, and in seeming disarray when compared with the utopian visions of Ruskin, Owen and others. Such sites can be related to both more traditional (Cockaygne) and unsettling versions of utopia, in particular the danger, uncanniness and unhomeliness that these sites/sights evoked. Here was unfamiliarity, difference, found within familiarity and erotic abundance. This presented the unknown in one's 'home' city and culture, which, as I have suggested, creates part of the impact of even more comforting utopias which tried to overcome the dangers of the Victorian City (like Morris, 1993). Moreover, Benjamin relates the arcades to the history of modernity, including an inclination to ruination held within the various 'tensions' above (Benjamin, 2002). These 'modern' cities themselves became the key sites for the utopian reimagination of modernity thought spatially - in the utopias of Morris and Owen, and as one horrific inspiration for Modern architecture (Le Corbusier, 1971), order (Matless, 1998) and Lefebvrian (1991) 'representations of space' which took the whole city, from 
above, by the scruff of the neck. Hence the unsettling was at the heart of various experiences of the nineteenth-century city, and (architectural) solutions to their problems (plans which were themselves often unsettling: cf. Frampton, 2000: 117).

\subsection{Risking 'public space' and 'community'}

Interestingly, such unsettling experiences of city spaces - or, often, 'public' spaces have not disappeared in academic or popular discourse. Fear of crime (Valentine, 1989; Oc and Tiesdell, 1998) is still rife, and a key element in the construction of contemporary 'safe' spaces for both community and consumption practices (Ellin, 2001). Yet with so many critiques of these projects (Davis, 1990) come nostalgic, often Romantic laments on the 'loss of public space' (Mitchell, 1995) and discussions of the problematic neo-liberal re-interpretation of community (D. Smith, 1999). All of these debates display a particularly ethical strand, often identifiably utopian. However I wish to pick up on one element of this, which continues the feeling of attraction to pain and disgust felt in the last section, in a spatial, usually urban and always unsettling context. I would stress that these views on public space - which share commonalities with Lefebvre's (1991, 1996), de Certeau's (1984), Benjamin's (1985) and the Situationists' (Sadler, 1998) diverse explorations of being in the city - can be critiqued for their Romanticism and homogeneity in similar ways to those of Lefebvre et al. (Thrift, 2000c). I then relate this to similar discussions of 'community'.

In a society besotted with risk, security and comfort (Lupton, 2004), the positive riskiness of urban life, an adoption of such urban unknowns as Benjamin's (Harrison, 2000) and a valorization of riskiness of the performative 'push' (Thrift, 2000b), can still be discerned. I do not deal with the politics of defining public space here (see D. Mitchell, 1997; Lees, 1998 Valentine, 2001 for more). What interests me is the backlash against notions of secure, seemingly boring, exclusionary comfort, in visions of the city that stress the importance of the unknown. The uncontrollable and novel, it is argued, help one learn how to conduct oneself in 'public', to negotiate difference, and enjoy the 
contingent excitement of city spaces (Fyfe and Bannister, 1996; Norris and Armstrong, 1999).

Much of this work, displaying at least elements of a drive to an ethical utopianism, is inspired by Sennett $(1978 ; 1996)$ and his more utopian presentation of pain as a positive (urban) experience:

"[A] new context of disorder and diversity... how dense, disorderly cities can become the tools to teach men [sic.] to live with this new freedom...there appears in [communities of abundance and resultant] adolescence a set of strengths and desires which can lead in themselves to a self-imposed slavery...[but] that it is possible to break through this framework to achieve an adulthood whose freedom lies in its acceptance of disorder and painful location...[and] can only take place in a dense, uncontrollable human settlement - in other words, in a city...something distasteful to most: the jungle of the city, its vastness, has a positive value" (Sennett, 1996: xvixvii).

This statement fits very well into my broader concept of the utopian unsettling (possibly distasteful to some), and its unhomely, ruinous elements. I do not necessarily agree that this must be located in the city (which city, after all?), but the utopian elements which aim to break from exclusionary comfort (adolescence to adulthood) through a little pain (cf. Nietzsche, Barthes and Bataille) are clear. Additionally, some utopian texts do take on Sennett's arguments to provide an excellent case for an urban utopianism rooted in the uncontrollable (Baeten, 2002b; Pinder, 2002). However, I do not agree with such a general stress on urbanism, and although I would not assert that such authors carry an overly generalised view of urban spaces, an element of homogeneity is apparent.

Discussions such as these cannot evade the problematic of communal living, which, as I have stressed, is a crucial part of utopianism, and in particular the ecological critique of capitalism (Pepper, 1989; Estes, 1989; Plant, 1989; Martell, 1994; Dobson, 1995). Again, a key concern is 'difference', thought through a deconstruction of the dualism individualism-community (and the more exclusionary characteristics of the latter) towards a politics of difference that is processual (cf. Sennett), understanding of others at a distance. Here, "[I]f institutional change is possible at all, it must begin from 
intervening in the contradictions and tensions of existing society. No telos of the final society exists, moreover; society understood as a moving and contradictory process implies that change for the better is always possible and always necessary" (Young, 1990: 315; cf. Sargisson, 1996; Sandercock, 1998). Despite a final recourse to a relatively community-orientated utopian vision, Young's politics highlights the moral role of utopia in the continuous production of alternatives that may not always be settled on either side of the individual-community debate (also D. Smith, 1999; Pinder, 2002). Moreover, this provides another entry point into broader contemporary social theory, and the relation between ethics, performativity and materiality that I discuss in the next section.

Similarly, Zygmunt Bauman (2000) asks what a critique of liberalism by a (utopian) communitarianism might offer. For him, contemporary life is characterised by anxieties over jobs, hazards (in cities) and old age, where an "absence of security is what unites all three, and the main appeal of communitarianism is the promise of a safe haven, the dream destination for sailors lost in a turbulent sea of constant, unpredictable and confusing change" (Bauman, 2000: 171, my emphases; cf. Chapter 9). Along with his later discussion of utopianism in 'liquid modernity' (Bauman, 2003), this depiction and critique of the haven of uniformity (through community) complements Young's argument, whilst appealing (I think) to take on some of the 'anxieties' of those modernities, turning them into more positive, if unpredictable, 'bases' for social interaction. This also recognises the continuing importance of ideas like 'home' and 'community' in wider society - and hence their relevance to my case studies. For Bauman, however, a notion of belonging may now lie in the panic, ecstasy and spectacle of ephemeral moments which have the power to draw people together in a temporary community, only for a new moment to forge a different collection of new-and-similar people and so on. This would replace the 'common cause' of solid modernity (Bauman, 2000). I discuss such contingency in the next section, the importance of ephemeral collections/dispersals in Chapter 4, and the emergent enactment of (utopian) ethics through a partial reading of Badiou (2003) throughout this thesis. 
I would also stress the importance of non-human agents to communities. Although I do not interrogate the individual-communitarian debate in any detail, the notion of community is crucial to utopia, and to the house and school. Yet I find few, if any instances of a full discussion of the importance of material objects to communities, in detailed explorations of how these are used, in an ANT sense, to construct ethical or utopian ideals. Hence, I begin to expand this in later chapters, whereby the unsettlingyet-comforting contingency of community is discussed. In particular, I focus on the role of architecture - discussed yet not given full consideration in writings such as Wates and Knevitt (1987) and more fully in Lerup (1977) - in the construction of such ideals, whilst developing various versions of critical geographies of architecture (Chapter 4). I would highlight, however, the tension within community as 'safe haven', and as fluid, material, contingent and unsettling itself.

\subsection{Performativity, ANT, difference and the utopian unsettling}

There are various ways in which post-structuralist thought has impacted upon the study of utopia, many of which have led to creative new openings. I would suggest that the opportunities of post-structuralist thought and the broader social actions with which it is implicated are partially responsible for the very recent popularity of utopian studies (Kumar, 2003; Sargisson, 1996). Yet I would argue that recent work on performativity and ANT presents much more than visions of inclusiveness and difference - although I discuss the latter briefly in the first part of this section. In addition, I re-interrogate notions of open-endedness which I discussed earlier, stressing the contingent enactment and experience of affect (and, I hope to demonstrate throughout this thesis, euphoria and utopia), and even ethical utopian 'truths'. In itself, this contingency is unsettling, as such utopias seem to come and go unexpectedly, and are hard to represent. I argue that the effect of utopias has often been hard to represent, as any notion which appeals to emotion and happiness might be (again) unsettling. Moreover, many of the aspects of the unsettling I have discussed so far are contained within, or informed by, notions of performativity - such as public space (Lees, 1997), ruination, or elements of the uncanny (which Freud himself has trouble defining - part of its uncanny effect, and thus 
the effect of the utopian unsettling). Hence, through the idea of difference, and Derridean differrance, this final section presents another version of the utopian unsettling. It argues that the dialectic between utopia and reality (and that even Blochian notions of 'escape' allude to), does not fully account for the performative, affectual and contingent construction of utopias. In fact, any mind-body split (Porush, 1999) where utopias reside 'outside' reality, in the text, a separate space, or merely the future, does not account fully for the experience of utopian moments as actualisations of virtualities (Deleuze and Guattari, 1987). I do not provide any final detail on performativity, as I discuss these ideas again in relation to architecture in Chapter 4, yet here I show how unsettling this version might be to both contemporary and historical utopias. In light of the perhaps surprising claims in this chapter, I then demonstrate a way to link performativity with Badiou's (2003) 'evental truths'.

\subsubsection{Differenceldifférance}

There is a large cross-over between utopian and non-utopian thought on difference, and that on performativity and materiality. For example, Deleuze is a key theorist of difference (see below), and theorists such as Sargisson cite the bodily performativity of Cixous as much as the textual differrance of Derrida. Yet what interests me are not so much the deconstructions of metaphysical binaries that provide a source for inclusive utopian visions such as Young's (1990), although the deconstruction of utopia/dystopia and utopia/reality I have begun is related to my argument here. Rather, it is the openendedness they proffer, and, in particular, the lack of firm grounding that Derrida opens up through his deconstructive differance. Moreover, this discussion contextualises my attempts to grapple with many manifestations of material-cultural difference at the house and school. I want to understand how the different can be utopian and un/homely, and how that is contextualised within 'real' world concerns, preferably thought nondualistically.

For Derrida, difference is other than purely a complex play of differences and samenesses (Derrida, 1991: 62). Différance - neither as word nor concept, a sameness 
which is not identitical - both defers meaning, and refers to a process of differing. It indicates "[T]he very possibility for the combination, dissociation and generation of ...the trace, the sign, representations, words, concepts, a movement that structures each dissocation" (Ormiston, 1988: 42). Différance is predicated on relations of presence and absence, the displacement of representation where "meaning is never completely fulfilled" (Wood, 1988: 66).

"In a language...there are only differences. .... But, on the one hand, these differences play... . On the other hand, these differences are themselves effects. ...What is written as differance, then, will be the playing movement that "produces" - by means of something that is not simply an activity - these differences, these effects of difference. ...Différance is the nonfull, nonsimple, structured and differentiating origin of differences. Thus, the name origin no longer suits it" (Derrida, 1991: 64).

Neither word nor concept, nor origin, differance characterises the movement of signification. When thought through, this helps us to reconsider the difference of pairs of opposites, not erasing them necessarily but allowing us to see "what indicates that each of the terms must appear as the différance of the other, as the other different and deferred in the economy of the same" (Derrida, 1991: 70).

Differ rance is thus a play or creative-destructive force that cannot be pinned down as a readily defined concept. Hence it holds many similarities with the idea of utopia I try to grapple with, in particular the unsettling and ruinous force it can exert, yet 'it' is not a definable concept in itself (indeed, that is what gives it force). In particular, Derrida argues:

"I say that there is no stability that is absolute, eternal, intangible, natural, etc. But that is implied in the very concept of stability. A stability is not an immutability; it is by definition always destabilizable. ...However stabilized, complex and overdetermined it may be, there is a context and one that is only relatively firm, neither absolutely solid...nor entirely closed ... without being purely and simply identical to itself. In it there is a margin of play, of difference, an opening... . These concepts come close to blurring or dangerously complicating the limits between outside and inside, in a word, the framing of a context" (Derrida, 1990: 151). 
Thus, rather, it forces us to ask how such stabilities and 'realities' are produced and how the outside of such stabilities (like utopia) - or their definable limits - are drawn (or traced: Deleuze and Guattari, 1983). To this end we can ask - what place has a utopia constructed out of reality, 'outside' of that reality when that reality is unsettled, undefinable itself, when that utopia is in fact what unsettles it? The deconstructive turn and play of différance that the unsettling utopian brings into the matter of things resists definition as form, concept or word, yet is an undermining, non-essential force that permeates our everyday activities, holds a bizarre and uncanny fascination for us, forcing us to go on. I try to explore later how much this uncanny attraction explains life at the house and school, set into the ways lives are lived there. At others, it is set into various other (more 'traditional') ways that the utopian manifests itself - as an example, a political critique, or escape - yet it radicalises the certainties that are inherent to those notions. Utopia, as a virtuality or actuality, constructed through material agents (see below), is not about another, different state, or space-time. I think, as utopias themselves are unstable and contingent, because they may be unsettling whilst comforting, they can be characterised as enacting a kind of creative différance. Some of them can produce a tingle of (un)familiarity which emanates not merely from a crossing of the familiar and unfamiliar, but of an-other relationship between everyday realities and those desires that appear different from that reality - but in fact constitute it, are emergent within it, question it, and make us anxious (cf. Freud, 1955). Hence anxiety can be utopian because utopian meaning is not merely constantly deferred (like any meaning), the 'good' (whether to come or already in the past) is not merely de-stabilised. For additionally, if the utopian is also the production of the new (and, after all, when does this not happen?), then it must be the experience of utopia - of imagining, deferring, playing, becoming (un)stable - in which this anxious différance is felt. This means a turn to performativity that must be aware of the ongoing ethical dimensions that a discussion of the good life involves.

\subsubsection{Performativity, ANT and an unsettling utopian ethics}


Performative geographies are an attempt to explore the ways that spaces are produced, experienced and enacted co-relationally. They follow in periods of spacing associated with subject and object, human and non-human (McCormack, 2002). This is an attempt to move beyond (textual) representation, to follow and "take seriously the world's own forces" (Thrift and Dewsbury, 2000; Dewsbury et al., 2002: 438). The point is to stress that not all of life is representable through explanantion, in particular contingency and affectual experience, and that neither actors nor space determine events but are codeterminant (McCormack, 2002; Thrift, 2000a). This is about entering the materiality of what happens - from a mid-point, rather than an explanatory beginning or (utopian) end, of "how thinking needs evental encounters...to emerge" (McCormack, 2002: 482; Deleuze and Guattari, 1983). Rather than abstracting universal laws or explanations against which to measure truth, we should bear witness to events as through attempts to respond to the singular moment. (Harrison, 2002). This highlights "[T[he nonrepresentational as contingent and exceptional rather than universal and mundane" (Revill, 2004: 208). However much this might instigate a dualism between representational and nonrepresentational (surely actions and texts can be mundane and exceptional), delivered in choices such as "not the what but the how" of life (Thrift, 2000a: 216), or a call for nonrepresentational forms of understanding and academic 'presentation' (Thrift and Dewsbury, 2000), I think this again stems largely from a concern to stress the performative, rather than see it replace the representational in a nostalgic utopian dream to return to the 'world's own forces' (Dewsbury et al., 2002). Hence Revill comments that, for example, "Musical immediacy as suggested by the movement of habituation embodied in dance is therefore only accessible only through socio-culturally specific forms" (2004: 207). These are universals, texts, if you like such that not only can we call for more nonrepresentational forms of writing, but recognise that almost all practices are both representational and nonrepresentational. I take the broad stance that such performances invoke and are co-constructed with various 'structures', which are also re-constructed simultaneously, both representationally and nonrepresentationally (see, for example, Fortier, 1999 on belonging and Catholic practices). 
The question is, of course, what of utopia? What of a strongly emotive descriptive that refers to questions of universality and perfection? One answer is that key authors in work on performativity include Deleuze, Guattari and Massumi (following the former: for example, Grosz, 2001), who, along with Derrida, Irigary, Cixous and Young, are becoming key sources for reconceptualisations of utopia. In these, the prospects for open-ness, difference and hence the importance of the actual/virtual all appear in various guises, attached to cities, bodily praxis, writing and (utopian) desire (Sargisson, 1996; Sandercock, 1998; Grosz, 2001; Baeten, 2002b; Pinder, 2002). Here, I focus on Deleuze and Guattari, and Grosz's reading thereof, before answering the above question through collections of elements in (geographical) work on performativity, and then ANT. I would note, too, the importance of architecture to this discussion.

The political and performative implications of Deleuze and Guattari's work have been taken in many directions, not least in (sub)versions of power (of 'striated space'), and in the heterogeneity of social events and actions that are always approached from the middle - from experience. These actions can divide, fold and conjoin bodies (without organs) in continuous variation: 'scrumpled geographies' of spacing (Deleuze and Guattari, 1987; Doel, 1996). Such politicised notions house in some ways similar desires to those of the Situationists (Bonnett, 1992). Yet it is the notion of the virtual and actual which attracts great attention in relation to geography, architecture (Lynn, 1998; Perrella, 1998; Kwinter, 2001) and utopia. Deleuze and Guattari distinguish between the possible-real (where no creativity, chance or newness is entailed in the realization of what could be termed here a 'plan') and the virtual-actual (Deleuze and Guattari, 1987). Here, lines should not be traced, rather mapped, rhizomatic connections forged as "Principles of connection and heterogeneity: any point on a rhizome can be connected with any other, and must be" (Deleuze and Guattari, 1983: 57). Following Bergson, then, such connections are open to chance and creativity, rather than the closure of the possible-real (and utopias created from such a dualism: even the impossible implies the possible):

"What is most important to understand here is that unlike the previous schema where the "possible" had no reality (before emerging), here the virtual, though it may have 
no actuality, is nonetheless fully real. It exists... as a free difference or singularity, not yet combined with other difference into a complex ensemble or salient form. What this means is that the virtual does not have to be realized, but only actualized (activated and integrated)... . The virtual is gathered, selected - let us say incarnated - it passes from one moment-event...in order to emerge - differently, uniquely within another. Indeed, the actual does not resemble the virtual, as something preformed or preexisting itself. The relation of the virtual to the actual is therefore not one of resemblance but rather of difference, innovation, or creation" (Kwinter, 2001: 8)

The actual/virtual has been used a great many times, although I think the creativity it opens out, the contingency, and performativity, can be re-connected to the utopian (carefully) in certain ways. For one, as Grosz argues for 'embodied utopias' (in a somewhat Blochian sense, and similar to Anderson, 2002): "The utopic is not that which can be planned and built, for that is to imply that it is already an abstract possibility that merely requires a mode of realization. It mistakes a possibility for a virtuality... . To concern oneself in the present about the future certainly does not consist in programming it in advance but in trying to bring it into existence" (Grosz, 2001: 136 \& 148). Such utopias should not be oriented to goals but process and time, keeping in mind the good as a radical role in exploration and innovation: a process of endless questioning. Playing devil's advocate, one might question why the planned might not be a part of a broader or other actualisation; or why process is not a goal in itself, here and in accounts such as Sargisson (1996). Certainly, then, for both Hundertwasser and Day specifically, the process of building is utopian in itself: and, as I have suggested, work, continual, Nietzschean going on, a 'performative push' are utopian in various ways. Away from Grosz, the creativity inherent in the actual-virtual - of newness, and a willingness to really link up with the world in its performativity, might be read as a utopian aim where utopia is not thought through perfection but - as I have suggested - contingent moments of euphoria, moments where, like in Chapter 9, one can call something 'paradise'. For instance, through 'nature' and even ruin, Hundertwasser argues, each person should build their own 'beautiful paths': not copies, but unique artistic creations (Hundertwasser, 1983). Again, Day's (2002) conception of 'growing form' from the contingency of human-non-human actions is imbued with a sense of the unexpected. Although both are perhaps not relational in the sense of work on performativity, a sense 
of creative contingency is present here. Moreover, a view to 'getting things done' is also at play (see below). I also like the sense of gathering that Kwintner describes above and elsewhere - and relate this to the idea of translation in the next chapter.

In all, then, there is a valuation and engagement of the contingent, unknowable and unrepresentable. This informs work on performativity, which can feasibly be read in the light of a Deleuzian utopianism, even events judged for their 'good'-ness. Here, one might follow "how thinking needs eventful encounters from, through and against which to emerge and move and that never knows in advance what kinds of encounters will prove most animating" (McCormack, 2002: 482, my emphasis). McCormack mentions playfulness, expressiveness and affectual intensities; Thrift (2000a: 243, citing Caygill, 1998) describes how "Benjamin insists that the experience of the City is ecstatic and futural, haunted by intimations of the future", where it escapes what its makers had intended, where dance can conjure "up the imaginary worlds which lie just on or across the border of perception" (Thrift, 2000a: 242). In this unknowability, there is a move to ecstasy, excitement, play, and a (ruinant) haunting future. These are all elements that are apparent in many constructions of utopia. Furthermore, the sense that Thrift gives of imaginary worlds, almost touchable, conjures up Bloch's 'not-yet' once again, as well as Hundertwasser's version of paradise which is just around the corner (also Anderson, 2002).

I would not wish to mis-'represent' this work too much as I am aware of the difficulties of connecting utopianism with work on performativity. Yet I think that such work gives us renewed vigour to ask how, not what utopias are or come to be. Performativity furnishes us with new tools with which to explore the experience of utopias, whether in literary, architectural or event-al forms. Much of this is un-representable, perhaps: this, then, is quite unsettling itself. Much of this simultaneouly entails the ecstatic, euphoric, but also perhaps the anxious (Dewsbury, 2000: 488; Krell, 1997). Moreover, the ways that utopia can emerge in the un-planned, and contingent, is equally unsettling, connecting again with many other versions of the unsettling I have discussed so far. Hence, although for Foucault (1986), heterotopias are situated in certain everyday spaces 
(cemeteries, libraries), which allow 'normal' life to go on there (see a good critique by Lees, 1997; also Pinder, 2002), here we escape defined spatial forms to encompass a still greater degree of contingency where the energy of utopia is contained within the virtualities of 'everyday life'.

One version of this emerges from the importance of the non-human. ANT equally gives space to the non-human agents in all events (Haraway, 1997; Pels et al., 2002). Again, such accounts are concerned with the performativities of experience that are emergent through combinative acts with non-humans (Turnbull, 2002: 131). Hence the stories of actants, such as Bush Pumps (Law, 2002) and wheelchairs (Moser and Law, 1999), that are mutually co-constituted in networks of spatiality. ANT demonstrates how objects take their place in events, in how situations, and hence how (in Law and in Moser and Law) problems and 'solutions' come into being.

The figure of the 'blank' also figures in ANT. In the sense of a game of solitaire, it is the movement of the blank that allows the game to proceed, not the counters themselves (Hetherington and Lee, 2000). The blank, or the joker, is thus imbued with the power to tack together heterogeneity. Thus more broadly, it weaves sociality, into a temporal condition of order whilst simultaneously presenting (the spectre of) disorder: a continual achievement (adapted from Hetherington and Lee, 2000). I would not assert that the blank itself is utopian, although utopias are often pre-figured by a sense of lack (Anderson, 2002), which can be a powerful, if unsettling 'push' to create. Instead, or related, difference can be tacked together momentarily, whether as community, or as an actualisation (cf. Kwintner), with this unsettling, laughing figure at the heart of moments like this, which moments could be utopian (for Young, Sargisson and Grosz). It is moments like this that are profoundly unsettling, inducing a creepy kind of laughter... . I think that, moreover, a strange desire within and for nothingness - perhaps lack is the wrong word for this is something unsettling - is apparent more broadly. As Metcalfe (2001: 249) comments: "In the moments when we appreciate nothingness, we live more vividly and creatively, with a greater sense of edge. We live also with a greater sense of soul or belonging... . In one sense, nothing is the door to paradise; in another sense, it is 
itself paradise or the flesh of God" (cf. Hundertwasser, 1997). Whatever the escapist fantasy here, I involve the notion of the blank, not necessarily as totally 'nothing' or death (although the relation between death and utopia is an interesting one - see Levitas, 2003 for more) but as part of utopian figures which reveal the dis-juncture, slippage and unsettling nature of life across registers, beliefs, imaginations and actions. I discuss ANT further in the next chapters, however stress here that non-human agents, and the accompanying discussion of ordering and the blank, are crucial in the construction of utopias, and utopian notions such as community. They also relate to the above discussion of ruination. Such a version of ANT is, then, entailed in the performative virtualities discussed above, in the unknowable, un-representable and hence unsettling enactment of 'affect' and euphoria.

However, there is one important difficulty here. Although Harrison (2002) does, for example, attend to the problem of 'truth' and ethics through 'witnessing', experiencing first-hand the whole of an event (how?), it is still difficult to attach a notion of utopia of 'the good' - to these discussions. Perhaps this is a problem or representation, or, a problem of a latent desire to retain or re-discover a more coherent ethics in relation to the performative event, which one might wish to evade. And in some ways, maybe I evade ethics by re-theorising utopia as emergent, performative, or eu-phoric (moving from the spatial eu-topic), which becomes easy once the utopian is theorised as unsettling: but are we so far from utopia now that we are discussing something else? I would say not completely, for two simple reasons that I explain below, both of which are inherently imbricated in spatial praxis. First, that even ethics, foundations (against which utopias have been 'set' in the past) are performed, are not purely ideal or textual, and are, as Harrison suggests, caught up in the ongoing accumulation of singularities as trends, truths, whatever you will. Second, that the utopian unsettling must appear in some guises despicable: how can a notion of 'the good' be attached to ruin, risk, war, violence and death? It is in this 'how', in following this construction and those relationships, that we can try to make qualitative judgments where something as emotive and ethical as 'utopia' is concerned. For instance, would people agree with all the connections I make between utopia and the unsettling in this chapter? 
I suggest that both points might be taken together, but briefly attend to the second, first. Law and Mol (2002) argue that various versions of 'the good' are implicated in inquiries surrounding train accidents. They argue that representational, managerialist notions of the good are bound up in a notion "that perfection is possible" (Law and Mol, 2002: 84). Hence, during legal hearings, all aspects of an incident should be open to the ordered, representational process of the juridicial environment. Yet certain practices evade such distinctions, namely the tinkering of signal workers (Law and Mol, 2002: 99), where ongoing, constantly folding practices are attentive to the contingencies, materials and priorities of given moments. Hence, when their mode of doing 'good' (which Law and Mol argue is not utopian) is opened out in this process, it is translated into the bad. However, I argue that whilst this might be the case, one cannot disconnect the two forms - new, 'good', utopian legislation, from the practices of signal-workers - as they are folded into and always differentially implicated in one another. Hence while these actions may not be utopian per se, these various manners of doing good are representational and nonrepresentational, and attached into a broader ethics of what the good or right might be (whilst all the time, this might also be bad: and unsettling?). This invites a similarity with Revill's (2004) argument on socio-culturally specific forms as they are invoked through the singularity of music listening, and with Fortier's (1999) position that such rootlessness nevertheless requires 'nodes' ( $p .41)$, a spatial attachment to various territories, a performative embodiment of these through and as structures like 'femininity' or 'Catholicism': "[T] he ways in which the formation of group identity is woven through the formation of particular subjects...follow[ing] male and female bodies...as they circulate, and embody, thresholds of meaning" (Fortier, 1999: 42). In particular, I agree with Fortier's double use of 'belonging' to incorporate material objects, attachment, and 'place', and argue a version of this in Chapter 13, in the construction of the house and school communities through the buildings themselves. Here, we are not merely bearing witness to singularities, but evoking connections through attaching these into the contexts in which they emerge, and the hopes (sometimes utopian) by which they are measured. Hence, stabilities are performative as well as performativities are constantly linked to broader, 'structural' notions of, for 
example, gender and belonging. Both and more are folded, collected and worked through chains or collections of events - as I show in later chapters.

The concept of singularity leads me (shamefully briefly) to the work of Alain Badiou. He is quite dismissive of postmodern philosophy (see Badiou, 2003: 47-50) and perhaps it is ironic that $I$ include his work here in light of the above discussion. Yet Badiou discusses in a similar way to Deleuze (with 'one' crucial difference: Badiou, 2000) how a subject cannot exist outside the process and co-relation of the unknowable, undefinable event. This is an ethics of the event, where 'the truth', as well as the subject, emerges out of an agent's capacity to define that event, and cope with it:

"For Badiou, the question of agency is not so much a question of how a subject can initiate an action in an autonomous manner but rather how a subject emerges through an autonomous change of actions within a changing situation...those extraordinary decisions and actions which isolate an actor from their context... . A subject is born of a human being's decision that something they have encountered, which has happened in their situation...does in fact belong to the situation and cannot be overlooked" (Feltham and Clemens, 2003: 6).

Badiou demands a philosophy remote from the world (cf. the above), a search for universals: "This supposes that philosophy will no longer be in pursuit of the world, that it will stop trying to be as rapid as the world, because by [this]...philosophy dissolves itself at the very heart of its desire, no longer being in a state to...know what a universal address is, or to take a chance and liberate existence" (Badiou, 2003: 52). Yet perhaps ironically, as Feltham and Clemens state, this must come from the singularity of the event and the fact that:

"The world we live in is a vulnerable, precarious world. ... We do not fundamentally need a philosophy of the structure of things. We need a philosophy open to the irreducible singularity of what happens, a philosophy that can be fed and nourished by the surprise of the unexpected. Such a philosophy would then be a philosophy of the event. ... A philosophy open to chance, but a chance submitted to the law of reason" (Badiou, 2003: 55-56).

Hence, a fixed point (not theological), where "one must be able to say that this is right and that is wrong," (Badiou, 2003: 54) is required to measure such events, in 
simultaneity with chance - and Badiou is optimistic that this is achievable (Badiou, 2003: 57). Truth comes from chance, the undecidable, where the subject must name an event through experience in order to institute an axiom of truth, a degree of fixing, where the consequences of that axiom can then be measured. However (cf. Harrison, 2002), although "A truth is uncompletable... what we can know, on a formal level, is that a truth will always have taken place as a generic infinity" (Badiou, 2003: 65). For this to attain potency, as a fiction becoming an achieved generic truth, this must be forced. "Thus, the ethic of truths...between the construction of truth and its potency, is that by which we take the measure of what our times are capable of" (Badiou, 2003: 68).

Again, I would not suggest that Badiou is utopian, although his search for such universals might seem as such to some. Instead, my argument is thus: that again, both conceptually and empirically, the notion of utopia (as a figuring of truth and the good), might be attached to Badiou's version of the emergence of the subject and truth. Utopias might be one notion of fixity - whilst being emergent - that Badiou posits. Moreover, they might (contra Badiou) be rooted in the unsettling, contingent, fluid, fast conditions through which they are very often constructed within 'social realities' (cf. Bauman). Where this is a philosophy open to chance, this might connect with utopias open to chance, but also the construction and connection of generalities (if these are, indeed, desired) at once seemingly transcendent and material. As I mentioned above, it is how this occurs - the forcing that is required - that structures the question of how utopia could be unsettling, and how this might be good, comforting, desirable, ruinant, and so on. This requires an effort of translation, through its spatialisation in which empirical performances (nonrepresentational and representational) are given consistency at empirical and conceptual levels (Chapter 4). Hence, open to the chance of performativity and contingency, and of Badiou, the utopian unsettling highlights the unsettling manner in which a utopian ethics comes to be forced (or suggested), how the utopian unsettling provides a considered version of utopias and their construction (and whether that excites agreement or disagreement), and how the utopian unsettling is entailed in a politics, aesthetics and emotive evocation of the actualisation of utopian moments. 


\subsection{Conclusion}

This chapter has opened out more versions of utopia than it has foreclosed, at times deliberately, in order to stretch out new workings of the utopian. It has re-theorised many traditional concerns - and particularly those surrounding difference, home and community - to express and construct a sense of the latent and sometimes obvious unsettling utopianism contained within them. I discussed many versions of the utopian unsettling, thought through revolution, work, the un/homely, ruination, sacrifice and the terrifying, Romanticism, risk and public space, the performative and the ethical. The utopian unsettling is not, I re-iterate, designed to replace any 'traditional' notions of utopia. It is partially, but not completely, a move from the eu-topic, the 'good' to the euphoric, spatialising, contingent and unsettling. I argue that I have illustrated many ways in which traditional notions of the good are not just founded on various exclusions, but a whole raft of unsettling, dis-comforting processes and desires, in which the eutopian and euphoric, the good and unsettling, are (ethically) mutually implicated. Furthermore, with deconstructions of familiar/unfamiliar, homely/unhomely and so forth, 1 argued that such notions as ruin and contingency were, contrary to the concrete havens desired throughout modernity (liquid or solid), in themselves goals, processes or emotions that were desired. Hence I question the relationship and dualism between utopia and dystopia, through these versions of the unsettling, where a complicated array of emotional, ethical and performative strategies must be used to negotiate the unsettlingyet-positive manner in which utopias can come about.

The notion of the 'goal', or the 'good', is thus problematic where I have stressed contingency, the unsettling and even war. On the one hand, I show how desires for the 'good', euphoric moment or satisfaction are emergent - hence the importance of performativity, and of the contingency of seemingly stable goals like homeliness and community. On the other, I ascribe importance (through Badiou, for example) to goals that are still emergent - they could never be totally removed from contingency - but are also implicated in past, present and future truths, structures or 'goods'. These may fail at any instant, yet a more sophisticated depiction of their construction and experience - 
driven by sometimes uncomfortable yet necessary energies such as the idea that utopia can be unsettling - would begin to highlight how certain 'truths' are forced into being. Alternatively, on a less grand scale, we might follow how utopian notions such as comfort and dis-comfort are evoked, chosen and discarded in a material, emergent and more 'structural' sense. Ultimately, much of this does remain un-representable (a key facet of what is unsettling about utopia). However, I suggest that, in a humble way, we attempt to make connections, forge collections/dispersals, and translate actions through the research process. Hence, I attempt to do this in the following chapters, and hence, as I have shown and will show, some of the ideas of the utopian unsettling were themselves emergent from my work at the house and school, contextualised by the critical geographies I encountered there.

Finally, I wish to indicate a few 'signposts' to later chapters, making clear the importance of the utopian and utopian unsettling to my empirical discussion. Firstly, and most importantly, many of these versions of the unsettling, and many empirical practices to which these might be attached, are just parts of other events which are defined as utopian in quite a different sense. For example, a chain of events and ideas leads from Hundertwasser's ideas on ruination, to difference (Chapter 6), to the appearance of tourists at the house, to the house as home, to a specific moment-assemblage becomingutopian (Chapter 9). It is these connections, chains and foldings that characterise the emergence of utopian ideas in context, and the translation of, for example, Hundertwasser's and Day's designs through practice into other ideas. Only some of these are 'utopian'. Secondly, 'traditional' and unsettling versions of utopia do become apparent in a more obvious sense, in particular through my consistent emphasis on difference, the homely and community. From reading Day and Hundertwasser, as I indicate above and in Chapter 6, their ideas share consistencies with utopian energies. For instance, in ideas about work, the actual/virtual, ruin, art, ecology and spacing, we see important links with their writing and practice. Moreover, in the various practices that I encountered at the two buildings, through the critical geographies of architecture I attempted to effect there (Chapter 4), these themes were folded into people's practices and discourses, the contingency of their actions there, the materiality thereof, their ways 
of doing 'good' (like making a homely school), the pain of nostalgia, or the work involved in making a material community. Again, at times these moments are not utopian - at least not as traditionally conceived - yet throughout the following chapters we see how a concern with utopian and architectural themes of difference, home and community emerge at certain instances as quite distinct utopian ethics and emotions. 


\section{Chapter 4 Critical geographies of architecture: collecting and dispersing buildings}

\subsection{Introduction}

Architecture is an important field for the study of utopia, intimately linked with the utopian imagination throughout history, as shown above. However, I am not merely interested in how architects have attempted to build or symbolise utopia as did Le Corbusier or Howard (Fishman, 1999). I want to follow how these designs interact with people's everyday experience of them, and the emotive spatialities these performances enact, enabling me to explore how emergent notions of utopia are actualised. What is required, then, is a joint material-semiotic, performative mode of thinking about buildings, as one way through which the emergence and importance of utopia 'today' (and historically) can be theorised and researched.

The second aim of the thesis is thus in many ways the primary (but not ultimate) goal. I question the stasis, and often comfort or homeliness, with which many architecturalutopian visions have been imbued, linked to the general stasis that characterises architecture as a pre-given, concrete container. In terms of the empirical chapters, although Day and Hundertwasser hold different ideas about utopia, I explore how these ideas interact with people's lives with these buildings. Therefore, I started with a general interest in the priorities and actions of the people there, an 'open', ethnographic methodology. Thus I looked at how collections/dispersals of discourse, materials and action might become utopian, how they become 'points' of interest or intensity, whether collectively, individually, ephemerally or 'structurally'. It is this collecting/dispersing that I discuss in the last part of this chapter as efforts of translation, of a critical geography of architecture in search of often ethical-and-emotive attachments which sometimes become utopian, sensitive in particular to the house and school. Here, I argue, it is through this motion, and people's attempts to understand and become attached to specific assemblages of Lees' (2001) 'messy geographies' - mixtures of texts, materials 
and performances - that various versions of the utopian (unsettling) emerge throughout the thesis.

Before that, and bearing in mind the importance of architectural performativity to the thesis, I examine Lees' (2001) 'critical geography of architecture'. To contextualise this, I briefly explore the 'symbolic' approaches of which she is critical (in which utopian elements are also apparent). Then, I discuss another 'non-representational' approach to buildings through ANT: the work of Gieryn (2002). I realise that these are not the only two recent approaches to architectural spatiality, although they neatly exemplify two differing, non-representational approaches. In the same section (4.4), I also discuss other recent approaches, some of which appeared in Chapter 2. Thereafter, I re-engage with non-representational theory, mixing performativity and ANT in order to develop all of these geographies. I enlarge the framework for critical geographies of architecture and utopia, and although not all of these discussions appear later on, they contextualise much of what I try to say.

\section{2 'Reading' architecture}

The relationship between previous accounts and those of Lees is less clear-cut than I make it seem, as very often 'symbolic' accounts are always already material (Nash, 2000). In other words, all of life is only material-and-semiotic: Lees, Thrift and others stress the non-representational elements of this, arguing that these have been underrepresented in explanations of buildings and spaces. Hence it seems a little unfair to characterise 'iconographic' approaches to buildings all as pure (and mis-guided) precursors to a seemingly more balanced approach. Moreover, there is not space here to do justice to the variety of these methodologies. These are also more fully discussed elsewhere (Cosgrove, 1998; Matless, 1998; Lees, 2001; Robertson and Richards, 2003), and are also found in attempts to 'read' buildings whilst setting them into wide-ranging attempts to theorise power and (post)modernity (Davis, 1990; Soja, 2000). Additionally I provide less room for these as they form less important elements of my methodology, which draws far more on Lees, Gieryn, ethnographic/performative literatures. I will 
therefore provide a basic discussion of 'reading' landscapes, demonstrating how these inform Lees' work and a few aspects of my own. Most of these are also related to utopia in some way (but see Chapter 2 for more - for example Jameson, 1991; Fishman, 1999; Worpole, 2000).

Research on humans' relationship with landscapes, and the ways these can be read, has been crucial in exposing the emotive and politicised meanings of places and often buildings. A variety of methods culminated in synthetic 'iconographic approaches', drawing upon humanist and Marxist work, often focusing on the spatial constitution and expression of Modernity/ies (see Barnes and Duncan, 1992; Cosgrove, 1998; Cosgrove and Daniels, 1988; Daniels, 1993). Importantly, where utopia has been intimately related to constructions of Modernity (Levitas, 2003), a whole raft of these examples - from colonialism to Modern architecture - can be fruitfully 'read' in relation to utopian aspirations and politics.

A need to account for the political importance of landscape structured these varied iconographic approaches (Duncan and Ley, 1993; Daniels, 1993; Cosgrove, 1998). Here, landscapes could be read to uncover the power relations that led to their spatial organisation and symbolism. So too could images of those landscapes be related (through inter-textuality: see section 4.7) to certain groups who wanted to legitimise, applaud or subvert those meanings. Landscapes (and buildings) are thus inherently imagined at the same time, as they are 'real' and practiced. It was argued that representations of these imaginations (paintings, photographs) are particularly important to understanding such conflicting meanings for various populations (from the Industrial Revolution, to US nineteenth-century expansion, to Inter-War rural Britain: see Daniels, 1993; Cosgrove, 1998; Matless, 1998). Such representations, and hence landscapes themselves (and architecture as somewhat of an intersection between them) can therefore be seen as visions, rather than pure, rational presentations of reality. Therefore purportedly 'scientific' texts (such as those of Ruskin) and educational practices (Gruffudd, 1996) can be re-read as politicised attempts to construct discourses around the nation, rurality, nature or empire (Shurmer-Smith and Hannem, 1994; Driver and 
Gilbert, 1999). Similarly, then, we can read inter-textual symbolism and appeals to both emotion and power in built forms, as complex reflections and gatherings of emotion, nationality, power and politics (for example, Gruffudd, 1995; Dovey, 1999: section 4.7). Again, through the importance of Modernity to many of these spaces and texts, we can expose and deconstruct the assumptions that led to these power-laden representations, in discourses over 'Modern' morality, education, health, science, the power of 'institutions', and technology (Philo, 1987; Ploszajska, 1994; Worpole, 1999).

Crucially, however, we see the power of ideal or even utopian interventions into spaces and their representations. In fact, it is in representations of Modernity that we find many utopian and dystopian legitimations and critiques: from Ruskin, Owen and Morris, to Le Corbusier and Rodchenko, Orwell, Lang and Wells, Ballard and Le Guin (see Kumar, 1987, 2003; Margolin, 1997). Aspects of colonialism (exploration, expansion, and the exotic), of US expansion, of revolutions, of National Identities - all have utopian connotations, desires, emotions and politics, and all represent key elements in the constructions of ideas about Modernity. I highlighted the importance of architecture to such readings in Chapter 2.

All of these 'images' have been interrogated by geographers, through following their effects on landscape and representations thereof (for example, Cronon, 1991; Allen, 1992; Gregory, 2000; Holloway and Hubbard, 2001). One could never argue that Modernity ${ }^{1}$ was and is always utopian, or that these representations can only be read through a utopian lens. However, in the perfect, stable, 'inclusive', ordered and often homely forms - from communities to buildings to nations - with which the (spatial) aspirations of Modernity and its many discontents are often associated, we see various versions of the utopian at play in the imaginative construction of pasts, presents and futures. For me, perhaps the crucial contribution of iconographic work is not merely an uncovering of the social construction of landscape and space, and the conflicting ways in which spaces can be represented. For additionally, they show that a kind of visioning

\footnotetext{
'Of course, not a coherent idea, things or process, or even historical period, if 'it' ever happened at all (Latour, 1993; Kwinter, 2001)
} 
was necessary - collective or individual - in which society is experienced and imagined, and through which a continuous spatio-temporal thread from past to future is woven in order to legitimise, subvert or overturn a perceived status quo. This may or may not be utopian, however the relation between utopia and ordering is clear (Hetherington, 1997; Parker, 2002a), and is expressed with other associated discourses in, for example, the organisation of ideal cities (Barricelli, 1999; Fishman, 1999). The critique of such work still stands: life cannot be reduced to a text, whether metaphorically or in terms of (academic) explanation and representation (Thrift, 2000a; Lees, 2001). However, such ways of reading provide many insights, and inform my approach to architecture in acknowledging that these symbols and power-relations continuously inter-weave and mutate through everyday use, and provide architecture with a particularly utopian impulse - whether affectual, political or both - throughout history. Moreover, many of the points I made in Chapter 3 emerge from these kinds of readings, again 'read' through the practices and emotions with which they were associated.

The argument I take forth into the next section is, then, not merely that we should knowingly explore the material and semiotic, visual-symbolic and performative-precognitive, although this conjoined notion is helpful (Nash, 2000; Mitchell, 2000). In addition, we must simply recognise that all of life is always already embodied and performed (even writing), and that those performances come to gain a degree of subjective consistency - when and if we want that - through textuality. I propose a way of following how sense is made - and, as Badiou (2003) notes, how ethical universals are 'forced' - through a notion of mutating collections/dispersals of heterogeneous elements ('texts', 'practices' etc.) as events, in section 4.7.

\section{3 'Critical geographies of architecture'}

In Lees' account of Vancouver's public library, she focuses on the stories and nonrepresentational 'meanings' (if that is what they can be called) that happen there. She argues that many geographies of architecture (for example, Goss, 1988) have failed to account for the complexity of architectural meaning, in particular where architecture is 
more than 'just' representation, also being practiced, inhabited and embodied. Importantly, she does not suggest that Marxist, symbolic, or traditional ways of investigating architecture should be jettisoned - just that the ways 'ordinary people' actively consume, interact with and produce architecture have open, inter-related characteristics, of which as many as possible must be included (Lees, 2001: 55). Drawing on non-representational theory (like Thrift's), Lees suggests that meanings and enactments of architecture are highly complex yet politically potent performative entanglements.

Lees examines a variety of architectural practices through the example of Vancouver's new public library through the design competition, and the 'vignettes' of library use by people from 'ordinary' readers to homeless people " $\mathrm{My}$ hope is that disclosing a selection of vignettes will convince you, as it has me, of the importance of the library's ongoing appropriation and use" (Lees, 2001: 72). Thus, Lees implies that it is impossible to 'know' fully all of a building's meanings, so that such short stories, examples of use, discourses and ideas might be indicative of what goes on there. Here, dwelling and architecture are simultaneously constituted by each other in a variety of heterogeneous, non-hierarchical ways, which are often 'messy'. Lees argues:

"If we are to take seriously this suggestion that an architectural geography must address itself to something beyond the symbolic - to questions of use, process and social practice - important methodological implications follow. Traditionally, architectural geography has been practiced by putting architectural symbols into their social (and especially historical) contexts to tease out their meaning. But if we are to concern ourselves with the inhabitation of architectural space as much as its signification...we must engage....actively with the situated and everyday practices through which built environments are used. In this regard, ethnography provides one way to explore how built environments produce and are produced by the social practices performed within them. Those pursuing such a project, Thrift argues, must be observant participants rather than participant observers. ... [However], adopting an ethnographic approach to understanding architecture should not mean abandoning questions about the meaning of built environments. Rather, it means approaching them differently, as an active and engaged process of understanding rather than as a product to be read off retrospectively from its social and historical context. ...If the aim of a more critical geography of architecture must be to engage with those...practices through which architecture is inhabited, its understandings cannot be produced through abstract and a priori theorising" (Lees, 2001: 56-57). 
Again, Lees is keen to show the "series of gradual steps I have taken away from [a] conception of architectural space as something...identifiable and stable" (Lees, 2001: 59). Thus even architecture, potentially one of the most concrete of arts, is rendered unstable in an acknowledgement of ongoing contingency. To return to the longer excerpt above, Lees is setting a precedent for geographers to engage more fully with inhabitation, both as reflexive researchers, and in attempts to develop an ethnographic approach. This has already been taken on in a geographical-historical context in Llewellyn's (2003) analysis of everyday negotiations with/in Kensal House in London. Here, he constructs a more engaged method of dealing with buildings as they were experienced in the past. He is thus not just concerned with the meaning of 'Modern architecture' defined posthumously through the eyes of the most important architects (Llewellyn, 2004). More broadly, this way of working shows how the symbolism and meaning of buildings is not merely something provided a priori and then read, but continuously constructed through use. For all its advantages, however, there is more to be gained from the performativity literature than Lees mentions, as well as there is from ANT and related approaches. Moreover, I hope to show how different buildings in different contexts provide very different critical geographies, with particular reference to ecological architecture, and discourses Lees does not attend to explicitly: difference, homeliness and community.

Usefully, Lees (1997) also routes these geographies through a discussion of public space, to a critical discussion of Foucault's (1986) 'heterotopias'. This is helpful in further indicating the link between architecture - and more practice-based geographies thereof - and utopia (as for Grosz, 2001; Pinder, 2002). I attempt to extend this emphasis on public space into other sites of community - which I argue is one of the major points of interest for utopias - in Chapters 11 and 12. Unlike Lees, I am keen to stress further the utopian and creative possibilities of a variety of notions, forms, functions and contents of utopia, many of which I have loosely grouped under the term 'utopian unsettling'. In particular, the uncanny and un/homely are major axes for this thesis and many interpretations of architecture (Vidler, 1992; Krell, 1997), and I think would take us in other directions than Foucault's much-criticised concept (see Curry, 
2000). Nevertheless, Lees' critical reading of Foucault highlights the combination of a postmodern utopia - an 'autopia' which "[I]llustrates the coexistence of heterotopia (a postmodern model of utopia) and the ageographia (a dystopic model of postmodern reality) in one place" (Lees, 1997: 343). This combines a consumer oasis with the terms of Foucault's 'contestatory countersites', and the ageographia, to render the everyday performances of the Vancouver library as (again) messy, complex and performative versions of utopia. Through the critical geographies of the Hundertwasser-Haus and Nant-y-Cwm School, I demonstrate how other concerns (some less overtly political) such as difference, the homely and community provide other images of 'postmodern' utopias, and many other versions in which the seemingly dystopian and utopian might be combined or worked through in an often more unsettling sense, which draws on performativity and contingency.

\subsection{Gieryn's 'moments' and other approaches}

Gieryn (2002) draws attention to the ways that buildings are artifacts that can be drawn into society in particular ways, in order to have specific network effects. He draws insights from ANT to describe how the building of a new laboratory - Cornell Biotechnology Building (CBB) - is constituted by a non-sequential, heterogeneous, negotiated design process, which enlists and seeks to stabilise various influences and claims. Eventually a degree of sought-after 'closure' is achieved, at least for an instant in an assemblage, an 'emerging social structure' of which the building is a lynchpin (Gieryn, 2002: 49). In this process, the other possibilities that could have been, right up until the first bricks were laid, are lost "in the seeming inevitability of the plan that did get built" (Gieryn, 2002: 61). Moreover, even the bits that were incorporated into the building are hidden in its materiality, so that the successful arrangement of political, biotechnical and academic intentions is normalised: "Biotechnology has become what the CBB was built to do, sealed up in a gleaming white skin" (Gieryn, 2002: 61).

The three moments Gieryn identifies in this stabilising of ideas into form follow the negotiation, materialiation and interpretative flexibility ('use') of the building. Gieryn's 
contribution is at its best in relation to use, and tallies with Hundertwasser's thoughts on the continued work done on buildings - which for him seem to be never 'built', just buildings". Gieryn notes: "Edifices endure, and they don't. Even in the first few years after its opening, the CBB did not stand pat. No building stabilises social structure absolutely because no building is itself permanent and untouchable. ... Itself an agent now in the stabilisation of biotechnology, the CBB never really ceases to be an object of human agents eager to tinker with it. Design continues forever" (Gieryn, 2002: 65). And again: "Buildings invoke endless narratives, not always consonant with those heard earlier as people and powers were enlisted and aligned to move dreams towards reality" (Gieryn, 2002: 65).

Gieryn watches how buildings are eventually stabilisations of many possibilities into one built form (a form of a utopian 'perfect' solution), but also how they are then open to "interpretive flexibility" (Gieryn, 2002: 41). This notion, I believe, can be augmented for watching the specific ways in which discourse and practice is collected into and dispersed from a building, discussed later. The form of perfection or stability sought after at the CBB is deconstructed by Gieryn, as well as the contingent constitution of any reality is fleshed out. As I demonstrate below, this interpretative flexibility can be related to the utopian unsettling. For, where buildings are intimately linked to utopias, and are unsettling in various ways in addition to those mentioned by Gieryn (see Vidler, 1992; Krell, 1997), the construction of utopias - of stasis, comfort, home or work - is equally imbued with mutability and anxiety.

There are some problems with Gieryn's account. It is perhaps too narrowly focused on the human actors at the building, in particular the various interests that go into shaping the building itself, rather than the action of materials themselves found in ANT (Latour, 1999; Law, 2002). He also falls back, in his conclusion, on notions of a more representational 'interpretive flexibility', rather than fully assessing the agency of non-

\footnotetext{
${ }^{2}$ I will return to this point in Chapter 6. For now, it is worth noting that Hundertwasser's and also Day's conceptions of buildings are more performative than Gieryn's as they stress the material act of building itself, as well as design and use. This also allows us to move away from 'moments', to Lees' 'vignettes' and the construction of architectural 'becomings', which are more consciously utopian.
} 
humans and the performative, affectual re-negotiating of the building after its completion (as Lees attempts). Although he is interested in the rendering material of a form, and although the building is a laboratory rather than a home or school, his very insightful analysis of the building requires more depth relating to everyday geographies of use at the lab, as well as the meanings and phenomenological attachment, and inequalities and competing power relations people feel there.

Lees' and Gieryn's approaches both have various, over-lapping advantages, but none more so than an emphasis of the contingent, often non-representational ways in which architecture is enacted. This is not to say that these two are the first to follow how spaces are produced and consumed, or to emphasise performance, as we find this in the work of Lefebvre (1991, 1996) and de Certeau (1984), for example (Soja, 2000; see Thrift, $2000 \mathrm{c}$ for a critique). Moreover, it would be false to assert, as I noted earlier, that attempts to 'read' architecture and landscape have not acknowledged such contingency or performativity. Additionally, in the work of Davis (1990), Jameson (1991) and Soja (2000), for example, although we do not always see empirical material culled from interviews and in-depth observation - and despite a bias on the power relations written into particular forms such as International Style and Post-Modern architecture - we see attempts to think how these developments affect those 'on the ground'. In Soja (2000), who follows a Lefebvrian dialectical (what Soja terms 'trialectical') conception of competing productions-consumptions of space, there is a concern with how excluded groups try to create a space for themselves in terms of resistance and creativity. Lefebvre himself (like de Certeau) draws on the rhythms of everyday life in the city, the gestures through which spaces and power relations are constituted, and thus architectural spaces are imbued with continuously new, if competing, affective and performative capacities (Lefebvre, 1996; Seigworth, 2000). Moreover, in such politics of resistance, we see a Romanticisation of particular practices and a utopianism that valorises such everyday, small-scale practices rather than large-scale 'Representations of Space' from above (Lefebvre, 1991; Merrifield, 1995; see Thrift, 1997, 2000b for critiques). This reconnects with a raft of utopian potentials geared around performative engagements with the city, discussed in Chapter 2 (for example, Grosz, 1992, 2001; Pinder, 2002). 
Although many of these authors may not mention 'performativity', there is a double connection with the gestural production of (architectural) spaces and utopian potential here. A concern with bodies and spaces, and especially the power relations constituted in their relationality, continues into very recent discussions of architects' 'ideal' conceptions of the body (Imrie, 2003) and the intimate, complex links between the domestic and the urban in conceptions of the ideal (masculine, utopian) city (Baydar, 2003).

Yet although there is a rich empiricism in many of these accounts, what those such as Lees, Gieryn and Llewellyn attempt is to engage particular buildings through ethnographic methods. I do not argue that this is the best way to research and theorise the performativity of buildings, nor that the powerful, more general theoretical insights of Grosz, Pinder and others are too removed from specific examples, as they theorise the general relation between bodies, power and architecture (and also utopia for these two). However, despite a concern for such bodily practices, we continue to see an emphasis on architects (Pinder, 2001; Imrie, 2003; Baydar, 2003), on symbolism rather than symbolism-and-materiality (Davis, 1990; Jameson, 1991), and on large-scale concerns such as 'the city' (Baeten, 2002b; Pinder, 2002). I therefore take much from the general insights of these approaches, and their theoretical valorising of the body, power and often utopian desire, but seek to engage these more fully with re-formulated conceptions of performativity, materiality and power/ethics. This means linking Lees and Gieryn with these other theorists above, as well as adding my own reading of ANT and performativity, with a concern for large-scale and specific ethnographic material, and the rhythms, ethics, objects, actions and (utopian) desires that emerge.

\subsection{Actor Network Theory}

Objects play a massive role in our society. They themselves, or the very idea of their existence, are able to tack together social pressures: at the same time they are the rendering frozen of these pressures in particular ways, perhaps modest reminders of the necessary materiality of life (Hetherington and Lee, 2000; Gieryn, 2002). A non- 
hierarchical sociology of socio-spatial constructions with objects can be found in very different studies, which I collect under the term 'Actor-Network Theory' (ANT) (see collections edited by Law and Bijker, 1992; Law, 1991; Law and Hassard, 1999; Bingham, 1996).

A key concern amongst those who deconstruct traditional binaries, and show how seemingly set boundaries are unstable, has been a focus on the mutual co-production of entities whose limits are hard (and undesirable) to define (see Deleuze and Gauttari, 1983). Doel points out: "So, anyone who cares passionately about social space must satisfy themselves with relations - and nothing but relations" (Doel, 2003: 141, original emphasis). Law similarly argues that ANT "[T]ells us that entities take their form and acquire their attributes as a result of their relations with other entities. In this scheme of things entities have no inherent qualities" (Law, 1999:3). Latour (1999) argues that ANT is less a theory, more an arontology, or an ethnomethodological move which listens to subjects, thus stopping sociologists acting as legislators and interpreters, letting "the actors...deploy their own categories" (Latour, 1999: 20; cf. Lees, 2001). For him, ANT focuses on the circulation of actors, again in sets of relations, whether human or nonhuman, allowing different actors different degrees of 'actantiality' at different times, although certain of these provide 'obligatory points of passage' and thus hold more relative 'power' (Latour, 1999: 18; Latour in Moser and Law, 1999).

ANT attempts not to give qualitative judgments (and I think, not utopian visions) as to the effects or running of certain networks, although it can comment on how certain effects are produced (Law, 2002). Moreover, a concern with the missing masses of society (objects), the necessary materials with which our daily social lives are held together (Pels et al., 2002), has taken on an almost moral edge. In fact, however, the relational thinking of ANT does allow a particular conception of morality, although not one conceived of in terms of the means and ends of a Heideggerian Being (Latour, 2002). Instead, this relational way of thinking, recognises that our moralities are constituted through others - both human and non-human, in a ceaseless mediation of power. "The work of mediation, in its moral organisation, requires instead the ceaseless 
circuit of concern...the anxious reopening of the tombs in which automatisms have been heaped, the redeployment of means into partial aims and aims into partial ends" (Latour, 2002: 258). This notion is also highly performative, in that it recognises that "[entities] are performed in, by, and through...relations" (Law, 1999: 4). This tallies strongly with the relational forms of power and resistance found in Thrift (1997) and Hinchcliffe (2000) (see also Popke, 2003 on ethics). The materiality of this ethics, I think, would augment critical geographies of architecture, as I illustrate in discussions of community later on.

A questioning of ANT has largely focused upon its seemingly a-political and nihilistic stance. It has prompted many (for example, Harre, 2002) to re-stress the importance of symbolic and representational orders, as well as to push for a reconstruction of 'humants' - a differential understanding of humans as distinct form objects (Vandenberghe, 2002). Others have attempted to link the material and semiotic, to negotiate their ways around worlds of technoscience (Haraway, 1997) or to show how "[T]hrough specific agential intra-actions...the boundaries and properties of the "components" of phenomena become determinate and that particular embodied concepts become meaningful" (Barad, 2003: 815). There is no need to recount the whole array of ANT studies here, or their critiques, (for more: Law et al., 1999; Theory, Culture and Society, 19(5/6), 2002). What interests me is what these insights say about space and hybridity, architecture and 'performativity' (section 4.5). I discuss space and spacing further in section 4.7, although I would note here that ANT stresses that objects exist in various spatialities, are involved in the co-relational production of space, held precariously in relations that may fall apart at any moment (Law, 2002; cf. Dewsbury, 2000 , below).

The other crucial point is that ANT stresses the hybrid, non-hierarchical, contingent and co-produced relations that operate in continually structuring our society, rather than allowing for stabilities or norms (other than discursively) to exist. ANT is concerned with the nature of boundaries between human and non-human, and in particular the combinations of technology and flesh that can create cyborg beings (Haraway, 1997). I 
think architecture can similarly be theorised as cyborg where it combines technology into its fabric and functioning (for a technological review, see Streitz et al., 1998; Wisneki, 1998; Frazer, 1998 - all on 'co-operative buildings'). This is not merely 'technological'. ANT has been taken into a realm of questioning the 'culture/nature' dualism (Haraway, 1997). And where, as Deleuze and Guattari (1987) suggest, wasps can become orchids, buildings can also become-nature or become-human and viceversa, such that the re-combinative virtualities for a cyborg or hybrid architecture are enormous. In this thesis, for lack of space, I do not discuss the potential for ecological architecture in particular to be crossed with such post-structuralisms, although there is a need for this when considering the either romanticised or hi-tech tones of ecological architects (Papanek, 1995; Wines, 2000). Nevertheless, I do show how Hundertwasser's and Day's approaches to living (in) architecture, as well as the basic tenets of ecological architecture, promote the fundamental role that the agency of nature itself has in architecture. This comes not merely in relation to design, but in the heterogeneous combination (which I term collecting/dispersing) of many elements into intra-active, sometimes meaningful, sometimes utopian, discourses and practice (Barad, 2003). Moreover, the important role that material and in particular 'natural' processes - active agents such as plants, mould and ruin - play in such networks, fascinates various authors (from Deleuze and Guattari to Hundertwasser), and I attempt to stress this too.

There are very few examples of buildings being treated as either assemblages of objects (through various scales), or objects within network-landscapes. I also argue that this would be very useful in theorising the inter-active meaning and agency of buildings and their constituent parts within the landscape relations of which they are a part. Even Gieryn's account, for instance, does not follow the various spatialities and scales in which buildings exist, and work on laboratories and other institutions also fails here (Latour, 2002). I am therefore interested in the various things that buildings can do as part of changing assemblages and over various scales (see section 4.7). Crucially, as does Gieryn, I relate this to the production of various discourses, but unlike Gieryn, I attempt to fuse this with the more emotive ways in which people experience buildings through difference, home, community and utopia, and to ask: how are these ideas 
produced at and by buildings, in context? This attachment of materiality to emotion, with performance, provides a means through which to theorise and follow various ethical debates. Interestingly, there have been recent attempts to cross ANT approaches with concerns for the meanings of places. This can be found in Cloke and Jones' (2001) discussion of a Somerset orchard, and Turnbull's (2002) re-'reading' of Maltese megaliths. Both, and particularly Turnbull, stress how phenomenological engagements with landscape - such as attachment to 'place' and religious spirituality - come through contingent and performative relations between human and non-human actors. This develops insights from Relph (1976), Tuan (1977) and Norberg-Schulz (1985), to stress how such deep engagements with space are as much a product of non-human agents as of human experience. On this note of experience, I now draw together some of the many above references to performativity and emotion.

\subsection{Performativity (and non-representational theory)}

Above, we see an opportunity to fuse and extend Lees' and Gieryn's work in various directions. In particular, we can use research on or beginning from buildings to interrogate themes of relevance to both contemporary theory, and those of interest to utopia: difference/unfamiliarity, the un/homely and community. However, an interest in such themes, in buildings, and in the non-representational enactment of utopian moments, also requires a discussion of performativity. I discussed this in relation to utopia in Chapter 3, so focus on the benefits that performative geographies might bring to geographies of architecture, in addition to those that Lees cites. I do this through notions of shakeability, contingency and creativity; the sensuous experience and production of space; collective individuation; rhythms; and power relations and difference.

Dewsbury (2000), commenting on the shakeability and mutually emergent character of human action and the environment, argues that performativity comes through convergences and ruptures (rather than unshakeable completions), and that in all situations: 
"It is a question of speeds and slowness, of relations of movement and rest...the building you walk through/within - what is the speed of flux that is keeping it assembled? It seems permanent...but it is ephemeral nonetheless: whilst you are there, it is falling down, it is just happening very slowly (hopefully)" (Dewsbury, 2000: 487).

Although taken slightly out of context, I think this statement can lead in a few directions. Firstly, the question of performance through/within a building is slightly disconnected here - the focus moves from the walking to the building itself, rather than the mutual coproduction of the two. Is the 'falling down' also performatively produced (as for Gieryn; also comments by Law, above), maintained or quickened by people's action there? Dewsbury goes some way to answering this: "Often it is our surroundings that appropriate what we do...such that we are forced into 'never-before-occurring' situations that 'become us'" (Dewsbury, 2000: 488; see also Deleuze and Guattari, 1994 on becoming-other than human and percept/affect; also Lynn, 1998 in an architectural context). This again highlights the un-decidability that a postmodern/post-structural deconstruction of traditional certainties is seen to have achieved (Norris and Benjamin, 1988), however does not show how this is cut across by various spatio-temporal disjunctures and attempts at stability that many people attempt to forge, especially discursively (Law and Mol, 2002; Revill, 2004). Secondly, and related, Dewsbury highlights the anxiety and insecurity that characterise these 'never-before-occurring situations'. There is here the worry that we may never perform as well again, that we should avoid places unlike any other, whilst the world is indeterminate, (even in purportedly 'solid' buildings), and full not of repetitious possibility but continuously virtual newness (cf. Deleuze and Guattari, 1983; Bauman, 2003; compare with the Freudian uncanniness of the unfamiliar). The acknowledgment of the unsettling, ruinous (architectural and non-architectural) nature of this existence was a crucial element in my discussion of utopia. Thirdly, Dewsbury's notion of the spatial relations that hold a building in place/as place can usefully be connected with spatialities identified in ANT (for instance, Law and Mol, 2001).

Again with architectural metaphor, Thrift (2000b) continues a line of thinking that can be traced through Heidegger, Freud and Dewsbury's quotation, which links up the 
concept of the unsettling and unhomely with performativity, and the euphoric therein. He states that ' $[P]$ erformance conjures up the precarious 'emptiness' of the now, and, in so doing, provides a distinctive force opposed to the representational economy in which we live; 'Non-preservable, fluid, full of uncertain architecture and temporary sets"” (Thrift, 2000a: 233, cites Phelan, 1993). (Too) Much could be made of this quote, in particular Phelan's metaphorical reference to architecture. But I would note not merely this metaphorical use of architecture, as a discursively 'stable' form or framework, that therefore serves to more forcefully underline the precariousness of existence. Nor does the quote simply illustrate again that architecture is itself unstable in terms of ruin, contingent use, or the (in)stability of the relations that hold (in) it (cf. Dewsbury, Gieryn and Law). Rather, the point is, following Krell's (1997) readings of Heidegger and Freud, that existence with or without architecture can be characterised as deeply unsettling and anxiety-inducing, shakeable, but full of virtual creativity. Importantly, I think, this in part conjures what Thrift (2000a) terms the 'performative push' to action a push to creativity and newness, not a seemingly deconstructive or pessimistic tendency to value and evaluate only contingency or even rupturing, falling down. Similarly, a valorisation of ruin, the contingency of 'natural' processes, and of seeming chaos are all elements that can be connected with the history of utopia and architecture (cf. Woodward, 2001; for instance, Hundertwasser, 1997). Again, as performativity draws on the actual/virtual, we find continuously new versions of utopia and the emergence of utopia as desire, creativity and contingency - yet through unsettled and even ruinous actions and emotions.

An example of this in a related direction points to the acknowledgment of the sensuous, often forgotten elements of experience that are lived before and within representations (Harrison, 2000; also Curry, 2000). Harrison is concerned in part with the life of cities as a facet of the experiential nature of everyday life. He develops a performative understanding of action that is neither individual nor generic, producing new spacings and surfaces that are '[E]nactments of a world and an individual' (Harrison, 2000: 502). Like Dewsbury, he focuses on what seem like almost minutiae of events, yet which illustrate the potential-filled, explosive nature of events in their unfolding. Harrison 
could be criticised for focusing more narrowly on human actors in these unfoldings than necessary (whereas perhaps aspects of ANT focus too narrowly on non-human actors), however this does not seriously detract from the debate he sets up. For him, the everyday life of cities (and, implicitly, of buildings) is not adequately characterised by the notion of building - the a priori construction of a world which is then lived in. Instead, following Heidegger and Ingold (2000), and again reminiscent of Deleuze and Guattari's (1987) concept of the actualisation of the virtual, he prefers to see practice as sensuous, pre-cognitive $d w e l l i n g$ - non-representational, affectual, newly built-as-it-is-lived, where we can only think of, as we dwell in the world. As part of this thesis, the question I sought and seek to answer, however, is: how much is this dwelling part of a desire to be at home?

The spatiality of these sensuous moments is key to enactment, explored through actions as collective individuations: "Embodiment revolves around an ever-ongoing combination of heterogeneous elements; a collective individuation of objects, things, contexts and other bodies. The unity of embodiment is a fusional multiplicity" (Harrison, 2000: 508, original emphasis). This notion of collective individuation will appear later in relation to the school and house, and hence in section 4.7. I go on to suggest that this collective individuation, this dwelling in space, involves architecture fundamentally, simultaneously as an 'object' within the collective individuation of an embodied subject or wider scaling, and a form of embodiment (a collecting together of objects, bodies, spaces, materials and discourses).

Harrison does relate this dwelling to urban spaces at least, in his discussion of the rhythmic relationship between the body and architecture in Benjamin's work. Here, "[D]istraction absorbs architecture into the body, and vice versa, via tactility...an embodied, geohistorically specific, sensuous knowing (enacting) of the everyday" (Harrison, 2000: 511). Again, this relation is complex, as McCormack shows in his tracings of bodies/spaces and rhythms in a corridor (McCormack, 2004). With an interest in virtualities, rhythms and gestures, and my own interest in how these might appear in the context of desire, euphoria and utopia, we not only re-connect with 
Lefebvre, de Certeau and Grosz, but also re-think the import of performativity in relation to critical geographies of architecture in yet more ways.

Another author not explicitly mentioning performativity, is Latham (1999), in his discussion of life in the Tacheles Park in Berlin. This also holds connections to the Harrison, McCormack and Lefebvre, particularly in the sensuous and psychoanalytical elements of life in the park (Latham, 1999: 161). He too cites Benjamin, in the self's desire to reach out into the (urban) world, and to catch the fragility and beauty inherent in it (Latham, 1999).

Finally, however, useful re-readings of power that performativity instigates also extend our consideration of the geographies of difference already highlighted. These also form another area not considered by Lees, in particular where a building, as part of a discursive and performed totality, is used as a (dis)play of difference - for example an artistic intervention into the city, or of a 'hippie' education. Performativity discusses how power and influence are exerted (Thrift, 2000b; Massey, 2000), in that "for a statement (be it a fact or an artefact) to exert influence, it needs to move... and in order to move it will change, as will the networks which constitute its conditions of possibility" (Hinchliffe, 2000: 224; cf. Badiou, 2003). An artefact and fact such as a building has the power to influence people, and particularly, despite the importance of embodied performance, in terms of its often representational meaning. But is a building mobile? In certain terms, no. But in Dewsbury's terms above, in the terms of ecological architecture that see a building as living and dynamic, and in network terms, a building can be endowed with agency, the capacity to change and be changed (along the lines of Giddens, 1984), and is thus often a key actor in "The dialogical or joint nature of action...[which] provides a means of working through the problematics of power and agency. One outcome of attempting to understand power in this way is the attention that

\footnotetext{
${ }^{3}$ There is, here, an implicit 'urbanity' to the images and readings of Benjamin, and performative literatures. One might question what place there is for ruralities, or sub-urbanities, for performativity, sensuous engagements and creativity. Certainly, utopia and architecture have never been restricted to 'the city', and in particular, where there are disparate and complicated linkages between places, the hybridity of such performativities must also acknowledge the importance of the rural, suburban and a whole host of differential, often unique spaces.
} 
is afforded to the situations [like buildings] within which conduct develops" (Hinchliffe, 2000: 231). It is in these power relations that articulate and are articulated variously by difference, home and community at the Hundertwasser-Haus and Nant-y-Cwm, that architecture/embodiment/discourse becomes power as it "moves promiscuously with all manner of assemblages, it is a teeming mass of multiplicities" (Thrift, 1997: 132). The moral geographies these engender, in combination with more representational approaches, also show how the utopian can be constructed with/in architecture in a problematisation and everyday working-through of power relations, in connection with different constructions of the 'good' or the 'utopian'.

With my interest in utopia, I am keen to follow how these various performative elements are bound up in utopian moments and desires, and also in my three 'structuring' themes. Hence, for example, the relational conception of power above has a capacity to inform utopian studies which in particular focus on utopias as a form of (romanticised) critique and resistance, and in terms of inclusivity (Levitas, 1990; Young, 1990). Therefore, in Chapters 6-8, I try to discuss 'difference' in various ways, taking on the continuous mixing and folding of texts, materials and practices that constitute the two buildings as aesthetically, emotively and ethically different.

In this section, I have discussed various ways in which performativity might augment critical geographies of architecture, take researchers in other directions, and begin efforts of translation and application to notions of utopia. I focused on contingency and unknowability, sensuousness, collective individuations, rhythms and power. I also acknowledged how my three key themes, and in particular difference (the un/familiar, power relations) and the un/homely (and dwelling) are a key facet of performative literatures, in particular where they discuss architectural and urban space.

\subsection{Collecting/dispersing buildings: translation}

Here, I explain my particular metaphorical and performative engagement with the house and school - the specific versions of critical geographies that emerged between myself 
and the case studies. This draws together much of the material (from 'reading' and ethnography) in this chapter, as well as demonstrating how I attempted to translate ethical, emotional and performative notions of utopia through these geographies. This I term collecting/dispersing. For now, by this, I mean that changing texts, materials, discourses, emotions, performances and spatialities (thought eventually as inseparables) are collected into buildings and dispersed out from them simultaneously. As agents within wider landscapes, and as landscape-assemblages made of smaller-scale networks themselves, 'buildings' can effect and be effected through various combinations and connections which are centred upon them as important midpoints in social action (here, the two buildings are crucially figured as 'alternative'). This structured my activity and approach to the buildings as the idea emerged, and appears at times in later chapters.

I discuss this through three inter-related strands. The first is recent work from nonrepresentational theory. The second is similar arguments from 'critical geographies of architecture'. At present, various critical geographies of architecture do not discuss either the field or translation, nor do they present any advantages that geographical studies of buildings might have for other geographical research. Third, with an emphasis on these 'messy geographies' (Lees 2001), it explores commonalities with (feminist) work on reflexivity (Katz 1994). The latter unpicks assumptions of the research 'field' as a predefined, bounded space that the objective researcher can enter at will, gazing upon and excavating ethnographic data (Limb and Dwyer 2001). In this research, 'fields of practice' have become questioned, and new approaches demanded for providing metaphors, conceptual and practical approaches for nuanced but 'relevant' geographical fieldwork - of which this is one attempt.

Naturally, there are many disparities in the above strands. However, I will demonstrate how working them together is a timely exercise. This only comes in thinking these through a story of my experience at these two buildings, where collecting/dispersing became apparent in more numerous and nuanced versions (through textual and then ethnographic material). I also identify and explain three versions of buildings through this: 'buildings'; 'building- 
assemblages'; and 'building-assemblage-events', providing some empirical material to illustrate this.

\subsubsection{Collecting and dispersing the Hundertwasser-Haus and Nant-y-Cwm: texts}

Initial empirical research on the texts produced about these two buildings led me to a simple notion of collecting/dispersing. I suggest that, as 'unusual' buildings, both attract varying amounts of attention from journalists, critics and tourists. Thus each is the centre of attention for many texts, at the same time as these texts are dispersed, often globally. This appeared as a simultaneous collection and dispersal of, around and by buildings as active and passive centres of attention. No duality should be inferred here, as the complexity of action at a building means each collection can also be an act of dispersal, and the singular 'identity' of a building is obscured by its many meanings. We can perhaps talk of a 'focus' or point of intensity, but this obscuring blurs any clear definition of a bounded, architectural field. This initial interpretation of the action of texts about buildings does present a simple way to define the field of buildings, and helped make sense of their 'difference' in Chapter 6.

Although heavily problematic - defining a building as an essential point for collection and dispersal of circulating texts - this presents the first of my three versions of architecture: a 'building'. This is the simplest version of collecting/dispersing, although it does evade 'bounded' fields in some senses. This provides in many ways an idealised metaphor, which although it does hold at times in the empirical examples I now present, is soon complicated by various versions of collecting/dispersing were performed with and by these buildings. These all display similar facets of the general notion of collecting/dispersing above, but, crucially, the specifics of these texts are already more complex. These texts at least partially constituted the meanings each building held, and thus helped 'define' their 'fields'. The point is (so far) that a building never gains meaning - and is thus not bounded - by its walls, or by any 'authoritative' text, alone. To some extent, their symbolism can be read, but, like any cultural product or landscape, they are set into relations of production, consumption, and even inter-textuality, perhaps dispersed globally (Barnes and Duncan 1992; du Gay et 
al. 1997). This quickly questions the simplicity of 'buildings' thought, leading to more inter-textual and inter-active 'building-assemblages', watching how these are produced relationally. This more complex stance is the position I take for the moment, but which again becomes problematised later on.

Before presenting that material, I would also note that these assemblages are produced at different scales, as each of the following texts do two things. Firstly, they construct a building at a 'larger' scale, as disparate flows - sometimes global - are collected into and dispersed from a building. Second, they describe or constitute some of the internal relations (collections/dispersals) at a 'smaller' scale - within a building - that hold it together as an assemblage. Very crudely, then, we can divide between constitutive 'internal' and 'external' relations, but as, in practice, these texts and the practices they describe operate at and across both 'scales', it is collecting/dispersing that constructs inside/outside simultaneously. Kwinter (2001: 14) discusses the intersection of macro- and micro-architectures in relation to Bergsonian virtuality in a similar vein, which I briefly return to later. Moreover, those categories are destabilised by the simplicity of this action. In fact, to attempt to divide between the inside and outside of a building or field is more complex, as it is a false ontological manoeuvre when we bear in mind the semiotic and material flows that render form or event (also Deleuze and Guattari, 1987; Lynn, 1998). Both architects and ethnographers advocate an evasion of the bounded field - particularly physical walls, inside/outside - yet here I highlight a particular group of ways to do and think this through texts and then practices. The notion of collecting/dispersing building-assemblages is useful in that it depicts the construction of internal relations and external relations, and of a concrete, often recognisable form ('field') at the midpoint of these scales, but that these categories are only produced through the specific motion of various actions. We see this empirically in a number of ways.

From textual material, the Hundertwasser-Haus collects/disperses in four ways. Firstly, simply, in the masses of books, articles, websites and other discursive media that surround 
the house $\mathrm{s}^{4}$. Through their movement, the house becomes known and is given meaning, and its status as a special place is constructed. Second, Hundertwasser himself collected/dispersed particular architectural practices and ideas into his work (Chapter 6). He also promoted his message through performance, such as his nude speeches, and the quasiconcentric, spiraling and holistic notion of humans' five skins. Thus Hundertwasser's body and identity literally became a locus for interchanges of ideas, practices and materials, exemplified through the notion and performance of the (nude) human body as centred within those five skins. Now the house became just one critical part of the collection/dispersal Hundertwasser himself undertook and identified. Nevertheless, the house is simultaneously 're-centred' as it represents a specific version of his aesthetic, itself collected with other (legal and practical) concerns. Tellingly, then, collecting/dispersing is far more complex than that around one 'point': the idea thought in this simple way cannot easily define the 'field' of architecture. Third, though, the materiality and symbolism of the house itself is a collection of heterogeneous elements: odd-shaped windows; golden domes; a staircase bought in a Paris antique shop; the work of the builders. These elements, and their aggregation by Hundertwasser and his colleagues, are in fact part of the attraction, the 'difference' of this house, replayed in various stories (see Restany 2001). Fourth, the appearance of the house in websites and promotional material is partly responsible for the very presence of tourists and Hundertwasser-'pilgrims', at the house, structuring the collection of people there, and their experiences.

However, all four related versions of collecting/dispersing, whether as texts or represented therein, are produced through, and complicated by materials and practice. In fact, it is the practice of disseminating these texts, the specific collection of materials and ideas into the house, which indicates how these texts are imbued with importance (and thus the house is) through collection/dispersal. Each text is sent out to do particular things - advertise the house or critique it - with inter-textual/active meanings of its own (Barad 2003). The houseas-text, or in texts, has been forged by a contingent but also deliberate act of collection of its

\footnotetext{
${ }^{4}$ A mass of sources too great to present here! I used material at the private Hundertwasser archive in Vienna. Other texts include Restany (2001), Koller (1996), websites like and articles found in archive facilities of Austrian newspaper websites like Die Kleine Zeitung or Die Presse.
} 
golden domes and trees, and as different authors write the house in various ways. This indicates that the 'centre' of attention here itself is dispersed, out into texts, people, materials, all of which perform and constitute 'centres' themselves. Such are the complexities of these collective-individual performativities (Harrison 2000) that the house as a 'field' for study, or as collection/dispersal, becomes near-impossible to define. Hence we can speak of how (bits of) the house (are and) is constituted in an ongoing sense by the collecting/dispersing action of texts and associated practices, creating and unhinging various scales, and connections with disparately located materials, texts and practices. This therefore requires a fuller, more balanced and performative notion, which emerges below.

There are far fewer texts about Nant-y-Cwm. For various reasons, few people in the surrounding community know the school. Although architectural students visit occasionally, most attention results from Day's books themselves (Day 1990), and texts citing his approach (Papanek 1995 ). The school has a small archive of letters and press releases, largely written by parents or teachers. It also appeared in a youth magazine programme for the Welsh-language channel S4C in 1995. The school is thus not totally isolated, but with more attention around Day himself, the notion of collection/dispersal in terms of (inter)textuality is quite weak. However, Day's own texts explicitly construct (through collections of ideas) collecting/dispersing in another way which links the symbolic, performative and material construction of buildings together and points to the next section of the chapter. It again highlights the spatially, scalar, (in)formative manner in which collecting/dispersing works on and in buildings. This emerges in Day's almost magical depiction of the 'spirit of place' (Day 1990), where, "It's easier if they [buildings] can grow as a oneness. This is why I put so much emphasis on the processes by which places can be developed, altered and grown, and the way architectural form can condense out of interacting fields of influence" (Day 2002, 158, original emphases). The actualisation of a representation, emotion and material form around the spirit of a place are specific to the methods and sites Day uses. Yet they point to the combination and condensation of elements - hopes, plants, stones, histories, traditions, labour... - which give a building form and invest it with specific

\footnotetext{
Also

longer operational.

, accessed $01 / 2004$. As of $28 / 05 / 2004$, this page was no
} 
meanings. This idea of a collecting meaning provides some tentative coherence to 'messy' critical geographies of architecture as the specific practices of building provide a focus for attention.

Crucially, this notion is not of a bounded field. Instead, as for Nast (2001) and Clifford (1997), it is constituted by flows. Indeed it is contingent, performative and relational as much as (and because) it is intentional and phenomenological. This bears links to Deleuze and Guattari's (1987) actual/virtual notion of becoming, and work from non-representational geographies which draws on this (Thrift and Dewsbury, 2000; Law and Mol, 2002). Hence, the following of routes becomes a methodology for constructing a critical geography of a building. But more particularly, these flows reinforce the powerful force of the particularity of these places, their difference characterised as a specific collection of forces, both contingently and deliberately captured, rather than a mere flowing through: a re-instatement of the phenomenological and performative 'draw' of (certain) buildings (on phenomenology, see Mugerauer 1994). The particularity of Nant-y-Cwm illustrates that such 'flows' are better characterised as giving, changing and enacting meaning through moments of collection/dispersal. This action, I think, might be recognisable for many other buildings too, in different ways. The crucial point is that although it seems obvious that a building is the natural 'focus' for attention in critical geographies of architecture, this focus is not bounded by its walls, or surroundings. Instead, it is politically, culturally and spatially constructed through the action of such texts, a collecting/dispersing which continuously constructs the building and without which such a focus would be impossible. It is also in particular configurations that ideas about utopia, and other ethical concerns, emerge.

These two buildings are figured as uniquely different by the texts that are involved in their interpretation and construction. It is thus useful to follow how they describe the collection/dispersal of a variety of elements into each building, to inter-textually but pointedly produce such uniqueness for particular reasons. However, the situation is more complex than this focus allows - this is still in many ways a definition or neat representation. Hence, the 'focus' for research now becomes still more multi-'centred' or blurred: I suggest we must add the importance of performances and events to building- 
assemblages, through ethnographic material as Lees suggests. My argument is, as I have in fact described already, not that events 'better' describe a building, or that we would hence provide a 'total' picture (see below). It is instead that texts should not be separated from the practices that they affect and are affected by: architecture as 'building-assemblage-event'. I provide a little more detail on practices not so involved with 'texts', in the next section, again for simplicity, yet well aware of their interactivity.

\subsubsection{Practices}

Spaces are not defined a priori and hence totalised as Euclidean containers but emerge through and as events (Crouch 2001). Thus, our question is: what is an 'object' for research, and what is its field, as defined through out engagements with its texts and practices? I suggest instead that we should follow how and why certain objects become centres for attention: why (bits of) the Hundertwasser-Haus? In particular, a concern for relations and the non-representational in life too cannot avoid a focus on some-thing, some-where, because not all of life can be represented.

Geographers, anthropologists, and feminist researchers in particular have considered various ways to define the field or object of study since the demise of divisive ideas about boundedness (Staehli and Lawson 1994; Katz 1994; Driver, 2000; Amit, 2000). Hence, recent work has focussed on practices located in multiple, changing locations, following flows through inter-linked places (Clifford 1997; Nast 2001). It has also questioned 'where' the field is in relation to home (Till, 2001; Saunders, 2001), re-imagining the field as a (reflexively experienced) set of political decisions (Hyndman, 2001). Others, drawing on performativity literatures, have emphasised field practices - those of the researcher and researched - in terms of a sensitivity to corporeal practices, the imagination and training (Dewsbury and Naylor, 2002; Powell, 2002). There is an identifiable concern with spatial practices, flows, and the deconstruction of 'the field'. However, in doing research, one must decide where to go, and what is salient. In fact, the flows that Nast (2001) describes, verge on my discussion of collecting/dispersing as she depicts her research at an African palace. Hence the performative spatialities that fieldwork creates can be tied into complex yet 
identifiable motions and notions of collecting/dispersing in various examples, in order to make a semblance of sense out of fieldwork sites, stress the 'point' of research, and explain research outcomes (of which one, as I have suggested, is 'the field').

From an ANT angle, a concern with spatialities is equally pertinent to field-work. Law $(2002,98)$ argues that things (objects, events) occur in a variety of spatialities: "Objects are always enacted in a multi-topological manner, and are dependent for their constancy, on the intersection of different spaces" (original emphasis). He identifies four types, Euclidean, relational, fluid and fire spaces (Law, 2002; Law and Mol 2001). There are thus various spacings, but these do not exist a priori (as Law at times seems to suggest). They are enacted, often collected together or dispersed themselves as bundles of heterogeneous elements, so that events (like buildings) can happen at all. Thus our concern for things and fields, the foci for research, is as much a collection of many emergent spacings as it is the priorities and performances that enact them. Hence, as I have been arguing, the field is emergent, as a simultaneous idea, place and category - in a performative and material sense, in between myself as researcher and those varied actors who help me, and the events that we encounter together and apart.

For example, the space outside the Hundertwasser-Haus can be divided into discrete eventsegments through different activities that go on there - but these bleed into each other, constructing spaces and spacings. Different types of spacing are evoked: a linear journey as a local man jogs past; a play-ground circuit for a young girl in a family of tourists, messing around on the hills in the pedestrian area (see Chapter 7 for more). Various emotions and concerns are felt: fitness, play, holiday, perhaps desire. These cut across the neat spatiality of collection/dispersal at the house that is indicated by my simple conceptualisation above, with other metaphors, spatialities, performances.

However, these occurences are not merely spatialities, they are events - spatial events, and in particular building-assemblage-events, which combine strands of texts, materials and themes, through which at certain points or collections, we can construct or translate a sense of utopia (see Chapter 1). And events, I argue, must be experienced or known to become 
such, as must the texts or qualitative judgments (for instance about difference, or utopia) that those events demand (Badiou, 2003). These rhythms, 'judgments' and 'events' must also, therefore, be collections of something (interpretation, intention...) in order for them to appear. This idea retains Harrison's (2000) evocation of collective individuations, often seen as micro-scale happenings described in enormous details. However, as each 'event' occurs so fast, it bleeds with (the virtuality of) the next, the last, the simultaneous, it is hard to identify or explainin the same way as the moments surrounding a 'lost wallet' (Harrison, 2000). The key is to ask, how do certain actions become 'events', and why, at the house and school, did they catch my attention, and why have I chosen to present these in this thesis? The answer to this lies partly in my general and specific research interests at the time, and thus the specific collection of research material I undertook. This gives moments or stabilisations of meaning (one building-assemblage-event). However much this deadens meaning and action, as it is collected in practice and in interpretation, it simultaneously opens up discussion and practice by dispersing this moment, through the imagination of other ways in which the event could have occurred, or been experienced, and new virtualities/actualities that that event might enliven (also Kwinter, 2001). Again, as a participant observer, events are overwhelming, yet the focus comes some-where, and can even allow us to produce consistent generalities (mainly from what people say, their own judgments, but not always), aware of the need for interpretation at the same time as the nonrepresentative nature of events. Some of this may be allayed by conceiving of these events as indicative of, or taking part in, more general rhythms or atmospheres (section 4.6): not as a total 'picture' but something experienced in the collective specificity of the moment, in connection with the conditions folded into and more generally predicating the mere appearance of tourists at the house, for example.

As researchers, our fields, definitions and collections integrate with the collections and understandings of those we interact with, and in particular the 'sense' they try to make of events in discussions such as interviews. Thus, for instance, the school's 'community' (a discussion of which was dispersed from that on the school-buildings) is largely discussed through more generic relationships and performances, although particular, ongoing events are crucial to the emergence of moral and phenomenological ideas about 'community' 
(Chapter 12). Here, building-assemblage-events are aggregated and collected together in specific ways in order to produce, in the main, certain 'practical' and ethical discourses (the conflicting 'good' - or utopian - ways to care for the school), and to disperse those ideas to me and others through their presentation here. This is, then, partly a matter of organisation, of the ways in which the 'good' is both structured and tinkered with (Law and Mol, 2002). For again, these ethics were emergent from these events (Badiou, 2003), but doubly emergent from the interview situation - complex, deliberate and contingent collections of ethical judgments, then dispersed throughout this thesis. These emergences also illustrated how beginning with the school and its buildings as a seemingly coherent totality could instigate (metaphorically collect and disperse) important topics for debate, one of which was 'community'. Moreover, the centrality of material artifacts (and ANT) such as the school buildings to these stories was surprising, and thus of real significance to honing my notion of the 'field' in light of these complexities. Most importantly, this approach, these artifacts, and the experience of collecting/dispersing questioned some traditional elements of the performance of community, in particular its (ironic) boundedness in terms of the buildings or otherwise.

Hence, collecting/dispersing is in the main concerned with how these events are experienced and represented, although this can be pre-discursive. It is thus interested in the manner of translation - how those spacings are encountered, collected and dispersed - as well as in how texts themselves are performative and non-representational in that the manner of that translation is difficult to represent fully: hence the various versions of collecting/dispersing here, and the caveat that it never can be viewed as the only way (just a very good way) to understand a building-assemblage-event. Collecting/dispersing, and translating is hence a method of intercepting how sense (and non-sense) is made of and within contingency, and how ongoing action is both differentiated and given continuity through individuation and connectivity. It also illustrates how specific elements are combined to present stories and arguments (like this thesis), but also that collecting/dispersing is also present in 'prediscursive', performative acts - what catches our attention, the sudden realisation of a lost wallet, and all the work that that wallet contains to render it important - but that these are never totally separated from processes of meaning-making and attempts to explain them 
(such as this, with Harrison's [2000] lost wallet). The field, if of interest (which I think it should be), emerges in mutating forms from this methodology, these events, and discursive aggregations thereof. I demonstrate the varied and changing fields that emerge in the course of conversation and participant observations throughout the following chapters.

Finally, if we are to research buildings through much-needed 'critical geographies of architecture' (or any specific practices), even if we undertake 'multi-centred' ethnographies or follow flows of practices, then funding, practicality and researcher sanity demand a research 'focus'. The particular ways we approach 'the field' are partially determined in advance, however we can attempt to balance this with the spacings and prioirites that emerge through our engagements with building-event-assemblages. This entails allowing the 'field' to emerge through the combination of our own and research 'subjects" collections/dispersals to contingently define the 'priorities' of a particular conversation or context.

\subsubsection{Summary: what about utopia?}

As I mentioned in the previous sections, collecting/dispersing is an effort of translation, one version of a critical geography of architecture which emerges from my empirical engagement with buildings themselves. However, apart from this, the question remains: what of the field of utopia? In a simple sense, utopia can be viewed as one element of life at the house and school, never interpreted essentially, but apparent in the buildings' initial design and construction, texts about them, and various moments throughout their lives. Hence, in a simple sense, utopian tendencies can be seen to characterise or represent certain elements collected/dispersed about these buildings (for example, in their architects' texts). This evades any notion that the buildings 'are' utopian in themselves, or that any essential version of utopia is found 'underlying' their lives as changing building-assemblage-events.

Collecting/dispersing highlight various important actions in the constitution of buildings and events: contingency; the simultaneous evasion (and hence) construction of scales, spatialities and boundaries; emergent generalities, which can be deliberately, temporarily 
controlled; the potential of an emergent research focus or foci; the inter-action of texts, materials and practices (although separated here for clarity) in the construction and experience of buildings. They also combine Lees' and Gieryn's approaches, as well as those from ANT and performativity, discussed above. Taken together, these approaches and actions expose and construct material regarding a variety of themes (for instance, difference, the homely and community), many of which were utopian, in other chapters of this thesis. For this reason alone, in that this approach allowed many versions of utopia and particularly the utopian unsettling to emerge (as specificities and generalities), it addresses the thesis' main aim. Additionally, however, I have stressed how collecting/dispersing was important in various specific senses - rather than as metaphor, as an action - and I would argue that facets of this action are embroiled in some of my conclusions on utopia.

I will be more specific. The concept of the utopian unsettling is not merely predicated on anxiety, but the importance of utopias as events, as work, and in relation to ruination. In the above discussion, I covered various versions of the building-assemblage-event, and the work that is necessary to make sense of that. Thus, where utopias are experienced, created and sense is made of them, this deconstructs boundaries between utopia and everyday. For each are constituted through the collecting/dispersing of elements in manners identifiably 'utopian' or 'not', the field of utopia is extended and distended through textual and performative play. This play, in many instances, involves collecting/dispersing, work in itself, of various elements into a utopian situation, and of those into buildings - a crossing of scales and object-event 'boundaries'. This does not merely involve folding of insides and outsides, or materials and texts, but a specific version thereof which is intentional yet aware of the unsettling contingencies through which it emerged. Moreover, and again, the ethics of difference, home and community are themselves collected/dispersed in manners which prove quite unsettling. Thus, the contingency of collecting/dispersing - yet involving the emotive and ethical dilemmas of utopia I sketched out in Chapter 3 - and the themes evoked from the house and school through these, can be profoundly utopian, and unsettling.

\subsection{Conclusion}


In this chapter, I discussed varied approaches to researching architecture. It strengthened my choice of architecture as a theme through which to follow the many ways in which utopias are produced through heterogeneous practices. I did this through a discussion of similar themes, an awareness of the utopianism of architecture which should be acknowledged by critical geographies of architecture, and a raft of novel suggestions relating to performativity, ANT and the notion of collecting/dispersing. This necessarily involved recourse to various textual, material and performative (to set them apart for a moment) elements of utopia and architecture I have already discussed. However, I explored how combinations and separations of those practices involve symbolism, contingency, creativity and the sensuous in collective individuations, connections and dissections of spatial, architectural phenomena.

Crucially, I argued that approaches to 'reading' landscapes or their representations should not be jettisoned or subsumed under non-representational research. It is clear in this chapter and the last that various versions of utopia and the utopian unsettling are apparent in practices read in these ways. However, I agree with Lees, Gieryn, Thrif, Law and others that we need to account for the various ways that buildings and spaces are performed, and that non-human actors are a part of those practices. This opens up and extends various notions of the utopian unsettling, as I indicate in Chapter 3. At the same time and in particular, it highlights how the construction of utopias - in this instance, architectural - is not set in (textual or material) stone. As buildings, practices and the utopias that emerge from them are all contingent, sensual, anxiety-inducing and ephemeral, even the very constitution and production of these utopias - even where seemingly stable and 'textual' - is unsettled/unsettling. I think performativity highlights this point perhaps above all others. At the same, the sensuousness, creativity and even euphoria also evident there are linked with desire in order to show how life can go on, be imagined-and-embodied, and be positive-yet-unsettling. The utopian unsettling appears in many guises, as I have proven, but perhaps it is in the constitution of utopias, architecturally, that we see very clearly at times a mixing of texts, materials and practices which becomes-ethical, or become-identifiable, as utopian, 'homely' or 
whatever else. Hence we see again the intimate relationship between architecture and utopia, between everyday life and utopia, and the unsettling with utopia.

In the final section of this chapter, I indicated how I interpreted my translation and experience of critical geographies of architecture at the Hundertwasser-Haus and Nant$\mathrm{y}$-Cwm, into themes such as difference, the homely and community, and ultimately, utopia. I argued that buildings collect and disperse assemblages of texts, materials and practices as 'building-assemblage-events' which operate within different spatialities and scales, through which they come to be defined (temporarily) in their performance and actualisation (Kwinter, 2001). This also helps me to show, as I identified in the introduction, how buildings do not merely symbolise utopian ideals, but how these are folded into many interpretations and performances of the utopian, many of which may be unsettling. With brief reference to empirical examples found later in the thesis, and a more detailed recombination of various literatures, I argued that, whilst it is still not desirable nor possible to represent any of these collections/dispersals fully (nor does the term represent anything fully), such combinations and events usefully provide various thematic similarities, identifiable emotions and emergent ethics, in some ways similar to the 'forcing' required as a subject encounters and qualifies an event, in Badiou's (2003) terms. Finally, I suggested that although utopias and the utopian unsettling are themselves hard to represent, following the collecting/dispersing of buildings enables us to explore those utopian desires, ethics, emotions and events that emerge as spatialising entities, through the intersection of our experience with those of other actors there. And if they can at least point to much that is left over in utopian events, perhaps with performative modes of writing (Thrift and Dewsbury, 2000), and to the excessive and unsettling character thereof, then so much the better. 


\section{Chapter 5}

\section{Methodology}

\subsection{Introduction}

This chapter explains the methods I employed in order to undertake the specific critical geographies I discussed in the last chapter, and to follow the emergence of utopian themes. I adopted a multi-method, qualitative approach to empirical research at Nant-yCwm and the Hundertwasser-Haus. I will discuss each building in turn, relating the methods employed there to the major aims of the thesis. I choose this structure as each building is involved in different stories and practices (for example, there is no real 'archive' at the school), and as the methods I employed were partly contingent upon the circumstances I encountered - sensitive to the event, as well as the building and intertextual/inter-active construction (building-assemblage-event). Moreover, in research practice, each building was explored separately.

Nevertheless, the methods themselves illustrate some of the many links between the buildings. For instance, similar themes were covered in interviews particularly, and generally similar methods were employed, often sensitive to Lees' (2001) ethnographic, performative and 'vignette'-structured approach. This allows a degree of comparison and generalisation to be made, especially where our focus on the buildings in interviews instigated discussion about certain topics, but where the buildings were only 'weak' or generic actors therein (the construction of community at both buildings exemplifies this). Additionally, themes from the Hundertwasser-Haus (visited first) incited discussion at Nant-y-Cwm - in particular the theme of difference. However, I allowed this and other themes to emerge through discussion and in very different directions from the house. In particular, therefore, I will focus on the methodological version(s) of critical geographies of architecture I deemed to be most suitable to the two buildings (the thesis' second aim). 
A brief note on my methods is required to explain the detail I provide on them. The major elements of my research come from ethnographic methods, thus I grant them more space here. These were designed to construct a sense of the more material and performative everyday lives and meanings residents, teachers, children and others held at each building (Lees, 2001; on ethnography, Denscombe, 1998; on performative methods, McCormack, 2002, 2004; Latham, 1999; Wylie, 2002). Textual methods were important in contextualising the buildings, and constructing initial versions of collecting/dispersing, and (unsettling) utopia, found in Chapters 3 and 6. Additionally, without this groundwork, and the contacts that I obtained from it, many of the other methods would not have been possible. However, I believe the ethnographic material although always implicitly and/or explicitly constructed with textual material - to be in general more sensitive to the buildings and my aims than textual material.

I have deliberately omitted a detailed discussion of utopia here. One reason is that as the aims of the thesis evolved with my research, it was only through a joint engagement with life at the buildings and the literature that the idea of the utopian unsettling arose. A second reason for this is that I did not endeavour to 'find' utopia at all, but, as most ethnographic work does, to 'construct' it with research informants (be they texts, people or technologies). As my research began, the major aim was to construct critical geographies of architecture for each building, sensitive to the particularities of people's lives there. This aim strongly implied utopian themes: I was aware of the often utopian design discourse of the two architects, and I wanted to understand how inhabitants viewed their own creativity, health, community and phenomenological attachment to the buildings. Such themes are, if not utopian, certainly ideal notions that figure perfection and happiness, and have related architecture to utopia for centuries: but how do people negotiate these themes, and are architecture and utopia important? These over-riding questions, asked through these critical geographies, addressed my main aims, so that utopia was not always a topic for debate as much as the buildings or discourses they evoked: but the three key themes of difference, the homely and community emerged again and again during interviews. 


\subsection{A note on collecting/dispersing and material-semiotic methods}

In many ways, collecting/dispersing is one take on the spacings of buildings and fieldwork (Chapter 4). It is also a version of Lees' (2001) critical geography of architecture which I feel could have wider import. To re-iterate, I see buildings as capable of collecting together, and simultaneously dispersing, texts, materials, practices and spatialities through design, building and use. A building is constituted by intertextual and inter-active flows - some or many of which may be labelled collecting/dispersing both metaphorically, and more importantly, describing empirical action, where a building is (made to be) a powerful nexus for action, a kind of performative phenomenological draw. Moreover, this mixes together representational and non-representational registers which for some have been falsely separated (Nash, 2000) - the advantage of this approach is that it focuses on how and why texts, materials and performances have been collected and dispersed as events, buildings or consistent stories. This necessitates a range of methodologies, which I discuss below.

This also provides enough relevant background to my own position. I feel it unnecessary to mark out fully my individual identity here, and treat this only where warranted, where questions of reflexivity have been rendered problematic, with accusations of research relevance and self-interest (Cant and Sharma, 1998; Skeggs, 2002). In any case, the aims and approaches I take are structured by the literature with which I engage, and assumptions within that, and the privilege which allows me to read in the first place. Additionally, with the emergent strategy I chose, my research identity evolved, much like the notions/motions of collecting/dispersing themselves did. To speak of 'my identity' would ignore this mutability, and the importance of my changing attachments to the research process and building-assemblages, occurring at mid-points of these collections/dispersals (hence the simultaneity) rather than beginnings or ends (Deleuze and Guattari, 1983). In the following discussion, however, I do mention those moments where I feel my position might have affected the research process.

\subsection{The Hundertwasser-Haus}


I was attracted to Hundertwasser's work for the promise a critical geography of ecological and artistic architecture held, in assessing the various practices and discourses that surrounded and were assembled into such buildings. With an accompanying initial interest in people's 'ideal', imagined spaces, Hundertwasser's versions of both are excellent starting points. However, it became clear that Hundertwasser's theories, designs and buildings are not merely of interest as examples for geographies of ideal spaces and ecological architecture, as many of the themes he discusses (art, individuality, health, home) are more pointedly salient to utopias.

I describe how I addressed these aims firstly through readings of texts by and on Hundertwasser and his house, to show how I began to construct geographies of utopia and architecture, and simplistic versions of collecting/dispersing. I then illustrate how the third aim of the thesis, and more importantly the first two aims, were revised and addressed through the ethnographic methods where the utopian unsettling most strongly emerged. It is interesting to note, however, that two key facets of the utopian unsettling (contingent collecting/dispersing and ruin) emerged from texts on the buildings and wider literature only after they were re-read in light of ethnographic material. This highlights the emergent, combinative approach I took.

\subsubsection{Texts}

I began with Hundertwasser's own texts (especially Hundertwasser, 1997) as an entry point into green architecture. As I read his texts looking for familiar themes to ecological architects (health, harmony, art, home), I was struck by the utopian tendencies of Hundertwasser's work. As these ideas exemplified the relationship between utopia and architecture in a contemporary context, I followed his ideas in more detail. This led me to his other texts (for example, Hundertwasser, 1983), and wider offerings which detailed or critiqued his work. Hundertwasser and his buildings appear in many newspaper articles and websites, and it was the dissemination of the increasingly commercial Hundertwasser brand which first attracted me to the notion of 
collecting/dispersing. These texts provided contextual material on the reception of Hundertwasser, as well as interpretations of the health-, creativity- and even utopiarelated capacities of his work, which I then re-read in light of the themes of difference, the homely and community.

1 decided to focus on only one of Hundertwasser's buildings. This enabled a pointed discussion of how texts about Hundertwasser were ordered around and into a material edifice, and augmented nascent versions of collecting/dispersing as ways to follow the inter-textual production of buildings. With this focus, I explored how the broad themes mentioned above intersected throughout the house's histories. This included, for example, Hundertwasser's thoughts on building practice and symbolisation (Hundertwasser, 1997) and the frenzy of discourse that surrounded the building's opening (Restany, 2001). In all, Hundertwasser's texts provided material on his version of utopia related to Blochian and more post-structural formulations (Sargisson, 1996), as well as the specific translation of this into the house's aesthetic. Other texts were analysed in terms of their critique or adulation of the house, the connections they made and themes they covered, many of which appear in Chapter 6 . I did not undertake any closer textual analysis, as I wanted to follow the 'material' geographies of the building itself, with which these texts were implicated. Upon my first visit to Vienna, I realised that a more ethnographic approach would provide more balance, and refine the notion of collecting/dispersing.

In addition to these texts, I made some use of archive material. The office at Buro Harel holds a private archive of Hundertwasser's original works, and newspaper articles about the house (those used are included in the bibliography). My time and reading there was supervised, and also structured by the thematic folders into which Hundertwasser's work was organised. Being supervised was in fact an advantage, as I was able to question the archivist about a number of texts, and use these to stimulate other discussions. As most of Hundertwasser's texts had already been published (in Hundertwasser, 1997 and Schmied and Fuerst, 2003), the triple part-structuring of folders, supervision and previously published material, all meant that little of real significance was obtained from 
this trip. However, I was able to use discussion there to crystallise my research strategy, and forge relationships for my next visit.

\subsubsection{Ethnographic methods}

To contextualise the Hundertwasser-Haus, I exchanged E-mails with architects (Peter Pelikan, Heinz Springmann), planners and site supervisors from various projects, as well as Hundertwasser's personal manager (and the manager of Buro Harel), Joram Harel. Like much of the textual material, this provided general background to the work and ideas that were collected into Hundertwasser's buildings (including Uelzen railway station and Bad Blumau thermal pool). I posed a few generic questions regarding respondents' relationships with Hundertwasser, general working practices and their opinions of Hundertwasser's work, although most questions were specific to the nature of the relationship between Hundertwasser and the respondent, or to their role in one or more of his projects. I was also able to interview the priest at Baernbach Church, Styria, which Hundertwasser redesigned, as well as the archivist at Buro Harel, Dr. Andrea Fuerst, both of whom could give accounts of Hundertwasser's personality, intentions and ways of working. The former interview was tape-recorded, the latter was not - both were in German. In the latter interview, we discussed the importance of utopia to Hundertwasser, and it transpired that a manuscript containing his thoughts on paradise was to form one chapter in a new book of his writings, still forthcoming. However, I felt it important to gain access to the house and, more specifically, to speak with residents to explore what were their interpretations of the many architectural and utopian themes that had emerged so far.

My second visit to Vienna was during February/March 2003, when I spent three weeks living near to the Hundertwasser-Haus. 1 undertook taped interviews with 11 residents (eight women, three men), all in German, and all of which were transcribed. Interviews lasted between 20 minutes and two hours, all in residents' own flats, apart from one. This was most comfortable for residents, and allowed me to observe some of the ways they had used their flats (for example, the use of window rights). The interviews were 
pre-arranged as follows: Andrea Fuerst enquired at the house on my behalf to register interest; one resident then took over organisation of the interviews, recruiting residents. Thus, my 'sample' is only representative of a certain friendship group, although a couple of residents not on her list also agreed to interviews. As a researcher and particularly coming from abroad, this was the best (and to all concerned most acceptable) way that I could gain access to the house.

The residents I interviewed had lived in the Hundertwasser-Haus for varying periods: six since 1986, and the others for between four and seventeen years. Some were interviewed individually, others together, and some with family members or friends present. Some of the dynamics of group conversation and impacts of power relations between family members were therefore unavoidable (Valentine, 1999), but at the same time provided stimulating discussions. I did not attempt to find a wholly 'representative' sample, similar to many qualitative studies (Dwyer and Limb, 2001). Instead, I was interested in the life histories, opinions and experiences of residents, in order to construct various themes relating to their lives in what, to me, was an extraordinary building. As the aims of my thesis developed during my fieldwork, questions were wide-ranging. A sample interview schedule can be found in Appendix 1. In this, the main themes discussed above (health, art, difference, home, community and tourism) were refined into broad questions relating to their lives in the house, as well as other questions that I deemed important in light of textual analysis and preliminary observation. As I mentioned in Chapter 1, I did ask about ecological architecture, however other themes were of more interest and relevance to respondents, as, following a semi-structured format, interviewees were relatively free to dictate the course of the conversation (as in Rubin and Rubin, 1995; Valentine, 1999). This was particularly important where, for instance, some had had no relationship with the press, whilst others did regularly. There were four types of collecting/dispersing here: my own collection of stories; assessing the impacts of that done by the many texts about the house; the collections/dispersals of which each resident was a part; and those in which they tried to represent their experiences to me. Throughout the thesis, all respondents' names have been altered to protect their anonymity. A list of the interviews can be found in Appendix 3. 
This method was tied into tours around people's flats and the whole house, so that those sections of the interviews, largely un-recorded, became opportunities to indicate the sites of particular stories. This became a type of participant observation structured by my 'guide'. It was also an opportunity to take photographs and make other observations about the house, decoration and difference, in particular the surprising amount of artwork on the walls. As stories were repeated, and willing respondents were not forthcoming, I decided to finish with the 11 interviewees and other informal conversations I held (for instance, upon taking part in a birthday party on my first night there).

I did not ask any explicit questions about 'utopia' for two reasons. Firstly, at the time, I was not fully convinced by a study of utopias in traditional terms at least, and was more interested in people's experience of buildings, following a critical geography of architecture. I did enquire about certain themes salient to utopias (community, ideal homes, health), but in fact it was residents' stories themselves which initiated discussions of utopian moments and other versions of utopia. Secondly, I considered asking direct questions about utopia - an abstract and, for me, un-definable term - very problematic. As the contingency, performativity and affectual un-representability of many of the residents' stories began to dawn on me (and early versions of the utopian unsettling rather than 'traditional' versions became apparent), I wanted to encourage people to evoke these moments through their own narratives, rather than ask 'about' any instances of utopia.

I also undertook observations and participant observations. Again, to assess the 'polyvocality' (Llewellyn, 2003) (or poly-activity) of claims at the house, and gain an insight into the materialities of its extraordinary and mundane lives, I employed various strategies with various levels of participation (Cook, 1997). I was less concerned with following specific people's lives for a long period of time, and more with the rhythms, atmospheres and events that emerged (Lefebvre, 1996; Seigworth, 2000). My observations on tours around the house took in the changes residents had made (as 
indicated by them), and decoration, toys, posters, plants, etcetera, that were traces of the many lives with/in the house. Some interview situations were themselves based more in participation. For instance, on my first night at the house, I spent three hours at one resident's birthday party. This was a useful occasion to make informal contacts, spend time in one of the communal rooms, and observe and take part in its usage.

Outside the house, I observed and talked briefly with tourists, spent time outside the house in Kegelgasse and Loewengasse, wandered around the shopping village, and talked (on one occasion in depth) to café owners and shopkeepers. I also spent time walking around the nearby area and the Donaukanal (Danube Canal), observing other social housing blocks, Hundertwasser's other buildings, taking basic notes on the usage and architectural styles of the area, and meandering away from the house in various directions to assess any impacts the house might have on the area. I therefore used the house as an axis or centre for my own experience (collection/dispersal) of the city, although the largely descriptive observations I made in my extensive notebook perhaps required a longer stay to be of anything more than contextual interest (Chapter 6).

However, the space in front of the house and in the Shopping Village was certainly different from other areas of the city, and in order to understand in particular the constructions of difference at the house, I tried to appreciate how tourist activity was embroiled therein. It is fair to say that the house is a magnet or collection point for tourists, whether 'Hundertwasser-pilgrims' or bored-looking bus groups, and that this fact in itself contributes to notions of difference there. There was, in fact, so much going on (locals walked past too!) that it was impossible to undertake observations of the detailed minutiae of life found in some work on performativity (Harrison, 2000). However, it was apparent that the house collected a range of interests, spatial practices and rhythms (de Certeau, 1984). Moreover, as it was experienced and co-relationally constructed in ways evocative of many spatialities, often messy, complex and personal, it was impossible and undesirable to gain an overall view of 'the space' outside the house. Instead I followed groups around, attempting not to interrupt their often ephemeral experience of the house - listening, observing, sometimes talking to them 
briefly in order to gain a feel for the types of events, reactions and emotions they took part in. I then discussed this activity with residents, to see in particular how it impacted on their lives, the theme of 'difference', and whether any utopian elements were apparent.

In all, I wanted to momentarily expose myself to various rhythms, collective individuations (between individuals and groups, or between them and the building), collecting these into my notebooks. This enabled me to compare meanings of the house expressed variously through bodily comportment, discourse and symbol, by various actors from tourists to residents, in and outside the house. Moreover, although this thesis does not include an explicit chapter on tourism, this approach allowed me to follow a perhaps unacknowledged theme for critical geographies of architecture: how meanings were constructed through events, in between the personal and group, in between the human and non-human, as event-meanings in-formation. For example, the presence and activity of tourists is often implicity structured by texts they are likely to have read (for example on its meaning on symbolic difference, so that they view particular parts). We therefore see a natural crossing of material and semiotic, and of collection/dispersal with and as spatial practices. I suggest that this theme could be pursued in more detail in later work, but that these practices were certainly folded into residents' experience of the house, and more general meanings that the house made in many texts disseminated around the globe.

\subsubsection{Interpreting ethnographic material}

Although the inclusive undertones of 'poly-vocality' (Llewellyn, 2003) might seem to suggest this, I in no way consider the above methods to be all-encompassing, providing a total view of life at the house. These methods aimed to intercept the house-as-event from many dynamic midpoints, and to follow how it was thus invoked in various memories, whether utopian or otherwise. These midpoints were the effects of various collections/dispersals, both my own and others', given meaning and transferability through repetition and dissonance. Using this emergent methodology, I tried to identify 
and interpret themes through this, adjusting my precise approach accordingly. This enabled me to interrogate similar themes, at the same time as remaining open to new directions, allowing perpetually new versions of utopia and collecting/dispersing to emerge.

Transcription of interview tapes provided the first opportunity to begin detailed analysis as I became more familiar with the conversations. These were transcribed in German to retain their original meaning, and only translated into English when used directly in the thesis. I then read them all through twice, marking key stories and noting important themes as they emerged within and across interviews. With a better idea of consistencies, disagreements and unique stories, I used a highlighting pen to mark key quotations and stories in each interview. The following themes were coded: difference and art; the impact of tourism; ecology/environmentalism; the impact of journalists; making 'home'; stories or depictions where utopian imagery or vocabulary (especially of perfection, euphoria or comfort, but also any unsettling versions) were strongly apparent. Once combined with material from Nant-y-Cwm, I used similarities and disparities in these themes to structure the eventual 'key' themes: difference, the homely and community.

As with any interpretation, it is difficult not to 'force' quotations to fit any argument, in particular one as abstract as that on utopia, or collecting/dispersing. However, in what follows, I have included relatively long excerpts to indicate as fully as possible respondents' intended meanings, their context, and the linkages between events and themes. In addition, as elements of the utopian unsettling do not appear utopian in the traditional sense (although they are still bound up in sometimes abstract notions of perfection and the 'good'), they may appear strange to the reader. Again, the length of the quotations indicates the contingency and work that unsettles the neat perfection of these stories, as well as drawing out indications of euphoria, nostalgia and paranoia. My version of a critical geography of architecture, employing ethnographic methods was, I believe, of great benefit in this process, and enabled me to make additional suggestions for those geographies (Chapter 4), contributing to aim 2 of the thesis. At times, this 
analysis necessitated qualitative judgments as to what constitutes 'utopia', although I hope my argument in Chapters 2 and 3 clarifies how the material in the following chapters might be utopian.

Observational material was organised into 'vignettes' in my notebooks, as Lees (2001) suggests. The process of identifying themes was similar to that used to analyse interview material. I also used the notebooks as a basis for interpretation during the research process and building theories. I use these in following chapters primarily as illustrations of my own reaction to, and experience of, certain phenomena, and to add 'nondiscursive' material to interview excerpts. It was particularly difficult to use observations to interrogate the notion of utopia, especially for tourists where action occurred so fast, and for this reason I chose to build this material into other thematic debates rather than try to force it to 'fit' the performative notion of utopia I discuss where other interpretations and examples are more viable.

\subsubsection{Problems}

There are obvious difficulties with covert observational methodologies, including invasions of privacy, the lack of opportunity for subjects to answer back, and thus the problematic representativeness of the data (Cook, 1997; Denscombe, 1998; SanchezJanowski, 2002). In this particular exercise, I am confident that these issues do not detract from the robustness of the analysis as I was largely interested in the house and the atmospheres that were actualised between it, residents and tourists (rather than individual tourists' stories). Moreover, I could in no way present recognisable personal information about any of these tourists.

For interviews, there are two issues. Firstly, I would have liked to return to Vienna to interview a few more residents after research at Nant-y-Cwm, although a repeat visit was financially difficult and in any case I collected far too much material for one thesis. My positionality as a researcher was a second issue but was largely overcome by my access route into the house (above). Having an English accent was rarely a hindrance, 
and was in fact a talking point for comparing the house's and Hundertwasser's popularity in the UK. Moreover, my being a non-native amongst natives I feel gave respondents the (correct) feeling that they were the experts, as well as they were put at ease by my introduction to them by other residents,. This instilled in them a sense of confidence that allayed most issues of power (May, 1993; Nast, 1994; Cant and Sharma, 1998; Mason, 2002). I will be sending a copy of my thesis to the house along with a summary, encouraging residents to comment on my conclusions.

I am aware of translation problems during and following interviews, although such problems beset any interviewer when it comes to transcribing other people's (and indeed, one's own) meanings from a conversation in whatever language and context (F.M. Smith, 1996; Gade, 2001). I overcame this as best I could by asking interviewees to clarify confusing statements (where confusion was not the point), through close reading and word-for-word transcription of the tapes.

\subsection{Nant-y-Cwm School}

Many of the methods and themes from Nant-y-Cwm were similar to those at the house. Most empirical research there took place after that on the house, and I was able to explore many themes from the house at the school, whilst leaving interview and observation schedules open. I joined these themes with those from Day's and other authors' texts, and was better able to ask broad yet focused questions, and to evaluate more critically the versions of utopia, collecting/dispersing, health, home, creativity, difference and community I had encountered at the house. Interestingly, on the latter two themes, I had not imagined them to be so important at the school, yet it was this open methodology which allowed the complex versions of difference and community, and their particularly material characters, to emerge. Some elements of these themes were also familiar at the house, others quite different.

\subsubsection{Texts}


There are far fewer texts about Nant-y-Cwm and Christopher Day. Nevertheless, I began reading Day's thoughts on very similar themes to Hundertwasser (health, creativity, individuality, ecology), to tease out points of general interest to critical geographies of ecological architecture, and utopia. Both Day's and Hundertwasser's writings were also contextualised in relation to broader 'green' movements (for example, Wines, 2000). I chose Day's texts for the startling resemblances in style and content with Hundertwasser's work, but also the disparities in site, scale and impact he and his buildings asked for (using Day, 1990a, 1990b; 1998; 2002). With these themes and tensions in mind (see Chapter 1), I used the texts to search for a specific building to observe how these themes were incorporated into a building's daily lives.

In addition to initial background reading, I undertook three preparatory interviews to augment my understanding of certain key themes. These were with Christopher Day at his house, with the wardens at another of his projects (a Retreat Centre in Pembrokeshire) and with one of the school's Kindergarten teachers. From here, I developed many of the above themes in relation to the three different buildings (house, centre, school), and began to explore where the above themes were set in relation to ideas about architecture and utopia (if at all) in these cases. The interview with Day provided helpful contextual material and the opportunity to discuss his written work, and the final interview with the teacher was used in the same way as the other interviews below. I eventually chose Nant-y-Cwm, as the Kindergarten building is one of Day's better-known, most unusual buildings, and as the variety of parents, teachers and children there in terms of beliefs and lengths of stay promised most varied material.

In terms of texts, apart from Day's publications, I could find very little on the school. My only source was Nant-y-Cwm's own archive, which comprised two folders containing letters and press releases, to which I was allowed access on the understandable premise that I did not divulge any sensitive information. These were again of contextual interest (Chapter 6), but largely backed up the basic information I had obtained in interviews. On a more general level, however, they show the inter-action between texts, materials and practices in the production of identities and atmospheres for 
buildings, and the specific, intentional collections/dispersals that people effect (they had no records of 'bad' press). The school also appeared in a short television programme for a youth show ('Fflic') for the Welsh-language channel S4C. Watching this five-minute programme, I noted the use of language ${ }^{1}$, imagery and atmosphere it evoked for the school. In all, these 'texts' presented a far weaker version of collecting/dispersing than at the Hundertwasser-Haus, and although they were occasionally important parts of the construction of a (homely) school, the video and other texts were backgrounded by much of the ethnographic material I encountered.

\subsubsection{Ethnographic methods}

Interviews with parents, teachers and (ex-)pupils took place between March 2003 and June 2003. The bulk of the interviews were 26 in-depth conversations with (ex-)teachers (6), (ex-)parents (15), founders (8) and (ex-)pupils (5). Seventeen of these were taped, and extensive notes were taken. The total of the numbers in brackets indicates that most interviewees had multiple (and changing) engagements with the school, and interviews were thus structured accordingly. Around six of the interviewees were interviewed as couples, or with others present. These interviews were more wide-ranging than those at the house, and often lasted longer: between half an hour and three hours. They often covered similar themes (Appendix 2), although again, the schedule was often halfforgotten in discussions which the interviewees themselves directed. A list of these interviews can be found in Appendix 4.

I was interested in the symbolism of the school's buildings and the activities and meanings constructed with them in terms of education, the school's phenomenological draw, and themes emerging from the first few interviews such as the importance of community, difference, and the school's future. These enabled me to interrogate all three aims of the thesis in various ways: through this critical geography of architecture and by now familiar themes, various utopian 'moments' of work, euphoria and paranoia emerged, as well as many material-semiotic 'good' visions of the school's futures,

\footnotetext{
${ }^{1}$ Thanks to Pyrs Gruffudd for translating the narration.
} 
which simultaneously allow me to interrogate further notions of utopia, community and difference within a post-structural 'framework'. Once again, this emergent approach was most sensitive (again, I rarely asked directly about utopia): for example, I did not expect the theme of 'homeliness' to be so important at a school, but through texts (Day, 1998) and importantly interviews and observation, it became very clear that this notion was evoked by various actors to structure and explain everyday activities there. This arose as I asked about people's attachments to the school (as ecological architects are strongly related to phenomenology), and then allowed me to relate this material to that from the house, and begin to ask related questions. Again, throughout the thesis, all respondents' names have been altered to protect their anonymity.

The divisions between participant observation, 'interviews' and the visual methodology I undertook at the school are blurred, in particular as I adopted a 'softer' approach with children, some as young as four. More generally, as all interviews were either undertaken at the school or in people's homes (some of which had been designed by Day), I was taken on tours, made to feel at home, and - at the school - able to spend time walking around, conversing with people more generally whilst observing. This was an invaluable way to build images of the cultivation of an educational atmosphere and community through 'informal' networks and practices.

The more structured elements of my participation involved organising some lessons, and helping/observing in others, with children aged between 4 and 13. Most geographies of architecture do not consider children's use of space, although they do take on board the varied actors involved with buildings (Lees, 2001). My research does not aim to totally redress this - as it too is interested in the different actions and communities collected into and around the buildings - but the 'place' of the children at the school is naturally crucial to specific meanings and actions experienced at Nant-y-Cwm. It begins to highlight various differences in children's engagements with built form, but further work with psychological and educational research is required here. 
The school organised a police check, and I attended lessons only after around twenty of the interviews had been carried out, so that almost all parents and teachers knew why I was at the school. The art lessons (8-13 year-olds) were organised with the art teacher (Phil Forder). I had a degree of input in deciding what the children would be told, but I was eager that the lessons fit Steiner education. We decided not to inform the children exactly who I was or what I was doing, as at the time we felt this might 'put them off', knowing that their paintings would be 'analysed' in a far off, abstract institution. I was introduced as a 'friend of the school'. After a while, the older children in particular began to realise what was happening, so we told them what I was doing when they asked, at which revelation they were both shocked and amused!. We also informed the younger children in the last of their art lessons with us.

The children were asked to paint from memory, and then observation, what the phrase 'My School' meant to them, and what their favourite places were. The rationale for the paintings was only partially to obtain children's representations of the school: the main reason was a chance to observe/participate in lessons, and use the paintings as a method to concentrate the children on their experiences (both as I had observed them, and from the past), opinions and desires. Other researchers advocate the use of visual materials for stimulating discussion with children (Punch, 2002; Hazel, 2003). In sum, this approach was so successful in observing how 'education' at the school was performed, and in eliciting children's opinions (Chapter 10), that formal interviews were unnecessary. As with other interviews, I felt it unsuitable to ask the children directly about 'utopia'. For most young children, such a degree of abstraction would be too difficult to grasp. Moreover, as I was interested in everyday practices, moments or desires that they idealised or remembered - rather than 'split' off visions of perfection, which I have already critiqued in detail - ideas about utopia only emerged where these were salient to those practices - if at all.

Participation in the Kindergarten (4-6 year olds) involved playing with the children (I soon became a surrogate classmate!), helping with painting, cooking, tidying, and outdoor activities (see Aitken, 2001 on 'playing with children'). I talked with the 
children, took part in their games, and conversed with the teachers, often simultaneously. I was able to ask about likes and dislikes, and follow the ways in which they interacted with the school's version of Steiner education, and the relevance of the buildings to these performances. As with the older classes, I began with general observations, but narrowed these to focus on certain themes such as the structure of the day, the use of 'natural' materials, and the creation of a 'home-like' atmosphere through toys, smells, tastes and sounds. As well as watching how these 'small-scale' events took part in 'larger' concerns about education and community, I also wanted to challenge these scalar hierarchies by watching how those concerns could be prioritised or deprioritised in each event - in other words how large scale or 'structural' factors could become just part of an event or events in the ongoing construction of a homely school (section 4.7). I also spent time in the playground at break times, usually talking with teachers, but often talking with children and taking part in games. Many of these activities were not specifically geared around research, particularly as I became better acquainted with the school and its community, so that most, but not all, of my experiences were translated into notebooks.

\subsubsection{Interpreting ethnographic material}

Analysis followed the same emergent and then thematic method I employed at the house. As the opportunities for observation at the school were greater, and my interaction with the community better, my use of interview material was betterintegrated with participant observation, and interview material generally provided longer, more engaged quotations, which becomes apparent in later chapters. I was able to return after observations, and discuss these with parents, teachers and children. This also meant that observational material could more easily be interpreted with members of the community (although I did this to some extent at the Hundertwasser-Haus). In addition to the thematic debates, I used all my ethnographic material to construct different versions of specific events, particularly the importance of community at different 'moments'. This also provided renewed room for analysis on the Hundertwasser-Haus, so that my analysis bounced between these two case studies and 
my theoretical positions. I was then able to illustrate to what extent these thematic and conceptual interpretations were viable by constructing my own narrative through lengthy quotations from others'.

Observational material and paintings were mainly contextual, but again used as critical elements in the construction of certain specific and generic activities and atmospheres at the school. Towards the end of my research, when the key themes at the house and school had become crystallised, I focused on the ways that 'home' (and, related, a 'good' education), difference and community were performed at the school, again combining observation, participation, texts and discussion. I mix these sources together in various chapters, and would remind the reader that events in different chapters are inter-linked through chains of connection and collection, rather than 'separate' interviews, texts and themes as they might seem (for clarity).

\subsubsection{Problems}

Research with children involves various ethical considerations. As an adult, despite the fact 'we were all children', experiences of one's own childhood blur how we view others' - and of course children's experiences change over time (Fine and Sandstrom, 1988). Additionally, each child is, like any adult, very different, and similar difficulties of sameness/difference recur here. My decision not to interview children is partly exclusionary as it suggests children cannot take part in such exchanges (Hazel, 2003), however the main reason not to interview was the success of other methodologies, and the specifics of the school's atmosphere which $I$ felt would be interrupted by formal questioning. I (and teachers) thought these methods were better suited to - and more enjoyable for - these children.

Other ethical considerations are the power relations and danger that children may be in. All of my time with the children was supervised, and I undertook to fit in with their lessons as well as I could. The children welcomed me very quickly, involving me in their games and conversations. Indeed, $I$ felt like the subject of their (natural) 
inquisitiveness, rather than the allegedly expert researcher, which I think balanced out divisions of power in some ways. Apart from the nature of the art classes, I attempted to be as honest as possible with the children when asked questions. Perhaps the children were not research assistants in my project to the extent found in other work (Morrow and Richards, 1996), but I attempted to use their views to guide my research with them. Again, a fully representational account of their lives is not possible, in particular as their experiences are only some of many at the buildings. I wanted some detailed stories and observations, but I also wanted to construct stories about the buildings, to follow how collecting/dispersing and folding such stories around the material/discursive place of buildings might provide an alternative, more incisive, integrated, route to various concerns and desires.

One note I would add is this: "According to western notions childhood is a time for playing and protection" (Jencks et al., 2000: 5). This returns us to both my own and adults' views of children, and in some ways the degree to which they were involved in the fieldwork. The crucial point is that the question of quite 'who' the school was for remained unanswerable throughout, and again this complexity was apparent in many respondents' views. However, it was the particular view of childhood collected from Stockmeyer's curriculum, each parent, the affectual capacity of the buildings, and versions of Health and Safety enacted at the school which was critical to the varied meanings and performances of Nant-y-Cwm as building-practice-ideology. The ways the children took part in these discursive and performative systems, whether temporary or with an air of permanence, required a 'focus' on not merely their practices but their relational construction as 'children' with the school itself - very much geared around play and protection, as it happens. This methodological and empirical concern is dealt with in Chapter 10.

Apart from the obvious differences in language, and an informal interest in teaching from my parents, many of the other questions of positionality and ethics remain the same as for the Hundertwasser-Haus. In terms of feedback, once I had completed the interviews, I discussed some of the themes I had encountered with various members of 
the school community in informal discussions, and visited the school in May 2004 where I also spoke with a few teachers about my progress (and talked about the idea of utopia, which they greeted quite warmly). I produced three posters with some of the children's artwork as a small token of thanks, which are now displayed in the hallway of the school. I will also send them a copy of my thesis and a summary of my findings.

\subsection{Conclusion}

These methodologies addressed and refined my three main aims in various ways. There are naturally problems with any methodology relating to positionality, representability and power relations, many of which can never be fully evaded if research is to proceed, but I think I adapted to most or all of these as sensitively as I could. That the aims evolved with the research is a necessary element of any project, in particular where ethnographic methodologies are employed.

In sum, I attempted to address concerns of relevance to (ecological) architecture and various versions of utopia in general (health, difference, creativity, community and home). Through these, three themes most relevant to the two buildings were crystallised (difference, home and community). Some of these were similar to my initial thematic concerns, and are often found in more 'traditional' versions of utopia. At the same time, as it has transpired, many elements of these themes are not traditionally utopian - and in both cases, elements of these more relevant themes provided new insights and provocations to literature on utopia (as unsettling), critical geographies of architecture and contemporary theory. 


\section{Chapter 6 Constructing The Hundertwasser-Haus and Nant-y-Cwm, and constructing difference}

\subsection{Introduction}

This chapter introduces the house and school, contextualising them amongst Hundertwasser's and Day's other works, discussing the many influences upon them, and situating them briefly within broader architectural trends. It can be read as an introduction to the construction of the buildings in particular before the users moved in. Hence it introduces the architects' texts and work, along with the other influences that were involved in the buildings' initial construction. It also begins an exploration of one of the key themes of this thesis, difference, by examining how the buildings were conceived as artistic or reactionary statements by their architects and the press in different ways. These sources are a key part of integrated, critical geographies of architecture (Lees, 2001). Much of this difference is implicit in a discussion of their construction and aesthetics (grass roofs, involving workers or parents in the design, colour, lack of straight lines), although I explicitly draw this together through press articles, in particular for the house (there are very few on the school). This simple version of difference becomes complicated in the following two chapters through analysis of ethnographic material. Although this separation of 'before/after' and of 'context-text/use' is problematic, a degree of chronological separation is in fact apparent at the buildings, in particular for the house. Moreover, at both, I undertook research at least fifteen years after the initial design, construction and press interest began. This chapter is intended to render a fuller picture of the complex processes that led into the buildings' initial construction. This then feed into the ways they are and have been continually constructed and experienced.

\subsection{The Hundertwasser-Haus, Vienna: built 1977-1986}

\subsubsection{The house}

"So it is imperative that we must break with a whole series of regulations. These regulations ...created at another time, under different conditions...are now, in the 
light of new requirements...directed against the environment and man. ...Everyone will be glad to return home. For the house sparkles in the sunshine and in the moonlight. It has fountains, and you can sit amidst the trees. And you look at the living walls and recognise the living windows with pleasure, the ones you can reshape yourself, behind which you are at home" (Hundertwasser 1997a: 258-260).

In 1977 , Hundertwasser was asked by the City of Vienna to re-design a house on the corner of Loewengasse and Kegelgasse in the 3. Bezirk (district) of Vienna. The location of the house is shown in Figure 6.1. The Federal Chancellor provided Hundertwasser the chance to demonstrate how a house built along 'aestheticcreative' principles had 'the chance to combat sterile uniformity' (Kreisky, 1977; cited in Hundertwasser, 1997: 250). In the quotation that begins this section, in a manner which typifies his architecture, Hundertwasser is adamant that Modernist lines of thought and building be broken and moulded into irregular curves. Then, the concrete plans for this new house would not only negate the oppression of people by buildings, but also add something extra to their lives. Restany puts it thus: "The act of constructing a la Hundertwasser was to imprint the hallmark of his creativity on the fragment of urban fabric entrusted to him, on the physical and human scale of the environment. And since this was a public housing operation, the political gesture was doubly meaningful...the Vienna City Council did not turn to an architect but a dealer in happiness, passing him an order for a complex of happy spaces" (Restany, 2001: 45).

Hundertwasser was disappointed by the first architect assigned to help him. Josef Krawina had attempted to design a square housing block, onto which Hundertwasser would 'paint' a colourful facade. He made amendments to Krawina's original plans: "I tried desperately to overcome the geometric grid system supplied by the architect Krawina. I didn't want to just decorate the façade and put some potted plants on the roof, but made organic intrusions into the anonymous sterility on the drawing" (Hundertwasser 1997: 253). In February 2003, during my time in Vienna, an argument was raging over creative 'ownership' of the house. One party now claims that the house should be named the Hundertwasser-Krawina-Haus, following the input of the latter (ORF, 2003). Although little resembling Krawina's efforts remains, a legal battle has ensued. This potentially threatens to change the many posters, postcards, models and guidebooks in which the 'Hundertwasser-Haus' 
Hundertwasser - Haus, Vienna
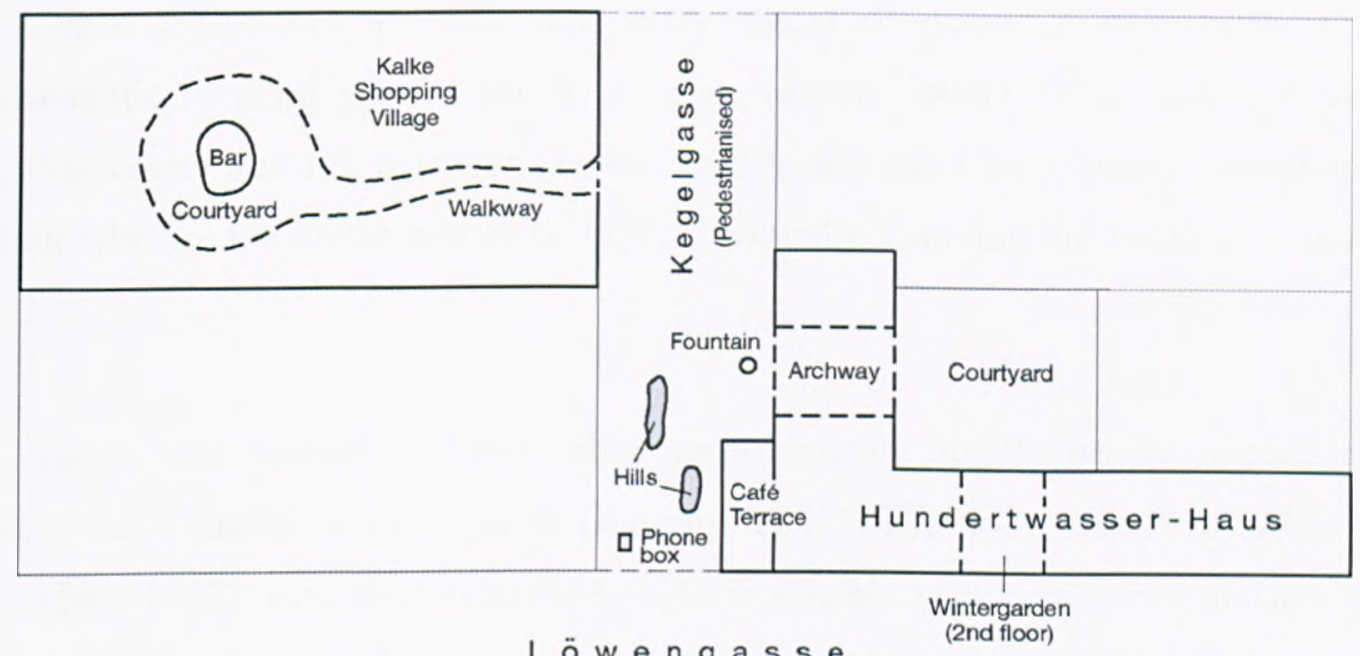

Löwengasse

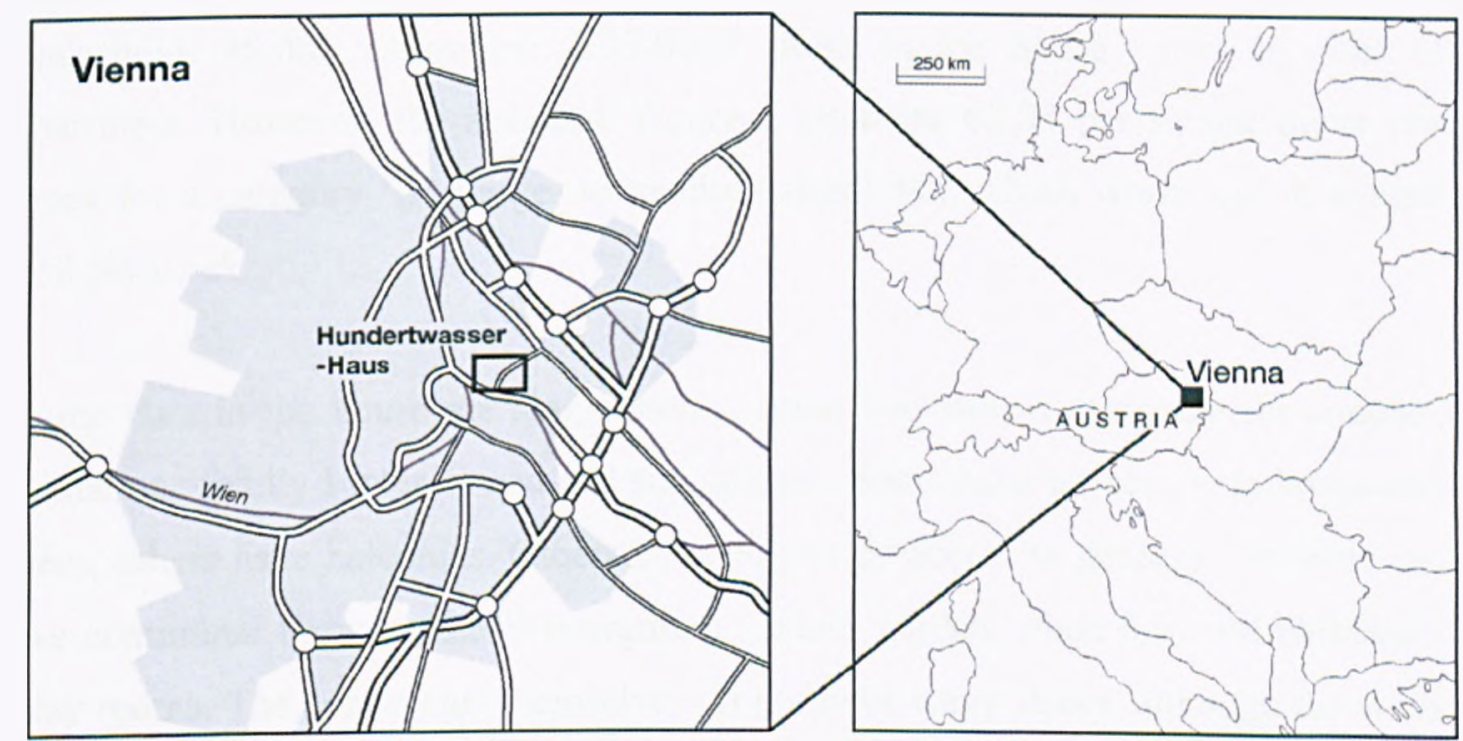

Figure 6.1: The Hundertwasser-Haus is located near the centre of Vienna. The latter lies to the left of the box in the above left diagram. The top image is a sketch map of the house and shopping centre (bold lines) and other major features mentioned in the thesis. Based on the author's sketches; cartography by Nicola Jones. 
features and which are dispersed globally. Even the house's name has been questioned; although I retain the original here for continuity. Another architect was assigned, Peter Pelikan, who worked closely with Hundertwasser's designs until the building's completion in 1986. The early stages of planning were beset with bureaucratic wranglings, so much so that various letters were sent between Hundertwasser and his manager (Joram Harel), and the City Council, repeatedly asking whether the house was to be built. Eventually, building did begin in August 1983.

The house was opened in 1986, when approximately 70,000 people queued up hoping for a chance to view inside (Restany, 2001). The house has 52 apartments (Bramhas, 1987), available to anybody who is eligible to live in social housing in Vienna. In Austria, social housing is more widespread than in post-1981 Britain, for example, and criteria for living in social housing are quite different. Applicants must be Austrian or EU citizens, or a 'recognised other' and have lived with a Viennese address for two years. The maximum income limits for eligibility are as follows for 2004: for a one person household, 25,000 Euros/year $(£ 17,000)$; for a four person household, 48,000 Euros/year $(£ 33,000)^{1}$. Rent in the house varies by size of apartment. However, the standard Viennese rates are $€ 2,08$ per square metre per week for a category 'B' (large- to medium-sized) flat, which works out at around $€ 50$ per week.

Some flats in the house are single storey, some two storey; some are for couples, whilst one family I interviewed had six children. Some have terraces with lawns and trees, others have balconies. Others have no private access to gardens, however can use communal terraces, the Wintergarten (indoor garden: Plate 6.1) and children's play rooms. The apartments themselves do not have wavy floors, although the walls are often off-straight. In the corridors (Plate 6.2), there are wavy floors and walls, as well as various tile designs laid out through the 'freedom' of the tile-layers. As illustrated in Plate 6.2, below a level indicated by tiles, the undulating walls are left white, for residents (mainly children) to etch into the wall, paint, write, leave posters

\footnotetext{
${ }^{1}$ Vienna social housing website:

Site accessed 13/01/2004. Exchange rates as of 13/01/2004.
} 
or place objects against them. Each resident also has a window right included in their formal contract, where:

"A resident must have the right to lean out of their window, as far as their arm will reach, and to re-decorate everything on the outside wall...." (Mietvertrag/rental agreement, re-printed in Koller, 1996)

However, as of February 2003, none of the residents had elected to exercise the window right. The house's facade (Plates 6.3 and 6.4) is very colourful, standing out in its surroundings (Plate 6.5), and the windows are all differently sized. Each flat is loosely individuated by a change in colour in order that passers-by recognise that different people live in each one. There are bulbous, colourful pillars both inside and outside the house: many of these are deliberately designed not to be load-bearing and are merely ornamental, in opposition to Adolf Loos' assertion that architectural ornament was tantamount to crime. There are many other unique features (such as gold onion domes [Zwiebeltuerme] and classical statues) evoking the many influences on the house (see below).

The house is also decorated with 'nature'. The many terraces have lawns and (fruit) trees, along with sandpits, swings, flower pots, washing lines and all manner of garden paraphernalia. They feel like small suburban gardens, although found at all levels, fifteen minutes' walk from the city centre! A couple of the terraces, and the ground floor courtyard, were re-planted and then left for 'nature' to take back. Hundertwasser elucidates the importance of the terraces: "If one includes those portions of green surface lying beneath perpendiculars, more than $100 \%$ of the ground plan is planted with greenery and trees. On the roof, nature was given back what the house had taken away from her" (Hundertwasser, 1997). 


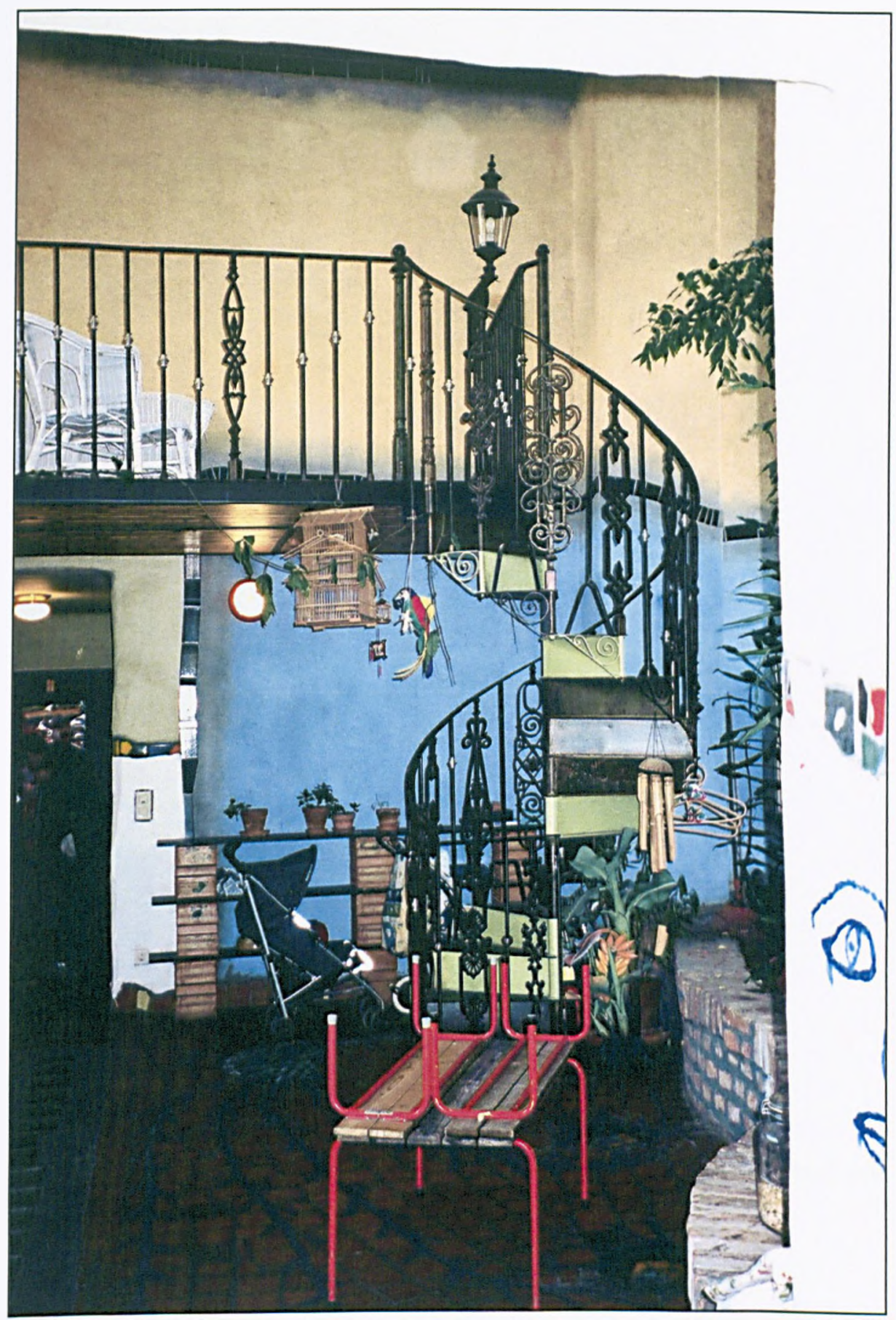

Plate 6.1: The Wintergarden. Note the spiral staircase bought by Hundertwasser in Paris. To the right, off camera, is a large plant bed, with a caged budgerigar. Author's photograph. 


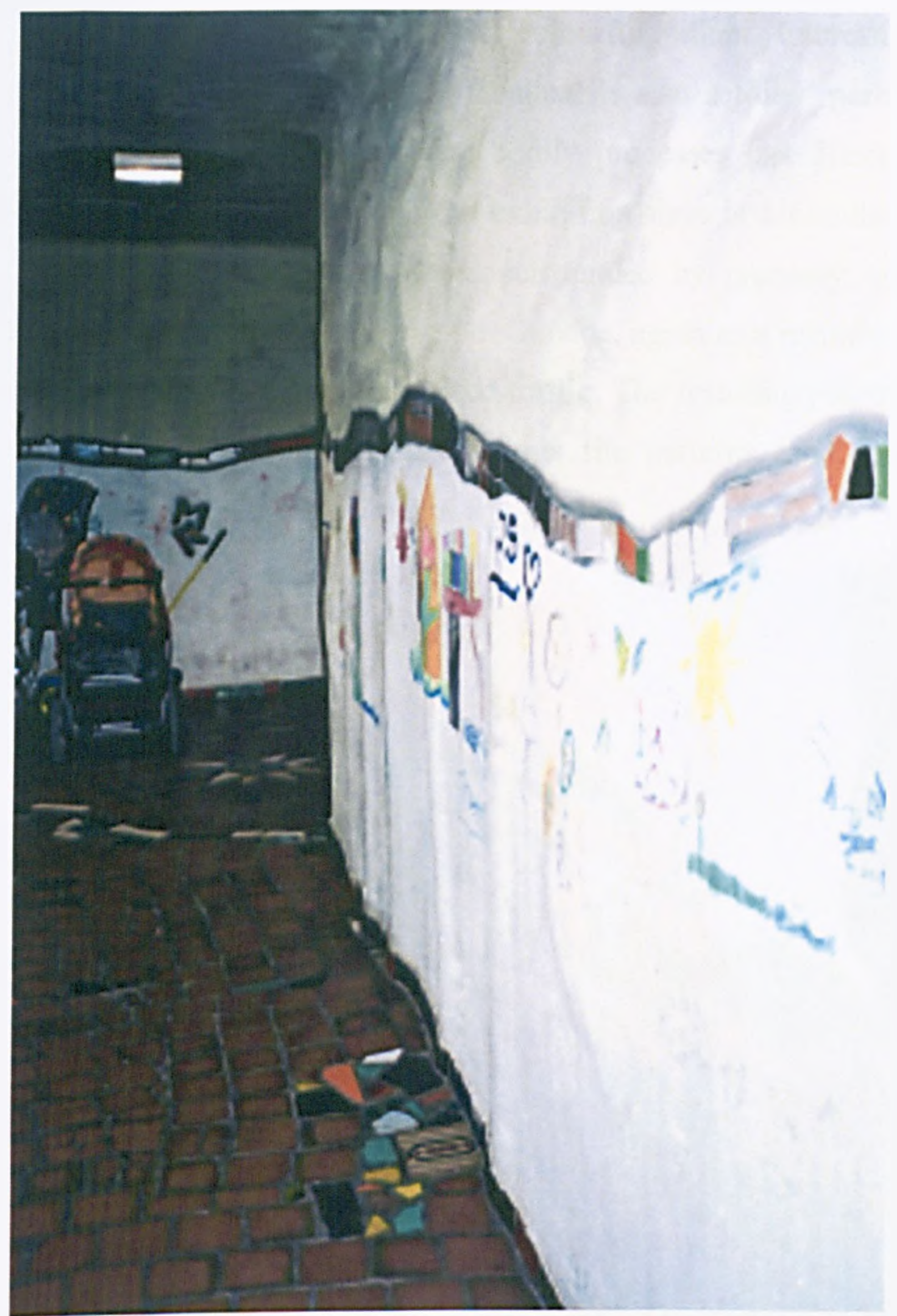

Plate 6.2 Corridor in the Hundertwasser-Haus. Note the wavy walls, adorned with children's and adults' drawings. Author's photograph.

Hordes of visitors are drawn to the house. With this massive pressure, the house itself was closed to visitors. When the Kalke tyre factory directly opposite closed in 1991, Hundertwasser re-designed it as a centre (Figure 6.1) with souvenir shops, where tourists could see and touch Hundertwasser architecture, and where shopping, eating and drinking could be facilitated. The roof is covered with greenery (see Plate 6.6), whilst the inside of the building is typically Hundertwasserisch. Of particular interest here are the 'Toilet of Modern Art', which can be enjoyed for a small fee. Inside, bewildered 'customers' are treated to a disorientating environment of wavy 
tiled walls, cracked mirrors and colourful pillars. Interestingly, Hundertwasser's most famous building in New Zealand is also a toilet, perhaps a reflection of his preoccupation with natural and bodily processes (see Restany, 2001 on the 'five skins')! In addition, outside the exhibition-shop is a circular courtyard with a bar, replete with running water and surrounded by greenery, giving the feeling of a vibrant yet hyper-real streetscape. Outside, again as a result of mass tourist presence, the street was closed to motorised traffic. The resulting pedestrian zone is broken up by small hills, a few trees, various tile patterns, and, bizarrely, a British red telephone box (Plates 6.7 and 6.8).

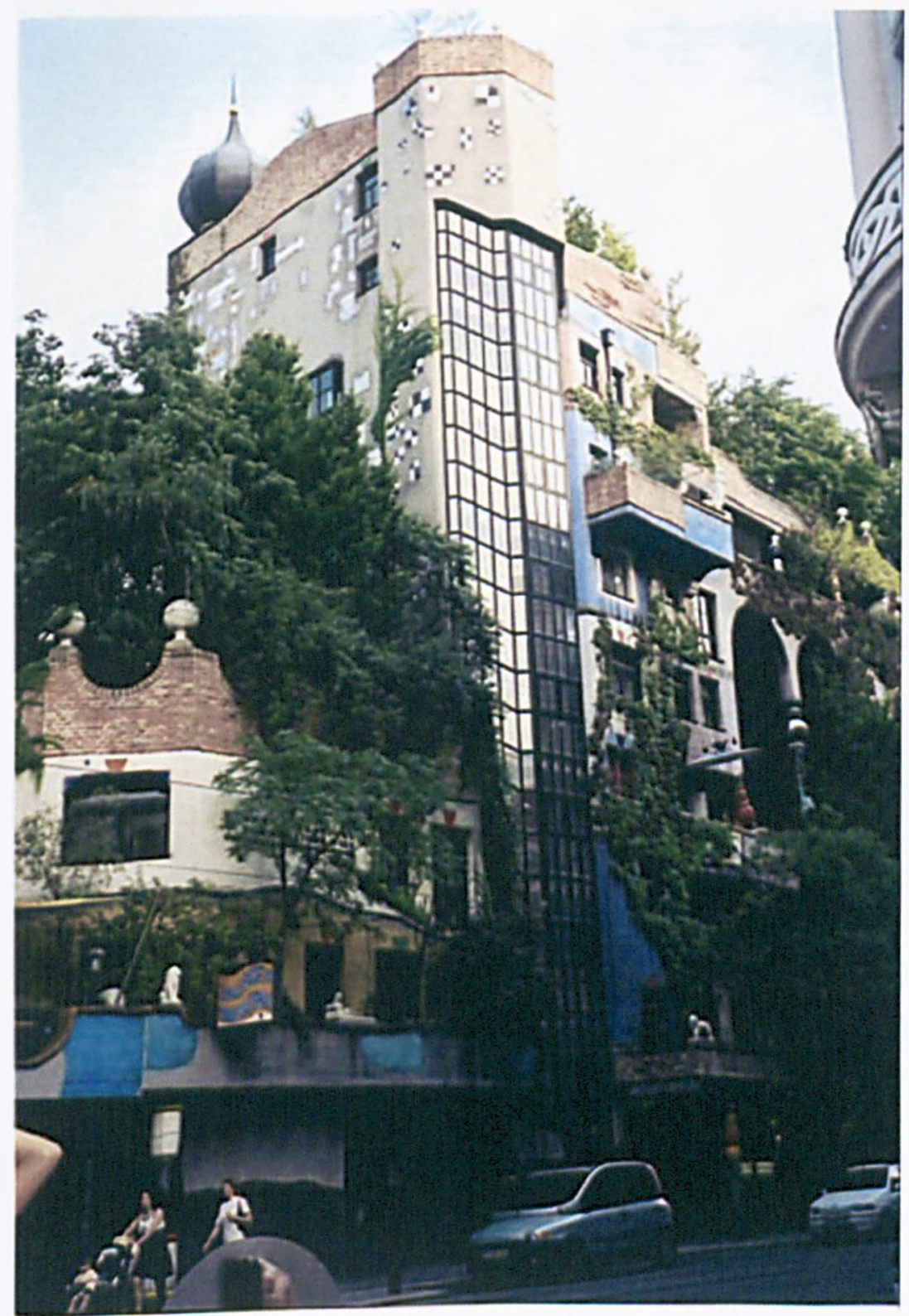

Plate 6.3 The Loewengasse façade. The Wintergarden windows are beneath the arches to the right, and two cafes for tourists are just visible at the foot of the house. Author's photograph. 


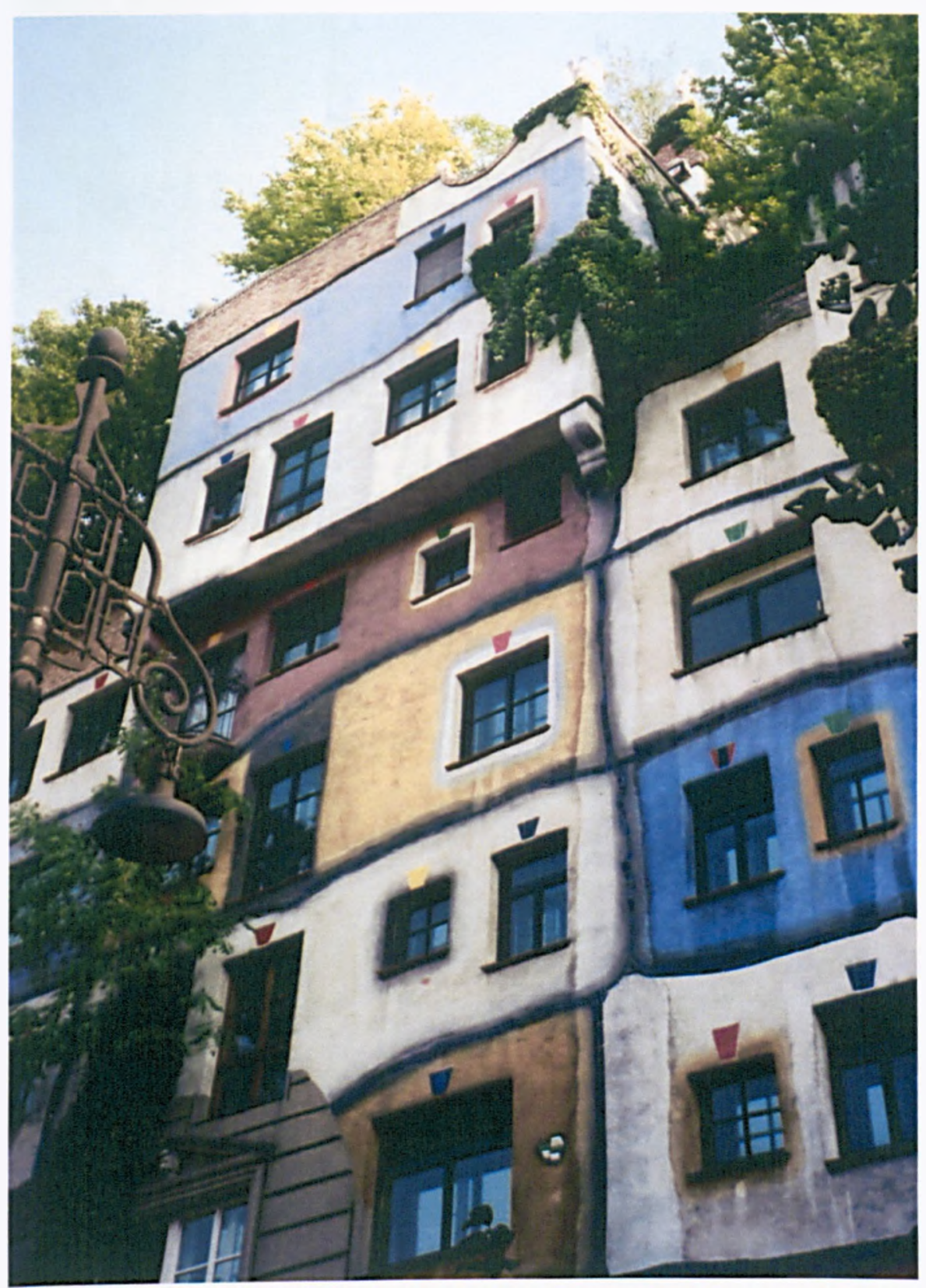

Plate 6.4 The Kegelgasse façade of the Hundertwasser-Haus. Immediately visible here are the windows of various sizes and different colours indicating each apartment. Author's photograph. 


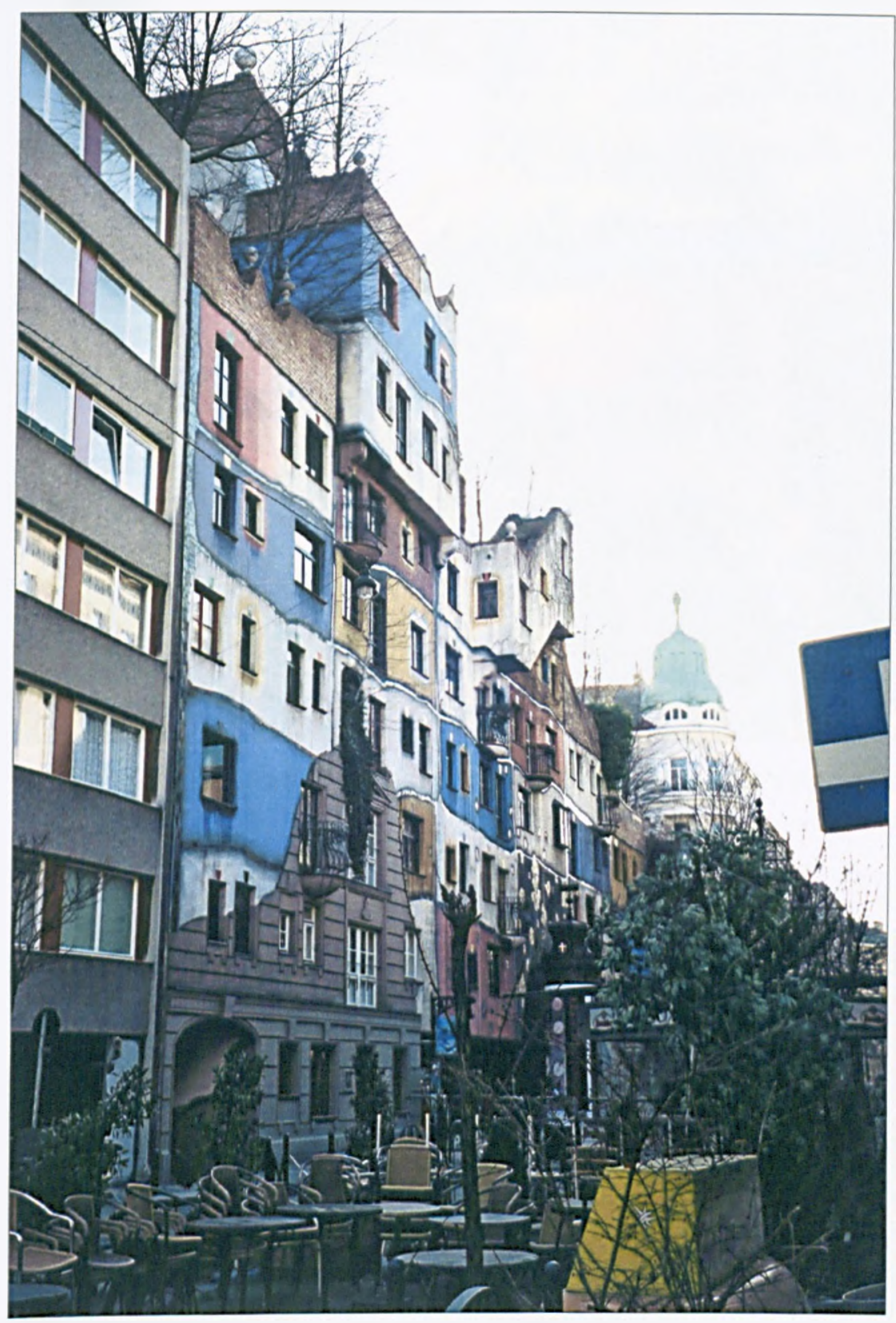

Plate 6.5: Kegelgasse. The building to the left is an example of the 'box-like' architecture of which Hundertwasser was critical, and, in the background, a Jugendstil house. In the foreground, the pedestrian area and café outside the shopping village. Author's photograph. 


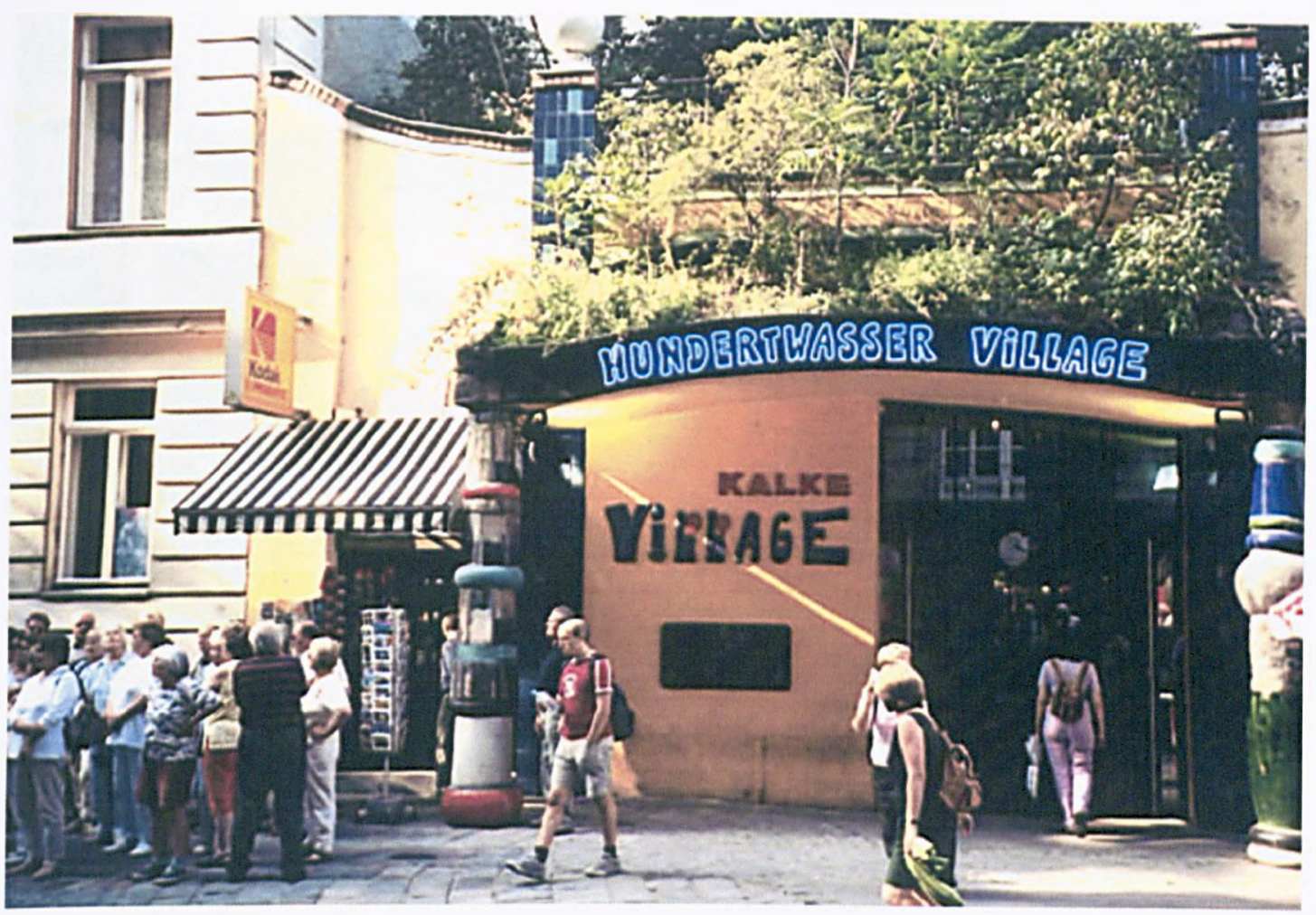

Plate 6.6: The shopping village exterior in September 2002. Author's photograph

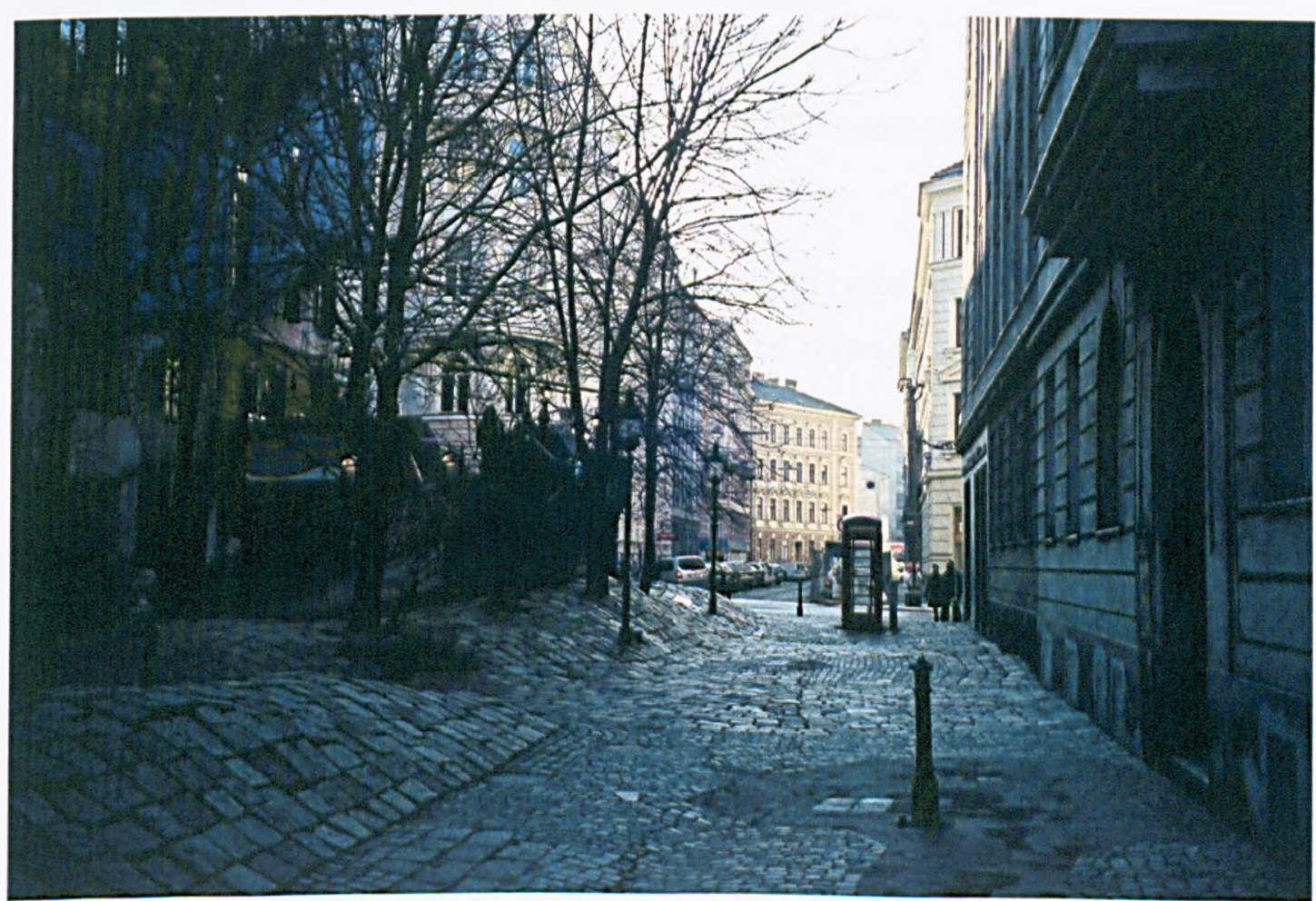

Plate 6.7: Kegelgasse, pedestrianised area. Note the hills and trees to the left, and telephone box! Author's photograph. 


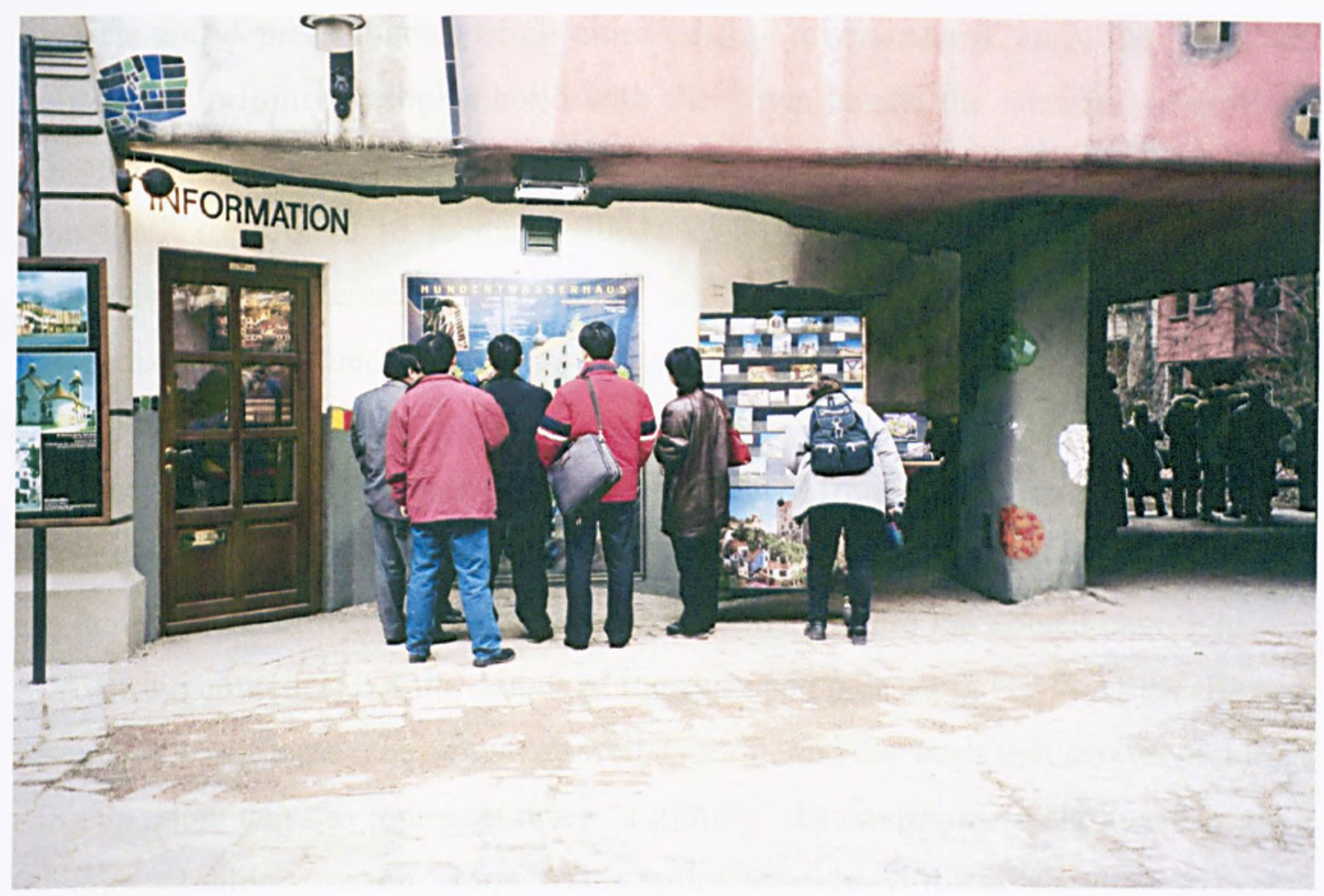

Figure 6.8: Tourists outside the Hundertwasser-Haus and under the arch (to the right, background). Author's photograph.

\subsubsection{The Hundertwasser-Haus: context and influences}

"The absolutely straight, dead skyline is an ignominious heirloom of the Bauhaus." (Hundertwasser, 1997a: 266)

I will concentrate here on my interpretation of the most important ideas, practices and aesthetics collected into the house itself, read through Hundertwasser and other commentators. For Hundertwasser, who drew on many and varied influences, and took delight in doing so, this task is quite troublesome. However, I attempt to present these 'major' factors with this caveat in mind, before briefly relating the house to Hundertwasser's other projects, and Vienna's architectural history. More detailed accounts of the latter are available (for example, Schorske, 1998), and such detail would be quite far removed from the aims of my thesis and thus that needed here.

Firstly, Hundertwasser lists those buildings that he argues exerted considerable influence on his building design: "Antoni Gaudi in Barcelona; Art Nouveau in Vienna; Simon Rodia's Watts Towers in Los Angeles; the postman Ferdinand Cheval's palace at Hautrives in the Drome department of France; the insalubrious 
districts and depressed areas of all cities (shanty towns, slums, etc.); the farms and houses that primitive peoples build with their own hands; the workers' houses and allotments; the walls of urinals and their inscriptions; and a few works by Christian Hunziker" (re-printed in Restany, 2001: 23-24). A varied collection indeed, but Hundertwasser's interest in irregularity, self-build and nature comes through here, and is discussed further below.

Hundertwasser travelled widely, visiting North Africa, Paris, and other parts of Europe, where he collected various insights now apparent in his work. For example, his famed Zwiebel-tuerme (onion domes) not only conjure the domed church towers of Austrian churches, but the domes of mosques and palaces in North Africa. He was fascinated by process (see below) as well as form, and the ways that certain buildings came in some ways to represent more 'truthfully' the environment and needs of their inhabitant-builders - even 'slums'. This tallies strongly with Day's attitude to design and the importance of site and context.

In addition, Hundertwasser took inspiration from the art world. He expressed a liking for various artists, in particular Klimt, Schiele and Klee. Elements of the work of these three artists, as of Hundertwasser's painted work, flow into his built designs and façade decoration. "His richness of surface and use of color suggest Klimt, while his scrubbed brushstrokes and moldy colors are reminiscent of Schiele. Hundertwasser's painting has been described as heavy, rigid, archaic and primitive. It is ironic that his deep awareness of the need for humanistic primitivism stems from a high degree of intellectual sophistication. This primitivism has been seen mostly through his use of color and line" (Thompson, 2000, no pagination). This excerpt, actually detailing Hundertwasser's painted works, could as easily fit Hundertwasser's designs for the Hundertwasser-Haus façade. Both are characterised by an infantile regression into nature or into the artist's own self, which lead some to label Hundertwasser's style as mole-like (Schmied, 1997). However, the simultaneously shocking impact of his buildings in particular point to a peculiar combination of regression and exhibitionism which also characterize Hundertwasser's psyche, found in his installations and speeches (see below). 
Thompson (2000) and others also acknowledge the broader artistic trends of the Twentieth Century upon Hundertwasser's entire oeuvre: Jugendstil and Seccesionstil - the Germanic attempt to come to terms with French Art Nouveau; connections to the surrealists, through Gaudi and other Modernist(a)s; the Vienna School of Fantastic Realism ${ }^{2}$; and the Paris and Vienna art scenes of the 1950s onwards. A fine example of Jugendstil in fact stands around the corner from the Hundertwasser-Haus at the Palais des Beaux Arts on Loewengasse. However, even many of these more curvaceous Art-Nouveau forms still expressed to a certain degree the strictness he abhorred, so that he turned further to 'nature' for inspiration.

The influence of Gaudi is undeniable, to the extent that Hundertwasser has been named the 'Austrian Gaudi'. His use of coloured, broken tiles, and zoomorphic and ecological forms is certainly reminiscent of the Catalan architect. His architectural discourse is too: compare "The straight line is godless and immoral" (Hundertwasser, 1997a: 48) with "The straight line belongs to man [sic.], the curve to God" (Gaudi, cited in Glancey, 2000: 70). Hundertwasser is perhaps a less avowedly religious figure. Nevertheless, the similarities with Gaudi's approach to form and colour are striking.

The range of influences at the house is multiple, a collapsing together of trends almost wholly in line with the post-1970 trend to the postmodern method of collecting historical style into colourful pastiches (Jameson, 1991; Venturi, 1977). Owing to these eclectic influences, the house has been labelled postmodernist by some, although a note from Harel on Hundertwasser's behalf refutes this:

"Postmodern architecture is not a free architecture, but a dogmatic one. Postmodern architecture is a contemporary intellectual idea of architects' [creation]. My architecture is true to people and nature." (Reply from Joram Harel to Iwert Bernakiewicz, 12/04/1989: archive article 4)

Despite this, Pierre Restany comments that: "Hundertwasser-Haus is a hostage of his [Hundertwasser's] own success. It has become the landmark of post-modern Vienna" (Restany, 2001). Whether this is the case as far as life at the house is

\footnotetext{
${ }^{2}$ This school (led by Ernst Fuchs and of which Arik Brauer, who was also later commissioned by the City of Vienna to construct a building, was also a member) was influenced by Surrealism yet
} 
concerned, is not strictly relevant. In fact, even the press attention the house receives constructs the house in along quite different lines - as we shall see. In simple aesthetic and methodological terms, Hundertwasser's architecture does bear similarities with postmodern architecture. Hence to separate Hundertwasser from this trend is perhaps a mistake: however to align him fully is to miss what were perhaps his deepest formative influences, as I argue in the next sections.

Nevertheless, it seems that Hundertwasser's particular conception of 'Modernist Architecture', guides both his discourse and design through a philosophy that is often highly deterministic. In some senses, his sensibility is as much rooted within some of those he derides as much as outside them. Jugendstil and Surrealism both played their part in the development of architectural Modernism, and some of Hundertwasser's aims (healthy buildings, roof gardens, breaking with the past, and utopian designs for healthy living) are similar to those of the 'Moderns' such as Le Corbusier. Nonetheless for Hundertwasser it is the stereotypical Modern - white walls, system-built boxes, lack of vegetation, repetitive sameness, all transferred insensitively from place to place - that incenses him. He lambasts particular figures:

"The irresponsible vandalism of the constructive, functional architects is well known. They simply wanted to tear down the beautiful stucco-façade houses of the 1890s and Art Nouveau and put up their own empty structures. Take Le Corbusier, who wanted to level Paris completely in order to erect his straightline, monstrous constructions. Now, in the name of justice, the constructions of Mies van der Rohe, Neutra, the Bauhaus, Gropius, Johnson, Le Corbusier, Loos etc. should be torn down, as they have been outdated for a generation and have become morally unbearable." (Hundertwasser, 1997a: 48)

Perhaps this attack is a little too generalised, as well as it ignores the close relation between Art Nouveau and Modernism. Still, Hundertwasser highlights that it is this stasis and 'vandalism' against which the more processual, movement-orientated elements of his design praxis had to act - which he did from 1950 onwards.

\subsubsection{Movement and the Hamburg Line}

The Hamburg Line (1959), drawn at the Lerchenfeld Art Institute by Hundertwasser and two poets (Bazon Brock and Harald Schult), was one of his first properly

attempted to depict more 'visionary' images through sharp clarity, colour and the use of religious references. See

for more. 
'architectural' expressions. The line, drawn continuously over two days, ran spiraling around a room at the Institute. Intended, as most of Hundertwasser's work was, to interrupt the smooth lines of Modernist Architecture, the spiral and the wavy line expressed architecturally and performatively for the first time there, became emblematic of Hundertwasser's building designs. In particular, the movement of the archaic figure of the spiral - inwards and outwards, burrowing underground through tunnels, like the mole - is the inspiration for much of his architectural thinking (Thompson, 2000; Schmied, 1997). This is also one of my own sources for the notion of simultaneous collecting/dispersing at buildings.

Other performances include his speeches 'Mould Manifesto' (1958), 'Speech in the Nude for the Right to a Third Skin' (1967) and 'Loose from Loos' (1968). Through his own 'ecological' architecture, all of these performances critiqued the straight line and Modern architecture. They called for a re-negotiation of the relationship between the human body, creativity, shelter and nature, and also outlined his philosophy that individuals should be able to change their architectural surroundings as they wished. For him, this represented a radical departure from the hegemony of pre-set design and form to a more processed based aesthetics (and practice). Examples of art installations include his Tree Tenant Demonstration (Milan, 1973) ${ }^{3}$. Here, trees were installed into the windows of a normal city block to disrupt its straight lines and show how a 'dynamic' nature could be returned to the city - a precursor to the 'tree tenants' at the Hundertwasser-Haus.

For the Hundertwasser-Haus itself, the presence of the spiral is perhaps not the most striking element, whereas the vivid primary, again regressive colours that particularly originate in Hundertwasser's education in a Montessori School in Vienna are more notable. The spiral is more evident inside, continuing through the corridors not as a geometric line, but as a labyrinthine pathway, reminiscent of a three-dimensional, walkable expression of the line on the wall at the Lerchenfeld Institute. To his delight, Hundertwasser even got 'lost' the first time he tried to walk through the house's corridors (Reed, 1985)! Such movement is also apparent in Hundertwasser's conception of architecture in 'harmony' with nature and creativity (see below).

\footnotetext{
${ }^{3}$ All three texts are re-printed in Hundertwasser, 1997
} 
The uneven walls of the house, Hundertwasser's 'unregulated irregularities', indicate a kind of Gaudi-esque organicism. These are also a function of his aesthetic identification with the wavy walls of seemingly pre-historic and indigenous structures in the ancient quarters of European and Islamic settlements. These irregularities are combined with the spiral to structure the internal walkways of the house. More importantly, such ur-forms have inspired other architects (including Day) for their apparent 'rootedness' to the ground.

Again, the complexities of such influences are impossible to document, as the final version of the house was unknowable. Despite architecture seeming to be one of the most concrete of arts, a contingent, flowing, latent energy, or even an excessive virtuality (Deleuze and Guattati, 1987; Seigworth, 2000) characterizes the dynamism with which the house, its construction and inhabitation are conceived. The house should be, at least aesthetically, shaped by the creativities of the workers, and random meetings of impulses that would change the texture or colour of its façade. This collection of elements, complicated by the freedom the workers were granted, mean(t) that the house's 'final' form could never be fully forseen, nor was it a 'utopian' goal. Instead, the utopianism was inherent in this material process, or more accurately in certain unpredictable moments thereof. Intended as a "concrete utopia for a green city" (paraphrased from Hundertwasser, 1997: 68) this was thus a dynamic utopia, an always unfinished vision of praxis, rather than a represent-able, achieved 'state'.

However, this raises two points. Firstly, this is not merely a result of Hundertwasser's artistic love of 'unregulated irregularities', or his active collecting of disparate influences. This centred collection is cut across by many others, by the actual performativities of the workers' and inhabitants' energies themselves, and the agency of the bricks, mortar and plants that continually become the building in an ANT sense (see below on 'nature'). Moreover, this performativity and utopian creative harmony is at least symbolically designed into the house - in, for example, the 'window rights' that the residents are granted. These 'collective individuations' (Harrison, 2000), these unknowable actions of mould, rust, ruin and individual paths in the city (Hundertwasser, 1997) point to a utopia that, disconcertingly, never existed at any point. Instead, they nearly always emerge anew in ever-changing situations, from building, to visiting, to inhabiting. This is another version of 
movement, collecting/dispersing and 'event', discussed fully in Chapter 4. Moreover, this brings us to the second point. Much of this, from the collection of styles to the collection of energies and agencies (perhaps not so explicitly or as knowingly artistically) also happens at any building. What is crucial is that part of the knowing construction and performance of 'difference' at the Hundertwasser-Haus comes from such a peculiar array of collections and performances, and the utopian valorisation of creativity, art and nature through 'newness'.

\subsubsection{Nature and artistic creativity}

We see this process where many of Hundertwasser's greatest inspirations - including the spiral - come from his experience of nature. All of us draw much of our inspiration from our surroundings, however for Hundertwasser, architects would usually rather rely on their formal education, and the dictates of style, form and function for theirs. As an ecologist, he was drawn to the processes of what he chose to see as 'nature'. He developed his methodological aesthetic for painting 'vegetative painting' (Hundertwasser in Schamoni, 1972), which evolved slowly, in a spiraling motion - almost in identification with the way a fern unfurls. This mode of painting, and of bodily expression - again in reverence of the spiral - as a mode of engagement with nature and art, in many ways re-iterates the ideal of movement informing his design-aesthetic.

Hundertwasser believed that nature, both as an aesthetic element of, and as a responsibility for, architectural activity was fundamentally important. Buildings should play second fiddle to a nature imbued with real agency (see also, for example, Clark, 2002). He describes the painting 'Singing Bird in a Tree in the City' (1951) in such terms: "The buildings on grass and the large tree in the city are as big as the skyscrapers. The bird is in the centre. This shows precisely my ecological tendency to bring green to the city. And right in the foreground, at that: the tree is more important than the architecture" (Hundertwasser, 1997).

As well this interest in the forms of nature, he was also interested in its processes, almost in a way in which post-structuralists stress the agential 'performativity' of non-human, natural agents or processes (Clark, 2002, 2003; Szerszynski et al., 2003). He criticised 'rational' ways of working, instead promoting a fluidity, and 'transautomatism', spiraling and proliferating like the growth of mould, by which 
Hundertwasser was fascinated (Restany, 2001; Hundertwasser, 1997: 46). Hence as well as the fern, mould and ruin too become signifiers of ways of working, as well as aesthetic achievements. This explosion of the straight line is for many a symptom of Hundertwasser's radical re-thinking of Modern certainties. Similar trends can be found in deconstructivist architecture (Tschumi, 1994), and in feminist critiques of 'rational' architectural praxis (Grosz, 2001). This is not to say that Hundertwasser effected his own 'deconstructive' turn, but that, following Mannheim's definition of utopia which "...tend[s] to shatter, either partially or wholly, the order of things prevailing at the time" (Mannheim, 1960 [1936]: 173), his thought provoked and unsettled debate, and incited indignation (Schediwy, 1999). His hatred of the straight line - a utopian posturing of the possibilities of more harmonious, irregular architectures - was expressed in his statement in the Mouldiness Manifesto that "The straight line is not a creative line, it is a duplicating line, an imitating line. In it, God and the human spirit are less at home than the comfort-craving, brainless intoxicated and unformed masses" (Hundertwasser, 1997: 48). For Hundertwasser, as there are no straight lines in nature, humans and their buildings should not be subjected to them, either (Restany, 2001).

On one hand, nature can be an aesthetic solution to ill-health, and a harbinger of artistic beauty: "I will fight to help nature gain back her rights, including her part in colouring architecture. If we let nature paint the walls, the walls will become natural, the walls will become humane, and then we can live again. We need beauty impediments. Beauty impediments are non-regulated regularities" (Hundertwasser, 1997: 70). On the other hand, this vision, which is partly comforting, joyful and happy, is also unsettled by the creative destruction that nature can do, and the uncanny utopian tendencies this can herald in ruin, rust and spontaneity. "The good intention has been completely missed. Nature has been told again what to do. ...I therefore urgently request: to be allowed to change the tree at my expense. I am thinking of indigenous trees... . Untended. Uncut. ...just like between the walls of old ruins..." (Hundertwasser, 1997: 84). The agency of nature (however conceived) is part of the continual performance of the house, and a further instrument of collection and recombination of disparate elements, apart from its role in a collapsing of aesthetic styles. More detail on ruin and utopia can be found in Chapter 3, as well 
as on the conflation of seemingly dystopian or negative processes into an unsettling utopianism, of which this is an example.

Such a utopianism is also concerned with the body and its perfomative and creative relationship with/in architecture. This is a communal vision of social harmony through architectural creativity and the (part) determinism of built form. This is also inspired by Hundertwasser's relationship with(in) nature. This notion of utopia, both unsettling and comforting, aesthetic and political, is one rooted in the materialities and performance of everyday life, in particular nature and architecture: "One can't flee to paradise... . One can only create paradises oneself, with one's own creativity, or with nature. In paradise, there is light and shade, bad and good, poor and rich...ugly and beautiful..." (Hundertwasser, 1976 ${ }^{4}$ ). This is both comforting and unsettling, much like my deconstruction of utopia/dystopia begun in Chapter 3. Yet this is always set in the relation of the individual, rooted into the world through their five skins, which concentrically radiate out from the body". He adds that "Paradises can only be made by the individual, with his [sic.] own creativity, in harmony with the free creativity of nature" (Hundertwasser, 1997: 70).

This is at least an implicitly relational concept of people's being in the world and with nature, although admittedly rooted in a deterministic notion of architecture. Hundertwasser's concept of creativity is, however, also more engaged. In practical terms, this is exemplified at the Hundertwasser-Haus in the residents' contracts for apartments (printed earlier). Moreover, the workers were granted a larger degree of freedom than is conventional for tile-laying, painting and plastering. This is consistent with many of Hundertwasser's projects, adding to his distinctive 'style' (Bacher, 20026). Hundertwasser argues that "The workmen on the project...are an amazing discovery to me, for they can immediately make use of the freedom of creativity. True joy in one's work is the liberation from the constraints of the machine, from the terror of the assembly line, from the dictatorship of prefabricated parts, from being raped by the straight line and the so-called rational grid system" Hundertwasser, 1997 [1985]: 294). The importance of creative work has not been

\footnotetext{
${ }^{4}$ This quotation is taken from the manuscript for a forthcoming text, made available to me at the Hundertwasser archive. My thanks to Andrea Fuerst for the opportunity to view the text.

${ }^{5}$ Those being: the human skin; cloths; architecture; society; the earth (Restany, 2001).

${ }^{6}$ Personal communication by E-Mail. Bacher argued that the workers at Bad Blumau (the thermal springs village designed by Hundertwasser) had far greater freedom than at any 'normal' project.
} 
lost on many utopians over time (like Marx and Ashbee), in promoting social harmony and well-being (Hardy, 2000).

Finally, where Hundertwasser was interested in the rights of nature, of which in his utopian imagination humans were necessarily a part, he was also interested in the rights of objects and the stories they could tell. This links loosely with some aspects of ANT, where Hundertwasser states that: "Some people say that houses consist of walls. I say houses consist of windows. ... if...three window types are part of one building, this is regarded as an infringement on the racial segregation of windows, as an offence against the laws of window apartheid. Why? Every window has a right to exist in its own right" (Hundertwasser, 1997 [1985]: 271). Apart from being quite funny, the importance Hundertwasser attaches to windows, pillars, plants and other often small parts of the house was crucial to its construction, as well as discursively framing residents' and visitors' experience thereof.

Hundertwasser's theoretical import into the Hundertwasser-Haus is thus very different from postmodern architecture. This is not, of course, to contend that all 'postmodern' architects merely rely on their education and an aestheticised sense of history for their inspiration. Interestingly, though, Glancey (2000) places Hundertwasser in the category of 'organic architects', with other architects such as Scharoun, Niemeyer, Wright, Fathy, Gaudi, and even Le Corbusier. However, I think Hundertwasser would have perhaps placed himself, and the house, in his own 'vegetative category', perhaps of a 'performative' architecture, or at least one whose aesthetic (like Day's and some ecological/organic architects) is ready, by design, to become enlivened by use. His style is very different from those of many ecological architects. Moreover, Hundertwasser (1997) himself, and many of the residents, stressed that the house is not strongly ecological - a symbol or stranger in the infrastructure, rather than complementing it or any 'natural' surroundings, in Ole Jensen's (2002) categorization of ecological architecture'. Moreover, green

\footnotetext{
${ }^{7}$ Ole Jensen (2002) discusses in material-semiotic terms how a building can- 'fit in' - with the local environment (variously defined) in a social-ecological sense. It can do this in one of three ways: as a 'supporter' (which follows but improves existing conditions); as a 'symbol' (making appoint with few infrastructural, material changes); or as a 'stranger' ('matter out of place', opting out of symbolically or materially accepted configurations of buildings and networks). Jensen's approach is useful, although tangential to the more practice-based approach I am interested in: nevertheless, I think the Hundertwasser-Haus is perhaps a cross between symbol and stranger, although I question any neat relation in Chapter 7.
} 
architecture is split into various camps which either use technology to improve their energy efficiency (and a technological aesthetic), or attempt to 'hide' away more, with 'soft' engineering approaches such as Day's (Papanek, 1995; Wines, 2000). The utopianism that Hundertwasser ascribes to nature joined with creativity is clear elsewhere (also found in Edwards, 2001; Edwards and du Plessis, 2001), yet perhaps the extroverted outcome is the largest difference from Day's and other work despite certain striking similarities.

\subsubsection{Hundertwasser's other built projects}

The Hundertwasser-Haus is the best-known of Hundertwasser's built projects, a full list of which is available elsewhere (Schmied and Fuerst, 2003). As already mentioned, artistic interventions and installations such as the Hamburg Line, in many ways pre-figured Hundertwasser's dedication to a holistic, ecological and vegetative architecture.

During the 1970s, however, Hundertwasser named himself the 'architecture doctor', beginning to receive requests to re-design the facades of 'sick', Modern buildings. His first was from Rosenthal AG, in Selb, Germany, who requested that he redecorate their porcelain factory and car park. He broke up the straight lines of the building and planted trees on the roof so that "A factory makes its peace with nature" (Hundertwasser, 1997: 118). Hundertwasser also re-designed, amongst other buildings, the Rupertinum gallery in Salzburg, a Church in Styria, a motorway service station in Lower Austria, the Spittelau district heating plant in Vienna, and the KunstHausWienn near the Hundertwasser-Haus (see Plate 6.9). Importantly, almost all of Hundertwasser's interventions and re-designs were for everyday spaces. This heightens the uncanny effect of his critique and its relevance to contemporary society, but also intensified the criticism he received.

Hundertwasser's new buildings, of which the Hundertwasser-Haus (1986) was the first, were generally built after 1990, with his executive architects Peter Pelikan and Heinz Springmann. 


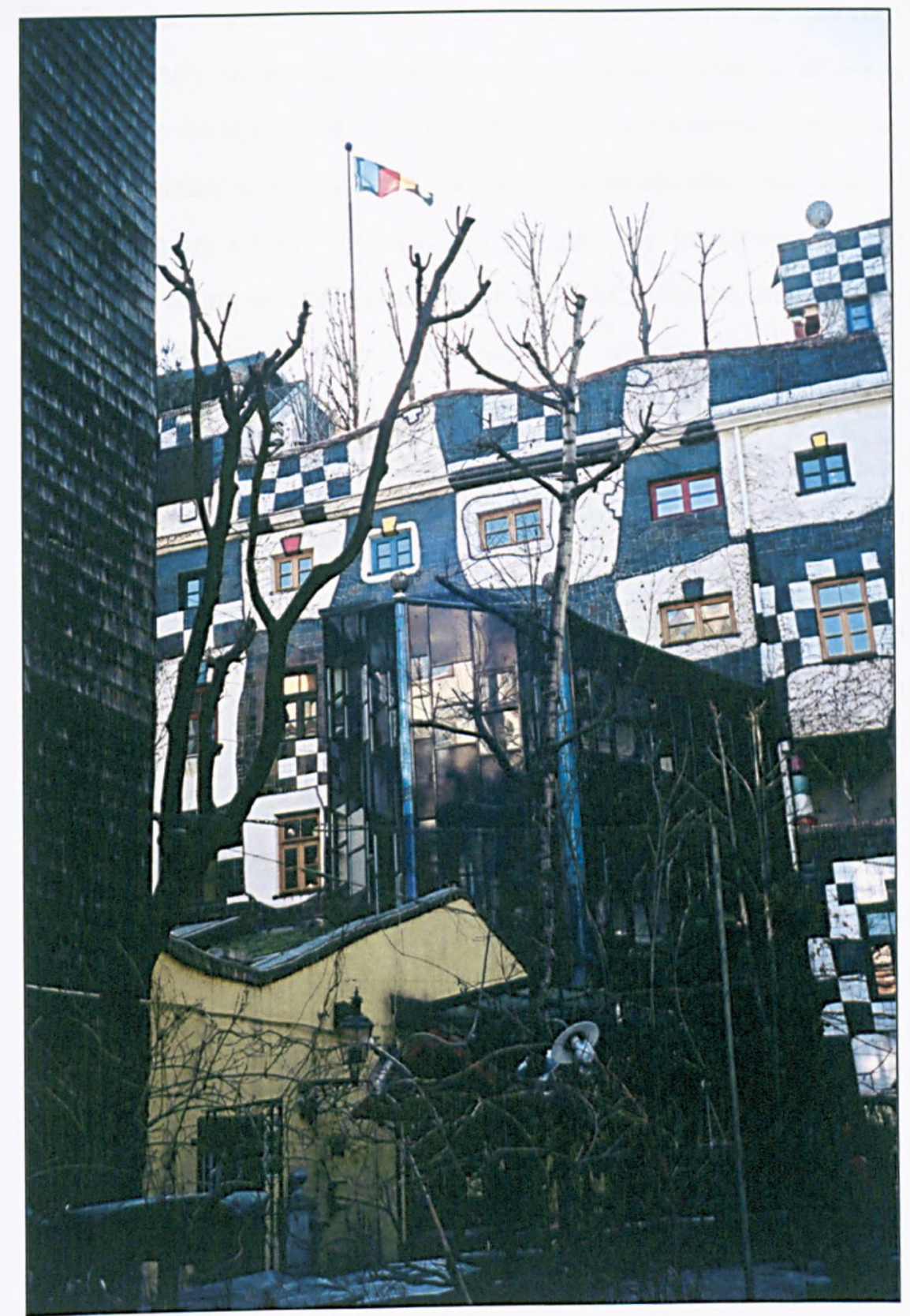

Plate 6.9: The KunstHausWien, about five minutes' walk from the Hundertwasser-Haus. The museum houses many of Hundertwasser's paintings as well as temporary exhibitions.

Examples of those built to date include a school in Heddernheim, near Frankfurt am Main, a winery in California, a thermal pool complex in Styria. His thermal pool presents another version of a relaxing, fun, comforting and colourful paradise, a consumer-orientated oasis of (healthy) pleasure, perhaps not so unsettling, but which there is no space to discuss here. Hundertwasser does however have a style, visible in his earlier paintings and buildings, of which the house is certainly reminiscent. Whether Hundertwasser's buildings ' $f$ it' their landscape is perhaps a contentious issue, as a wide range of responses to this question from residents at the 
Hundertwasser-Haus bear testament (Chapter 7). Where Christopher Day attempts more ardently to mould a building from its surrounding landscape, Hundertwasser utilizes the metaphor of mould to articulate a knowingly artistic practice stemming from a vegetative way of being/working as an architectural artist. For Hundertwasser himself, many of his projects, do fit into the landscape (perhaps better than the house), in terms of their grass roofs set into hillsides, and their spiraling/vegetative forms. At the same time, however, they are not the result of a unique relation between body, building and landscape that rests in the idyllic version many organic architects hold of green architecture (Day, 1990a; Ole Jensen, 2002; Dearling and Meltzer, 2003). There is a tension here between landscape, or the ideal of hiding or being hidden, or more accurately for Hundertwasser, burrowing (buildings halfburied into hillsides), yet at the same time exposing one's surface as an extrovert (colourful, eye-catching facades). This is once again aesthetically and performatively demonstrated by the figure and motion of the spiral (Schmied, 1997). As we can see in Plates 6.3 to 6.8 , the house is certainly aesthetically along more extroverted lines as far as its surroundings are concerned. On the other hand, this deeply personal and ego-centred artistic act is tempered at least by Hundertwasser's yearning to include the voices of many (hand workers, residents, passers-by) into an active engagement with the (re)construction of his architecture. This gives an idea of the messiness of the house's symbolic and material agency (for instance as a tourist attraction), and hence for example its complex relation to the rest of the Viennese urban landscape, to which I turn next.

\subsubsection{The Hundertwasser-Haus in the context of Viennese architectural history}

Various linkages and disjunctures with other buildings in the city (both intertextually and materially) are important to the house, in particular the concept of often utopian 'difference'. At this scale, the house is an important 'land-mark' or actor in Vienna's cultural history and landscape. It is also a further thread-assemblage in the inter-woven practices of tourist, commuter and leisure routes that relationally and performatively connect and disconnect Vienna's material (and imagined) landscapes, in various scalings. Here I do not intend to provide a detailed overview of Vienna's complicated architectural history. In fact to contextualise the Haus in terms of its place in the Viennese urban landscape is impossible, as this cityscape is by no means a coherent whole. I will briefly outline one accepted version of Vienna's architectural 
history, discussing the strands of that history that most closely run into the construction and background of the house.

I begin with the mid-nineteenth century, since this the period 1850-1990 is that from which most of Hundertwasser's influences (and critique) originate, although he does mention aspects of rococo and baroque architecture. From 1848, however, the Viennese inner cityscape was markedly transformed following a wave of revolutions in Europe. Kaiser Franz Joseph I ordered that a magnificent ring of buildings (the Innere Ring) be constructed surrounding the city $\operatorname{core}^{8}$ as a display of grandeur. The many European architects who responded to the Kaiser's call erected a historicist, eclectic collection of buildings, including the Austrian parliament building, natural history museum and opera house. Architects such as Semper and Hasenauer harked back to earlier, more glorious forms and times than the baroque or rococo, for instance choosing neo-Classical or neo-Gothic styles (Schneider, 2001).

At the turn of the twentieth century, and with technological advancements in glass and steel, architects (Wagner, Loos), artists (Klimt) and theorists began to question the excesses and decoration of the Ringstrasse and similar buildings. They reinterpreted the Art Nouveau or Modernista (Gaudi) movement into the German Jugenstil, and more specifically, the Vienna Secession-Stil. Adolf Loos believed that the hollowness and corruption of the second half of the Nineteenth Century were screened behind the ornament of these buildings, and argued for a more honest architecture, incorporating what was to become a Modernist, technological aesthetic, where ornament was tantamount to 'crime' (Schorske, 1998). His Looshaus was termed at the time the building 'without eyebrows' by critics. In 1968 Loos became the focus for Hundertwasser's attack on Modernist architecture. Jugendstil in Vienna was less harsh, and Hundertwasser approved of this to a greater degree (Restany, 2001). 'History', as well as function, were to determine a more 'natural' form (Restany, 2001). The Moderns' artistic reaction to the excesses of the previous century were thus incoherent, as were those earlier architectural trends, and hence of Hundertwasser and those who followed. Nevertheless, the Modernism, Expressionism and other versions of Avant-Garde architecture that influenced the architecture of Vienna at this time were associated in the city and elsewhere with a

\footnotetext{
${ }^{8}$ http://www.geocities.com/Vienna/1605/glory.htm
} 
strong utopianism (Sharp, 1996; Fishman, 1999; Frampton, 2000; Worpole, 2000). Hundertwasser (with his own utopianism and suggestions for 'healthy' housing) thus exhibits a fascinating relationship with these local and more widespread trends.

After World War I, the Democratic Party in Vienna became concerned with public housing and services, leading to the city of this period being termed 'Red Vienna' (Schneider, 2001; Blau, 1999). Perhaps the most famous building erected at that time was the Karl Marx Hof, built between 1927 and 1930, containing over 1,600 apartments and stretching for over half a mile (Schneider, 2001; Glancey, 2000). Many other similar projects constructed until the late 1950s are to be found throughout Vienna, and in particular along the banks of the Danube Canal, a mere five minute walk from the Hundertwasser-Haus. These houses, although influenced by the High Modernist, rational aesthetic, do not exhibit the same elegance as some of the more exemplary buildings of the period. The straight lines and box-like rooms of these houses, for which he held Loos and others responsible, were regarded by Hundertwasser as fundamentally opposed to the forms and forces of nature he desired in his buildings. Many of these were also built shortly after World War II.

After the war, the Viennese renovated historic buildings, in particular those damaged during wartime bombing, and turned to the mounting trends to postmodernism, the return of decoration in architecture, and the 'International Style' of large-scale glass, steel and concrete edifices. Hans Hollein (Haas Haus), Hermann Czech and Co-op Himmelb(l)au (Gasometer) have all completed projects in the city. Moreover, UNOCity, erected during the $1990 \mathrm{~s}$, is the first concentration of taller buildings in the city, but with a hint towards decorational styles atypical of traditional skyscrapers. Again, Hundertwasser was appalled by the formalism and smooth glass facades of many of these International-Style buildings.

Most architectural and touristic histories of the city (Bramhas, 1987; Schneider, 2001), end with a discussion of Hollein, Czech and other architects, however Hundertwasser usually figures, discursively categorized as a postmodernist. It is also important to remember that Hundertwasser's more openly artistic intervention is not an isolated case in Vienna, although it is the best-known. The colours and irregular forms may differ from other new buildings to render him more 'unique', however architects such as Co-op Himmelb(l)au can also be categorized outside the 
postmodern, as well as sustaining an argument that they too are more deliberately decorative, and aware of their clients' intentions.

Nonetheless, Hundertwasser differs in one way from the sometimes International Style of Co-op Himmelb(l)au and others. He was asked by the City of Vienna, more as an artist than an architect, to provide a house in his style, for the city. Hundertwasser is not the only artist who has asked or been asked to perform such an act in Vienna. Pelikan himself, inspired by Hundertwasser's buildings, constructed his own social housing block, as did Arik Brauer at the Gaudi-esque Brauerhaus. Hundertwasser thus had more in common with these architects, but was probably the first in Vienna to be commissioned in this way. So the importance of art in the city, in particular to social housing, has become somewhat of a concern for the Viennese authorities, as well as rapidly becoming prominent in affordable ecological housing schemes elsewhere (such as at BedZed, London).

\subsubsection{Press responses to the Hundertwasser-Haus: difference}

Difference is one of the key themes that I have identified in my discussion of utopia, and is implicit in the above discussion, where Hundertwasser produced an artistic statement as much as a harmonious or utopian building. Moreover, the commission from the City of Vienna, and its place alongside similar projects mentioned above, merely increased the levels of attention paid to the house so that it was almost destined to be something rather unfamiliar. The press have, however, been a key element of the construction of the house as an artwork, and as a rather different element of Vienna's cultural landscape. I explore a selection of the opinions which have been sent to work away from the house, which constantly construct such an artistic difference.

I should note that the impact of this on the residents - whether they find this difference as utopian as the design, or as ridiculous as the press, and what impact tourists have as a result of all this attention - is folded into discussion in the next chapter. The construction of difference that is effected at the house often has less to do with the residents than the many press articles, books and websites 9 produced about it - although the interaction between these registers provides unforseen results. 
I will turn to some of those texts now, bearing two elements in mind. Firstly, how the house is constructed as a piece of artistic kitsch, itself an artwork to be critiqued in relation to other artworks. Secondly, how the house is 'placed' in its Viennese context.

Even before the house was built, it received mass press attention. When disseminated around the world, this constructed a degree of 'difference', although worries emerged through this about how 'ecological' it would be:

"An architecture-sensation has been planned, the eighth wonder of the world, so to speak. ... Has any artist in the whole world ever had the chance to build such a large and expensive monument?" (Santner, 1984: 63)

"The 'Bio-Burg' [eco-castle] runs the risk of diminishing into just a completely normal housing project, with a beautified façade and a couple of trees on the roof" (Krause, 1981:21).

The crossing of normal and different is already apparent here, but also found in various headlines, such as 'Art instead of (lime)stone ['Kunst statt Kalk']', 'Onion dome instead of humus toilet' and 'From the book of the gnomes' (respectively, Ferch, 1985; Christoph, 1985; Sotriffer, 1985). Again, the problem of ecology is important here, as critics begin to wonder what use the house has, and whether it really is any different save for its more artistic, monumental (and for many, ridiculous) aesthetic.

This frenzy of press activity around the house caused a massive stir in Vienna and beyond. This added to the lure of the building, so that 70,000 people were drawn to the house on its opening day (Restany, 2001), including one of the interviewees. Further responses, highlight the importance of utopian fantasy (or madness) to the house:

"At the beginning of the 1980s, Hundertwasser...was given the chance to realise his dreams... . There now stands a Neuschwanstein for consumers ${ }^{10}$... No

\footnotetext{
${ }^{9}$ For example: Accessed 07/2004

${ }^{10}$ Neuschwanstein is a fantasy castle built in Bavaria by 'mad' King Ludwig of Bavaria during his reign in the nineteenth century. Another commentator, Horst Christoph (1980) similarly called the house 'Neuschwanstein fuer Gemeinde-mieter' (Neuschwanstein for social housing residents),
} 
ecological design...so that the mad thing stays up, it needs an extra thick dose of concrete. ...It is not architecture but a provocation..." (Santner, 1991: no pagination)

"It is an architectural wow-experience, for all the tourists who come to the $3^{\text {rd }}$ district all year as pilgrims, to see how life can be otherwise..." (Flatscher, 1991: no pagination).

"Living with the plants - art or utopia, absurdity or utopia? Hundertwasser's 'Eco-house' is nearly finished, is stirring emotions, and is above all - no ecohouse" (Khittl, 1985: no pagination).

"Hundertwasser House is in effect rich in lessons to be learnt. First of all, it is a commission by the city to the artist. Sensitive as much to his painting as to his theoretical statements, the local councillors offered Hundertwasser the opportunity to realize his utopia. Political power was addressed to Hundertwasser because it was determined to take up a challenge concerning the power of art" (Restany, 2001: 45).

"...the younger generation passionately praises the building's defiance of postmodern ornamentation. ... But the [house] is a city-owned apartment building of fantastical shapes and delirious effects...the structure seems a delightful prank....and is a splashy addition to Vienna's staid third district. ...To recapture the magic, one need only turn left (or is it right?) and follow the undulating line to the weedy terrace and breathe the daffy fresh air blowing across the architectural scene" (Reed, 1985: 60).

As a joint artwork and tourist experience, the house clearly makes a big impression, whether positive or negative. Many wonder exactly what it is about this artwork that attracts so many people. One journalist is puzzled as to whether the house is "Art or curiosity", asking why people are attracted to it - “...[D]o they seriously see the house as art? (Plener, 1992: no pagination). An implicit degree of fantasy, and a ridiculed utopianism or futurity (Horvath, u.d.) that is meant to provoke - 'life otherwise' - runs through even the more positive articles which stress such curiosity, difference or outright weirdness. This provocation is a key aspect of traditional and unsettling utopias, linked by Santner and Khittl above (in a somewhat elitist manner) to the utopianism of consumerism, and hence I think other Post-Modern offerings such as Disneyland or Las Vegas. For them, however, this is something both architecturally and aesthetically negative. However, for Restany and Reed (more humorously), this is more positive, a symbolic lesson, and something worthwhile.

invoking the crossing of difference, normality and fantasy which appears in a quite different guise in chapter 7 . 
This is signified by the City's trust in Hundertwasser: there are many who do like the project, despite those critics in the architectural world. There is also a feeling of the artistic difference and avant-garde radicalism that both Hundertwasser and the house evoke, in relation to a 'normal' social housing:

"He set about transforming the Hundertwasser-Haus to create a brighter and more harmonious environment for its inhabitants... . Controversial architect Friedensreich Hundertwasser has confounded his critics to become one of Austria's leading lights" (Leary, 1996: 206)."

"The world of architecture has always boasted mavericks, who produce buildings utterly outside the reigning aesthetic, barely complying with regulations, yet escaping ridicule or suppression through their childlike authenticity, embellishment and logic. Elmer Zalotay [...and] Lucien Kroll [did, and] [b]oth were born about the same time as the Austrian artist and architect Friedensreich Hundertwasser. ...From the outset, he ridiculed and rejected rationalist and functionalist architectural theory...[and] sought to create buildings that were giant versions of his own artworks. ...The result was an architectural anthropomorphism that never succeeded in transferring convincingly to full, built form, despite the anarchic [utopian?] promise of the sketch and model stage. ...Hundertwasser was an artist who relied on attack and inspiration, and neither ever let him down" (Pawley, 2000: no pagination)."

Opinion about the house was divided, although naturally following Hundertwasser's attacks on Modern architecture, much was derogatory and irreverent. Already, however, the nature of such debate was largely centred upon the position of the house in relation to the world of art. The house became-different, I think, as a result of its uneasy position as architecture, home and art object. It was thus different from 'non-artistic' apartment blocks, especially as it was 'performed' through Hundertwasser's character and writings. Pawley, Restany and Santner (all above) criticise the building as an artistic-architectural object, relating much of its (failed) promise to its fantastical, kitsch aesthetic, rather than the unsettling crossing of such an aesthetic with the occupation of the house, its status as a social housing project, and residents' direct negotiation with the house-as-artwork. It is these ('critical') elements that I stress later.

As well as representing a different art-object, the house's uniqueness also relates to its position within Viennese cultural history. Here, it is seen in many ways as a bit of a joke, an irrelevancy, a fantastical but ultimately throwaway artistic gesture. As Bramhas (1987: 158) comments on all four of Hundertwasser's projects in Vienna: 
"The Viennese will not laugh at the same joke four times. Even if it is good." He is also adamant that this house, as he cites its various name from the press ("Fairy-tale castle"; "Bluff-architecture"; "dream house") is neither a proper part of Viennese architectural history, or a really radical, different example for future architecture (Bramhas, 1987). For another commentator, Hundertwasser had begun changing the landscape of Vienna quite insensitively:

"For a few years now, the tourist topography of Vienna has become more colourful. With the building in Loewengasse, the Viennese painter Friedensreich Hundertwasser has changed his paintings into three dimensions. Then the nearby KunstHausWien followed, and - opposite the house - the Kalke Village, a pilgrim's shop the size of an average shopping mall... . With their shrill colourfulness... his buildings affect the body and make no effort to correspond with their architectural surroundings" (Adam, 1994, no pagination).

Yet this draws the house into a tourist topography rather than Vienna's landscape proper, perhaps normalizing it in a touristic sense (although it is far from a typical tourist attraction), yet not in the sense that it fits its surroundings.

Glancey (2000: 116) is less critical, merely calling the house "Social housing like no other". More generally, he argues that Hundertwasser's methods at least were relevant to the cultural climate of Europe during the 1980s, in particular of the crisis in social housing that had occurred in Thatcher's Britain, for example. Nevertheless, he poses the semi-rhetorical question "But, is this a real improvement on, say, Vienna's Karl Marx Hof [an important pre-WW2 social housing block]?" (Glancey, 2000: 116). Like Bramhas, he asks what the real difference is - a theme which will return later. Ironically, on this note, we must also remember that none of the residents were involved in the initial design and construction process (cf. Nant-yCwm), although they have been since.

Overall, in terms of its artistic merits, and place in the Viennese landscape, there has been a large amount of generally negative press, yet this difference perhaps incited still more tourists to visit, and perhaps improved its more positive popular reception. The sheer presence, collection and dispersal of so many texts about the house, and 
yet more fan sites devoted to $\mathrm{it}^{11}$, mean that there is something different about the house. This adds to the slightly uncanny effect the house imparts, for, as well as being aesthetically different, it is also a social housing project and tourist attraction. Perhaps this difference is utopian in a variety of ways, and perhaps the house does fit into the landscape in an uncanny way. However, in the next chapter, I examine how this relation is complicated through ethnographic material from derived from my engagement with residents and tourists. I move now to look at the school before offering a brief comparative conclusion to both architects' works and buildings.

"For example, 


\subsection{Nant-y-Cwm Steiner School, Llanycefn, Pembrokeshire (b.1979,} Kindergarten b. 1990)

\subsubsection{The School}

"In no way should [children] be forced into a mould by the architecture, but should be free to move, live and imagine in their own world.... Any imposition of standardization would negate this. The more individual...each situation...the better." (Day, 1990b)

Nant-y-Cwm Steiner School is situated in a small, almost hidden, wooded valley, in rural West Wales, just beneath the Preseli Hills in Pembrokeshire (Figure 6.2). In terms of its exposure to passers-by and tourists, it represents an almost polar opposite to the Hundertwasser-Haus. It comprises a Main School - a converted Victorian schoolhouse a Kindergarten, a gym hall, a temporary standalone classroom and an old bus used as a café, all set on a hillside above and bordering the Eastern Cleddau River (Figure 6.2).

The school was begun in the late 1970s, when a few interested parties from all over Wales came to discuss the possibilities of Biodynamic farming - developed by Rudolf Steiner - in West Wales. With this interest in Steiner, and his educational philosophies (below), the collective decided that since there were no Steiner Schools in the area, and that many of the group demanded an alternative to State education, they would attempt to build a school (A, Female, founder ${ }^{1}$ ). The school developed in a rather organic way, from a Saturday school and Kindergarten, with lectures to gauge interest, until various parties (including many of the founding parents) found enough money to buy the old village school, which at the time was in a state of disrepair. Through donations and largely volunteer work of parents, the renovation of the school began.

Today, for its on-going re-production and survival, the school demands both fees (it is officially a private school) and continuous work from parents. Many are unable to pay full fees, and must make up this shortfall by helping to maintain the school buildings,

\footnotetext{
${ }^{1}$ For each interviewee, I indicate and initial identifying letter, their gender, and relationship to the school founder, parent, teacher, pupil and so forth.
} 

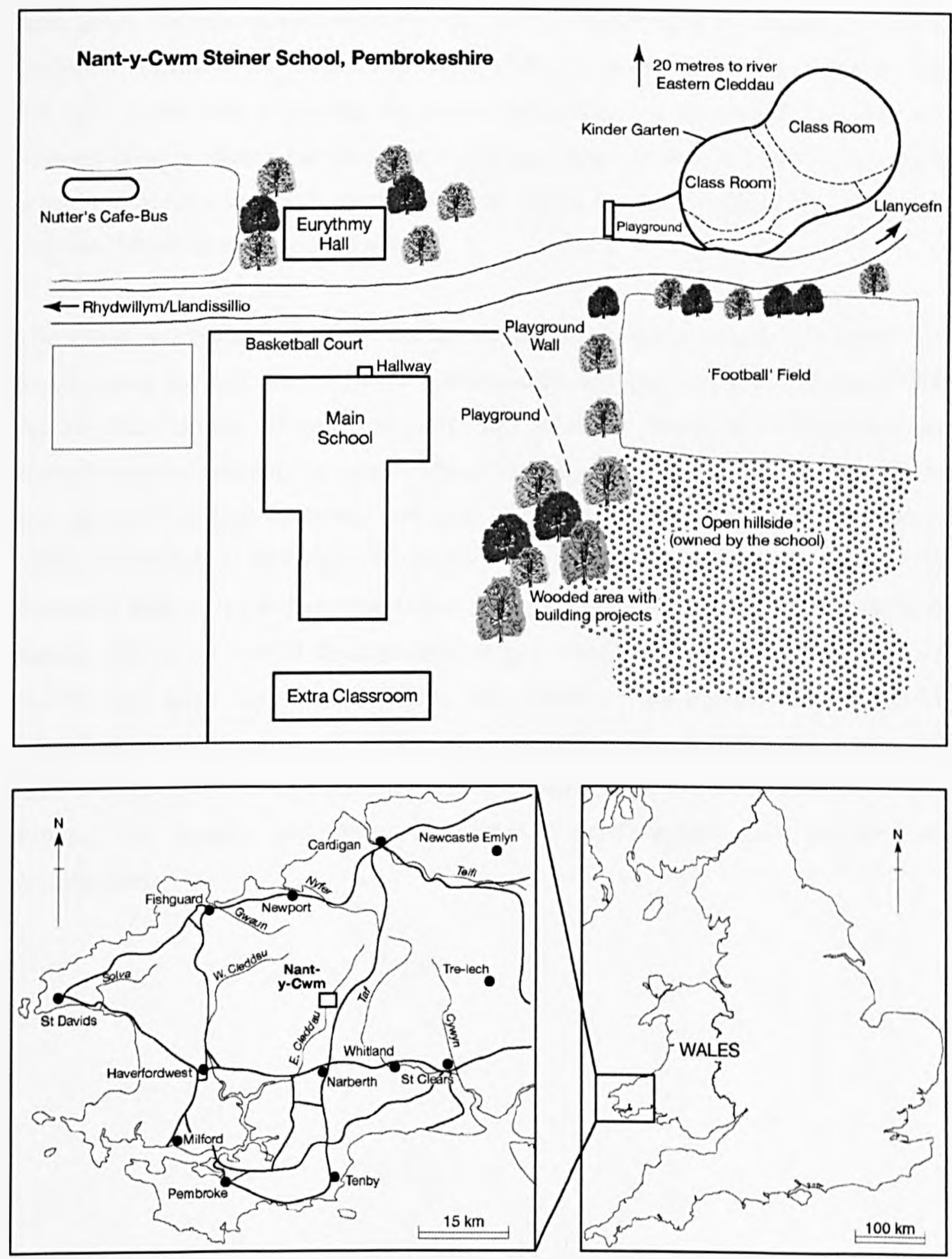

Figure 6.2: The location of the school (above), with a sketch map of the school's features that appear in the thesis. Based on the author's sketches; cartography by Nicola Jones. 
raise funds through various festivals ${ }^{2}$, as well as contributing to classes and extracurricular activities. The cost, per term, per child, for attendance at the school is $£ 760$ per term. At the time of writing, the school was undergoing financial difficulties, and, amongst other problems, the danger of losing the Kindergarten to finance the rest of the school has become very real. At its peak in the 1990s, the school catered for around 100 children. However now, only 50 attend.

The school was built in a series of ad hoc stages, largely corresponding to demand and loosely along the principles of Day's 'Consensus Design' (see below). In the late 1970s, the old Victorian schoolhouse was gutted and extended. The high windows in many classrooms were lowered, the harsh walls softened by hand plastering, with cubby holes and alcoves, and then coloured, generally in accordance with Steiner's philosophies (Plate 6.10 and 6.11; on Steiner, see below). The outside of the school, in local Welsh stone and slate, is more traditional-looking. The school is designed to nurture children through different, essential developmental stages outlined by Steiner after his study of children and adults (see Steiner, 1909). The colours of the classrooms in particular (pastel pinks, blues and yellows), and the combination of irregular curves (cf. Hundertwasser) and straight lines in windows, door frames and walls, are specifically designed to engage and enhance children's psychological and physiological development.

\footnotetext{
${ }^{2}$ This includes a yearly visit of the fundraising arm of the School, a cafe outfit called 'Nutters', to the Glastonbury festival. A large proportion of outside funding for the School comes from this source. See also the school's website:
} 


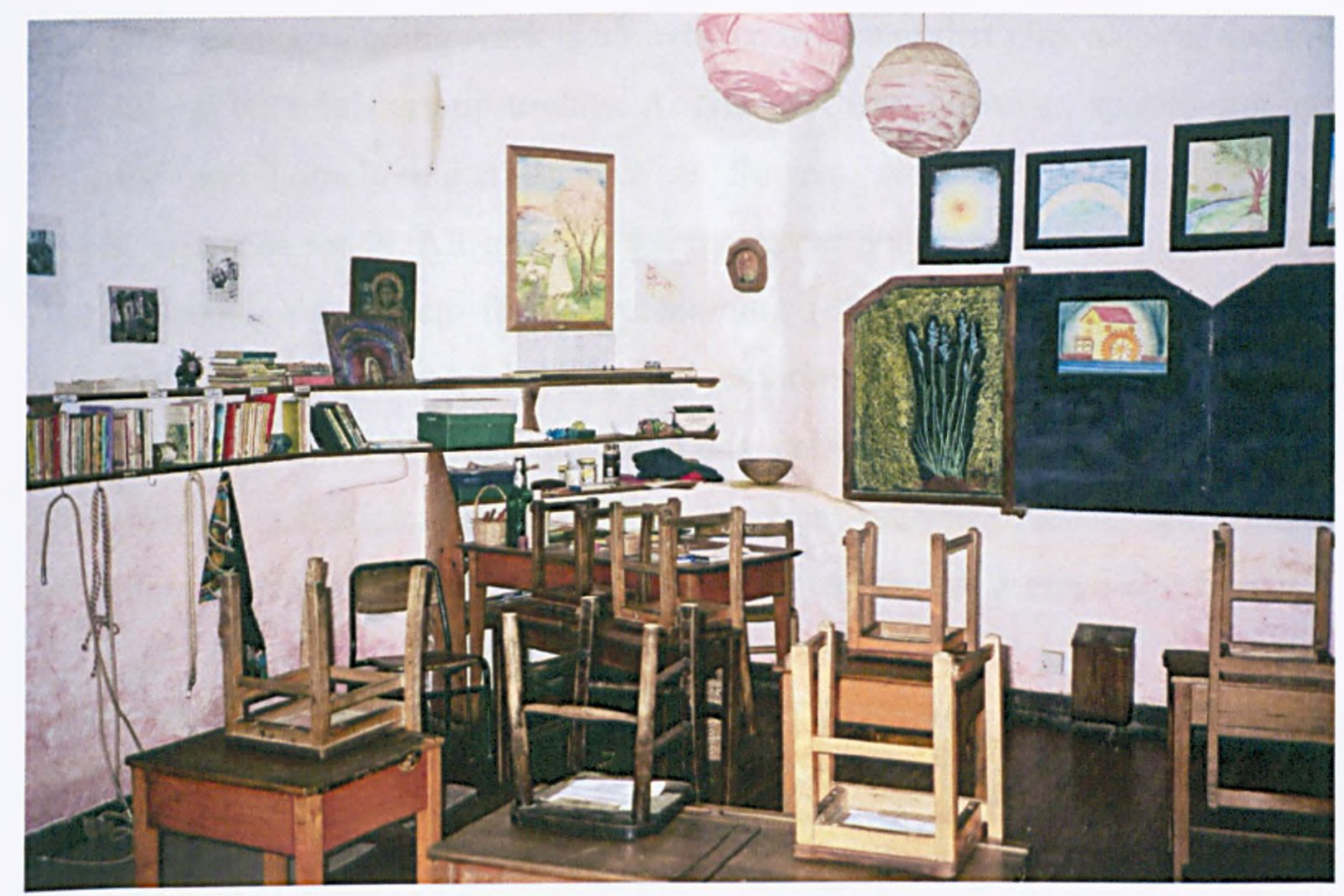

Plate 6.10: A classroom in the main school. The moulded corners can just be seen, as can the pastel shades.

Author's photograph.

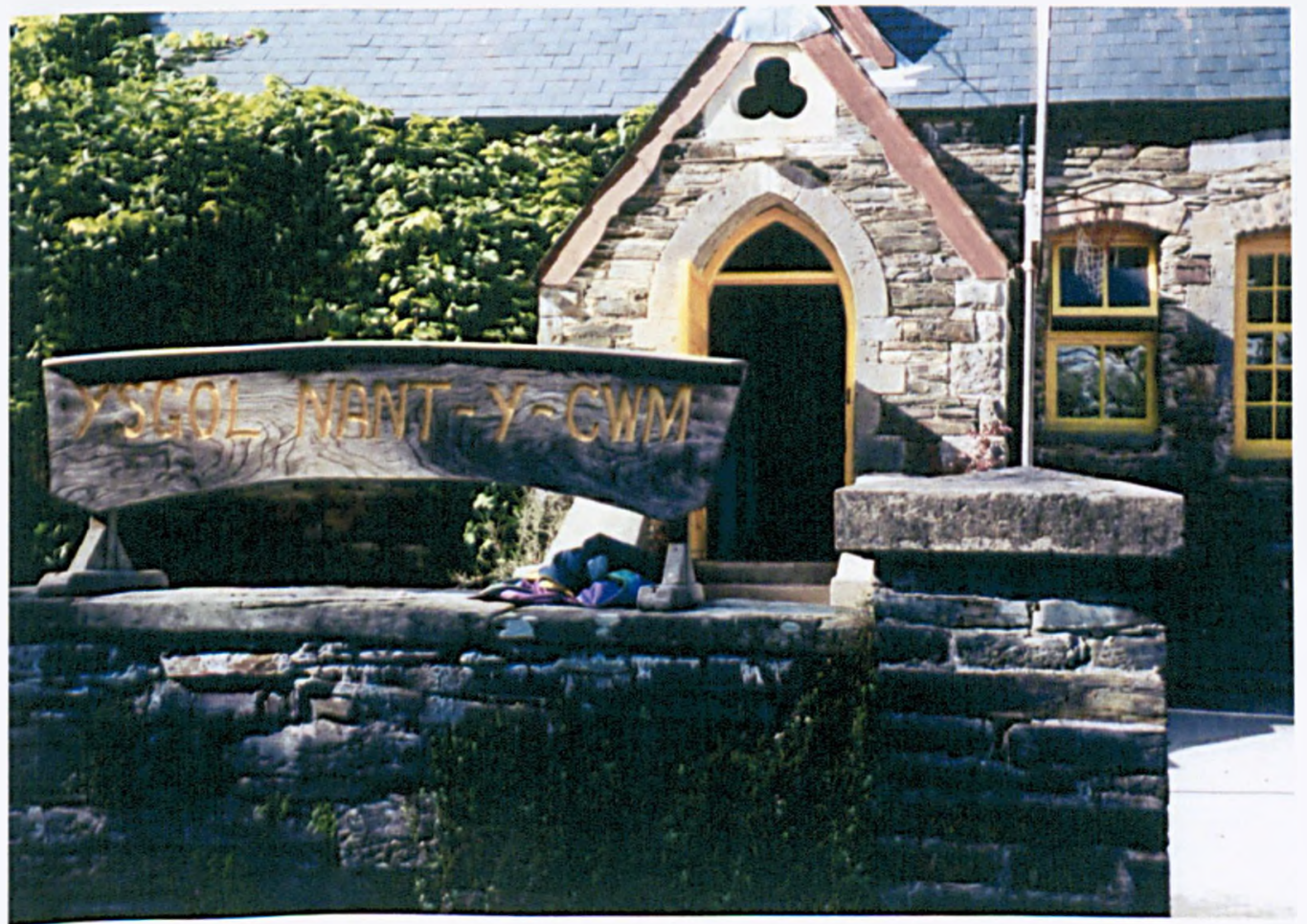

Plate 6.11: The entrance to the main school, with yellow front door, and the wall in the foreground where parents, children and teachers sit outside teaching hours. Author's photograph. 
As in any school, ongoing work is undertaken to ensure that play objects, decoration and educational materials are up-to-date. At Nant-y-Cwm, however, special emphasis is on 'natural' and homely materials such as flowers, wooden toys, naturally pigmented paints, seasonal foods. All of these are displayed and used, decorating the building as well as providing objects for active learning (Plate 6.12). The relationship between building, objects, teacher, children and environment is intended to be holistic and harmonious, enacted through the relations created and sustained by the particular interpretation of Steiner's curriculum at Nant-y-Cwm. Hence, the school is an environment where 'true' versions of childhood can be safely enacted (Chapter 10).

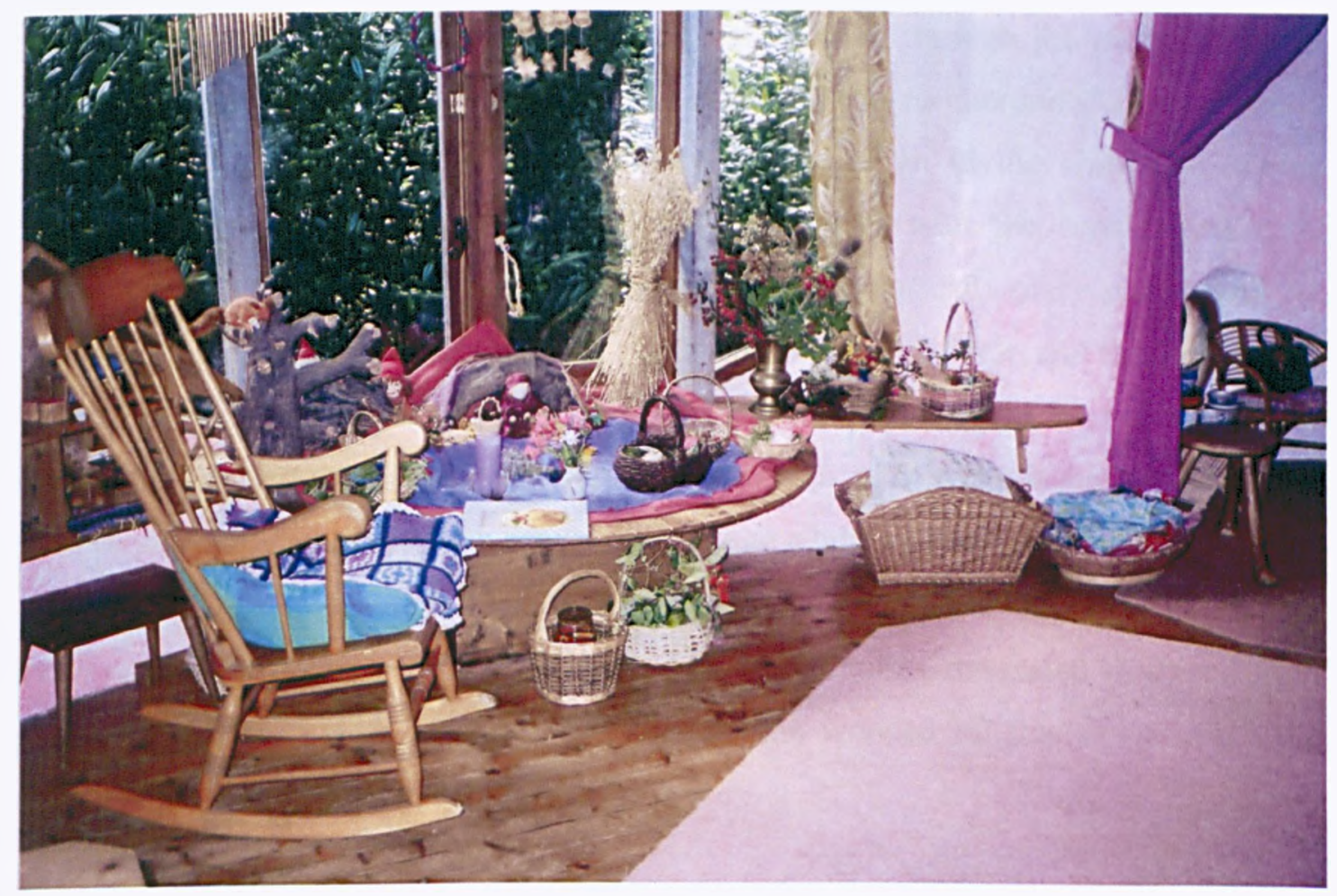

Plate 6.12: The interior of the Kindergarten. Here, Day's windows are just visible, as is an alcove, to the right. As with the rest of the school, there is a 'nature table', with various seasonal objects and artefacts made of 'natural' materials. These objects, the chair, colours, cushions and curtains all add to the 'homely' feel of the school.

The Kindergarten was completed in 1990. and is the best-known of the buildings at the school. Its grass-covered roof is to many reminiscent of a hobbit-house, although it connects to buildings emergent from Steiner's philosophies, and those of the ecological 
architecture movement as a whole (Plate 6.13). The interior is similar to the main school, although the purpose-designed classrooms are circular in shape, again in line with the prescriptions of the curriculum (Plate 6.14). It is designed to be womb-like: dome-shaped, with pink walls and enclosing. It should be comforting, with its alcoves, fireplaces and little hideaways. As Day (1998: 25) comments: "[T]hese are the places children seek as 'houses' for the worlds they construct in their imagination." Again, here, the assemblage of a discursively-constructed whole is completed by the scattering of flowers, nuts and grasses on a nature table, the cupboards around the room spilling well-worn simple wooden tractors and other toys, and the smells of apple crumble warming the room as the teacher tells a story to the children gathered on the rugs about her rocking chair. This and similar images, called upon through the performance of teachers, children, building and toys, and one rehearsed or re-interpreted from Steiner's writings during the early-Twentieth Century, is one of an idyllic childhood hidden underneath a grass roof that blends almost seamlessly with the surrounding rural landscape of forest and fields, in a nature which provides a ready-made playground for endless exploration (see Matthews et al., 2000 for more on children and the rural idyll). The title for Christopher Day's (1998) book about the school is 'A Haven for Childhood'. This is an image of warmth, perhaps a now unattainable cosiness and introversion (cf. Hundertwasser above) and a stage adults can set for their children here - perhaps a (painful) utopian yearning for a perfect, protected childhood. There are various other buildings too, such as a eurythmy ${ }^{3}$ hall (almost a renovated shed) and extra classroom (a temporary structure), all set onto the wooded hillside upon which the school is situated (Figure 6.15).

\footnotetext{
${ }^{3}$ Eurythmy is a form of dance or movement, carried out with music, and is a key part of the children's education at the school. More generally, bodily expression is viewed as a crucial method through which children learn diverse concepts, from 'nature', to the alphabet, to the meaning of certain sounds or rhythms. Usually, there is a dedicated hall, however at Nant-y-Cwm, this doubles as a main hall for assemblies and so forth.
} 


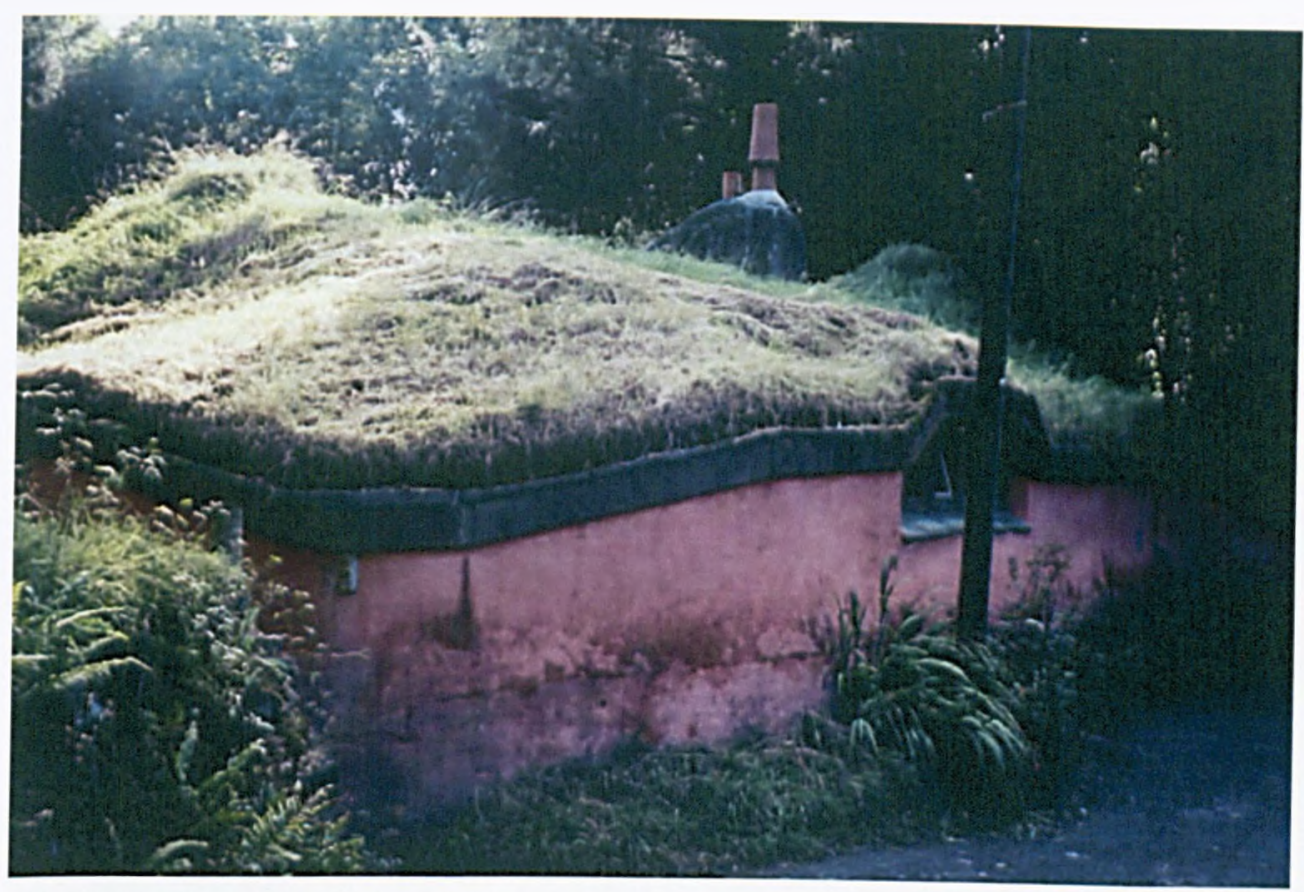

Plate 6.13: The Kindergarten, with its uneven grass roof and pastel shades. Author's photograph.

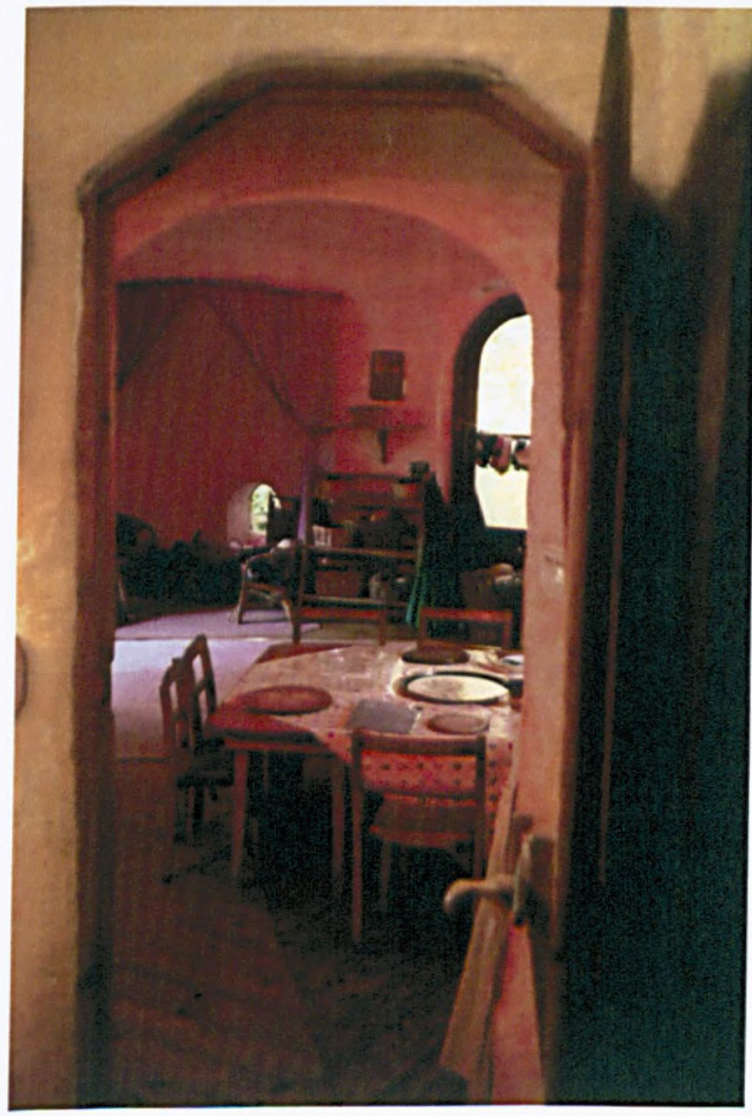

Plate 6.14: The Kindergarten interior, designed to be enclosing and homely. Note the alcoves, wooden door and handle (right) table set in the kitchen area, and dark, softness of the colour. Author's photograph. 


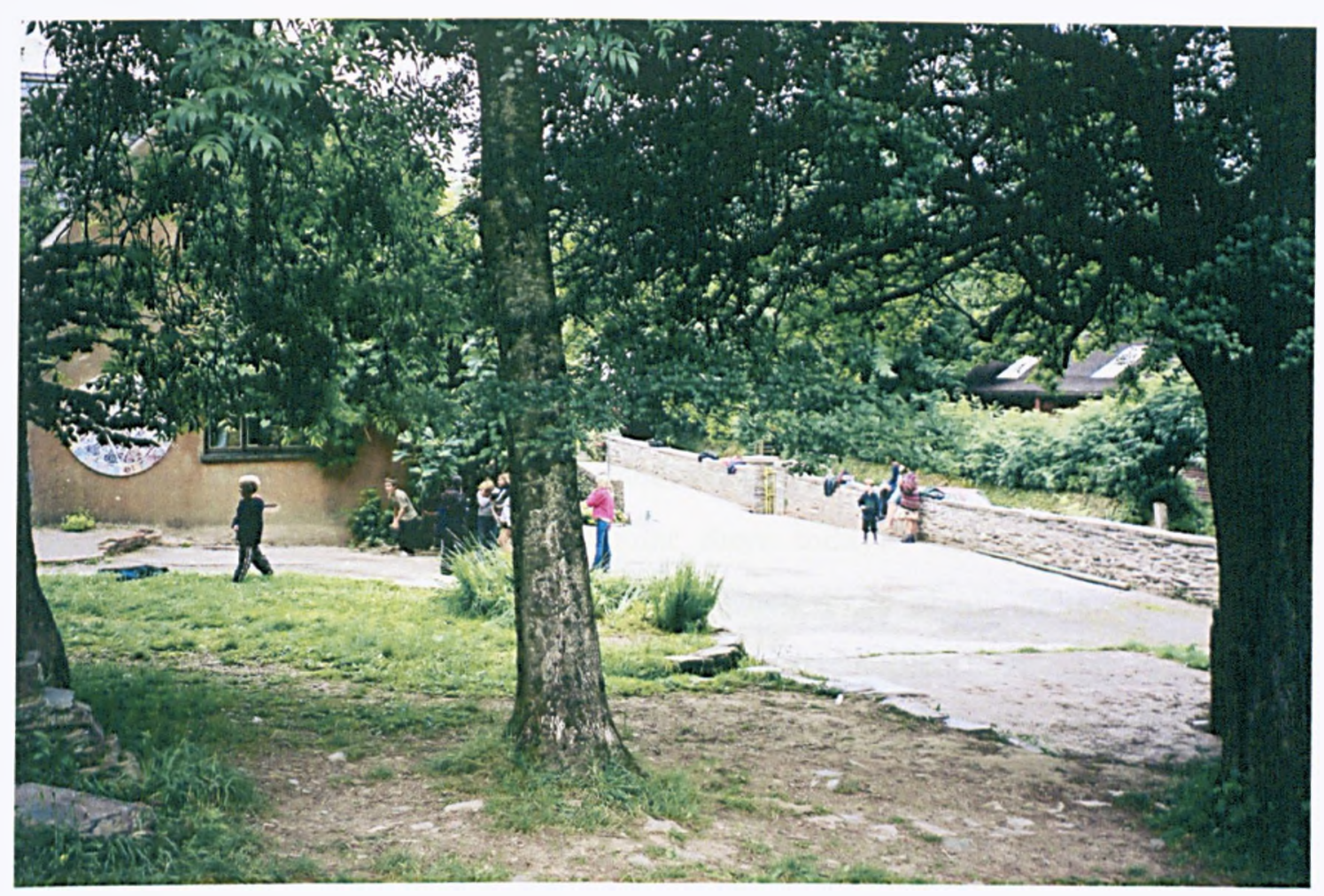

Plate 6.15: The playground (tarmac-ed area), with wooded area in foreground. The main school is to the left, the eurythmy hall background right, over the school wall is the road, which, going right, leads to the Kindergarten roughly fifty metres away. Off camera to the left are the children's building projects and the terrapin classroom. Author's photograph.

The following sections demonstrate which elements of Day's written and built work, and which elements of the local landscape and others further afield, are collected/dispersed around the school. Beginning my 'critical' geography of the school, some of these stories overlap with those we hear later - for example about the parents who founded the school. Again, as for the Hundertwasser-Haus, certain cross-cutting themes in Day's work, such as ecology, health, creative work and artistic building, are important.

\subsubsection{Rudolf Steiner and Anthroposophy}

Before discussing Day's writings themselves, I want to briefly outline the anthroposophical writings of Rudolf Steiner, whose writings on architecture infect some of Day's designs, and whose philosophy is so important to the School's education. 
Steiner was influenced by Goethe, and through his scientific-religious writings, one of the developments of this was an educational curriculum (the Stockmeyer Curriculum) (Steiner, 1909, 1919). He incorporated observations from anthropology, Christianity and pre-Christian religions, and the physical and natural sciences, towards a holistic theory of people's development and actions in the world. This became known as 'anthroposophy', from which branches of medicine (homeopathy) and farming (biodynamic farming), for example, along with education, were developed by him and others. Steiner built a school in Switzerland where many of his ideas were trialled and developed (the movement is still popular there today). This was housed by an Expressionist, wooden, domed building from which many of his architectural design recommendations were taken (Sharp, 1996). There are utopian tendencies in Steiner's work, from his ideal vision of how children and adults develop, to the general utopianism inherent throughout much expressionist architecture (Sharp, 1996). On the former, Steiner argues that life, and children in particular, should be conceived as plants, or seedlings, whose future is unknown but overflowing with potentials, "a future state within its hidden depths." (Steiner, 19094). On the latter, Steiner's architectural ideas are meant to be set into a more general, holistic system of education, represented in and materially benefited by the buildings (Chapter 10 discusses this for Nant-y-Cwm). He goes on to describe the stages through which a child develops, and the artistic, comforting and performative manner in which this should be encouraged in school (for example through dance - eurythmy) (Steiner, 1909). For our interests, it is the interpretation of this at the school that is most important. Hence I allow a teacher I interviewed to take over this explanation:

PK So, in what other ways would it differ from a State education, in terms of activities?

P You have Kindergarten, Middle School, Upper School. And, there is a key word for each one of those. And the key word for the Kindergarten is - imitation...the child would learn through imitation, rather than through, the head. As a Kindergarten teacher, you would be there in the classroom as a person, for the children to imitate. And that puts an enormous responsibility on you, because, the child, when a child is first born, is totally a sense organ, it doesn't just perceive the outside world through

\footnotetext{
4 All quotations are taken from Steiner, 1909, The Education of the Child in the Light of Anthroposophy, accessed on the internet on 12/06/2003 at
} 
it's eyes and ears and nose, it perceives it through it's whole being. It's at one with its environment, so, for the environment, the Kindergarten is very very, special. It needs, and that includes the people in the environment, everything in the environment, because the child is learning by imitation. The second phase of school, the Middle School, it's on, (short, quiet chuckle) this terrible word of authority...it's like in the same sense of the word author. And, the teacher is the author of the knowledge. And the children, they learn from the teacher. And, the other word there [for the Upper School] is discipline, which is often, again a horrible word, but, take the word disciple out of that, and you've got author-disciple, and that's the relationship, it's one based on, a great warmth between the teacher and the child. ...That you learn with, the young person, you don't tell them. (Male, teacher)

The specific use of Steiner's philosophies and the combination and interpretation of these (not as a 'structure') with the community, design, notions of homeliness and difference are explored later. There, I draw out the utopianism of aspects of the school's practices. However here, I would point again (as with Hundertwasser), to the processual, 'natural' and performative versions of utopia that are implied.

\subsubsection{Influences and Day's written work}

As already outlined, there are distinct similarities in the theoretical and methodological positions of Hundertwasser and Day. A crucial one is the particular critique both developed of the straight lines and 'soulless' character of many Modernist (sometimes utopian!) buildings. They both offer critiques of the places of architecture and architects within contemporary society. Moreover, they both provide utopian connections between new possibilities for architecture, 'traditional' forms, and those that incorporate what they differentially conceive of as creativity, health, soul and nature. Christopher Day's buildings, Nant-y-Cwm included, arise out of this critique, from the material 'healing' of buildings where, "surrounded by harsh hardness, the aesthetic sensitivities, and with them moral discernments, are blunted" (Day, 1990a: 9). For him, "The international style - be it functionalism, post-modernism, or any other -ism..., [n]eo-vernacular and revivalist reactions... [are all] more concerned with style than responsiveness" (Day, 1990a: 15). Illustrations include 'crime-including' tower blocks in New York, which ignore both the particular qualities of their location, and the well-being of the people who use them. He wants not only to heal places but to add something to them. In this 
sense, they can be health-giving, building upon the foundations laid by the environment, collecting them up and cultivating them, rather like 'growing' a place (Day, 2002).

As for Hundertwasser, the specific qualities of the site, those of local and vernacular architecture, and the forms and processes of 'nature', are the inspiration for a building. Unlike Hundertwasser, Day's buildings are more understated, and fit better into their environments, at least in the sense of their (in)visibility: more of a 'supporter' in Ole Jensen's (2002) terms - at least at first glance. Day's experience of vernacular architecture around the World (like Hundertwasser's), in particular of traditional Welsh (farm)houses, ancient towns, and traditional villages in Nigeria, inform this desire to 'fit' in. With his interpretation of the processes of 'nature', these influences have combined so that "I try not to have a style, but it is easy to lapse into one. ... The underlying issues of what environment does to people are not limited to national, regional or parish boundaries but, if they are to be appropriate, the forms they give rise to will be intensely local" (Day, 1990a: 12-15). So rather than specific architects or buildings per se, inspiration comes from experience, and 'design as a listening process' (Day, 1990b, 2002). He tries to listen to and 'grow' the natural and socio-cultural elements of a place, as well as the desires and requirements of those involved in building and living with a structure. This involves practices familiar to sustainable design, from incorporating locally-sourced materials, to assessing potential impacts, to passive heat gain and the insulating capacities of turf roofs and thick walls and to community-led design (Estes, 1989; Wines, 2000; Dearling and Meltzer, 2003). Day's way of working bears greatest similarities with 'softer' approaches to design which in particular attempts to save or create energy and healthy spaces with minimal technological intervention, and attempts to 'fit' a building into its cultural and particularly 'natural' landscape (Mugerauer, 1995; see Papanek, 1995 - who mentions Day and writes with a similar focus and style).

Thus influences on the school come from a critique of Modernism, ideas gleaned from vernacular architecture, the particulars of the site itself, and the builders and future inhabitants themselves. The latter two elements are crucial to Day's notion of 
'consensus design'. This draws together - collecting/dispersing - his phenomenological concern for the inherent natural and historical qualities of a place (which often take on the tone of Tuan, Relph, Norberg-Schulz, Seamon and others), the oft-conflicting needs of future users, the creativity of the builders involved, and implicitly, his ecological and healing attitude towards architecture. I examine this process next.

\subsubsection{Work, health and process-based design}

Work, and its health-giving, form-giving, and artistic-utopian aspects are crucial to Day's conception of the design process. Interestingly, these emerged (at least partly) through the practical and spiritual experiences gained whilst building the school. A variety of people came to work there, as well as the groups of parents who founded it. It was therefore necessary to build a process - seemingly intuitively - where the needs, desires and skills of those people could be put into conversation, even where they were often conflicting. Day's role as architect was not to make executive decisions, but to solve and direct these conflicts so that, at some almost transcendent moment, all of the people involved could realise what the inherent qualities of the place were, and how they should be developed. This process is formalised in a series of stages for group integration and 'learning to listen', which he later termed 'Consensus Design' (see Day, 2002: Ch. 5, for more). The importance of community design is also found elsewhere in ecological architecture and beyond (Wates and Knevitt, 1987; Harries, 1993; CooperMarcus, 1993; Ward, 1995; Madge, 1997).

The process of work and the health-giving, artistic benefits it can have are quite utopian at times. This is a quite different sense of utopia from either the satisfaction of a finished building, or the comfort of an achieved utopia (see Chapter 12 for the parents' and teachers' experience of this, and more on consensus design). Instead, almost like an opposite side to the effect of ruin, the unknown shell of the school is a location filled with potential, with virtuality and lack. It is hence a site for the imaginative capabilities of a range of different people, as well as the performative energy and joint purpose they 
pour into a project. These can - despite or because of being hard work - provide a quite utopian feeling.

The key, it seems, is one of 'conversation'. I think this idea can be taken more broadly to mean a material, performative and discursive collection of a variety of energies into a building and its design, as was crucial at the Hundertwasser-Haus (conversation appears in Day, 1990a and b and Day, 2002). Day makes some interesting comments about how a building collects energies in an often unknowable, contingent way. Perhaps, like Hundertwasser, this is involved with the idea of natural processes, and humans' interrelated performances with those, as not fully controllable (also Szerszyinski et al., 2003). This is hence an unsettling process where:

"As the building rises and becomes formed, so many potentials, invisible on the drawing-board, unfold. Design, freed from the constraints of a paper monologue, can become a process of conversation... [and] can unlock the potential inherent in the place, the building, and the people involved" (Day, 1990b: 8).

"What has evolved? It is not just a matter of little details but of listening to a whole being, something which has never been imagined or frozen on a drawing, something we can only work towards by listening. Only by working in this way can it find its physical form.. ... The form and place are beginning to grow. The ideas with which we started have determined the way we have gone about the work, but the meeting between ideas and action, between existing place and future intentions, is growing into a living being. A being that is more than either work or ideas" (Day, 1990b: 52).

"Process-based design enables buildings to condense out of life. ... More than this, it awakes the latent architect in every person.... How else can we grow a future to look forward to" (Day, 2002: 9, emphasis in original).

Despite the spiritual and anthroposophical undertones of these quotes, Day is keen to stress that this is also a notion of work grounded in material reality - in solid stuff (Day, 2002: 9). This performs a fascinating connection between three ideas discussed elsewheres: Bataille's (1985) critique of head-in-the-clouds transcendent utopias and advocation of base material social change, where utopias and ideal visions are rooted within such everyday, material practice; the collecting/dispersing of those practices that actualise these latent virtualities (Deleuze and Guattari, 1987; Kwinter, 2001); and the

\footnotetext{
${ }^{5}$ See chapters 3 and 4.
} 
connection between the imagination and an 'incomplete reality' that ruins can effect in an often utopian manner through the sense of lack (Woodward, 2002), here inverted to an unfinished building site. Much like at the Hundertwasser-Haus, except with less of a division between builders and users (a blurring which Hundertwasser also desired), the collection and dispersal at the school can be followed in a joint material-semiotic sense. However, this is also cut across by a variety of practices, which herald an array of utopian- and non-utopian-related insights for the critical geographies of these buildings and of architecture in general (for instance, the performative geographies of building see Chapter 12). The important thing here is that not only the building itself, but the moments of work, agreement, creativity and recognition that dawn at a building and the often limited materials at hand, are collected together to construct a sense of utopia. This is folded into the production of a homely environment and community at the school which (intentionally) emerges from this process, and is part of the 'alternative' education the initial group of parents wanted - the push to make a difference. Again, my three themes can be identified together as critical factors for this building.

The health-giving effects of a building, both in its impact upon the environment, and its users, are part of Christopher Day's call for a more sensitive, organic architecture. Day actually provides an often deterministic argument with very similar proposals to those of Hundertwasser. For him, again in 'conversation', the meeting of purportedly opposing qualities, such as curved and straight lines, can provide a stimulus and a harmonious synthesis of opposites (cf. Hundertwasser, above). For the various stages of childhood at the school, for example (see above), different stimuli should nurture and provoke children in different ways (Day, 1998). He does not attempt to get around these dualisms, more to show how, materially, their aesthetic resolution can 'ensoul' buildings, enliven a place, and provide a materially and spiritually healing or enriching experience for people and place (see Day, 1990a, chapter 9). This is not just a purely visual health, however, and neither is it merely grounded in less tangible discussions of the 'soul'. The effects upon mood and physiological health of the properties of a building are crucial: 
"It is no accident that these [buildings] 'feel alive', for they are life-enhancing, in a strictly biological sense: growth and other hormones have been found to be controlled by the pituitary...glands, and these are stimulated by light. Not any light, but...particularly daylight endlessly changing throughout the day. That is why light from two windows...is always more pleasant and healthy than one. ... What nourishes the soul nourishes the body" (Day, 1990a: 21).

"Buildings can be seen as the third human skin (skin is the first, clothing the second). The skin performs many functions: it breathes, absorbs, evaporates and regulates as well as enclosing and protecting. A building which through its fabric is in a constant state of moderated exchange between inside and outside feels - and is a healthy place to be in" (Day, 1990a: 42).

"Imitating architecture with bodily gestures makes more conscious cramping, expanding, unstable and other qualities that soak into us subliminally" (Day, 2002: 130).

Apart from the obvious similarity with Hundertwasser in the second quotation, and the influence of Goethe and Steiner (see Steiner, 1909) in the third, these three quotes are some of many of Day's suggestions for a healthy architecture. The third quotation also relates to performative versions of the city outlined in Chapters 2-4 (Lefebvre, 1996; Harrison, 2000), and of interior spaces and notions of health (McCormack, 2004). Interestingly, the style and content of these quotations also creeps into some of the parents' and teachers' descriptions of the school, discussed in later chapters. Later, I attempt only to relate this to and read this through the specific education practices at the school, and notions of difference, the homely and 'truth', relevant to a discussion of utopia.

As well as 'conversation' in design, Day argues that (community) work is in itself beneficial, in terms of spiritual and physical health - which again tallies with phenomenological work on architecture (Seamon, 1993; Mugerauer, 1994). As with Hundertwasser, this links to those utopians who stressed the importance of free, creative work. However, the euphoria he and particularly parents attach to various forms of work (not just building) are far broader, more intense, and more unsettling than these images of a craft-based, often rural utopian idyll. In particular his processual, semi-planned way of working, which emerged from his own and others' practical work at the school, can 
be taken on and worked with other processual utopian and non-utopian theories to provide new ways of thinking about building and space. Day says of material work, geared around the gift principle:

"It is a cruel irony of modern civilization that the most important work cannot be paid for. It, and with it the quality of the society we live in, depends upon gift. ...[T]hat takes, and gives meaning to, time and effort. ...The bringing together, with effort, inspiration and matter, the meeting of need with service through gift, brings a stream of health into the world, opening at the same time the gates of inner development" (Day, 1990b: 74, 77, 84).

The utopian tones of this collection of material work and the imagination I expressed above are apparent again here, added to the principle of gift and the uniting of daydreams with deed.

\subsubsection{Parents and the local area}

One of the most important aspects leading to the school's construction is identified as the 'pioneering spirit' of the parents and other volunteers who were involved with the school during the late 1970s (Chapter 12). As for the Hundertwasser-Haus, in addition to the architect's writings, the place of the school in the surrounding area and architectural context was important (below). But unlike the house, the future users, also the builders, had far more input. Thus the beliefs and practice they carried out are vastly important to the school, and to a contextual discussion of its utopian elements.

Coming from a variety of backgrounds, but holding a general interest in constructing the physical and conceptual framework for an alternative (and more specifically Steiner) school and community, the opportunities and structure of feeling the volunteers drew upon at the time both facilitated and were interpreted in a particular collection of actions and materials. Without providing enormous detail, it is possible to suggest that certain elements at play during 1970s Britain in general, and this region of Wales in particular, led to the school's construction. At a time of rapid de-industrialisation, many groups coped with loss of employment and income in different ways, of which this was one (for 
some founders). Moreover, although environmental interest was perhaps not at its height, there was a trend at the time towards alternative styles of living, in particular in Pembrokeshire. Here, there are strong ties to pagan religions through standing stones and other landscape features, as well as (still) thriving artistic and alternative communities. Additionally, numerous utopian or experimental practices emerged at this time (Pepper, 1991).

Many of the interviewees felt that this environment was suitable for volunteer work to be carried out. Alternative lifestyles were prevalent enough that groups could form together - in this example for biodymanic farming and then a Steiner education. In addition, the local alternative community meant that there was a catchment area of parents who might be interested in supporting the school. Additionally, as planning laws were viewed as less stringent, in particular in this relatively remote area of Wales, and with the comparative ease with which people could sign on (in contrast with Job Seeker's Allowance in the UK today), the school could be worked on almost unnoticed, and people could give of their time quite freely, without severe financial worries ${ }^{6}$. This became more difficult during the 1980 s as Thatcher came to power and promoted what founding parents today see as a wholesale turn to consumerism in the United Kingdom. However the generosity and spirit with which the Kindergarten was built, instilled in stories still told about the process of its construction, seem to have been a major factor in its completion, and nostalgia about this work. This discussion is continued in Chapter 12.

For Day, the local landscape that surrounds an intended building, in a deep and indivisible connection with the richness of its traditions and the creativity of a building's future inhabitants, provides the 'materials' with which he can shape a project. Day grew up in Wales, and its landscape, and in particular this green valley with steep wooded hillsides, grass fields, a rushing river and surrounding farms and houses built from local stone, as well as locally-sourced materials, converge at the site of the school to provide a

\footnotetext{
${ }^{6}$ However, the School had difficulties financing itself from the outset. Some parents provided savings, although a substantial amount was raised through donations.
} 
unique collection of ideas, forms and artefacts that can be moulded up, literally out of the ground (Day, 1990b). The area itself, which is relatively rural - with sheep farming and grazing on hills, surrounding small villages and coastal towns, as well as the more remote Preseli Hills area of the Pembrokeshire Coast National Park - is North of the Landsker Line. The line separates the Welsh-speaking north from the English-speaking south of Pembrokeshire, an area known as 'little England beyond Wales'. In the south of the county, approximately $22 \%$ of the population are defined as 'Welsh-speakers' by the 2001 UK census $^{7}$. In the north of the county, where the school is located, the proportion is approximately $60 \%$. Therefore English language speakers - and schools - are in the minority, and feel as such.

One significant influence is the notion of a rural idyll, explored in terms of a performative 'homeliness' in Chapter 10. The draw of the Pembrokeshire area itself, and the mystical and 'pagan' elements of its landscape (D, male, new parent), illustrate how specific notions of rurality are collected into the school's (ongoing) construction. This not only convinced parents to come to the school (often as a result of many other decisions), but is bound up in the construction of images and practices about the school. More broadly, this can be related to general notions of the 'rural idyll' which have been involved in the construction of the British countryside for centuries, and structure people's experiences there today (Halfacree, 1996). The place of children within this image is crucial, yet complex. On one hand, "The overwhelming image [of the countryside] is that of a glorious place where children can grow up in safety." (Matthews et al., 2000: 142). This image is apparent at the school, although it is moulded in particular ways - often through the buildings - in order to construct versions of ideal, safe, communal and homely childhoods through the school's education. Yet this is as much for the parents ( $M$, female, ex-pupil), and hence, on the other hand, the exclusions, lack of integration and boredom that children feel are often glossed over (Matthews et al., 2000). In fact, the countryside is seen as a site of multiple exclusions, including women, racial minorities and 'New Age Travellers', where, moreover, dynamics in those identities are related to changes in the rural idyll itself so that those

\footnotetext{
${ }^{7}$ Figures obtained from www.bwrdd-yr-iaith.org.uk.
} 
groups and the 'stability' afforded by the idyll are constantly mutating (Halfacree, 1996; Millbourne, 1997; Holloway, 2003). Moreover, the anti-idyll portrayed by many horror films reverses the utopian, Edenic image of the idyll into versions of terror, alienation and fragmentation (Bell, 1997), although I argue in Chapter 3, through the utopian unsettling, that some of these unhomely, uncanny experiences may well be euphoric and positive. The point is here that a generalised rural idyll was and is an important part of the school's construction and its attractiveness to new parents. Moreover, some of the exclusions experienced in other places are often experienced there too, although in sometimes more complicated ways, as I discuss later on. Thus the collection of 'influences' from the local environment and landscape is entrained in this more generalised idyll. At the same time, however, it is the performance and representation of this through this (Steiner) educative landscape that distorts and re-works this idyll. For instance, in Spring 2004, the school bought some woodland nearby for educative and play purposes ( $\mathrm{P}$, male, teacher) which appeals very much to notions of 'free' play that many educators promote (Bruce, 1991). The idyll is thus apparent, although evoked and performed in often very different and removed ways. Additionally, the contingencies involved in such an idyll-ised, communal, homely or educative utopia are such that I choose in later chapters to describe how these utopias are created - and hence in many ways unsettling and unsettled - so that, as Holloway (2003) suggests, the rural idyll is mutable, and only one element in the foldings of utopian and non-utopian elements of life at the school.

However, the surrounding (rural) area is also problematically related to the school. At least in intention, the school attempted to integrate its new buildings and community with 'local culture'. Sadly, these intentions have become more difficult to sustain over time (apart from in a pure aesthetic sense). It transpires that the intention of the school in the 1970s was not actually to be alternative per se, but to provide an alternative opportunity. This arose through building a Steiner education that could be for anyone who was interested in that, in the area. Thus, the school's relative isolation in the area, and from the highly prominent Welsh culture and language was never intentional, nor was any particular connection to alternative lifestyles or generalised difference. For the 
language reason in particular - Welsh is not taught at the School - as well as the perception of activities, dress and the buildings of the school, it is seen by those in the outside community who know it as a hippie, drug-taking school, an English retreat where the children run riot. As one woman told me: "Well people have different perceptions of the school. I guess some people think this is a hippie, school...well, I've heard some people say that, the children are wild, and they don't behave themselves. I don't believe that..." (J, Female, teacher). Naturally there are various constructions of 'Welshness' and 'Englishness'. Yet at least in this area, the double problem of English incomers also eventually becoming isolated from Welsh cultures, and constructing an alternative and 'competing' school has been quite troubling for the ongoing construction of the school and its identity. More generally in Wales, there is "an interaction of competing...identities of Englishness and Welshness, with key facets of Englishness viewed by some Welsh-speaking residents as an important threat to everyday lifestyles a 'significant other'..." (Cloke et al., 1997: 17; Millbourne [ed.], 1997). The 'double' nature of this otherness in the case of the school-as-idea has contributed to its almost complete isolation and a problematic side of its construction as a 'haven for childhood' (Day, 1998). This othering is usually far more complex as I describe in Chapters 8 and 12 , however contributes to a measure of the school's present difficulties.

Apart from a few people who live in nearby houses, and owing to the school's position, very few people actually know the school is there. I spoke with a friend of one of the families at the school, and she informed me that most children and parents at other schools in the area are simply unaware of the school. If they do know it, they either disregard it as 'alternative', or react negatively, particularly to its Englishness. In any case, the school and its history also represent a series of performative and discursive acts which collect, fold together and disperse some influences and processes, but which exclude others. This act, collecting and working together the philosophies of Steiner, ecological principles, select parts of the physical and cultural nature of the locale, the intentionality and energy of parents, and the material artefacts of building, is one designed to phenomenologically and aesthetically 'fit' this convergence. However, this convergence is always a contingent and problematic notion of 'ftting', one de-stabilised 
at once not only by the problems of 'falling down' (Dewsbury, 2000) or 'uncertain architecture' (Thrift, 2000), but also those processes that have been excluded, or (ethically) question the particular configuration of intentions and materials at the school. How these contingencies are negotiated through selection, collection and performance and in particular how notions of utopia are constructed through them - becomes a key concern of the following chapters.

\subsubsection{Day's other projects in Wales and elsewhere}

Day himself has completed many projects, in particular in the Pembrokeshire area. Although he, like Hundertwasser, denies any particular style, the windows of his houses in particular are quite distinctive (see Kindergarten and school pictures for examples). Day has renovated many houses in the area, and was involved with the homes of some of the parents I interviewed. It is fair to say that the similarities each building has with others (use of local stone, wood, rounded corners, little cubby holes), are reminiscent of a style. However, they are also inspired by and correspond with traditional Welsh buildings from the area. He also designed a Christian Retreat Centre in Pembrokeshire from local stone (Figure 6.16), incorporating familiar aspects of contextual design, health and spirituality into the building, where again the notion of 'haven' is applicable $e^{8}$.

\footnotetext{
${ }^{8}$ As the wardens informed me during an un-taped interview, 09/2002
} 


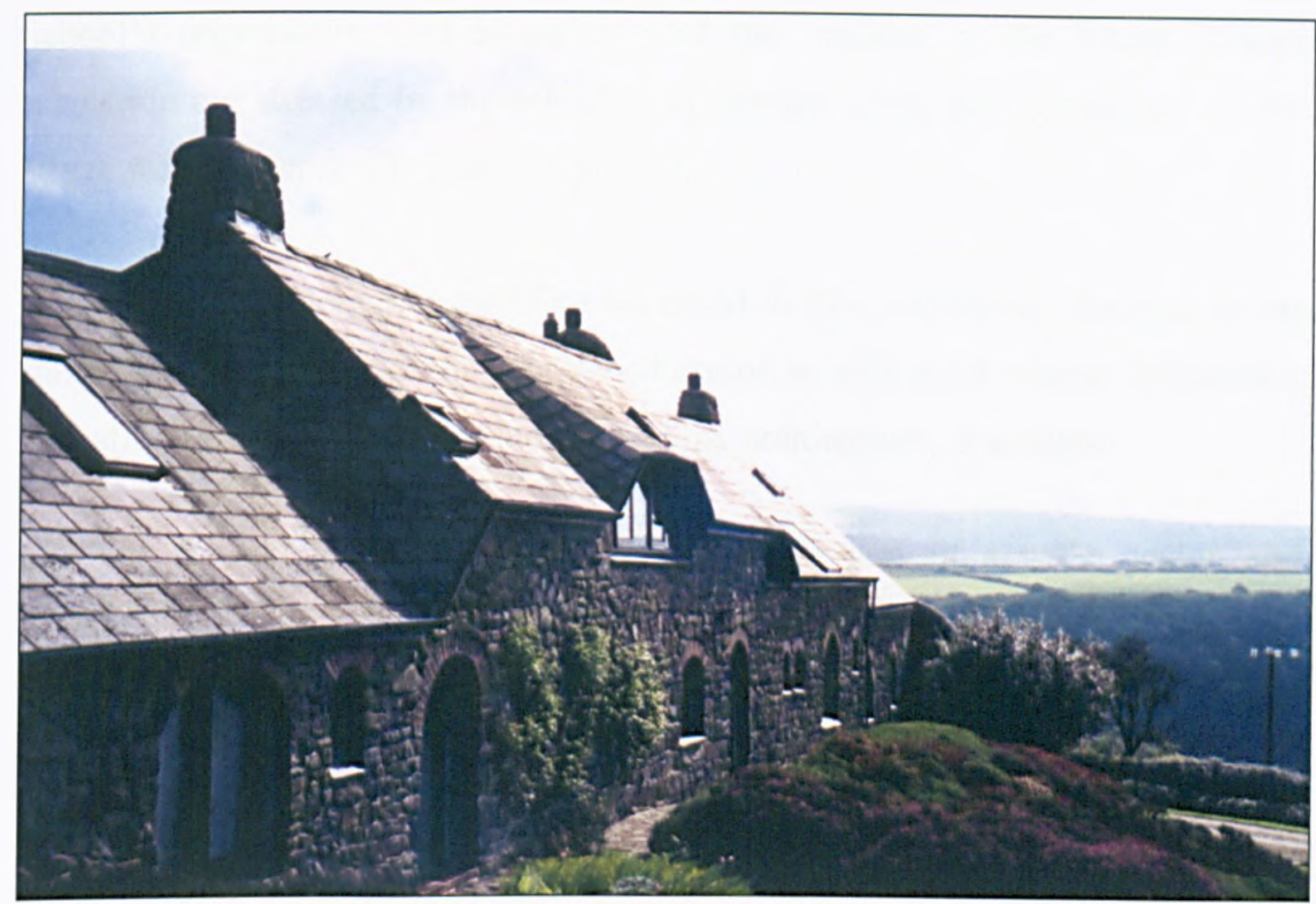

Plate 6.16: Retreat Centre in Pembrokeshire, built using local stone. The upper window, centre, is typical of Day's wooden window frames. Author's photograph.

Day's other projects in Sweden (an intentional village), California (a small urban shopping and business area) and Scotland also fit well into their surroundings. However. certain aspects are transferable (many people like Day's picture windows), and in particular the influence of Steiner on room shapes and Day's general building philosophy is recognisable (for example at a project underway at Pishwanton, Scotland ${ }^{9}$ ).

\subsubsection{Press attention and difference}

There has been far less attention surrounding the school. For this reason, discourses about difference are contained within people's experiences and depictions of their own identities rather than written material. However, there are a few examples of the school's appearance in the press, all of which I obtained from the school's small archive. Some of these have been published by the school as press releases, although the difference in the 
school's organisation and education, and the 'holism' of the whole community of education are stressed by the selection of articles which have been kept by the school (there were no especially negative pieces).

In 1991, the Kindergarten building appeared in The Architects' Journal. In this piece, the importance of the building for the education as well as for various (utopian) concerns including aesthetics, ecology and community architecture, is stressed:

"For its architect, Chris Day, the project is part of a wider vision and public message... for the community architecture lobby, Nant-y-Cwm could be another flag for the crusade. ... On an educational front... [there is an] intimate and appealing cohere and consistency of values that connect Steiner educational philosophy and the philosophical underpinnings of the kindergarten's architecture. Day argues...that any building for small children should be 'magical and full of reverent wonder as an ancient fairy-tale'. Nant-y-Cwm is certainly that" (Hannay, 1991: 42).

Note here the positive tones of the article, the invocation of Day's poetic vocabulary describing the school, and the homeliness of the coherence that is explained as the school, eduation, parents and children are discursively pulled together into a holistic network. How far this coherence is practiced is questioned later. Note also, however, the use of the word 'fairy-tale', a nostalgically utopian production of alterity from 'outside' (in this article, State nurseries) also used by press and residents at the HundertwasserHaus in a multitude of ways.

A programme for S4C (a terrestrial Welsh-language television channel) also draws on the Kindergarten's voluptuous curves, with soothing music and a careful choice of toys and other objects at the school, scattered liberally to create a particular homely, magical mood ('Fflic', u.d.).. The absence of children in the piece is striking, and reminiscent of much contemporary architectural photography. But the tone of the programme is one which stresses both the unusual design, and its impact on the children. The presenter explains: "I am not walking on a field, but on the roof of a school... This unsual architectural design reflects the unusual ideas of its founders." 10 She continues, "There are alcoves for the children to retreat - bathed in sunlight from stained glass...the ceiling

\footnotetext{
${ }^{10}$ Thanks to Pyrs Gruffudd for translating the narration of the programme.
} 
and walls flow into one another, and the teachers in the Steiner School don't like to stress the boundaries between subjects either...these dolls were made by the youngest children...everybody has the opportunity to learn music with a tuneful lute - by experimenting." The performative differences emnbodied by school, dolls and lute are clearly important here. The use of poetic language and music plays on the school's strangeness, yet in a non-specific way which does not contextualize many of its concerns, especially the relationship with the outside world, although this is implicit in the dreamy homeliness - yet unsettling strangeness - of the programme's use of the building. Yet again, this crossing of homeliness and unfamiliarity is a key attraction here.

An article from the mid-1990s, when the school was flourishing, is very positive. Nevertheless, it again implicitly constructs the school as different and pioneering, wherefore it should be inherently beset by difficulties: "When the little former village school of Nant-y-Cwm was re-opened in 1979...numerous eyebrows were raised and few thought that it could survive for long. But the school...running on a shoestring budget, and situtated in what used to be one of the most isolated and thinly populated little valleys in this part of Wales, has not only survived, it has thrived" (Wales Western Telegraph, 1993, author and exact date unknown). This article, which goes on to mention an open day at the school, is clearly designed to attract new children. It plays on the school's difference, demonstrating to the surrounding community that such a project could survive despite popular opinion. The author was unknown, but it seems to be a joint effort between a journalist and the school. Again, difference is more implicit here, yet the thorny issue of the lack of Welsh being taught at the school is (of course) avoided, so that a particular version of difference is drawn on here.

Crucially, drawing on various discourses of education, homeliness and ecological architecture, these articles begin to show how the buildings at Nant-y-Cwm are inescapably drawn into various, cross-cutting wider networks of concerns, both normalized and differentiated within such discourses. However, the buildings themselves begin to become 'back-grounded' where the atmosphere and practices at the 
school (as in the programme for S4C) take over as more potent signifiers of the school's practices. It is hard to concentrate solely on the buildings without focusing on how they are embroiled into - and often lost within - ideas and practices about a different but 'good' and thus 'suitable' or 'normal' education at the school. The production of this more general difference/normality, along with and in relation to a right education 'at home' in the school and its community, structures Chapters 8,10 and 12.

\subsection{Conclusion}

In this chapter, I have discussed the various collections/dispersals of influences and practices through which the house and school were and are constructed. There are certain similarities and disparities between the two buildings which highlight a range of potentially fascinating themes. The rationale for choosing these two buildings and architects is covered in Chapter 1, but I will conclude by very briefly summarising the key elements discussed in this chapter, and certain linkages with other architectural practices and theoretical insights I have evoked here.

There are many similarities between Hundertwasser's and Day's architectural philosophies, many of which were and are entailed in the material-semiotic construction and experience of the buildings. These include: the importance of work; various versions of the health- and soul-giving capacities of buildings; the importance of creativity, and in particular the agency of nature in connection with individual's artistic productivity; buildings as people's 'Third Skins'; the design and construction process rather than an idealisation of a finished form; the creation of the homely and comforting (through health), yet within these conditions of contingency and unknowability (and work); the utopian elements of these aspects of their work. There are also many disparities in the ways in which these were 'transferred' into the buildings, and the versions of, for example, 'nature' and 'health' each architect promoted. Other disparities include: the ways buildings 'fit in' or evoke a disruption to the surrounding landscape; their location (urban versus rural!); the amount of publicity both architects and buildings receive; the incorporation of future users into the design (Hundertwasser does this far 
less so, although this is in part owing to the nature of social housing); and the importance of aesthetics. Both promote a sculptural architecture. However, Hundertwasser is more concerned with an artistic imagery than Day. There are also differential conceptions of ruin/lack: Day valorises the potentialities of an 'unfinished' site; Hundertwasser the euphoric, creative and utopian potential of ruin(ation)s themselves. Many of these themes are interrogated and combined in various directions in subsequent chapters.

These similarities and disparities also relate to an array of theoretical positions. Many of these do so directly, and appear in Chapter 3 and elsewhere - those of work, ruination, difference, the homely, euphoria/paranoia/nostalgia, contingency, performance and materiality/non-human. Others engage more indirectly with key themes of poststructural thought, including the importance of material artefacts, the actual/virtual, and of (de)constructions of difference. Others still can be connected with currents of architectural work, in particular with the dis-orientating and questioning associated with deconstructivist architecture, and notions of community, health, home and 'green-ness' explicit in various versions of ecological and phenomenological architecture.

Finally in this chapter, I have provided a flavour of the buildings and their intertextual/inter-active construction. I drew out some of the general utopian elements that are apparent, in particular in their design, initial building and ongoing construction as 'different' in the press. This has been more negative at the house, which, owing to Hundertwasser's fame and the house's prominent location, is far greater in volume. The press depicted the house as an artwork, a failed ecological experiment, yet as extremely popular in particular with young people, with an often satirical acknowledgment of the ('consumerist') utopianism of the house. Most would agree, however, that the house, and its difference, have been provocative in various ways. The school, in line with its hidden character and attempts to 'fit' in, provokes other discourses surrounding difference. These feed more fully into the practices that go on there and in particular the type of 'homely' education that teachers try to cultivate. It is different in a much more subtle way. However, this more 'holistic', performative, material and symbolic 
difference runs through the little material there is on the school, and its striking isolation from the surrounding community (at least for the school-as-idea, perhaps not all of its members). I re-think these arguments in the next two chapters. The chapter also provided examples of the collecting/dispersing I theorise as crucial versions of critical geographies of architecture in Chapter 4, for example in the 'gathering' Day describes in his ideal building process, and in the mass of press material surrounding the house. Finally, I have attempted to indicate and summarise some of the key themes (difference, the homely and community) which emerge through such geographies in the next chapters, and through which certain versions of utopia (and the utopian unsettling) become apparent. 


\section{Chapter 7 Living with difference: The Hundertwasser-Haus}

\subsection{Introduction to Chapters $7 \& 8$}

'Difference' is one of the key concerns of postmodern critical thought (Young, 1990; Saurup, 1996). Various notions of difference are also crucial considerations for theorists who link visions of social (and natural) harmony with utopian depictions of inclusiveness and community (Harvey, 1996, 2000; Sennett, 1978, 1996). However, as I have already stressed, I am also concerned with the material differences that buildings can make, both in relation to their environs, and those actors that inhabit and constitute them. In other words, through the lens of ANT, I am extending the concept of difference to look at how 'different' material spaces are conceived, constructed and interpreted, and how this (often uncanny, discomforting) difference is frequently bound up in constructions of utopian alternatives. This presents less a move away from other versions of difference, and more a multiplication thereof through two particular buildings. In these two chapters, this entails a more complex examination of difference than that in the last. As I re-examine some of the themes of Chapter 6 through more 'critical geographies' of both buildings, I would also stress that the many versions of difference we encounter feed into more distinctly utopian moments and discourses than those in this chapter. However, figures of difference - and the unfamiliar - are a crucial component of the impact of those moments in, for example, the construction of an alternative community, or the uncanny attraction of the house. Utopian experiments have often been identified with alterity and withdrawal from 'everyday life'. Yet at these two extraordinary buildings, it is precisely their normality and homeliness (see Koller, 1996 and Day, 1998), which intersect with such constructions and unsettle the boundaries between difference and normalcy, and thus the everyday life/utopia distinction on which utopian escape is often predicated. However, these combinations see the emergence of various utopian moments and ethics, as I document throughout the thesis. I think that in many instances in this thesis, we can also often conflate attempts to do 'good', or experiences of utopian moments, with a concern to 'make a difference'. 
But who or what does this is not always clear or controllable, unsettling both simple constructions of utopian 'difference', and unsettling similar, often literally related instances later in the thesis. This also allows us to follow how unsettling themes that emerged in Chapter 6 (ruin, work), and that were productive of alterity, are drawn into the performances at both buildings, and into actions where users make themselves $a(t)$ home.

\subsection{Introduction: Hundertwasser-Haus}

Most studies of difference tend to focus on those (racial, age, ability, gender) groups and identities that are in some way excluded from society. In this chapter I focus on what (in Vienna) is a relatively 'normal' group - social housing beneficiaries - in an unusual setting. In other words, rather than focusing on individual or group identity, I tease out the ways in which material and performative difference is enacted in often complex ways through the Hundertwasser-Haus, and highlight the moments where this is connected to threads of utopian thought or practice. Through the variety and quantity of press attention the house receives, I was not surprised that residents were prepared to discuss the theme of difference and related issues. I often began by asking residents for their opinions on the house as an 'artwork', before discussing the impact of the press and tourists on their daily lives. Whilst analysing this material, it became difficult to separate our discussions along these lines, and at times with notions of home and community. With this problem in mind, the chapter is still organised along those chronological lines for the sake of clarity. The first section discusses the house's aesthetic, and its relationship with the surrounding area. The second summarises the impact of the press (minimal, for most residents) and tourists on their lives. I attempt to demonstrate the complexity of differences residents experienced. These contrasting geographies of the house illuminate how (and why) certain boundaries and versions of 'the good' or 'happy' are drawn in relation to art, city and work. 


\subsection{Living with an artwork}

The question of the house's façade in particular in relation to 'art', was quite emotive for some respondents, especially longer-term residents. We have heard how Hundertwasser's utopianism, so explicit in his artistic valorisation of 'unregulated irregularites', was informed by a desire for healthy, egalitarian spaces where humans and nature could live in creative harmony. This is the crucial underlying design philosophy for the façade: a philosophy which evokes both desire and disgust (sometimes simultaneously), and draws thousands of pilgrims a year to sample a little utopian alterity (or madness). However, for one resident, Hundertwasser's intentions were less than noble:

J This house is - and I say this intentionally - made for tourists to look at. We are meant to be exhibits/exhibitors [Exhibitionisten]... I knew Hundertwasser, I discussed many things with him - it's not about practicality, he had no idea about children.

PK So is it, like an artwork [Kunstwerk] then?

$\mathrm{J}$ Yes, exactly. A three-dimensional picture [Ein Tridimensionalesbildpunkt]!

PK And do you think that was the only reason for it to be built? Not for the people inside...

J No, just in order to realise his ideas. ${ }^{1}$ (Female, lived at house since 1986) Another resident answered similarly:

R Yeah, well, it is really an artwork? Yeah, it's got kitsch elements... but I wouldn't be a preterite and say whether it's art or not...it's just how it's received, what is artistically rich, and insofar as that, it's an artwork. (Male, 1986)

The first respondent is stronger in her views about Hundertwasser's intentions, although both excerpts correspond with what most residents thought about the façade. Many agreed that the house's extraordinary nature was most visible there, but that its production as an artwork was also a result of the global dissemination of images, texts and discourse about the house. This was expressed in how $\mathrm{J}$ felt like an exhibit or exhibitor, and how $R$ suggests the building has been 'received'. The residents have very mixed views about the touristic and journalistic attention which the house attracts as a

\footnotetext{
${ }^{1}$ Quotations from Vienna are printed in English owing to space constraints. Where there is ambiguity over meaning, the original word or phrase appears in the quotation or a footnote. All translations are my own.
} 
result. Moreover, it seemed to be the house's aesthetic impact - as 'artistically rich' that concerned them most in our interviews.

What is striking, however, is the enduring importance of a collection and dispersal of visioning about the house. The woman in the first quote feels like an exhibit or exhibitor, as a collective touristic and journalistic gaze (Urry, 1990) is cast upon the house both locally and globally. At the same time, the house and its inhabitants have a privileged vantage point from which to look from the house onto a world outside (non-homelike), but always held in relation with it. The house's production as a work of art needs constant working. An ongoing stream of gazes is simultaneously centred upon the house but also sent away, in the form of articles, pictures and opinions. These then draw more gazes inwards and so forth. The residents are drawn into this simultaneity in a different sense as they both gaze inwards upon themselves as they tell me about the house, and outwards at the connection of the house with other houses and people. Yet they are also involved in the construction of difference that supports these gazes - ironically, perhaps most strongly in their everyday actions - as I detail later.

Whether the house 'fits in' to the local landscape was a key concern of critical debate. The residents themselves illustrate the complexity of this topic, whilst connecting it with that on the house-as-artwork:

PK Why does it feel Viennese?

$\mathrm{R}$ Well, because it looks exciting - why it's Viennese...?

J Yeah, it's simply well marketed, well known, I mean, you see it on every postcard...

$\mathrm{R}$ Thus it is Viennese but it's, it's, not Viennese, so I would rather identify a Viennese element, that it's, the grand façade and very little behind. It is...like, the Viennese attempt to shield themselves a bit. And with the more Modern style, yeah? The Viennese have always been very grey, in other words very used to their grey heart. (Married couple, 1986)

Like most residents, this pair have difficulty defining what actually is Viennese, and thus the position of the house within the city. For both the art critics and those who see the house as part (or not) of the city, the house becomes an object or actor within varying 
sets of relations, at various scales, at the same time as it is an assemblage of relations itself (Chapter 4). And this is also confused where the notions of process and cultural trends (having little behind a façade), also perform similarities and disparities with elements of Viennese culture, so that we are not purely concerned with aesthetic considerations here (Vienna's 'grey'-ness also being a reference to its general conservatism). Most of the residents seem to think the house is marketed, as J suggests above: but although it does appear in numerous guides and postcards, there is no offical marketing strategy ${ }^{2}$. Yet it is this feeling that it is marketed, as both 'just another' attraction in Vienna, as well as something different for the tourist than historic castles as well as the house being labeled as 'kitsch', or a 'fairy house', that means that it is difficult to place the house into any single set of relations. In addition, those relations are always changing and unstable themselves, as definitions of fashion change, and residents of a city struggle to define its cultural realities (above). Certainly the house both differs from the 'grey' heart of Vienna but shares certain similarities with the ornament of the Ringstrasse era of which Loos was so critical (Schorske, 1998), but whose critique Hundertwasser in turn derided. But already this difference and fitting in, becomes hazy, as we ask the question - difference from what exactly? The complexity of collecting/dispersing of material and cultural trends, press discourse, tourists, their actions, the traces they leave in visitor books, and the various 'gazes' upon the house constitute complex relations between the house and its blurry 'outsides'. One can stabilise these relations in relational constructions of difference - some based in Hundertwasser's utopian texts or the utopianism of certain pilgrims' desire to visit and live in the house (see below). Yet these differences, which become messier as our critical geography becomes involved with more and different actors, show how an 'artistic' or different building is relationally produced, yet in sets of relations which simply do not hold still in terms of context or use. This renders such alterity, and the utopianism therein, unsettled itself.

\footnotetext{
${ }^{2}$ Joram Harel, personal communication by E-Mail, 2002. The house is not marketed by any official body, and in fact its popularity is almost wholly due to its appearance and dissemination in newspaper and magazine articles, books, and, latterly, websites. Publishers of city guides soon grasped its popularity, and its place as a tourist attraction is ensured as a popular stop on any sightseeing tour. This is ironic, given that the KunstHausWien, just a few hundred metres away, is open to the public for a fee, is marketed and advertised around the city. This again attests to the attraction of the house as home.
} 
A second quotation is more aware of the historical background of the house. With an acknowledgment of early-mid twentieth-century utopian design, this woman is much more involved in the almost magical difference the house has to offer:

\section{PK Is it like a part of Vienna?}

C No...well, it is a wonderful thing...very interesting from the viewpoint of New architecture, like in the inter-war years, with Loos, and the wonderful garden cities. For those who needed social help...

PK And Le Corbusier...?

C ...Corbusier, that's another story but - in the inter-war years there were such lovely things, and this is in that direction - you have a house, and right on the roof, a terrace. And here there are seventeen. ...So [I] mean, that is unthinkable, this is unique in the world. (Female, 1986)

As an artist, this lady takes a general interest in the building's form, and its relationship with radical (often utopian) trends in architecture. She feels in particular that the effect of the house on those with the most social need is great, especially in terms of the garden terraces. She places the house into a history of 'avant-garde' designs, the impulse for radical social housing projects being in fact quite widespread. The house does not necessarily fit the buildings styles of the Bezirk, but can be placed into a general centuries-long trend in Vienna and other European cities (Barcelona, for instance) to produce progressive architectural designs. It is thus 'normalised' into an 'Avant-Garde' (utopian) fashion. Moreover, the translation of early-twentieth century utopian solutions - such as those of the Bauhaus and Le Corbusier into familiar landmarks in contemporary society suggest that she is hinting that this is a suitable form for the future, and hence a persitent desire to make a difference - the like of which will be incorporated into more general building practice in the next few years. However, she dismisses the possibility that the house is a giant artwork, ironically contradicting other residents:

PK Does it feel like you're living in an artwork? There are so many people, who want to see how life is here?

C No. It is splendid, yeah? Actually it lives, it is alive, and it is so welcome, it is actually a State project, [almost] where the thought was, like in a museum, that it will hopefully be entertaining too. So it's living, and the tourists downstairs who look at it...that's normal, I'd do it. (Female, 1986) 
Therefore we see, from an artist and a resident of 17 years, a commitment to the house as a living entity, assembled by and of living parts. At the same time - highlighting the complexity of her perception of the house - she likens it to a museum (cf. J, above and the 'exhibit'). She is not particularly critical of the gaze it receives, but keen to stress that the entertainment, and the excitement it engenders result partly from the fact that it is 'living'. For $\mathrm{C}$, this living museum crosses difference with everyday life to actively draw people in, as she admits she would be - it is 'splendid'. I do not think her everyday engagement with the house, or that of other residents, is structured by this difference or entertainment, although the constant murmur of tourists, punctuated by the odd camera flash, is a constant reminder of this museumised place. With her depiction of the house as a living example, and contextualisation in terms of utopian architectural history, we see one version of utopia here. Her version ironically places Hundertwasser's impulse to design 'healthy' social housing squarely in the domain of Le Corbusier and others (Worpole, 2000). A second underlying element of utopianism comes through the 'entertainment' that accompanies the crossing of difference with (everyday) 'living' (also section 7.4). As I have shown, a crossing of the familiar and unfamiliar (an artwork that is literally a(t) home), is a key impact of utopias that can render them unsettling. We begin to see, through the various threads of difference discussed so far, how this happens in complex ways at the house. However, the utopianism of Hundertwasser's design is not merely found in his philosophies or collection of bizarre materials, but in the ways that this is crossed with the house's intertextual, inter-active construction by tourists, press and residents - in often 'mundane' ways. Overall, this resident is aware of the house in a more contextualised sense in terms of art, difference, the city and various architectural trends. $\mathrm{C}$ provides a complex interpretation of the 'place' of the house that is neither wholly different from, nor sensitive to, its location. Some of these threads are collected in different ways into other concerns later in the thesis.

In some ways, the status of the house as an artistic object is very much at odds (at least at first glance) with the practical needs of the residents, which emerged as important concerns in most interviews. This theme was expanded upon in the next excerpt, where 
one woman recalled her (children's) experiences of living in the house soon after completion:

PK Do the children play much in the house?

J Well, [in the other flat], I must differentiate - the other terrace, was very, very, dangerous. Because it was very big, and you couldn't see when the children were playing, and the children could easily climb onto the parapet. Long discussions with Hundertwasser [smiles, as if telling a joke], he came with architects and ideas - perverse, yeah? With glass barriers, and it was always about what the tourists see. And then I thought, how can I discuss this, when he's got no idea what I'm talking about? And I left him alone for twenty minutes, with three children - up, on the seventh floor. And I went down into the flat and drank some coffee. And he called X! Come here! He was completely knackered after twenty minutes. And then eventually I had a fence, really very simple. And that was all it was about, so that the children couldn't climb up. (Female, 1986)

This quotation illustrates something important. It is not so much the case that residents are subverting the intended use of the house or the artistic gaze through their actions (cf. Lefebvre, 1991), or even merely changing it for their own needs regardless of the design. The relation is more complex for three reasons. Firstly, the house has become an artwork, a different building through a variety of practices which also occurred after 'completion'. Thus J's actions, and indeed those of all the residents are a form of interaction (the eventual fence) with this becoming rather than a subversion of it. Secondly, the quotation speaks of an acute awareness of the house and its academic and touristic importance. This 'intellectual property' is meant to be separate from the home life of its inhabitants, almost as if the walls and what are contained within them are mutually exclusive, such that difference is meant to discursively and materially construct a boundary. Instead, this woman's discussion with Hundertwasser explains how problems were caused by the house's difference, how difference was retained, but also how it became normalised, and rendered other (and, I think, more interesting still), through a performative use. As I suggested, a collecting/dispersing of elements can help us 'define' a field of concern. Here, Hundertwasser attempted to use a collective 'gaze' upon the house as a rationale for preserving its original design. Yet, as I suggested, such simple collections/dispersals are cut across by those that are more complex or directed otherwise. As this happens, a seemingly mundane concern demonstrates the 
continuously mutating, perfomatively negotiated 'boundaries' of the house (see Kwinter, 2001), and any utopianism attached to it. Thirdly, the crossing of normal and different here, and more particularly of different registers (artistic-discursive/practical-embodied) which led from mis-understanding to understanding is especially interesting. It tallies somewhat with Law and Mol's (2000) understanding of the 'good' - solutions to train accidents where a crossing of registers caused misunderstandings between bureaucrats and signal operators. Here, as well as misunderstandings, the crossing of this woman's practical experience with Hundertwasser's desire for an artistic building led to the construction of a compromise - a safety fence. But this also led to a source of great amusement - a story she was eager to tell in our interview.

This crossing of registers demonstrates more forcefully how, as Dewsbury (2000) highlights, even buildings are falling down, and that such stabilities as even a building and the seemingly normalised and mundane activities that go on inside are anything but stable. They are also rarely mundane, as this 'different' building perhaps more forcefully highlights. Forcing actors into unforeseen circumstances, this induces a variety of new situations that may be anxiety-inducing, may be unsettling, may be amusing, and may be instructive, but are always constitutive of a creative, (per)formative 'push' (Thrift, 2000b). Thus where everyday practice becomes the object of difference (different from the overall aesthetic), a confusing and now entertaining array of circumstances is set into motion which displace the previously seemingly stable realities of both Hundertwasser's and this woman's relation to the building. These relations enact a literal tangling of semiotics, everyday practice, tourism and ideals, rather than a simple subversion of text by practice.

At times, this tangling became more identifiably utopian, in more of a traditional sense of the word. At the same time, it was more contingent, and based in everyday performative practices, retaining some of the brief moments of 'escapism' found in Bloch (1995), Goment and Herrion (1999) and Anderson (2003). This was particularly true of one couple who had lived in the house since 1999, and from whom we shall hear more later (demonstrating the threads of practices which run throughout the thesis). The 
couple, interviewed separately, were not so much interested in the house-as-artwork, rather in the affectual impact of this strange house (note they had only lived in the house since 1999). They acknowledged an awareness of Hundertwasser's ideas, yet their reactions to the house were intensely personal:
PK When you moved in, did it feel sort of extraordinary ${ }^{3}$ ?
J Yes.
PK And how long did it take until it sort of felt normal?
J Well, for example, when I come home on Fridays, then I go into another world. It's like my castle [mein Schloss]. And I probably wouldn't see that in another social housing block. I mean, the others [are] also practically furnished, and you've got distance heating, and warm water. You must feel it, here it's just like young love ${ }^{4}$, right? You can only love this house. It was noticeable for one and a half years, and it's still like that really. (Male, 1999)

His wife is perhaps stronger still in her positive depiction of life there:
PK And what was your opinion of your previous apartment, in comparison with this house?
D Well, the last flat was basically a flat, right ${ }^{5}$ ?. It was $O K$. And here, this is like a fairy tale castle [Maerchenscloss]. With the garden, and play rooms. This is the second flat we've had here, we were over the other side before, we lived with a garden, it was complete paradise [ueberhaupt Paradies]! (Female, 1999, original emphases)

Interestingly, the word 'Maerchenschloss' has been used negatively by many members of the press to describe the house. Yet such utopianism, often identified as consumerist and thus derided by the press, is specifically evoked here. For D, the possibility of living in such a fairy tale house holds a utopian or paradisiacal quality. And for both husband and wife, the difference the house holds, which is out of the ordinary (and thus potentially unsettling and un-homely) also ironically holds that certain homely quality - going into an-other world, a fairy tale world which is still protective and enclosing. Their journeys redraw the boundaries of inside/outside once again, as a result of embodied boundary-crossing. Difference is again the key here, and it

\footnotetext{
3 Aussergewoehnlich: 'wohnen' also = to live, to be 'gewoehnt' means to be used to, or familiar with. This evokes a crossing of the familiar/unfamiliar and a move from the homely to the unhomely (Vidler, 1992: 23).

4 'halt wie die junge Liebe'

5 'war halt a' Wohnung, nett'?'
} 
is a difference which is once more performed in a crossing of ideas about semiotics ('normal flats'), practical use, and performative, contingent materialities, which are always done with the house as it is dwelled in (Harrison, 2000; Ingold, 2000) - a 'building-assemblage-event' rather than a priori object. We will encounter this performative element of utopia again in a fuller discussion of this couple's first few weeks at the Hundertwasser-Haus in Chapter 9. We find out there exactly why the house retains such a powerful, utopian impact for this couple, in a less deterministic way than the psychology of aesthetics to which the above quotations point.

As part of identity construction, the house is sometimes actively used to promote a particular identity, to create a working atmosphere which can be used profitably in the construction of non-homely (not un-homely) activities such as a home business. The same female resident relates this to the spiritual energies (cf. discussion of Nant-y-Cwm) and creativities the house helps enliven:

PK Would it change your everyday life much if you had to move out?

D I would never move out! I'm self-employed... and I feel that, because I work from here basically - with clients, when we have meetings - I'm convinced that [my success] has got lots to do with the energies in the house. Because, simply much more creativity is set free, much more fantasy. When they come here - I do sort of personality coaching - and when they come here, I can invite them into a fantasy world. (Female, 1999)

The extract is again overflowing with utopian tones, an other-worldliness of energies, creativities and fantasies which this woman sees as inherent to her success. The house is a key node in her work and home identity/ies, as she spends so much time there, uses it as a tool for her meetings, and as she includes it on her business cards. I would suggest that the cards are themselves important actors for her business and its identity, which function as an implicit result of, and dispersal of, the house's difference. Thus in addition to artistic nodes for collection/dispersal, the house becomes a tool or object for identity-construction, and is used in particular ways to produce a particular working atmosphere in an interactionist manner. Thus the artistic nature of the building is drafted into people's identity-making processes in a variety of performative and discursive (in our interviews) ways. 
Overall, however, the theme of identity was not such an important one in the course of discussions with residents. Moreover, although 'difference', and the impact of Hundertwasser's artistic philosophies did emerge in debate regarding the construction of home and identities for residents' flats, I would suggest the Hundertwasser-Haus was often a background concern for many (but not all) residents. In fact, conversely, some residents avoided talking about their buildings much, lest people think less of them, or they felt as if they were showing off. For instance, at the house:

PK Do your family ask what it's like to live here?

S Well, my parents of course. At the beginning, there were lots, but now it's quite normal. But, the children, they talk about it in Kindergarten. But still so, I don't like talking about it, because it sounds so - it... . I just don't like it, with acquaintances who I don't know so well, you know...? (Female, 1995)

This 'hiding' of the house, or its perceived irrelevance to 'everyday' considerations, is also apparent at Nant-y-Cwm in a more general sense. Yet here, with the stark visibility of the house in Vienna and beyond, and reputation for housing a 'privileged' few (not strictly true ${ }^{6}$ ), residents can be reluctant to discuss the house for fear of seeming to 'show off'. S has a little trouble explaining why this is the case, although this probably also originates from the identifiable annoyance (often veiled by sardonic amusement) of residents continuously being asked the same mundane questions about wavy floors and humus toilets.

In general, however, we can appreciate that the construction of difference at the house is dynamic and complex, specifically the result of changing combinations of Hundertwasser's work, the press, tourists' and residents' actions. The house 'fits' the Viennese landscape in slightly strange ways, as well as it can be set into utopian traditions in Vienna and beyond which attempted to 'make a difference' in some way. However, I have demonstrated that this is no simple or pure difference. In fact, as I

\footnotetext{
${ }^{6}$ The house is a 'normal' social housing project in terms of income thresholds, rent and provision of services. However, many residents were able obtain apartments through knowing previous or present occupants, so that a little controversy surrounds the present allocation policy!
} 
illustrate through a discussion of the impact of the press and tourists in the next section, much of the attraction of the house - its un/homely effect - comes from a crossing of difference and normalcy, fitting in and standing out. This complexity has illuminated an array of relationships with the house so far which sometimes explicitly bear a distinct, uncanny, utopian tone. At other times, residents' experiences marked out a pure escapist utopianism - yet one which is not as simple as it may seem...

\subsection{Living with the press and tourists}

All of the residents had had dealings with tourists at some stage: these were effectively unavoidable. The impact of the press was more person-specific - in fact, the majority of residents had had very little interaction with journalists. Aware of this, I present two opposing views which illustrate the varying effects of the house's difference, and its inter-textual production by journalists, on the everyday lives of residents. I then move onto the more wide-ranging experiences with tourists that residents chose to speak about.

\subsubsection{The press at the house}

For the residents, the mass of press attention and critique which resulted in many academic 'tourists' visiting the house hides varying effects. The general constructions of the house as 'different' or artistic impinge on their lives in many ways, often subtle, and often folded into other practices. For instance, the presence of tourists is as much a result of press attention as commercially-organised trips, and the reluctance of $S$ to speak about the house in the quotation above is partly a result of negative press attention (and hence the reception of the house). Moreover, certain residents had been interviewed by members of the press. Interestingly, when I asked them about interaction with journalists it seemed like a perfectly understandable question, such that press attention had become normalised.

Unfortunately, some residents had had negative experiences: 
PK Have you had much contact with the press?

J No, not really.

$R \quad$ Yeah. There was more at one stage. At the beginning, there was always something... [journalists] taken on tours through the house. And then a report, in some fashion magazine, and so on... But I had a nasty experience. What happened was - there was this woman, and she asked me questions about the house, perfectly normally, but she simply had a closed opinion about the house. And she was really unpleasant, somehow she changed everything I said into something negative. And I had invited her in, with my baby here, and she was really unpleasant. (Male and female, 1986)

Thus such press attention could have a profound effect. For residents, it has become normal that they and the house have become subjects for attention, but the indirect influence of the house's construction as 'different' impacted upon $\mathrm{R}$ very negatively. The often pre-conceived attitudes of many journalists to the house are also reflected in the twisting of words she notes. In fact, our interview was the first she had given since that occasion, over ten years ago.

However, it seemed that ultimately, the attraction for both journalists and tourists house was to observe how residents coped with the house, forging their everyday lives there. Again treating my question about the press as perfectly normal, another woman had a more positive experience, more recently, but she makes this important point:

D Not many [journalists], but...sometimes with $\mathrm{ORF}^{7}$, when they want to film? And I did, well housework, looked after the children...sort of short films, and then I played with the children, and they filmed it.

PK What sort of programmes?

D That was for an evening programme, 'Kultur Heute' ['Culture Today'] or something, about the house. (Female, 1999)

I argue that part of the attraction of the house is the crossing of the uncanny with everyday life (the homely and un-homely), a crossing of a very different type of architecture with the normality of social housing and the families inside, rather being than an 'alternative' community per se, as Nant-y-Cwm might be seen. As I indicated in Chapter 2, many utopias play on such a crossing of difference and normality, of reality conceived otherwise. In this case, the pull of this woman playing with her children,

${ }^{7}$ ORF is the Austrian television and radio network. 
actually going about her daily business in this strange house was as strong for the press as for tourists, although perhaps more grounded in what might seem 'entertaining' to readers and thus sell newspapers. For her, this was a more positive experience too, such that we could not characterise all press attention (as a result of this crossing) as detrimental to residents' habitation of the Hundertwasser-Haus. However, this crossing was an attractive proposition for tourists outside the house, whose actions and impacts I discuss in terms of the house's difference in the next section, and whose presence relates to more avowedly utopian concerns.

\subsubsection{Tourists at the house}

"Living here, you are at home even before you walk into the house... . It really has a lot to do with "coming home" when your feet feel the trusted unevenness of the ground, the gently swinging hills and valleys - your body has them all within its memory. ...A special magic comes over you here, creating a mood of connectedness. ...The statements made by visitors [from the visitor books] ...simply document how emotionally people react to this house" (Koller, 1996: 9-11; resident of the house).

I round the corner, past the telephone box, and catch my first glimpse of the house since last summer. In a way it's like coming home. Even in the dark early evening light, the skyline silhouetted, colours just about visible, vegetation unmistakeable, it seems very familiar. Why should it be like coming home? I've thought about it, and read about it so much that it's funny but familiar to see it again in the flesh, yet there's so little I can actually say about it... (my own reflection on seeing the house, from my notebook, 02/2003)

At least initially, I encountered the house as a type of tourist. Yet I had the funny feeling of 'coming home', that I think Koller extends out to the first visit of anyone (tourist or otherwise) to the house. Freud (1955), in his concept of the uncanny, discusses how the repetition of the familiar might become unfamiliar. Moreover, he stresses that this is one way in which in more general terms the Heimlich (homely, familiar), can become unheimlich. This could be applied to my own encounter of the house, repeated through endless pictures and texts before my physical visit there, an uncanny encounter with that seen in the flesh after viewing so many simulations thereof. For Koller, it is exactly the 
difference of the house which reminds one through (the repetition of) tactile and nonvisual sensorimotor responses to the hills and valleys of the undulating floor which evokes the (magical, utopian) feeling of home. Koller's text is unmistakably utopian in this homely sense. It again illustrates how the uncanny-and-different are connected to the uncanny-and-repetitious, and to the homely, in a utopian thread which runs throughout the house and this thesis (his book is aimed at those who are attracted to the house but cannot get in). This strange meeting of familiar and unfamiliar is, of course less deterministic than this might suggest, produced in the very interaction between tourists (and their 'emotional' reaction to the house), the house-as-different, and residents.

One example of this was an episode outside the house. I was waiting for an interview outside when one resident put his pots and pans out on the windowsill to dry. I was compelled, along with a good number of tourists, to take a photograph. Why? Exactly for the crossing of difference and everyday, evidence of the very fact that people are audacious enough to live their normal lives inside that house. This moment may not have been utopian, but speaks of the house as a 'museum', or 'entertainment', as we have heard residents say. That residents relate this and Hundertwasser's design philosophies to utopian and futuristic trends in avant-garde architecture and art (as does Koller himself), and that this emerges more strongly in the un/homely effect of the house depicted above, demonstrates how small-scale actions such as this are folded into similar experiences whereby the merely entertaining becomes fully utopian. The residents are fully aware of the part they can play:

M It is sometimes quite funny. I wake up in summer, open the curtains, and then Flash! Flash! Flash! (gestures as if taking pictures, a big grin on his face)

PK So it's like you're famous?

M A bit like the scene in [the film] Notting Hill, you know, when Julia Roberts opens the door, and [press photographers stand outside taking photographs]...?" (Male, 1986)

D What I always find funny are the stories, they tell, there are these absurd stories. But it's something that's always funny. And the other funny point are these everyday, household daily things, like when I shake the bed clothes out of the window, and then I'm on twenty photographs. But sometimes, it's 
really nice, if there are only a couple of people down there, we really like inviting people in to have a look around... (Female, 1999)

For them, these incidents are merely amusing, but indicate a certain pleasure on both 'sides' - residents and tourists - that is derived from the everyday geographies of the Hundertwasser-Haus. For fans of Hundertwasser and his ideas, this effect is doubly pleasurable, where they are aware of Hundertwasser's utopian intentions for social housing, and, as Koller (1996: 13) notes, to see that idea 'realised', to find people living in Hundertwasser's dream (also Restany, 2001). This folding of actions within this realm of difference leads to threads of utopianism that emerge as these disparate elements of practice are collected together in certain configurations or chains of events or explanation, rather than characteristic of these single events themselves.

The very appearance of tourists at the house, at least partly as a result of this uncanny difference, is also folded into a very different utopian atmosphere:

J I think to myself, I live in the house and three thousand tourists come by every day, stand in front of the house, so I go down too to see what it's all about! Or I go into the Village, it's like going on a short holiday, as a tourist, yeah? (Female, 1986)

S It's so wonderful. It's a lovely feeling when you come in here. And part of that is - I really like it that the tourists are down there, lots of people are really annoyed that there are so many tourists. But like I said, for example I always have the feeling that I'm constantly on holiday? There are Japanese, English, it's super! (Female, 1995)

For many people, the opportunity to be constantly on holiday would be a utopian dream. This might be allied with desert islands or cruise ships, rather than a social housing project in the centre of Vienna, but the basic idea remains: many entries into the visitor books represent a desire to live in the house, or to fill whole cities with HundertwasserHaeuser (houses). I was surprised at the enthusiasm of $S$ in particular, who had by then lived in the house for eight years. However, the tourists were still a key part of life at the house for her. Their mere presence punctuates her daily life (as a mother and Kindergarten teacher) with this pervasive feeling - this is not located somewhere else, or 
in some abstract no-place, but rooted in what she and tourists do daily. The point is that that feeling could not always be completely repetitious: one would soon lose interest. Hence this is not purely an effect of the house itself, but the rhythms and appropriations of the space outside by tourists - for this woman, their smiling, laughing, photographtaking, playing and so forth. To repeat the by now well-worn point: a chain or collection of practices and texts, from Hundertwasser, through the press, to tourists and now residents, is apparent. This takes in the full complement of differences and utopian positions we have already discussed, but is more than anything contingent upon the specificities or the collective individuations through which 'good' moments come to be named ('home', 'magic', 'holiday'). Many of these moments are themselves far from utopia, or utopian discourse, but some are sometimes entrained in collections which emerge as identifiably utopian.

Tourists present, for Koller (1996), a rich tapestry of events and emotions which continuously re-make the space outside: "The area in front of the house, remade into a pedestrian zone, is sometimes a stage or a front hall, a village square or a foyer - each scene flowing into the next" (p.9). Their actions render the geographies of the house yet more complex, short-term, overlapping and contingent. What types of actions might provoke two residents to identify a holiday atmosphere, beyond their sheer presence? Three examples from my notebooks shed light on this:

Hardly anyone is outside at the moment, although it is now sunny. An English-speaking couple hang around for over twenty minutes, hugging and having a good time (as the man in the café I spoke to told me they do [see quotation below]. I don't hear what they are saying, but they run up and down the hills, and she jumps off the top of one, into his arms. They are both laughing all the time... 
A young woman with a little girl comes around the...corner, child, holding one hand, dressed in bright pink, camera in the other. The girl gets excited upon seeing the house, constantly looking up, running onto one of the 'hills' in the pavement. The mother looks at me, smiling. ...Another tourist catches my eye - as I turn back... the mother takes a picture of the girl. Then they wonder up the steps of the café, stay on the terrace a few minutes, come back down, and disappear under the arch.

A man walks across from the 'phone box and almost stumbles into me by one of the hills. He has walked from the 'phone box without looking up, peering into the lens of his video camera which is firmly pointed downwards, tracing the spiraling patterns of the cobbles. He is video-ing the pavement.

As I mentioned in Chapter 4, I argue that the rhythms of spatial performance are equally important to both critical geographies of architecture and utopia. In much the same way, those rhythms are crucial to utopian, Lefebvrian appropriations of city spaces (Lefebvre, 1991, 1996). The moments from my notebooks exemplify Koller's flowing of scenes, as they present some of many moments, overlapping, which happened so fast that I could not note them all, or note them in any detail (an important consideration for any methodology). Nevertheless, my attention was drawn to these, and I was drawn to present this specific collection here, often for contingent reasons. The final moment presents a crossing of mundane and extraordinary (filming the pavement) which occurs at many tourist sites: the house is thus not so unusual in this respect, except for the inevitable sniggers of residents at actions such as this. The first and second moments are, I think, those which affect $\mathrm{S}$ and her holiday atmosphere more profoundly - laughing, smiling, playing, a mix of actions and people that is forever changing (although also quite repetitive). For the owner of the 'art-café' under the Hundertwasser-Haus, there is something deeper about these and similar actions which has an almost nostalgic, painful and euphoric utopian strand: 
"There must be something about this place... if you don't like a picture, you walk past it with your eyes shut, like I did. If you don't like music, you turn it off. ... But you always have to live with architecture. Hundertwasser knew that, [he] knew how you must feel well there. It's not psychological, or psychoanalytical, but psychosomatic. How you feel when you sit here, or there, if the curtains are closed... Architecture, for me, is so important, because it has an effect on everyone... . It's usually women who come into my café. They tend to come here on their own, or drag their men in here. They are the ones who want to spend longer here, and leave comments in my guestbook. You can see the house has an effect on them, they start hugging their boyfriends, some of them even start crying. But the men don't seem to notice. I would say it is a building for females - some know lots about the house, others want to know more and just be here."

This effect is, then, quite unsettling in another sense than that of the crossing of difference/normalcy, but I think structured by this and the 'homeliness' of the house (Chapter 9). This is an uncanniness which Krell (1997) links through chapters of his book to the feminine, that 'space' which allows for creation, engenders being, even encloses. Is the effect of the Hundertwasser-Haus so powerful for women in particular as a result of the conflation of the uncanny and the homely, a love-making which Krell suggest has been lost to a large extent throughout the techniques of our now-normalised 'architectures'? We might hypothesise this, yet either way, I think, an unsettling joy and homeliness is felt as the literal or indirect result of the many constructions of difference we have encountered so far and feeds back into S's quotation. This might not be indicative of the large majority of tourists who stay for perhaps fifteen minutes before moving to the next stop on the tour, but the effect that I identified in my own encounter of the house, and that Koller outlines, is one that seems to speak to many Hundertwasser-'pilgrims'.

As a balance, however, I would highlight the negative effect of tourists on the house. This is again largely the result of a desire to see the everyday functioning of the house inside, as well as to experience a 'real' Hundertwasser building.

PK I heard that some tourists tried to break into the house.

\footnotetext{
${ }^{8}$ The owner had worked here and observed life outside the house for many years. Informal interview conducted 01/03/03.
} 
J Over the washing room, through the window when we were airing it, then in front by the children's playroom - the playroom at the front is like a cage, like at Schoenbrunn [the zoo there] - and that's got something to do with the fact that Hundertwasser wanted the playroom as an exhibition room for his things - yeah? ...If Hundertwasser had really thought about people, then the playroom would have been properly inside the house, perhaps in the cellar. And the difficulty was, that when the children were playing down there, and when there were no curtains, the tourists, like in Schoenbrunn with the apes knocked on the windows and frightened the children terribly. Yeah, my oldest child, they didn't go down to play. Or, tourists would try to tear the door out of your hand [to get in]. The children couldn't go in alone... (Female, 1986)

S You see, at the beginning it was open - when the house had just been finished - and loads of people came in, in the Wintergarden you just couldn't get out, out of the flat, there was such a mass of people standing there, with the tour guide, and [also] loads of things kept going missing. That was a real burden - you know, the bannister tops, a tile - well, really... (Female, 1995)

J If your flat is over the motorway, that's a strain, and the tourists are also a strain. ...when it's spring and summer, then they stand outside. And usually, it's no problem, but when there's a bit of an aggressive mood [I think he meant when he's in one!], then it really pains me when there are so many standing there, in the middle of the street, when I want to just drive out of the garage, there are hundreds of tourists... (Male, 1999)

Again, the presence of tourists is largely a function of the house's construction as different in a variety of ways. Clearly, although some residents enjoy interaction with tourists, many are annoyed by them or worried about the effect of over-zealous attempts to experience the house. This necessitated an ethical decision on the part of the City of Vienna to close the house to tourist groups, in order to ease the more direct effect on residents, and prevent various items from wandering off! The mass of tourists were an unexpected result of the house's construction, though the effects on residents have been partially offset by the shopping Village opposite the house. The Village caters for tourists' thirst to experience a Hundertwasser building, distracting at least some attention from the house.

In fact, however, very negative impacts such as for B in the first extract were rare: most people explained that they just got used to tourists, and were quite ambivalent: 
E Does tourism have an effect on my daily life?. No, of course it doesn't (slight laugh over answer) (Female, 1986).

The presence of tourism outside the house perpetuates and complicates some of the discourses of difference that surround the house. In particular, it demonstrates how various threads of action and discourse that are attached to utopian differences identified earlier are contingently collected into other utopian moments or discourses - of the homely, the holiday, or the nostalgic. Only some of these moments, can sometimes be connected into these threads, or allied with utopia (as we have heard from ' $E$ '), although I have demonstrated how the unhomely, contingent and unsettling are evident in some of these instances. I leave a discussion of the un/homely for Chapters 9 and 10, turning instead to a brief conclusion.

\subsection{Conclusion: Hundertwasser-Haus}

The presence of tourists at the Hundertwasser-Haus is merely indicative of the power of the house to attract discourse and action, and the impact that the house-as-artwork or difference has imparted. First and foremost, however, I was interested in the specific versions of difference that were performed at the house, viewing them as thematics which emerged through the critical geographies I attempted there. Additionally, I identified utopian elements within these differences, and I connected these to diverse threads of utopian meaning which run throughout the thesis. As I argued in the last chapter, the difference that the house is designed to make, or with which architectural criticism has endowed it, is in itself varied, and attached to various utopian debates, not least those of Hundertwasser. Yet these simply do not exist without the actions and interpretations of those who interact with the house, in particular its residents. For it is through those actions that we see a degree of deferral, departure, subversion and even agreement with the artistic, utopian difference the house makes in symbolic and material terms - a degree of différance, perhaps. More importantly, I identified the crossing of the different, unfamilar, and artistically unusual with the homely, normal, and familiar, and attempted to exemplify the crucial, spine-tingling effect that this might have. This can be linked, sometimes quite simply, to utopian desires and moments, from those of 
holiday, to nostalgia/euphoria, to specific, utopian appropriations of spaces. This attraction, sometimes utopian, sometimes not, is a strong one for both journalists and tourists, yet is produced only through the on-going usages of space that tourists, residents and journalists themselves effect through their bodily comportment, and in traces of their visits left in visitor books or newspaper articles. In many instances, the residents are ambivalent about tourists and the effect they impart through this difference. Similarly, many bored-looking bus-groups passed by as I stood outside the house, and I would be unsure whether to characterise their relationship with the house as either uncanny or deeply euphoric.

More broadly, the difference that the building makes is allied with other utopian notions - from a connection to avant-garde architecture, to the house as fairy-tale castle, a consumerist dream-home, or a 'true' home before one has even stepped inside. All of these ideas are carried forward into the other thematic discussions and observations that I was party to at the house. In particular, the simplistic difference the house makes as a fairy-tale home is complicated when we hear how and why such strong emotions relating to that home have emerged. Finally, more broadly still, this chapter has highlighted the importance of a relational 'difference', contingently constructed (thus, différance?) through symbol, text, material and performance. Difference has emerged as a concern through my specific critical geography of architecture, and the motion of collecting/dispersing in many ways characterises how this difference - and changing, often ethical definitions of inside/outside - are created and experienced. This complicates what we know about difference in that it comes to be attached to utopianism in various ways, and, simultaneously, in that these critical geographies show how and even why difference is constructed through assemblages of multiple, changing agents. 


\section{Chapter 8 Living with difference: Nant-y-Cwm School}

\subsection{Introduction: contextualising the difference of Nant-y-Cwm}

In aesthetic terms, Nant-y-Cwm is almost the polar opposite of the Hundertwasser-Haus. The Kindergarten in particular is almost invisible from the hill above, and very few people in the surrounding area are aware of its existence. As I indicated in Chapter 6, the theme of difference throws up very different considerations here than at the Hundertwasser-Haus. This makes for fascinating comparisons in terms of the ways in which material and performative differences are experienced and attached to other 'good"' ways to make a difference, although the design philosophies of both architects were quite similar. This chapter is more wide-ranging, with natural cross-overs ${ }^{2}$ into my accompanying themes of home and community. As with the previous chapter, though, I would note that threads running through this chapter come from Chapter 6 , as well as they inform later themes. Hence, in order to show how utopian moments and discourses emerge, it is necessary to follow how they emerge through connections between these themes, chains of events and collections of examples, rather than assume any simplistic or essential separation ${ }^{3}$. The nature of my discussions with parents, teachers and children meant that the buildings often were background-ed. However I begin with a discussion of the part buildings play in the construction of a 'different' education and community, which is often framed in symbolic terms in relation to the ways the building represents (as of course it is enrolled in) 'artistic' practices. I then move onto a more general 'culture' of difference, instigated by our interview discussions of the buildings, but where their importance is often assumed. We are thus on more familiar ground in terms

\footnotetext{
${ }^{1}$ I would re-iterate my notion of the word 'good' here as allied with the good life (More, 1988), with visions, and, more broadly, evental moments or ethics felt to be ideal or ways of expressing ultimate or generally trust-worthy viewpoints (Law and Mol, 2002; Jacques, 2002).

'For instance, the construction of a 'homely' space in line with a 'true' education is an element of the school's perceived difference from the mainstream. The community also thrives in some ways on being inclusive, artistic and 'different' from other school communities.

${ }^{3}$ In fact, to remain true to much of the empirical material, and contextualise the utopian elements of this chapter, I have not merely picked out a few utopian examples to pretend that these wholly characterise the school (that would be unfair), but drawn out all of the key debates I encountered around 'difference' there.
} 
of individual and group identity. Nevertheless, attempts to stabilise what is 'different' about Nant-y-Cwm are often explained through practices (speaking Welsh, playing rugby, artistic work) rather than any shared vision or structural identity - although there is a feeling of a more 'general' culture about the school than the house. In the final section, I discuss how constructions of difference are inevitably bound up with ideas of 'normalcy' and 'fitting in'. This paves the way for discussion in Chapter 10, where we see that what 'makes the difference' at the school is a highly complex, contingent combination of the curriculum, individuals' identities, notions of homeliness, ideal childhood and the 'good'. This comes through appeals to, and critiques of, different times, places and practices. However, the overall impact of the school is one that unsettles any neat, single vision of a homely education, and is a very different crossing of difference and normalcy with very different effects from the Hundertwasser-Haus. As

at the house, though, the key thing is to follow specifically how these constructions of difference are performed and collected together to make particular meanings (if they do). Through this, I examine what role the buildings and constituent parts play in these complex assemblages and events.

\subsection{The buildings}

For some interviewees, the buildings were important in various ways to the school's difference. In particular, the Kindergarten is seen as an irreplaceable locus in the relations of educational ideals, teachers, children, parents, toys and landscapes that make up the different education the school offers. It too is seen as an artistic, sculptural building, but which also follows Steiner's and Day's (1990a) architectural philosophies. Thus at first glance, in opposition to the house, the school buildings 'fit' the landscape, and fit the ideals of all those who use it, in a holistic, artistic and homely sense. This is also involved in a more general idea of alterity, as $\mathrm{C}$ mentions below, and as we hear in section 8.3. The connection of the building with these artistic activities, in terms of housing them, a setting for them, and as an active part in them is emphasised by some in a way which questions this initial idea of fitting: 
PK You were saying there's a preconception that the school's hippie-like or New Age. Does the building live up to that as well?

C I think it does a bit. If you come with the idea of, bloody hippies, then yes, because it's all furry, and, coloured and, all the rest. With yellow windows, oh my goodness. And the Kindergarten will automatically make people think, oooh that's weird. Anybody who's less of that view, would be drawn. My sister came, and said oh wow, I love the Kindergarten, it's just fantastic because it's different and, it's a really nice place. And the same in the Main School, l've seen people from the local area coming in to fairs. And they're just oh wow, it's beautiful, and it's lovely and unusual. And I think 'cos you see a lot of the workmanship that probably was very common, people are pleased to see it. So from that point of view, I think the building's actually a good advert for the School. It's perhaps a hint of what's going on inside... (Parent of five years, female)

The buildings do seem to symbolise a degree of difference, although this depends on the expectations of the viewer. Either way, though, this is "because it's different", something that "was very common" but is not now, which is what makes it "nice" and pleasing for those who do subscribe to the general culture of the school. $\mathrm{C}$ identifies a temporal difference, such that buildings like the school were more common, although are now out of place with contemporary building techniques. Again, this is rooted in building practice and educational ideals rather than a pure aesthetic, as the school - and particularly Kindergarten - embodies the unusual amount of work that created it. Moreover, as a 'hint' of what's going on inside, the building is itself important, a powerful tool evoking varied emotions ("bloody hippies" and "just fantastic"). According to interviewees, this is often described as generally 'alternative' or 'hippie', despite the fact that many may not individually see themselves as such. The point is that unlike the house, it is difficult to discuss the buildings separately (as art-objects) from the education and people's practices as a whole. Nevertheless, in a simple way, the initial impact is one of 'making a difference' ("fantastic") which, as I have mentioned previously, can be related to utopianism in various ways.

The buildings' importance at the school are thus often imbued with the capacity to make an initial impact as part of a more generalised (although contradictory) difference: 
PK What impact do you think that the Kindergarten has on people outside the School? Is it part of this distinctive difference?

J Well a lot of people come and look at it. It's quite romantic. I think people wouldn't come and look at it unless they were interested. So, it would have an impact on those that were interested. And may be capture their imagination, and their hearts a bit.

PK Do you think it could have any negative implications?

J It might do, but the Kindergarten isn't what comes to my mind. If $I$ was worried about those sorts of things, I'd be much more put off by the bus, which is the co-op now. At least the school's clean, it might present an alternative, but it's essentially something soft and quite cuddly. And I haven't got much sympathy with people who don't think children deserve to be cuddled. But as far as putting people off, I think, it's more the hippie image. I don't find the Kindergarten that hippie. But it could be seen that way by some. (Parent, female)

The school buildings are viewed as objects or tools set within the local landscape of the school (the bus), as well as symbolising, enacting and taking part in an image that is both hippie and comforting (cuddling children, being romantic). In fact, often without focusing on specific details, the buildings are able to take part in various sets of relations about ideal childhood, education, and a hippie alterity. Both women note that this alterity is part of the school's almost utopian draw, "quite romantic" for J. However, this may not be as enticing to everyone, thus it is the symbolic, affectual and performative ways that the school is experienced as 'different' (and for her, normal to some!) through individuals' expectations and conditioning which colour the utopian potentialities the buildings and the school as a whole hold. Finally, it is interesting that in both excerpts, the Kindergarten's 'ecological' status and difference, and the impact of this upon the design, is not mentioned. This is naturally a thread which runs into the buildings' construction, although other factors (such as 'softness') strike more resonant chords as far aesthetic difference is concerned.

Like most interviewees, both women soon turned to depictions of the Kindergarten as a homely space, embodying an idyllic, nostalgic vision of childhood, which is better described in Chapter 10. They also related the buildings to a more general and hence more identifiable difference in terms of practice and identity. It thus seems false to separate this discussion any longer, where the school relies in many ways upon more 
general artistic, performative differences from mainstream education for its 'marketing' - for which the buildings are, of course, a key tool.

\subsection{A general 'culture' of difference at Nant-y-Cwm}

At the school, the buildings themselves are often back-grounded, as parents, teachers and former pupils discussed how the alternative practices that constitute the school and its education, render it different from mainstream school communities. A by-product of this has been its virtual isolation within its locality - and, where it is known, such practices present a key way through which difference is encountered there. This section demonstrates how attention in interviews was dispersed away from the buildings, illustrating how a critical geography of architecture must try to focus on buildings-asassemblages and partial collectors of action - as stimuli for debate - as well as how those buildings are relationally produced within wider social-material assemblages. Through this, it demonstrates how a general culture of difference (sometimes utopian in itself) at the school crosses with notions of the 'good' - and a suitable, 'normal' education, provided by 'normal' educators - to produce general and specific versions of difference which are quite unsettled. In themselves not always utopian, these relations of difference/différance nonetheless help highlight the instabilities and mutable boundaries through which the school's practices, history and underlying assumptions are constituted, questioning how and why they might appear to be 'good' or ideal.

Difference at the school is largely encountered and promoted through artistic and movement-orientated teaching methods:

PK How did you get involved?

F Well I had two boys. The eldest was around about six, and started at a State School, I hadn't heard of Steiner education. And I moved to Wales, around then. He was quite happy in the local school, but if there was any way to have a day off, he would. It's such a big part of their childhood, education, and I felt there must be something a bit, dif-[sic]. I went to a festival in Narberth, and the school $[\mathrm{N}-\mathrm{y}-\mathrm{C}]$ had a display. They had a marquee with children painting, and, that's what drew me actually, in the first place, the 
difference in their work, which is so colourful. Just full of colour, full of life. (Teacher and parent, female)

The school buildings recede into the background here, in particular as the children's practices are dispersed into a nearby town (Narberth). For this woman, though, it is these practices that can be exploited to promote the school. Difference is symbolised in these practices, through artistic activity. Where the buildings were a key attraction for some parents, it is such broader (artistic) practices, education and ideologies that were a deciding factor in this mother's choice to come to the school. The types of difference the school helps enact vary by person: for some, the school is actually a normal experience, as they are devoted to anthroposophical teaching methods rather than taking part in an alternative school or community per se. For others, (like F) its alterity, through colour, 'life' and movement, is its defining feature: or, at least, its not being a mainstream school. This variety (difference) is borne out in a number of opinions, some of the most telling found below.

In this first extract, the same woman expands upon her argument. This time, she mentions how the children themselves - the 'fruits' of the education - are very different from those in mainstream education:

F Having been through State School myself, and with four children too, gone through this school, one of the main differences, I feel, is the artistic approach, and how much their imagination is stimulated, and their motivation. And, people comment on that being different from someone who's been through the State system, often it's, to do with their selfmotivation and inner confidence, and I think that comes form the fact that it is appropriate at each different age.

PK And how much of it is from the unique sort of atmosphere that's built up here?

F Well I think to do with the curriculum and the way of teaching, based on Steiner's philosophy, that would be similar at any Steiner School. [...]But, there are things here which would feel different from, say if I went to visit Winstone's. Partly because we're much smaller, partly because we're, rural, and a lot of what is in the school is actually to do with actual community of parents. (Teacher and parent, female) 
Here, we see the beginnings of another strain that some parents are keen to push. This is the normality of the school in terms of a 'proper' childhood and education, which emerges as a result of the strictness (contra to a perceived freedom) of Stockmeyer's curriculum, and the standardisation of approaches across Steiner Schools. Thus, as with the Hundertwasser-Haus, although the school and its buildings are distinct from their surroundings (in some ways), they are also normalised in sets of other relations (Steiner Schools, and an 'appropriate' education - see below), so that value judgements as to the 'good' the school does and represents are bound into crossings of relations of difference/normalcy embroiled in heterogeneous arrays of spatialities. In simple terms, two different landscapes and spacings are invoked and crossed here - the local one (see below), and the Steiner Schools network.

The teacher in the next extract also relates the attractiveness of the school to Steiner education-as-alternative. At the same time, this is crossed with the practical and phenomenological lure of Wales for jobs, quality of life or the spirituality of the Pembrokeshire landscape in particular (see D's quotation, below).

J Some parents want their children in a Steiner education, in Wales, for whatever reason. But, I would say...the majority of parents that come to us, have not necessarily heard of Steiner Schools, and are looking for a different education for their children. (Teacher, female)

I look at the reasons for choosing a 'different' education a little later on, yet parents (from founders to recent arrivals) all stressed this basic point, sometimes over the lure of a school that provided a homely, 'appropriate', even child-centred education. Through a thoughtful evocation of both positive and negative feeling about the school, another parent provides a sense of how and why the school should be different:

PK Are there any particular rumours [about the school] that you can remember?

J I've heard some people say that the children are wild. I don't believe that. I think there's, always an element of that, in any group of young people. And anybody could focus on that, and exaggerate it.

PK Why do you think people have focused on the negative?

J I suppose whenever there's something different, there's always an element that wants to reject it. It can be seen as a threat... . But then again, I met 
somebody the other day, and she said I've heard some negative stories about that School, my son went there for three years. But then she talked about what a wonderful and magical place it was. And how, those two years had made her son's life more enriched. So, you know, both sides go out. I think it's really important that it exists. Because there's no sense of an alternative to the National Curriculum, and what can be achieved through alternative viewpoints. But while it exists, yes, it's ignored, but many different people do come and look, and they're actually inspired, it's freer. Pluralism, isn't it, you don't want everything to be a mono,-culture, of, this is the only way, that just crushes creativity. And so there should be lots of different types of Schools, not just Steiner Schools.

PK How much do you think it's also a part of people's identity, that they're at the School?

J I think for some people it's very important. Because, there is quite a lot of birds of a feather here. I guess waiting outside the School gates is an experience in itself. 'Round here people feel they can actually have deep conversations. That they may be wouldn't feel in a small village School elsewhere. It sounds like I'm trying to say, we're it. And I really don't believe that... . But a lot of people come here and have a sense of belonging. Some people come here and never quite get that. Identity, yes. It's definitely a part of your identity. (Parent, female)

Again, in the beginning of this excerpt, $J$ stresses how what the children do, how they play and act is actually in a manner that might be found in any school. In particular, the strict method of teaching that is adhered to means that many, like this parent, clamour for people to see what the children $d o$, not what the parents or even the buildings look like, or merely the importance of the school to people's identity (end of the excerpt). Her opinion about the negative views of those in the surrounding community is implicated in a simultaneous process of othering both by the Welsh community as regards the school, and by the school community as regards outsiders. Yet this process is always more complex where the community at the school itself, and the people therein, are also constituted by other relations and activities outside or cross-cutting the school. Moreover, the types of difference explored in the last quotation are multi-faceted. These move away from the alternative education the school offers, and into different facets of the school's general culture, such as its inclusiveness or 'hippiness'. This flows into nonrepresentational practices and emotions, which were hard to express in the interview, and are still harder to understand here. For example, the simple act of playing football and kicking (which, according to Steiner, has a negative sub-conscious effect on 
children) has now been allowed, partly for the children's enjoyment, but partly in order for the children to feel 'normal'.

Furthermore, $\mathrm{J}$ stresses how standing outside the school gates is an experience: yet far from being merely a deliberate symbolisation of alterity by parents, it is felt that the particular culture of the school allows and includes various people's beliefs (the 'pluralism' in the above excerpt) to be performatively enacted without fear of ridicule, even if the education itself is well-structured. This is also geared around a desire that the school could be one of many opportunities or choices for educating one's children. Although it is essentially a private school, some parents manage to send their children there whilst earning relatively low incomes - yet the point is that a wider array of forms of educating increases choice, improves the chance of finding a 'right' school for an individual child, and encourages dialogue between different service providers. Whether everyone would agree on this point is another matter. Nevertheless, this double vision of pluralism (the inclusiveness of the community, and more general choice), is certainly a 'good' for this woman, related to the inclusiveness that post-modern utopias seek through democratic participation and choice in future action (for example, Sandercock, 1998). Finally, the school becomes 'a part of your identity', as J argues. This is forged in a space hidden in the Welsh countryside, which draws on a variety of elements (the school buildings and practices surrounding them being one group, clothes, beliefs, festivals being others) to constitute that identity in ongoing praxis and any 'goods' attached to it.

As in Vienna, some are also reluctant to discuss the school, so that this part of their lives (which we have identified as important) remains hidden:

PK What about the people outside the School? Do you make a point of saying that you're involved?

A It depends, if it comes naturally, you know. I meet people who are very interested... But I don't go out there pushing it. I certainly don't let it dominate. You know, if I'm at band practice, I don't say, oh, this has happened at School, because it's really boring, it's not what you're there for. But obviously I carry it, in my heart. But I don't let it wear me down. (Parent, female) 
The school is a large part of her identity, as she feels her life is dominated by the school - yet she does not let it 'take over'. There is a feeling that the school-as-idea has the potential to dominate conversations and everyday activities, in particular in relation to a perceived outside world which perhaps does not understand the normality and mundanity that they are keen to stress in their everyday practices (see below). At the same time, the school and its community are not totally isolated, taking part in other activities and other communities - but it is interesting and perhaps unfortunate to hear how for this woman at least, this facet of her difference from others is kept hidden - far from being utopian.

However, the difficulties the school faces in terms of its non-Welshness are clearer, but again bound up in the actions of the children and teachers. This is noted by $D$ and two ex-pupils:

D Because Steiner education isn't into competitive sport, you never do rugby. And I think some of the children there, miss that. And it's one of the main things that separates them from children in other Schools... . Children don't want to feel odd, they want to feel normal, and we didn't want our children to feel odd. But there are a lot of alternative families there. It is very inclusive, even though they're all white children, from very similar backgrounds. But, coming back to competitive sport, I don't like the way competitive sport makes some people, behave. But, gardening as an alternative to playing rugby? I don't know, Wales is rugby land. But I think that's the other issue really. That there's no Welsh at the School. ... But, I think the children need to feel like they're in Wales as well. (Parent, male)

PK So how do the two Schools compare then?

$\mathrm{R}$ Umm they're definitely different. I kind of, just get on with whatever I'm doing. But, X school, everything was more set out by what you had to, abide by the going rules. Whereas, Nant-y-Cwm is much more, freer. It's a lot smaller, that made quite a big difference to me. Going into the, big Secondary School straight away was quite a change, some of my friends took the mickey a bit, but not badly...the lessons were, different, as well! (Former student, male, now sixth-former at local school)

M We felt very isolated. Like I remember wearing a watch when I was eight, and someone asked me the time, and I couldn't tell the time, and you sort of feel a bit ashamed. Because, you're aware that all the sort of six year olds in the rest of the country can read and you can't. And I just want them to feel, 
that they're [her children, now in a mainstream school] really part of things, and not that they're, different. (Former student [when school began], female)

As a parent, D highlights again the importance of feeling normal, although, ironically, in the second quotation, $\mathrm{R}$ thought Nant-y-Cwm was freer, whereas most teachers argue that it is more structured. This builds towards the sense of normality that the school also tries to promote, in particular through some of the children, their work and their performances. This also emerged in several interviews as a key reason that self-defined 'alternative' types chose the school - not so much (or at all) an expression of identity, but as a place where their beliefs and practices might be more readily accepted. This, though, is set against an educational climate in which other differences become apparent. Performatively, competitive sports are seen as detrimental to the developing spirit of a child by Steiner, which this parent compares with (for him) the greater importance of the psychological effects of feeling 'normal'4. Yet how this plays with the sense of normality (within alterity) and the inclusiveness and pluralism he and others sense at the school, is unclear. The relationship is difficult, and compounded by the financial situation the school finds itself in at present as it tries to increase pupil numbers to augment revenue, and find a suitable image(s) to do so. Additionally, the differences embodied by pupils' activities (not playing rugby, not learning Welsh) are perhaps more important than the symbolism of people in alternative-looking clothes standing outside the school. Perhaps the most important element is that, although the two ex-pupils did not feel it harmed them significantly, the homely education that is created through this alternative (artistic, with "gardening") approach - in the context of a slightly different building with complex experiences of alterity - did impact upon them in specific ways, like feeling 'ashamed'. This comes through the relatively simple material act of wearing a watch whilst not being able to tell the time. Again, we see complex, performative versions of difference being discussed here through particular activities, yet in ways which reach away from the buildings into identity construction (see Bell, 1999) and concerns with 'fitting in' (also a concern of ecological architects, ironically).

\footnotetext{
${ }^{4}$ Another parent, J, who discussed pluralism above, also talked about playing football in a very similar sense - whilst the children were playing in front of us!
} 
One of the key problems for the school has been its inability to 'fit' properly with the surrounding area - not aesthetically, but socially (Chapter 6). As $\mathrm{J}$ indicated in section 8.2 , although the buildings are not central to this difficulty, the Kindergarten, along with such things as the bus, are easy symbolic targets to indicate a further lack of integration with what has been defined as the 'local community'. At the heart of this lies the problem of language-related identity, compounded by the school's other 'differences'. For one of the founding parents, this lack of interaction with the local community reaches painful proportions in a nostalgic memory of the school's pioneering years, and the sense of lack as to what place it might have held in its locality:

A This [the issue of why parents come] is very difficult. Because, I mean it would depend whether they were interested. I wouldn't want them to come to Wales, unless they were sympathetic to the Welsh language. This is why it's extremely painful to talk about it in a way, because, it didn't go according to plan. And, that's what happens when, other people who don't share the same vision come along, at later times. But we actually promised, the Welsh Language Society, before the school opened, that we wouldn't encourage people to move to the area. So everybody who has come, I have felt, I'm breaking a promise. ...Especially when you get people who move in, and say oh, we're not interested in Welsh, we just want, an alternative school. And, you get fewer who want it because they think Steiner's educational ideas are, what would be helpful for a child. [...]But, it seems to me, that more people are interested in Nant-y-Cwm, because it looks a bit artistic, it looks a bit different, it's not, State education, let's see if our children would be happy. And so, these people have been, quite alternative folk, and, unfortunately have no interest in involving themselves in the ordinary community.

PK So they come as it's isolated from?

A $\quad . . . / /$ From anywhere. And it isn't. There are real people living around you.

PK It's not an ideal sort of, plane.

A It's not a desert retreat, you're still in the real world, in the middle of the country. And, there are people farming, ordinary people all around. And that has really, really, really upset me. (Founder, female)

This long quotation makes several points, summarising some of the debates about art and alterity made above. Yet one point in particular is made very forcibly. The original intention of the school's founders was to create a school for those who already lived in Wales, embracing the Welsh language. Although many of the founders I spoke to were in fact not Welsh, and label themselves 'alternative', they, like this woman, speak of 
how the community has changed to become more interested in being an alternative community. With this, the school has become a greater part of identity-production as well as an alternative way of educating. Hand in hand with a dis-connection with the Welsh community and language comes the alterity that so-called 'alternative' types have brought with them, a mixture which parents themselves see as potentially provocative. Part of the problem of this idealism (and, I have argued, the problem of 'traditional utopias'), is what she views as a 'desert retreat' attitude, almost the construction of an English, alternative enclave in the Welsh landscape, a haven for children and parents. Perhaps her view is a little extreme, yet the more forceful point is that this has become part of an unintentional culture at the school. Her (nostalgic) memory of the past is rendered still more painful by the utopian draw of alterity that the school-as-haven of difference for new parents engenders. Her nostalgia is very painful, at the same time mixed with the problematic of difference which besets many a utopian experiment or theorist - an ideal ontological isolation from 'reality'. This crossing is fundamentally unsettling. This unsettling may be associated with utopianism, yet I would not argue that A sees her viewpoint as utopian. Nevertheless, it does highlight how nostalgia, and a temporal amalgamation of visions of 'the good' can be quite unsettling at the same time as their end is always a 'homely school' - whether exclusive or not.

Simultaneously, the school has become more isolated, such that very few local people realise it is there at all, so that the question is repeatedly raised - different in connection with what? A has great difficulty defining what the Welsh experience is, despite implicitly including it in her answer. Therefore, where the local community is generally indifferent to the school, the complex relationship of alternative to normal is compounded further, where the school bizarrely 'fits in' because it is hardly 'seen'. How to define a Welsh community, whether that in fact is coherent, how people's activities cut across simple boundaries such as 'school' and 'non-school' which are only partially bounded by the walls of the buildings, and how alterity is related to normality (here, one does not predicate the other in a simple way): these all relate to the positioning of the school within and as part of complex, contingent relationalities and identities. These also change in relation to constantly mutating versions of 'the good': at first, a pioneering 
Steiner School, then alterity, and now integration. These do not represent distinct phases, or discrete 'camps' in the school community, but complex associations and dissociations of ideas and performances with different people, groups, buildings, performances and other materials. In addition, individuals often contradict themselves, sometimes arguing the school is hidden away. At other times, they suggest that Nant-y-Cwm is antagonistic to Welsh culture, another English intrusion, the likes of which have caused considerable problems in some areas of Wales (Cloke et al., 1997; Millbourne [ed.], 1997). For instance:

PK [We had been talking with a friend from the local Welsh community off tape before this conversation]. It was very interesting what $\mathrm{X}$ was saying about the lack of knowledge in the local community.

S Yes, that is, actually.

PK Were you aware that people didn't know about it that much?

S Well, aware that there wasn't a great deal of interest. The local people are the ones who are the most antagonistic really. They pulled our sign down, advertising. At various fairs. The ones nearest the School were thrown over hedges.

PK So there's enough, feeling, for people to do that?

$\mathrm{J}$ Yes, people see it as an English, enclave. The hot-blooded young Nationalist, element, regard it as another intrusion, into Welsh, culture. (Founder parents, male and female)

As with interviewee ' $\mathrm{A}$ ', the relations of activities, buildings and location that have led to the school becoming a utopian 'retreat' or 'enclave', have become very problematic this was never the intention of the no(ta)ble utopianism of the 'pioneering' stage. The school cannot, in some traditionally utopian sense, exist outside the cultural relations which bind it into its corner of Pembrokeshire, cannot be a desert retreat as the earthships of the U.S. desert attempt to be $\mathrm{s}^{5}$, and cannot even be a separate 'island' (Huxley, 1972). This again raises the question of the relationship between utopia and reality $I$ introduced earlier, as well as the now messy relationship (hidden and tolerated, ridiculed and ignored) between the school and its surroundings. Nevertheless, this picture is complicated still further by the deliberate normalisation of practices, discourses and ideals at the school.

${ }^{5}$ See 


\section{4 'Right' difference, 'right education' and a 'fitting' time}

The importance of normalisation is continued in the context of 'homely', 'right' practices in Chapter 10, but some initial indications of particularly the construction of a 'right' education for young children (age four to seven), in direct contrast with this perceptible difference, balance out the argument above. The tensions that are fundamental to the school in terms of this difference, in particular in light of its survival in the next couple of years and the connection between this and its history (third quotation below), are best outlined by various parents and teachers. The first excerpt is from a new parent, who is talking about those who want to attract funding by making the school more mainstream, in order to retain the different cultures the school offers. This is not merely about compromise, as the type of alterity various parents desire is tempered by changing versions of what the 'right' difference might be - similar to the unstable, performative 'good' of Law and Mol (2002):

PK Does the School, want to make a different impression do you think?

C Oh yeah, I mean we definitely want to look different. But it's got to be the right sort of different. You know, I don't think anybody wants the School to be, written off as druggie people. Because it's actually more serious than that. I think the other problem is that if people think that's what it is, they also think, it's very lax, and it's not, it's very very structured. And I think that is a big, perception problem. A lot of people come because they don't believe in rules. And I often have to say, you do realise that it's very structured. (Female, parent)

Thus the drive to promote the normality of the school heavily stresses the structuring of teaching there (rather than the eclectic parent body, or the atmosphere of the buildings). There is, moreover, a feeling that a crossing with more 'mainstream' ways of acting will enable them to promote the school's structured character:

A Well we have, to use marketing language, it's a business. ... We have an incredibly difficult challenge, because it's always been viewed as, a hippie School. .... None of the teachers are really hippies at all. And they're very straight, ordinary people, who work really hard, and there's not this sort of, free-roaming education. ...It's a kind of stigma, because hippies have to go to School as much as anyone else, you know.

PK So you could also promote those sorts of elements that are different as well? 
A Yeah. Because I think people just don't realise. And initially, that wasn't a problem, because people just came because they love[d] it because it was alternative. But now we have to change that and, re-educate the community if you like. To, understand that what we offer is great, and it's totally normal. And, of course it's got wacky individuals, hah!, but they're everywhere, and they're part of humanity... .

PK So, sort of, how normal it is, but also, how different it is at the same time?

A Yeah. It's normal but it's, it's, difference. (Long-term parent, female)

More than the previous quotation, this parent highlights that 'hippies' too have ordinary needs, and that whether or not the teachers are labeled as such, they are 'ordinary' and 'disciplined' - as if normality comes with this structuring. This is, funnily enough, about educating the local community - raising the school's profile and hence awareness rather than changing their own practices, although perhaps these too would have to change with greater integration. Moreover, the importance of this kind of art- and movement-based education is brought into discursive normality by those who stress it is the 'right' way to teach - 'totally normal' according to A. It is this structured, yet alternative, yet somehow true, yet somehow contingent (upon the relational specificity of the school's socio-geographical position) character that most struggle to speak about but are keen to attempt to communicate. This appears at the end of A's quotation - a highly complicated version of the 'good', which is still aware of the nostalgic and homely vision of childhood they wish to protect, and the alternative, artistic ways through which this is produced and which present the school in its best light. This conundrum is exemplified by the sheer number of proposed solutions - to change the school's image, to attract more 'mainstream' pupils, to retain its original 'heart', and to offer an alternative education that remains suitable to an ill-defined society at large. Whatever does happen, this will be rooted in contingent visions and ideals, but situated within more 'everyday' concerns such as lesson plans, marketing statements, grant applications and toilet cleaning. In other words, utopian visions and utopian moments in the future are likely only to come from combinations of the very 'mundane' practices that make up this alternative school.

The crossing of difference and normality is even more messy than at the HundertwasserHaus, where at least the building offered a handle on activities there, a visibly semiotic 
and affectual, collective draw. For instance, another complication is that in a strange way, the school does have some commonalities with the area, which is in itself popular with alternative religions due to the presence of standing stones and other landscape features ${ }^{6}$. It is thus not that the house or its meaning are better-defined, or that the type of dwelling that goes on there is less intense and thus less complex: instead, the situation at the school presents a wider complication that moves away from the buildings into a confusing play of what difference/normality are, and what they mean to the school.

Yet the buildings make effect a cutting return in this play of complexity, as the school struggles to decide whether it should sell the Kindergarten, and tries to re-invent a spirit which has perhaps been lost, through backward-looking appeals to the 'pioneering spirit' which characterised the early building days. This provides a nostalgic yearning, remembered in the stories and memories of the physical building of the Kindergarten and main school (Chapter 11). Interestingly, this pioneering spirit and visionary alterity, identified as rife during the 1970s, was explained to me as a 'normal' feeling within society as a whole at the time, and West Wales in particular. A publication based on an HTV television series during the early 1980 s adds weight to this, describing a range of activities from ecological building (including various references to Christopher Day) to alternative health practices (Osmond and Graham, 1984). They comment that: "We have been fascinated to discover that just beneath the surface of society in Britain today is evolving a whole new fabric that makes up the Alternative Movement" (Osmond and Graham, 1984: 6). Indeed, a a whole chapter is devoted to schooling, and Nant-y-Cwm is one of the two examples, depicted in its nascent stages as already different: "Nant-yCwm is far from being a typical 'private' school. The parents are not well off. Many are single parents and most are struggling to make ends meet, living alternative lifestyles, often off the land" (Osmond and Graham, 1984: 49). Hence an idea of 'fitting' the time further complicated the relation/boundary between the school and its outside:

S It was very different from now. It was the time as well. People were still full with this pioneering spirit and you never thought about money or anything like that, we just thought about ideas, and how to make them come true. So

\footnotetext{
${ }^{6} \mathrm{D}$, new parent, post-interview discussion.
} 
we sit around now in our fifties, sort of harking back to the good old days when, you know, it was possible to do that sort of thing. And it was great.

G Just like the children of the Sixties, with their first lot of families, wanting to do something, positive, without the money!

$S \quad$ In the way of material things, everybody was happy to hand down old clothes, and old cars which were barely moving. Yeah, it was really a wonderful time. (Founders, ex-parents, male and female)

The difference between then and now, tinged with a dash of nostalgia, is very much grounded in the work the founders of the school undertook. Yet this work, the spirit in which it occurred, and the utopian memories it jogs, were grounded in and drew upon the broader conditions of 'the time' and locality, as well as the group of people who came together. Simultaneously, this memory, the crossing of how things were different then, is painful for this couple, but it is this memory which, it seems, is able to unsettle the relations that operate the school and its context today. Both symbolised by the building itself, and embodied in past and present actions at the Kindergarten, the painful, unsettling crossing of a temporal dis-juncture cuts across the relations between school and its outside now. As a result, there are renewed calls upon the community there to push, to work towards creative and new solutions to the many tensions between difference and normality that the school has (had) to work through. The community is asked to find a new 'good', a future imagined through the virtualities inherent within these tensions, a working through of nostalgic memories and unknowable futures rooted in the material realities of difference/normalcy played out in the present (2003).

\subsection{Conclusion: Nant-y-Cwm}

The final extract offered a further appeal for the school to work towards a set of solutions which take into account a bewildering array of tensions: a Kindergarten building which fits its landscape aesthetically, yet which some call a 'hobbit' building; an extraordinary relationship with a tenuously defined mainstream society; concomitant tensions between reality and utopia and between present, past and future; painful, unsettling thoughts about the buildings, their construction and use in the last 25 years; and a relational set of differences/normalities which operate variably within ongoing 
landscapes of action, so that both difference and normality, and how both are defined, are powerfully deconstructed by the practices that have been identified by interviewees, and many more actions besides. This calls on solutions to take into account various 'goods' that do not always sit easily with the unforeseeable situations humans and nonhumans (such as the building, which must now conform with strict Health \& Safety standards) co-produce. The euphoric memory of a pioneering spirit is evoked, as are arrays of other, often 'foreign' practices, to forge new and often utopian futures for the school. However, these are given such a forceful affect by the unsettling situation in which the school finds itself with regards to its outside (and thus its inside), its past, future, its buildings and its practices, which are all called into question. At all of these instances (through the building, through a more general culture, and through a 'right' difference), specific versions of difference are evoked which attempt to overcome the tensions the school is caught in, through discussions of 'feeling normal' and 'inclusiveness'. At many times, interviewees collect together or conflate practices to produce emergent, contingent notions of the good, rooted in a discursive and experiential biography that must negotiate difference. This brings us to a final factor of normalisation. For could not the second half of the sentence above ("with regards to its outside...") be at least partially relevant to a variety of situations which occur in, and unsettle the allegedly stable nature of, our own versions of 'mainstream society' or 'reality' or 'normality'? As I am trying to argue, it is from the complications these two seemingly different buildings effect between difference and normality that we begin to see how the unsettling is a crucial part of utopias both past and particularly present: that similar discourses go on at other places, in locally specific ways.

\subsection{General conclusion to chapters $7 \& 8$}

The idea of difference has appeared in many guises in the last two chapters. Still more opinions and experiences could have been included which might have complicated the picture further. As Lees (2001) suggests, a critical geography of architecture that recognises the different claims to and performativities within spaces is necessarily 'messy'. This geography, I suggest, must be aware of how often ethical concerns such as 
difference are dissipated from buildings, both in the interview situation and more broadly. It also demonstrates how buildings are backgrounded and brought back into various assemblages of difference, for example, effecting a problematic return as a place's future is both in doubt and imagined in conflicting ways. Thus the materiality of buildings, which I attempted to question in (the) terms of difference, is itself of relational, local importance, although crucial as regards some of the utopian meanings and practices folded into that difference.

I do not wish to claim that the deconstruction of the different/normal afforded above is in itself anything new. However, there are two points I wish to make here in relation to both buildings. Firstly, that the two buildings give us a critical insight into exactly how difference/normality is produced and performed through 'mundane' practices, and what part a material building, conceived differentially itself through strands of heterogeneous practices, can actively play in that performance of difference. In other words, new versions of difference are constantly being worked upon, often quite explicitly. Secondly, the currents of difference that (per)form such a crucial part of life for these two buildings bring other, new concerns to attention. The multitude of ways that the extraordinary crosses the everyday at these two buildings questions our understandings of the relationship between utopia and reality, but more specifically in this thesis, how utopian ideas about experiencing and encountering 'home' (Chapters 9 and 10) are produced in uncanny, unfamiliar surroundings, through these many contingencies. As we see the ordinary in the extraordinary (particularly at the house), people's real lives in pieces of art, a tingle of recognition affectually opens up lines of new, unsettling and thus often utopian sensibilities and potentials. At the school, the un-homely pain of a nostalgic past can unsettle the relations and boundaries drawn between a school and its outside, so that we realise that the traditional utopian dream of a sacred, separate community distinct from everyday life cannot survive without it. There, more than at the house, 'difference' seems more complex, with a utopianism of a different character, rooted in a temporal difference (the 'pioneering time') and identity difference (what should the school be in this complex situation?). The question we need to ask at both buildings is thus: what really makes the difference? 
One way to answer this is by waiting: to see, as I have suggested, how ideas about difference are folded into later events at each building - and how the idea of difference at both buildings is collected into those of home and community, drawing the two aesthetically very different buildings together. Again, we should be aware of the discussion in previous chapters - where ruin and artistic difference folded into Chapter 7 , and where the contingencies of Consensus Design (pioneering) and work are folded into Chapter 8.

Another way is to focus on the negative. In the preceding three chapters, from press attention, to tourist activity, to the identity of the school, there has at many times been a pervading sour taste (even dystopian), which is what 'sticks out' for many actors both 'inside' and 'outside' both buildings. But this is not what I mean by the utopian unsettling, however dis-comforting it might be. What we see are contingent ethical decisions and critiques, which are collected into or aid the construction of sometimes longer-term positions (such as the 'Welsh problem' at the school), which must be dealt with carefully - as they are encountered - in order to 'go on' at all. These are qualitatively different from some of the experiences that have emerged as positive (yet still often unsettling - like first impressions of the Hundertwasser-Haus) so far. But these (dystopian?) negatives are sometimes connected into other, utopian moments, and render those ideal moments unsettling or painful now - such as the 'pioneering spirit' of the school, or the utopianism with which tourists have been associated at the house, This comparative, experiential ethics emerges where we are aware of a collected, fuller (but not full) picture. This is one of the key strengths of a critical geography of architecture: through the contradictions and complexity that we encounter, emergent, local and more generalised ethical positions emerge, from the middle of events experienced with buildings. This occurs through a comparison, through memory and biography, of a chance to find what makes a difference, through changes in mood, ideological position or (common) 'goods', as these are encountered through (building-assemblage) events. Is difference thus at the heart of a utopian ethics, in at least as many ways as the last 
chapters have suggested, and not just in a plain idealisation or symbolisation of 'inclusion'? We will again have to wait a little longer to answer this.

A final way to ask - what makes the difference? - is to remember that most of these differences are non-dualistic, partly non-representational and affectual, and notionally comparable with Derridean différance, even in comparisons with 'normality', positive or negative. For instance, in the construction and (re)presentation of the two buildings as 'artistic', and in the corresponding complexities of practice that are attached to these identities, relations of sameness and difference are intimately connected to those of collection and dispersal. As the buildings are constructed as different by this collection of ideas, practices and images about them, simple collecting/dispersing (cf. Chapter 4) is complicated in a way which questions 'inside and outside' (cf. Kwintner, 2001: 14) through more contingent practices of gathering attention about particular events, from all sorts of sources and physical materials, and perhaps aggregating these into ethical 'goods' (or 'evils'). It is difficult to discern a dualism here in anything more than shaky, poorly 'grounded' cases - yet ethical concerns, and utopian moments or 'goods' still emerge in many places: although, as indicated in the last paragraph, specifically not in others; yet this is also not meant to be dualistic. We might also remember that much of life is neither about producing the 'good' (although this, I think, is more usual) nor the terrible, but purely going on. This is perhaps a process of deferral, perhaps one of hope, perhaps the two are the same: although, of course, whatever happens always makes a difference (unless you believe in fate: if not, difference from what?). We might attach this into performative, non-dualistic (yet unfortunately exclusionary) universals which Badiou (2003) insists emerge as the subject encounters and defines an event. Thus in all I have tried and will try to follow where, and how, this difference becomes 'good' or 'euphoric', specifically in relation to two buildings. How much we escape a dualistic conception of difference is a function of remaining open to the constant (re-)invention of universal or general ethical 'goods', as well as to the heterogeneous flows through which events and ideas are actualised (not 'realised' to the exclusion of all which in any case was never destined to 'fit') (cf. Kwintner, 2002: 6-11). 
On this point of relationality, however, people's identities, although related to the activities at and appearance and materialities of the two buildings, are also held in a relation of deferral between themselves and the buildings. For, with all this talk of relations, one never knows (nor can one ever, I suggest) quite what that relation or phenomenological attachment is. As identities are always mutable, affectual and performative as well as knowingly produced, the buildings are part of people's changing, personal collections of objects, people and ideas, which they (and others) can combine to make their identities, for instance. There is always a deferral of meaning, more adequately characterised by the performative engagement people have with those buildings and their activities there, with which their identities are produced in relation to those places and others. But, in quite a 'commonsense' way, it is through these experiences that people are able to forge comparisons between 'good' and 'bad' attachments, and through which very different emotions regarding tourists, for example (attracted, lest we forget, by difference and normality) are felt. Perhaps the crucial way to think about this relation and the importance of utopia in 'making a difference' is through a key theme to utopianism and the house and school, discussed in the following two chapters: home. 


\section{Chapter 9 Constructing home: The Hundertwasser-Haus}

\subsection{General introduction to chapters $9 \& 10$}

One of the over-riding characteristics of utopias, as I showed in Chapters 2 and 3, is the implicit or explicit appearance of comfort or 'homeliness'. The ideas of home and comfort, related to identity and material consumption, have a long history, and are closely aligned with constructions of Modernity (Rybcinski, 1987; Baudrillard, 1996; Taylor, 1999) and health (Coyle, 2004). Hence where Modernity is so closely aligned with utopia (Levitas, 2003), the drive to comfort (sometimes through utopian nostalgia) is a key facet of the utopian. In the last two chapters, it was difficult to discuss difference without impinging on the theme of homeliness, demonstrating how the two are interrelated, and how the construction of homely spaces can be interpreted as a powerful way to 'make a difference'. Moreover, the idea of home or belonging is closely linked to group identity or community - and is thus folded into a focus on (alternative) communities in Chapters 11 and 12. The idea of home (and the un/homely), then, is perhaps the hinge of the empirical chapters of this thesis, as it was a crucial idea in my discussion of the utopian unsettling. What I want to stress so far is that practices at the house and school are not merely about being different - I do not think this is altogether utopian, nor is it a fair reflection of the daily lives of residents, parents and children.

In each case, however, the initial drive to make a difference has been to construct a house or school where alternative conceptions of dwelling might be accommodated. In each case, and particularly at the house (as a tourist attraction, in which many visitors would like to be at home), each building's impact has been this uncanny crossing of difference with the homely. Therefore, in the following two chapters, I look in more depth at how their inhabitants cope with this difference (or ignore it) in terms of their production of homely homes and identities, and the perhaps ironic importance of homeliness at the school. This is jointly discursive (what does 'home' mean?), material (how are homes literally constructed?) and performative (what actions render these 
discourses and materials meaningful?). Hence I stress how the utopian moments and ideas with which these are associated are unsettling in at least three ways. Firstly, in our awareness of 'difference' in the previous chapters. Secondly, in the performativity and contingency of 'unplanned' utopian moments, where many of the elements of difference we have encountered so far are folded into those moments, but where the specific 'collective individuations' that occur as events (and memories thereof) are functions of dwelling at the house and school. Thirdly, at the school, in the slightly bizarre manner in which an ideal childhood and education (the school's 'real' function) is constructed through an idyllised, ruralised homeliness that is literally, to use Heidegger's terms, notat-home (Heidegger, 1962). I would finally stress that the relationship between ecological architecture and home is a crucial one (in fact, part of the discursive difference that those architects attempt to make), in terms of 'fitting in' with landscapes, the body's needs, and local architectural traditions (Relph, 1976; Mugerauer, 1994; also Day, 1990: 109). Again, discussions about 'ecology' were not a high priority for interviewees, although I should make the reader aware of the importance of dwelling/home to both Hundertwasser and Day, their designs, and in particular the ways that the school draws upon 'nature' in various ways to produce a homely, 'right' education (for example through its nature tables). As with previous chapters, I would never characterise all of what follows as utopian and/or unsettling, however I attempt to contextualise and demonstrate the complex actualisation of utopian moments and 'goods' through the variety of experiences I encountered at the Hundertwasser-Haus and Nant-y-Cwm.

\subsection{The Hundertwasser-Haus: Introduction}

In such an odd-looking house, some of the materials upon which residents can draw to 'make home' are qualitatively different from those in other houses. Yet there are also many similarities that can be drawn with other homes, in the resources and discources upon which the residents draw, and in the ways they are engaged in sets of relations with each other, the house and their belongings, as well as things outside the walls of the house. At the house, although important, not all activities were directed to the 
construction of homely, comfortable, cosy houses - and ironically, we engaged in this type of discussion far less than at the school. For this reason, I explore three themes of importance to residents. In the first part, I explore the ways that people construct their homes as part of their identity or in relation to their particular readings of design fashions (including Hundertwasser). Secondly, and continuing this discussion of decoration and home-making, I investigate how practical considerations in people's flats interact with more aesthetic or identity-related activities. There, I hope to balance some of the more spectacular claims I make about identity and utopia in the first and last sections. In the last section, this leads into a discussion of how people use the house, and changing collections of objects, to create or take part in particular situations - such as a birthday party. I explore how these becomings at times emerge as, or take on, various utopian moods. This includes a discussion of my own appearance in one event at the house, and continues my thematic consideration of the events collected into another event - that shortly after a couple's marriage.

\subsection{Home and identity}

For many people, their homes are not merely places for safety, comfort and rest but also for the display of interests or identity. As I began to show in the last chapter, there is not necessarily a tone of subversion, annoyance or submission about the strength of the Hundertwasser identity. Naturally, all of the residents are aware of the symbolic importance of the house. However, their house and homes are cross-cut by other identities, other concerns, and there is not necessarily a neat correspondence between their homes and their identities, or between Hundertwasser and their flats - bounded as they are by the regulations that govern the decoration of rented housing, for example.

Some residents draw on Hundertwasser as a simple way of decorating their flats. They struggled to say whether this influence was purely the effect of the house and constant exposure to it, as some already knew about Hundertwasser and had copies of his work before encountering the house: 
PK And, have you got Hundertwasser pictures here?

D I've got a calendar....And I collect together the sheets from each month once they've gone by, and then - because I'm self-employed, and want to have an office at some point - then I want to hang them up in there (Female, 1999).

She was a fan of the Hundertwasser-Haus, and had persuaded her husband they should live there. This would be a simple way in which Hundertwasser images would be collected into an office space she would like, perhaps incidental to that space. In her flat, there were other hints of Hundertwasser, as a small reproduction of one of his works hung on the wall of the living room, with colourful paintings by other artists. At the house itself, large-scale changes are often not possible ${ }^{1}$, so that a full adoption of Hundertwasser's (utopian, 'artistically different') ideals of residents constantly changing their flats is, apart from the appearance of posters and knick-knacks, not that easy to effect. The excerpt is also an interesting comparison of people's use of consumer objects, with Hundertwasser's opinion of consumerism. For the pictures are commodified objects, but it would be wrong to conceptualise such objects as inauthentic or non-artistic merely because they are reproductions. At the same time, Hundertwasser argued that his way was just one 'beautiful path' (Hundertwasser, 1983), exemplifying what a purportedly free creativity could achieve, rather than a copy-able style. His success, particularly with regards to tourism, is held in tension with his often anticapitalist, anti-consumerist stance. For Hundertwasser, this woman would not be exercising her creative potential (and thus following an individual path towards a healthy, artistic utopia) as she is merely reproducing a particular aesthetic through consumable copies. In other ways, of course, her particular organisation of objects, and relation to them, is necessarily individual: for her combination of flat, pictures, furniture and intensely personal reasons for that collection could only be unique. Furthermore, this combinative strategy of making home from sets of pre-designed objects or massproduced decoration is nothing different from the practices of millions of people who go about making home in many other situations. In themselves, the pictures represent a simple transferal of Hundertwasser onto the walls of her flat as a colourful picture. But

\footnotetext{
${ }_{1}^{1}$ Although many of the corridors are decorated, the rooms of the flats have completely white walls. Only the bathrooms and kitchens have irregular elements such as broken and colourful tiles. Aditionally, the landlord (the City of Vienna) requires that the flats are returned to their original condition upon moving
out.
} 
set into the practices she tells me about, they become re-defined, re-imagined, as the identity of her home is continuously asked to form part of her own identity - in particular in terms of her business (which, as we heard in Chapter 7, drew on the house for its affectual 'energy').

Still more complex acts of decoration occur at the house, involving processes and materials of which Hundertwasser might have approved more strongly, yet still performed through these combinative strategies (the collecting element of collecting/dispersing comes through here). Whether people are in awe of his thought and try to carry out his recommendations, or whether they pick and choose elements thereof varies greatly. There is certainly not a feeling that one must adhere to a Hundertwasser design process, aesthetic, or identity. Thus people use his theories in different ways. For example:

PK And which of Hundertwasser's...theories do you like?

L Well, what I really like is that not everything has to be the same. Errr, this irregularity, which is also deeply resonant with nature. ...And many things which we've taken into the house we built in Niederoesterreich [a province of Austria]....For example, we plastered the walls by hand ${ }^{2}$. I don't know if you can get this feel with machines. Then it would be too straight. So it gives it another structure, when you ask the workers to do it by hand. And we didn't just paint the walls white, we used a technique [like lazuring] that gives more structure.

PK So there's more light...

L Exactly. And we took that into our house, as it inspired us, not to have our environment completely white, you know?, instead we brought in some colour and life. Also with the doors, like Hundertwasser, we haven't got any locks. We did that in our other house too, because it's really stupid to lock yourselves in inside the family. And we also had different doors put in, one with two windows, another with one, and that's an idea we took from here.

PK Was that just for the ideas, or only because it should look good?

$\mathrm{L} \quad$ As well as an idea, that it should look optically good. I'm personally an optically-orientated person, I have a strong feel for aesthetics.

PK So what else have you done here to make the flat your own?

L Yeah, there's the colour. Then, also, we've kept this open-plan character, no dividing walls or anything, and to separate it by colour - this is the eating area, the kitchen with the yellowy orangey tones...

PK Have you used your window right?

\footnotetext{
${ }^{2}$ This is reminiscent of Day's method of working with render: see Day, 1990a and Chapter 12.
} 
L Window right, no, but there is also a door right, like around the door outside?, in the corridor, our friends and guests leave their mark there. Mainly, children, treasure it when they can draw on the walls. But with social housing, there's this thing that you have to leave the flat in its original state when you leave it.

PK So you didn't want to paint outside?

L No, no. As I'm really satisfied with the colour scheme. We've got blue windows, and around that it's white. That's fine for me, yeah? (Female, 1989)

She continued later:

PK What about furniture?

L Well, there's these teacups[!], three red, three blue, three white, and it's quite satisfying to mix them [the cups and saucers] up to make it more colourful. Or, if you have a look, we've got different types of chairs, around the table. So we've said, there are so many irregularities in this flat, let's try to continue that[. A]lso the chairs are an example of the story of the flat. About fourteen years ago, we went around flea markets, and collected these bits together. On each market stand, another model. So we bought them, and renovated them. So there's a bit of an accent in Hundertwasser's direction.

The decoration and knowing production of an aesthetic, and also an identity at least for her two houses, follows a fascinating interpretation of both Hundertwasser's life and work. She neatly summarises the work they have done on their houses with the word 'accent' at the end of the excerpt. Without copying Hundertwasser's aesthetic exactly, or reproducing even elements of the façade inside, she and her husband have taken certain tenets of Hundertwasser's thought ('unregulated irregularities', wavy walls, colour) and undertaken a mutating transfer of ideas between their houses in Vienna and in Niederoesterreich, almost a kind of personal (and privileged) inter-textuality. Running the risk of pressing the idea too far, her reading of Hundertwasser's architectural praxis is also fascinating in terms of the systems of objects, rooms and houses she constructs about herself. As costs were kept down, instead of finding hand-crafted windows, handles and furniture for the house, Hundertwasser found old imperial bricks recovered from other buildings, mass-produced windows of various sizes, mixed and matched doors and handles, and found the staircase for the Wintergarden in a Paris antique store (Hundertwasser, 1997; also repeated to me by various residents). Her buying of chairs, 
mixing of cups and saucers, and transferal of window rights into 'door rights' indicate a kind of accent in Hundertwasser's direction which is written into the decision making and everyday praxis (we were using the cups and saucers in the interview) of this resident. Although to an outsider, her connection to Hundertwasser is not immediately obvious from the flat (there were no Hundertwasser paintings in the room I saw), an interpretation of his material-semiotic practices has led to the particular configuration and decoration of her houses. It is both part of and extraneous to her identity - as an 'optically-orientated person', as someone interested in Hundertwasser, and as something she finds satisfying and engrossing.

Still, the transferal of identity onto the flat, or vice-versa, is not simple, or neatly corresponding, although all of what she has done is characterised by a concern (a bit like Hundertwasser) to be a bit different. Her idea of 'home' is hence clearly bound up in notions of identity and difference, yet which are effected through personal activities and material collections as well as class, interests or clothing. However, this is cut across by other factors, brought into and away from the house (visiting children's scribblings, the rental policy of the City of Vienna), and complicated by her ongoing demands on the flat - for example the open-plan design. Her flat is also part of an assemblage that makes up the house, although it is on view to certain people only (not tourists), and it is part of my own collection of experiences about the house. Simultaneously, the flat, house and her second home are also an element in an assemblage that makes up her identity, life spaces and everyday landscapes of home(s). Again, however, these landscapes are hidden, personal and often unreadable as they are processual. A material-semiotic translation of praxis presents a flux of ideas from façade to theory to flat and reaches out into other aesthetics, flea markets, and other houses, collecting and dispersing elements about dwelling. However, without any direct or indirect acknowledgment from this woman (apart from 'accents'), I would not try to suggest these paths or collections were utopian in any sense.

Another woman showed me how she had built a bathroom in her flat in the style of Hundertwasser. This represented, more than the woman with her calendar, an attempt to 
directly copy the bathrooms in the house. The room was replete with broken tiles laid in a wavy pattern, in the main black and white with a few colourful tiles throughout. She was keen to show me this yet stressed most of all the subtle differences with the bathrooms in the rest of the house. Although each bathroom is different as the tile-layers were quite free, she is proud of the coloured tiles as they are slightly brighter than those used elsewhere. As an element of choice, such an easily missable and subtle inkling of creativity, it nevertheless gave her great satisfaction that the tiles differed slightly, although she had virtually copied every other aspect. This was the woman who in the last chapter had been very critical of Hundertwasser's motives in relation to the safety of her children. She thus carries the house in a more complex way than that of a critique of its practicality. She has dwelled in the house since 1986 and clearly its meaning and Hundertwasser's style are important to her in some ways, perhaps in a 'love-hate' attachment to that style, and the ways the house has become home in and through her anecdotes about Hundertwasser. With almost subversive irony, the near-copying of Hundertwasser's bathrooms playfully questions both his argument that nothing should be copied, as well as the type of creativity he advocated in the construction of the original bathrooms, and of individual, beautiful paths. How much she takes the house as part of her identity it was difficult to tell. Yet the bathroom was important to her - why show me a usually private room when we skipped past others at great speed?

A final consideration in relation to identity is that of 'window rights' (section 6.2). This rule is perhaps the best-known way in which Hundertwasser attempted to instill a culture of utopian creativity at the house through a practical law. Some people feel that they have creatively interpreted the window right:

PK Have you used your window right?

$\mathrm{T}$ Definitely, I've got like a, a flower bed outside my window. ...And I can go outside, and decorate it. But I have to go out the window 'cos there's no door! (Male, 1989)

As with the woman with her door rights, this man has mutated the window right potential away from reaching out and painting. He sees this as a fun activity rather than a facet of his identity, however, and he went on to explain to me how he liked to ridicule 
the tourists by hanging out his washing or putting pots and pans on the window sill to see the effect (I was unsure if he was the culprit in Chapter 7). He is aware of the draw of difference/everyday, but renders this a fun activity for his own entertainment rather than a knowing display of identity or home.

In sum, however, nobody has yet reached out of their windows to paint anything. Some are quite happy with the facades as they are - such as the woman above with her teacups - yet others are critical of people's attempts to use the right as mis-understood, and critical of the window-right:

PK Have you used your window-right here?

J No-one has.

PK No?

J Hundertwasser said that people communicate with the outside world using windows. What a load of rubbish! There are two aspects to window-rights, as I see it - on one side, a neighbour was allowed to put in an extra window, and he thought he'd used his right, completely wrong, he hasn't understood it at all. ... And on the other side, I must say is that yeah, there's a window-right, but you've got to ask [the City of Vienna] twenty-five times if you want to use it.

PK So do you feel creative living here?!

J No, I'd say not. (Male, 1999)

Evidently, the prospect of a house as a communicative tool, and thus an element in one's identity, is a foreign concept to some residents. Moreover, $J$ at least would not find any added 'homely' attachment to the house coming through the use of this right, although he is well aware of the intended value of window rights. Nonetheless, most residents did agree on two uses of the right. Firstly, the opportunity to 'use' both the right and the unique artistic statement the house makes, combined with a political demonstration to produce an event that still occupies the residents today. In 1986, 1988 and in 2000, banners were hung outside the house for various political events or protests ${ }^{3}$. The importance of this is written into the lore of the house, as almost all residents informed me they had not used their window right save for these actions. Again, the politically disruptive potential of utopia to disrupt or shatter the prevailing notion of reality

${ }^{3}$ See

for more. 
(Mannheim, 1960) rests here in the potential political disruption that such a protest heralds when making use of an unusual building. Adorning the building with banners both unsettles the traditional sites of political protest (banners hung outside otherwise 'normal' buildings) and the familiar use of the house itself as a tourist attraction or artobject with a coherent façade. The right to subvert or resist through symbolic appropriations of space (in this case, a symbolically utopian space as far as Hundertwasser is concerned) is a political act that has been identified with utopianism and architecture (Lefebvre, 1991; Lees, 1997). Perhaps this represents a form of this, a momentary heterotopia, yet only a weak form in that no 'alternative vision' was being proposed.

The second use of the right rests in people's painting and inscribing the walls of the corridors. In a mutation of the window-right that is particularly popular with children, paintings, murals and poems adorn the walls of many of the corridors. Importantly, as well as the aesthetic value of this right, the physiological act of painting or scratching the wall is a key element of play and performance at the house. In fact, Hundertwasser's promotion of window-rights and the health-giving effects thereof are in some ways vindicated by the popularity of this right. Some residents have mixed opinions, however:

$\mathrm{R}$ If you've been living here for years, then this painting on the walls is not so attractive any more...

J No, I find it great, that you can use the right... . And I see it as, if it's repainted then it's like a type of artwork here, which I find...should be continually developed. So, keep painting it, that's really nice... (Female \& male, 1986)

As the man who comments on window rights above states, some people are slightly cynical about the right. However, the image of the house as a sort of continuing artwork is attractive, and balances interestingly with the normality that other actions produce (like the use of IKEA furniture below), the construction of the outside of the house as artwork, and Hundertwasser's utopian theories of creativity. In all, however, the production of identities follows less along the lines of Hundertwasser's beautiful paths (although, as I suggested, all of these decorations have been unique in some sense), or 
window rights. Instead, we find collections of particular, personal elements, many of which may be attractive for no reasons in particular. If utopian at all, these elements are only weakly such, balancing out some of the arguments I make later in the chapter and thesis. These notions of identity/difference are also counter-weighted by the practical considerations of living in a flat, where home is rather about the construction of the mundane and ordinary ${ }^{4}$ (particularly in interviews) rather than specifically homely. This is interesting, given the work involved in constructing the school as homely, which we encounter in the next chapter. In the next section, I turn briefly to these practical considerations at the house.

\subsection{Practical considerations}

The actions in the above section are themselves not only related to identity or art, but to practical choices of furniture and colour schemes in the creation of nice-looking homes. I did not follow up these more practical elements (nor were residents that willing to talk about what seemed patently obvious), but they should be noted as they are perhaps a key element of people's performances in their homes, going about their daily business. In particular, the normality of the house as social housing is implicitly stressed in relation to its 'difference' (something I found uncanny), as in comments about rental arrangements:

PK So that's your own kitchen?

E Yeah - that's less usual to have your own.

T The flats are basically empty. They all are in Vienna.

PK And the walls were all white, or...?

E No, well these were [points around living room], but the bathrooms are somehow colourful. And over the tiles, there, that's colourful. $I$ changed that. ...It was pig pink before. And now I have sunflower-tiles!

PK So, there's lots of work to do here, to make it personalised?

E Well yeah [as if obvious]. You have to completely furnish it, new colours on the walls, it's like that in any flat, wherever you move in, there's nothing specific about this one. But what is difficult is that some of the edges we've been given - where it's all rounded off. You can't get any [equivalent of] BOG standard furniture in, as somewhere it'll go wrong. So you have to get

\footnotetext{
${ }^{4}$ This is, I suppose, ironically un-homely in another sense than the 'difference' or uncanniness of Chapter 7.
} 

individual pieces then. ... So you have to think about it, how am I going to
decorate this? (Female, 1997; male, 1989)

PK Was it quite a bit of work, decorating the flat to your own taste?

$\mathrm{J}$ On the contrary, the house - in the flats at least - is really, really normal. All this stuff here, it's all IKEA around us - pretty good value. Basically in the bedroom you've got a niche where stuff either fits or it doesn't. That's practical. Apart from that we haven't done anything, apart from changing the floor but you usually lay that in a new flat anyway (Male, 1999).

These comments are, at first, issued always in relation to a perceived sense of normality and framed by the discussions about art, difference and tourism we had been having in the interviews. This is also contextualised by the implied normality (and obviousness to anyone who is familiar with Viennese rented accommodation) of 'basically empty' rented flats. But the implicit normality contained in the choice of objects - like the good value IKEA furniture - suggests choices made less on the basis of identity and more on the basis of 'everyday' concerns, such as value and taste. Whether furniture fits is a difficulty for $E$, whereas $J$ argues that if it does not, one must merely search elsewhere for something that does. Either way, these decisions, grounded in the materiality of the building and furniture move from a stressing of normality to the implicit normality of mundane lifestyle choices that lead into the construction of everyday, homelike places. In fact, making home is conflated with a display of normality (for instance, stressing IKEA, and often through a reluctance to discuss this) through the interview situation.

I think this contrasts sharply with the story of the woman and her chairs. The amount of work that people do in order to create (a) dwelling points to a conflation of dwelling and building that sees these flats continuously newly built as they are lived (Harrison, 2000; Ingold, 2000), yet types of dwelling that vary in consistency and effort, contingent on huge arrays of other practices, beliefs, fashions, symbols and materials. This was reflected in the length and intensity with which people discussed their flats during interviews - with most residents, I spent five minutes on the subject: with the woman with her chairs, over twenty. For a critical geography of architecture, it is interesting to see how such performances vary so greatly, and how they draw on the building people inhabit and the processes (not pure aethetics) that went into its design and construction. 
However, conversation about this was more usually very brief and difficult, and never reached the intense meaning and use of those objects in details as does Bachelard (1964). I only gained brief insights into how people construct familiar, homely flats out of a previously unfamiliar space in a very unusual building, but it was very difficult to get a handle on the minute, daily changes, and uses of objects or spaces that are brought out by performativity theorists. The contingencies and performativities of such ongoing$s$ were impossible to grasp bearing in mind the priorities of most interviewees. Joined with the discussion of identity above, where I think performativity is really useful in a critical geography of architecture (and utopia) is in showing how such everyday, takenfor-granted practices are important and are contingent and mutable, but that these practices are so hard to represent fully, particularly where they are taken-for-granted or seem unworthy of attention.

At the same time, however, 'home' and 'normality' had to be achieved (in the interviews) - even if these practices were 'obviously' mundane - so that such a normal, homely identity for the flats was sometimes a weak, utopian dream, or at least an abstracted 'good'. I could have explored, for instance, how being 'good consumers', or the dream of an 'ideal home' ${ }^{, 5}$ fit into their everyday practices at home, and structured their purchasing decisions and priorities regarding decoration. However, we must also bear in mind that the pure opportunity to live in this specific house, and just be 'ordinary' in an almost decadent sense, was an important dream for several residents, including the newly-married couple and the woman who felt constantly on holiday ${ }^{6}$. I asked the latter:

PK What was your opinion of the house when you saw it for the first time?

S Great - wonderful, I really liked it - that's a thing, I've got a story, I was about...twelve or thirteen when the house was built, and at that time in

\footnotetext{
${ }^{5}$ By this I refer to taste defined by class, identity or friendship groups, or by the plethora of television and magazine articles, exhibitions and advertising images which construct various versions of 'ideal homes' and comfort. I did not have sufficient interview material, nor do I have space here, to explore these interesting but also already well-documented (utopian) themes and connections (see Bourdieu, 1986 and Baudrillard, 1996 for more)

${ }^{6}$ See Chapter 7.
} 
Hungary there were lots of adverts for the house. Like postcards and so forth. Some acquaintances were here, and looked at the house, and I was just a child, and was like aaahhh, it would be a dream to live there, but I had no contacts with anyone, and I liked it so much? And then, fourteen years later...it's so funny! (Female, 1995)

In acknowledging how this desire was folded into people's biographies - also a function of artistic difference - we remember Koller's (1996) statement in the last chapter, as well as that certain residents are sporadically aware of their continual pleasure at the opportunity to live there. This utopianism, again in some ways quite weak, and also more traditional in terms of an 'ideal building' ( $\mathrm{S}$ only viewed this through its intertextual production as a child, not its performative use), is apparent within the more 'mundane' everyday concerns that people bear at the house. Her dream was just to be in that house, to be at home there, and lead a normal life therein. This is quite different from the quiet comfort the school affords, homely in the sense of an affectual appeal which absorbs architecture into the body's apparently enduring desire to be at home, to dwell (Harrison, 2000; Heidegger, 1967).

In all, these concerns are rarely utopian themselves, and rarely unsettling. However, in the specific ways that certain elements of certain residents' practices mix with their past desires and other actions at the house, uncanny mixtures of events and ideas occur. At times, these do emerge as utopian (like the presence of tourists, as we will see in 'S's' case). It is to these that we now turn.

\subsection{Everyday moments or utopian escape?}

The last quotation is an example of the impression that the house has on people, from the point of view of an 'insider'. A key part of this is of course the 'difference' of the house, as an artistic and affectually attractive place to be. This flows into the ongoing use of the house in terms of people's stories - embodied memories - written into the house and their changing experiences thereof, and in relation to the multitude of other spaces and events they encountered. Yet this is interesting in that it demonstrates how people first feel when they encounter the house as visitors, and when they first come to dwell here. It 
is from these first experiences that many avowedly utopian moments were relayed to me in interviews, both at the house and at the school. These were often powerful experiences that intermittently or perhaps more continuously affected their daily lives, and specifically the stories they chose to tell about the house.

Bearing in mind the difficulties of 'fully' representing and explaining any event, in particular one as ethically and emotionally loaded as 'utopia' (Thrift and Dewsbury, 2000; Dewsbury et al., 2002), I will allow three examples to try to 'speak' of these specific situations and their relational capacity to invoke ideas like attachments to home, and utopia. Each bears unsettling and comforting, paradisiacal characteristics, but I also want to be aware of the rhythms and atmospheres of each example (Lefebvre, 1996; Seigworth, 2000), and the moods of celebration, happiness, change and comfort that are created through them.

The first example is an account of my first evening at the Hundertwasser-Haus (also Chapter 7). After a bewildering tour through the corridors of the house at twilight, walking at speed along twisting, undulating corridors, and after mounting spiral staircases, brushing past bulbous pillars, hands on odd-shaped banisters to steady myself, completely overwhelmed, I was thrown into a birthday party in the winter garden. Three men were sitting at a table smoking, talking quietly, their activity hardly seeming to fill one side of the two-storey room. I recorded the experience in my notebook:

This is the Wintergarten - I have seen pictures of it, but never imagined entering it as we did. As I trip over a hoover, and a toy (there are also young children running around who I didn't see straight away), I am already being introduced. After shaking hands with them, I find only one is a resident, and they are preparing for X's birthday party. I am left alone with them, which panicks me slightly at first, as the whole situation seems a bit bizarre. ... We discuss the house for a time before talking about Britain. As 
we do, food and drink keeps arriving at the dimly-lit table, smoke wafts around above our heads. I look around at the lush trees and bushes behind the large man opposite me. Behind me, a young girl is attempting some gymnastic leaps and rolls on the floor: I turn around and see a cage in amongst one of the plant beds, with an exotic bird inside; to my right is a wrought iron staircase bought by Hundertwasser in Paris. ... There is lots going on around us now as more people come in from their flat. It is relaxed, but noisy, I try to take in the room but the conversation and the food takes over. ... Everyone is sitting at the table now. We toast $X$...I still feel guilty for gate-crashing the party but everyone is so friendly, even using the familiar 'Du'. The whole thing seemed quite surreal to me, especially as I left to take an interview 2 hours later.

The notebook can only hint at how I felt about the situation, or the many things that were going on in building the party atmosphere. A bewildering array of inter-related processes constituted this situation. Firstly, my appearance at the party is predicated upon the status of the house. As far as I know, the party had gone on as it would have done without me, yet of course I had an active part there. I become part of a situation but am unsettled by the lack of knowledge as to my exact part in the whole thing (I only see one of the people there ever again). Secondly, the house (or at least the winter garden) is enrolled to do certain things at the party. Rather than a quite empty space which at first seemed in need of filling, this emptiness is in fact a moment in a rhythmic process which sees the potentialities of events folding into that space, but where the space (or room) is an active part in that process. People must cross it to get to the table, must avoid the pillars supporting the mezzanine, and have adorned the staircase and table with streamers. Thirdly, as different events capture my attention, so does the importance of a variety of objects forge the folding of events as I perceive it, cut into by the interjections of others into a conversation, or a change in rhythm as the birthday cake is brought out. Plants, lights, table, food, wine, staircase, become actors embroiled in changing systems 
as well as settings for situations to occur at different scales. Fourthly, the unsettling nature of my appearance at the party is not lost on anyone as an effort is made to make me feel 'at home'. In fact, a double reinforcement of home is enacted through the atmospheres that are created. On the one hand, certain conventions that cut across nationalities that created a comforting, welcoming mood are enlisted to enable me to take an active part in the situation - asking me about my background, providing a drink, and so on. On the other hand, the action is actually taking place in a communal area, as the home is extended out into the winter garden, in a liminal space, centred around the table in the garden which is made our own. This effort, this dwelling that is effected through a variety of objects, and which creates the birthday mood (a collection of relatives around a family table) creates a home-like atmosphere which is also literally not-at-home. It is unsettled by its nature as a special event (which by definition cannot last) as much as by the fact that home is temporally where the table is. This feeling is lost completely two days later when the party has cleared away, but for those moments caught up in an atmosphere which seems to slow time and space down into the intimacy of the space around the table. I must stress that this is one attempted representation of the party as I saw and felt it, where I was very nervous, had just arrived in Vienna, and had been into this un/familiar house for the first time. Yet the actions of the residents in making me feel at home - and the atmosphere in the house leave me with fond memories. The singing, the warmth, the taste of the food and the chatter of voices are all left as echoes of mutating combinations of actors which led to the evocation of particular moods and a particular folding of the house for the use of a birthday party. I would stress, however, that the peculiar unsettling (but not necessarily utopian - yet) but comforting mood of the party, its construction, its 'homeliness' and necessary contingency, and its subsequent 'loss', is specific, yet anything but particular. It speaks of birthday parties created within the material realities of the co-relations they constitute, that are perhaps far away.

The second example equally folds together various concerns and materials into an exciting, possibly risk-laden time, when the first residents moved in and encountered the house. This woman has remained impressed by the house and its capacity as a social 
housing block to instill a sense of community and belonging, yet in 1986, upon moving in, this bordered on a depiction of paradise (although the literal use of the word was my own):

C The first thing I can remember - there was [just] so much... . It looked very different from now, for example under the terrace it was full of sunflowers, the grass was over a metre high [she smiles, gesturing the shape of the flowers]! And it was wonderful, wonderful...

PK It was summer time?

C It was in May. Unbelievable numbers of sunflowers...the trees were smaller of course - and, I thought I was on another planet. ...It was strange, exciting, and unbelievable, and that we had the luck to get this flat, yeah, with this terrace, it was...I thought - it can't be me!

PK Could you use the word paradise?//

C Paradise - yeah, absolutely (Female, 1986).

We see here a significant confluence of the euphoric with the unsettling ('wonderful'...strange, exciting and unbelievable'). Her memory of the first weeks is of a time quite different from now, although this memory remains in her experience of and enthusiasm for - the house. She is aware of its faults, and critical of what she sees as a disappointingly large number of similarities with Gaudi, so that her adulation is by no means unreserved. The utopianism that is apparent is perhaps derived from a simplistic, deterministic view of the house and its effect - yet this is her experience, contingent not merely upon the house, but her assumptions at the time, experiences since then, the specific combination of trees, sunflowers and flat, and her active position within those configurations of agents. C's vivid descriptions, exaggerated gestures and enthusiastic tone infect this part of our conversation in particular, and the interview more generally. Her attachment to the house as her home, augmented by her artistic interest in its aesthetic, mean a conflation of artistic difference and home are (or at least were, in our discussion) the key ways in which she experiences the Hundertwasser-Haus.

Such enthusiasm is similarly apparent in the third example. This comes from two interview excerpts from the husband and wife from whom we heard in Chapter 7. They are both speaking about the time shortly after their marriage when they moved into the house. Although there are natural differences in their accounts, the collective 
individuation of things and ideas help produce a feeling which is neither wholly individual nor wholly collective - as work on performativity illustrates. Importantly, although I interviewed each of them separately, it felt almost as if both would have told me about this event even had I not asked:

PK Can you think back now to the first few weeks here?

J I've got to tell you about this, when we moved in, we had a flat in the other side of the building. And it was a really brilliant time [smiles a lot, seems very happy], and, it was in high summer? We had a flat with a terrace - a big terrace - with...cherry trees, yeah?, and that was the time, we moved in in July and got married in August, yeah? And it was a heilige time!, and this new flat, in this extraordinary house... . We experienced it, it felt like the whole environment was part of it...there was loads of work...but it was totally beautiful, the whole thing in the new house. ...And I must add to that, we had a window to the North, where the tourists are. And as we had so much time, we sat there and talked with the tourists down on the street...yeah? It was really grand ['Grandios']. And on top of that, I must also say, our neighbours had a garden next door and we really got to know them...perhaps closer than we would in other houses...and it was all probably a bit more than we expected (Male, 1999).

PK Can you think back to the first few weeks here?

D //Yeaaah... (laughs as if amazed/struck by awe)! It was absolutely fantastic, as it was just after our wedding. And we had our wedding presents, and flowers in our new flat, yeah? And it was a completely different way of life, we only had the most important things there then, and the flowers, it was a flower world, the whole flat was flooded with them, it felt like paradise ['Paradies'], we were on holiday, and we were up there for about one and a half weeks - I didn't want to come out again, it was just, with the garden...and it was in summer...and, it was paradise ['Paradisischer'].

PK Was it a distraction form work?

D Yeah, that was miles away, the topic of work was completely - no it was just another world. (Female, 1999).

There is so much overflowing from both this quotation and the context of its delivery itself (both husband and wife had slightly hazy expressions) that goes beyond this that was and is patently unrepresentable. Nevertheless, what can be represented, and what is left over - again, a non-representational notion of utopia - can be rendered carefully into a few points. First, the unique combination - of presents, events leading up to this time, the flat, flowers, the tourists, neighbours - of things and their particular performance are

\footnotetext{
1 'Heilige' means holy, but also moving or spiritual.
} 
a collective individuation of which the building was a particular part at different scales, as at the birthday party. Second, this particular individuation or actualisation (which could have happened a million other ways - cf. Dewsbury, 2000) was emotively characterised as 'like a paradise'. Developing a Blochian notion of utopia, this was felt as a distraction within everyday life, but also an integral part of their ongoing lives at the house, over a longer period of several weeks. Third, this points to the phenomenological power of memory to re-create a utopian moment, that dwells firmly with the house both in the past and during the moments of these interviews. Finally, it points to the utopian unsettling in a different sense - more of absence than presence. Accompanying this quotation is the sobering experience of this re-telling as a memory. Perhaps what characterises our moments of happiness, of 'a paradise' the most, and what gives them such potency, is the fact that, inevitably (although we know not when), they will, at least in that form, come to an end and lead into new ways of dwelling which may become utopian again. The crossings of home life with tourists, of a special period with an interview two years afterwards, show us both how these utopian moments were lived as parts of everyday life, and how even in memory or the imagination, they can be contingently conjured into perhaps shorter and less extreme moments of happiness (that point in the interview), only to be half-lost again as we moved on, and as they are further deadened in their re-re-telling on this page.

As with the party, whose experience I found unsettling at the time as well as in memory, potential loss, or lack is at the heart of this un-homely feeling. Yet this loss is necessarily inveigled in the realities from which is is produced, and into which it falls back - in fact it does not 'stand out' of them save in the telling, as both party and marriage involved a degree of working those realities in the face of such potential loss (or interruption). This loss is literally re-placed in the memory, and its enlivenment in the context of the interview: although this is also a 'deadening' in representation, it also emerges as a lived moment - an act of telling or nostalgia. How one or both situations become utopian is inevitably a great difficulty, overcome partially in the latter two example by the use of vocabulary. In all three, the importance of dwelling is drawn upon to produce particular constructions of home at the house, which do not merely represent activities going on 
inside the façade, but instead are well aware of the importance of the building in constructing home-like situations. Yet these situations are also unusual - special occasions, distractions from work, other worlds - and thus in some ways unfamiliar, crossing the homelike and producing it through other (but not other-worldly) streams of material realities. How utopian the example of the party is depends perhaps on the experiences of those that were there, and the affectual impact of the story in the retelling. There is a difference, in particular in the intensities of the three events which renders the second and third examples more identifiably utopian, although perhaps a utopian strain (not a definable word or concept) runs throughout the former to a lesser extent as the relationship between reality and its outside, and between home, comfort, happiness and their relational construction, are all called into question.

Additionally, such enactments of utopia as the last three, whether or not they accord with what Hundertwasser intended, and whether disruptive or comforting or joyous, are always spatial. All three are contingent, un-boundable events (or building-assemblageevents), into which bundles of practices and discourses (especially difference) are collected, and which mutate through these into other stories and events (like community). They are held together by particular arrays or collections enacted by the house and the people and things that gather there: momentarily; they could easily have been other, or may indeed collapse, but perhaps not through the falling down of the house per se but a change in use or a re-painting of the façade completely white...(Cf. Dewsbury, 2000 and Law, 2002).

\subsection{Conclusion}

This chapter demonstrates how the idea of home emerged during interviews with residents at the Hundertwasser-Haus, and in my own experience there. It contextualises various elements of utopia - particularly in the final section - within demands upon the house that are more mundane - although this is not to say that practical or identityrelated concerns are neither utopian, nor connected to utopian themes. These differ from those we encounter at Nant-y-Cwm in that they are less about ethics of the 'good' and 
more of good (euphoric) times - a visioning of the past, and of performative, phenomenological moments of attachment to home. They are also less geared around child-like comfort and more around the encountering of a kind of homely difference and excitement through the interactions of residents, non-residents and materials.

The more critical geographies I attempted to draw out at the house led the chapter through various routes, often away from any distinct feeling of utopia. I began by highlighting how the theme of difference was folded into the experience of home at the house. We must realise that (in contrast to the school), the house is not seen as so much of a totality by residents, as home is an individual flat (and perhaps a friend's), such that the un/homely effect of the house is more apparent to visitors and tourists. Either way, many concerns regarding home-making were orientated towards aesthetic choices and practical necessities. I discussed the relationship between these and Hundertwasser's 'Schoene Wege' (which, in their utopian valorisation of newness, bear similarities with Deleuze and Guattari's actual and virtual: see Grosz, 2001), concluding that any configuration of materials is unique, and in some ways new, but that this in many cases does not present any overtly utopian force (nor necessarily actualisation of the virtual). Similarly, the little use residents had made of window rights bore few, if any, utopian characteristics. Nevertheless, I discussed how abstract, but perhaps practical versions of 'the good' might be entailed in certain decisions. However, residents were not forthcoming on these topics, so that these elements of 'making home' remain a mystery.

These provided a little context for the more avowedly utopian moments I attempted to represent in the last section. All three events displayed the elements of contingency through which attempts were made to feel 'at home' upon certain persons' (including my own) arrival at a strange, new and unusual house, bearing in mind certain facets which were unhomely or uncanny, such as the aesthetic 'difference' of the house, or my own recent arrival and sudden crashing of a birthday party. A sense of loss or lack was apparent in all three. There is a painful nostalgia - yet this was replaced in the relationship between these events, and residents' longer-term experience (dwelling) of the house-as-home. Excerpts two and three in that section presented utopian moments 
that including various versions of the utopian and the utopian unsettling. These I would summarise as follows: lack and nostalgia; risk, excitement and strangeness; contingency, performativity and materiality; comfort and (aesthetic) paradise; difference (folding through the actions of tourists); homely community ${ }^{8}$ (friends); and utopian spatiality. Although, as I noted, these provided the tools with which to criticise other buildings and practices $^{9}$, and make qualified judgments after the event which named these in particularly ethical ways ${ }^{10}$, these remain, in their telling at least, specific moments or collections of utopian euphoria. In the next Chapter, I move to the school to compare how the notion of home emerges in relation to utopia there.

\footnotetext{
${ }^{8}$ In the sense of comfort Bauman (2000) suggests, and in the 'warmth' of community images (Forsey, 1993).

${ }^{9}$ See quotation from D in Chapter 7: "The other flat was basically a flat...".

${ }^{10}$ Although, as Badiou (2003) suggests, ethical decisions - and particularly those as strong as utopian 'goods', I would argue - emerge from the subject's encounter of/in an event.
} 


\section{Chapter 10 Constructing home (and school): Nant-y-Cwm}

\subsection{Introduction: Nant-y-Cwm}

In this chapter, I explore how at Nant-y-Cwm, the notion of home applies to a more general idea (not individual flats), and thus appeals to broader and larger communities of action. Although these emerge through singular events, these are often conflated to point in some ways to more general visions of the 'good' than those apparent at the house.

The notion of home might seem a slightly strange topic of debate for a school. However at many times, making or becoming-school is inherently linked to processes of becoming-home. This was particularly evident where often nostalgic ideas of the perfect childhood, the rural idyll and the 'right' way to educate and house a growing child are espoused - protected by a variety of cultural and physical markers, such as the school buildings. This was particularly the case for interview material with parents and teachers, again bearing in mind how the school presents a 'different' education (a large part of which is a perceived sensitiveness and protection of the developing child). This comes through a 'safe' and Steiner version of the perceived risks (cf. the utopian unsettling) that a child requires for free play. A healthy balance of safety and risk is more broadly considered to be the ideal, organic state of childhood 'free-flow' play (Bruce, 1991, 2003; Valentine and McKendrick, 1997). Thus difference - and the alterity of the community - is conflated with various utopian, nostalgic 'goods' about a right, comfortable education and environment, especially at the Kindergarten. This tallies closely with the construction of community in Chapter 12 - another key locus for 'home' at least traditionally (see Bauman, 2000, 2003). In this chapter, I explore this broader notion of home firstly through the ways in which the school was designed to provide a homely environment ${ }^{1}$. There, discussion soon moves to the ways in which the

\footnotetext{
${ }^{1}$ Again, this topic emerges in the construction of the community with the school (an 'ideal' educative community) where children were involved in and watched the construction by their parents, as well as stories and identifiable people's work is embodied in the school buildings, giving them a dwelled in, homely feeling. See Chapter 12 for more.
} 
general curriculum and its local performance are designed to be sensitive to the needs of a developing child. This emerges not only from more abstract principles, but also through events encountered on 'normal' school days, in which the parents, teachers and children all take part: I discuss this in sections 10.3 and 10.4. In the final section, as with Chapter 9, I demonstrate how all of the themes we have discussed so far fold into more identifiable utopian moments, before concluding by summarising the key similarities and discordances between the house and school.

\subsection{Constructing and compromising a homely school}

For Christopher Day, the connection between the children's needs, the education, the building itself and its ongoing adornment is one of protection and warmth:

"The starting point of the kindergarten design was to look at the state of being of children between four and six and a half years old and at how Steiner education and the whole school day relate to this...an underlying requirement for any small children is that it is harmonious and gentle...placed along the road edge, it shields the "child-world" magic grove from occasional passing traffic...[inside] the colour now is rose, and the classroom always seasonally decorated, perhaps with a blazing fire in the grate. Its gentle light, smells and warmth are different to all that has gone before...[this is] a place to stop and to be in...leaving chaotic sensorially unbalanced over-stimulation and stepping into a socially harmonious wonder-filled quiet, stable security - a magical world" (Day, 2003: 6-7).

Day's words, as architect and former parent, echo with the views of many upon seeing the building for the first time (section 10.5) and who have a deep attachment to the school. These take on similarly utopian tones. As well as it is enacted on a daily basis, the sense of the school as a haven and as child-centred, is perpetuated by such discourses about the development of the school, during its 'initial' construction, and thereafter:

PK In your experience, what have you done in the buildings that you were in?

$P \quad$ In the main buildings, I know there have been some things I would actually subsequently change. ...I know when we first started to think about - well I'd done workshops with Chris - working on developing the school, and the Kindergarten, we literally got down on our hands and knees to see everything from a child's perspective. In the Kindergarten and the school, we have got 
things like low sinks and things, which I know as a teacher, have almost crippled my back. (Teacher, male)

The act of seeing things from a child's perspective transfers from a purely physical sense into a psychological experience and nostalgia of an 'ideal' school for children. Most (although not all) of the design and physical work was undertaken by adults, as is the constructive work on the school-as-home/haven done subsequently. As well as a concern with children's physique, however, this is rooted in deeper visions of childhood which are essentially nostalgic, as much as they draw on Steiner's curriculum. For some, the buildings themselves were capable of embodying such an alternative ideal, as a hint or symbol of this general identity and the alternative version of childhood constructed at the school - a childhood inescapably attractive for many parents:

PK Do you think the building itself, as in the Kindergarten, is actually part of that ideal as well?

S Well I think the Kindergarten is one man's vision of, how to integrate, designs coming out of anthroposophy, into the local landscape. And, it has always been extremely successful in making people look and wow!, isn't this amazing? And you keep meeting people all the time who come to visit us, oh, I wish I'd been a small child in this place (puts on high whiny voice), you know. All the time, people would like to, shrink, back into childhood and, and experience that, because it has a sort of certain magic about it. (Former teacher, parent and founder, female)

Its overall impact is almost its key marketing tool, a symbol of what the school stands for, and something tangible with which people have a deep phenomenological attachment, even after only a short time. It is also one which heralds nostalgic, almost painfully utopian yearings to return to childhood oneself. For some, this can be temporarily offset by sending children to Nant-y-Cwm, and helping to construct what this 'haven for childhood' (Day, 1998). The affectual power of the buildings to evoke these yearnings, paradoxical anxieties and near-painful renditions of the 'good' that new parents hope(d) the school could do are important elements in many histories of early engagements with the school. I discuss these in more detail in section 10.5 
For others, this ideal vision of childhood is not merely evoked with the buildings, but found in a total world (cf. S, above) into which children go:

M It's meant to be dreamy and sleepy and, in their imaginations, in their own little cubby-hole kind of areas. Playing with dolls, or playing kitchen. Going off to imagine, role-play really. And also, a lot of what they've experienced at that age is just like being in the home. So they want them to feel, I suppose what a Steiner home might feel like. Like, there was a little kitchen in each classroom, and they do baking. Because I suppose proper Mums would do baking (laughs through last phrase), and they do little bits of carding sheep's wool and knitting... (Former pupil, female ${ }^{2}$ )

As a result of these and very similar comments regarding the ways in which the school caters for children's needs holistically, I discussed these elements informally (off tape) with one of the Kindergarten teachers, whilst in the Kindergarten. She agreed with this assessment of the early years education in particular, and the importance of activities like baking, role-play, unstructured play in the woods, and story-time, in the production of such an atmosphere (see section 10.3 for more detail). However, she stressed - as did other teachers - that for older children, although such homeliness and the possibilities of exploration in a safe, rural environment were important, there were also other concerns, geared around that age group's (4-7) specific needs. Hence the importance of 'home' was particularly important to this particular age-group, rather than the school as a whole. However, this was one of the pervading discourses and 'goods' that emerged in almost all interviews, and was forwarded as a key reason for keeping the Kindergarten buildings during the present crisis.

Therefore, the idea of home incites a variety of utopian concerns around childhood, nostalgia, homeliness and certain 'goods'. Inevitably, however, these seemingly coherent ideals are interrupted by other practices which highlight how comforting and homely (yet how contingent and unstable) those ideals are. Firstly, with the concerns of new parents and the increase in discourses about accountability in the last twenty years

\footnotetext{
${ }^{2}$ Ironically, this quotation comes from a former pupil. She was however acutely aware of Steiner's phiosophies and those structuring the school, as the daughter of one of the founding members.
} 
in the UK, Health and Safety regulations have compromised some of the school's aims. These are often geared around use of buildings:

S Well, the school has changed in that, when we started, it was just people wanting to to carry out their ideals. And, then, over the years, things like Health and Safety, and all these sort of legislations all of a sudden, they applied to you as well. ...Fire officers come along and then they'd say, oh, you've put a cooker in this room, you have to have a fire door. So, all of a sudden you had to become more aware of that. ....all these things that would risk the, not at all in our realm. ...And these, mad rules came out where you weren't allowed to touch children under any circumstances. Which was so alien to us, you know, if a child cried, you'd put a child on your lap you know. ...It was like being thrown into, into a colder, colder time all of a sudden. ... Yeah, I mean, some people may say it has dragged us into the Twentieth Century! But it was maybe, leaving this sort of blissful and rosy time behind all of a sudden. (Female, founder, ex-teacher, parent)

Health and safety regulations are seen as alien to the ways of working at the school, in particular to the ad hoc way in which the school has been built and the 'alternative' identity of its community - people carrying out their (utopian) ideals. These regulations have proven problematic, particularly in connection with the unstable financial future of the school, and are engrained into debates about the directions the school should go next. These take in discussions regarding the best identity(/ies) Nant-y-Cwm should try to present, and how the construction of a safe environment should best be actualised. But they highlight how certain activities - cooking and putting a child on your lap - are associated with more homely, 'rosy' times, which are very much the ideal of Steiner education at whatever age. Moreover, there are different versions of 'safety', 'home' and comfort here, competing versions from Health and Safety boards and from the 'traditional' view of the (Steiner) school, performed in locally specific ways. Although potentially dangerous to the future of the school, these Health and Safety and financial concerns have opened discussion up to the multitude of ways in which the image and nature of the school is perceived and constructed, as well as the ways in which its past, present and future can be imagined.

In many ways, the buildings symbolise and are performatively drawn into a Steiner education which provides a general and also local (Nant-y-Cwm) vision of childhood. 
For some parents (and ex-pupils), this seems to be as much for adults as children, as they almost live their fantasies of (re)turning to an ideal childhood through their children. Yet it would be unfair to characterise parents as selfish enough for this to be the only aim, or indeed suggest that 'homeliness' or 'free play' are the fundamental ideals of Steiner education. Instead, the curriculum, as it is performed at Nant-y-Cwm, provides a set of ideals which view the developing child in a particular way, through which an educative environment and 'learning' are produced. These should be more sensitive to that child's developmental needs - and hence allow them to develop more fully. The 'rational' and 'emotional' are hence intertwined (also with a rural idyll) to produce various utopian versions of the good childhood or education. I will now turn to some of the specific practices through which this homely education is constructed.

\subsection{Performing a 'homely' school: Structuring the day}

Here I wish to stick closely to how particular atmospheres are performed and called upon in relation to those general philosophies and their combination with the specific underlying ideals at Nant-y-Cwm, as well as exploring the place the buildings play therein. I want to be clear that Steiner education is seen as art and performance based, and that the creation of a performative learning atmosphere with a variety of elements is key. Hence (as in Chapter 9), activity is not merely about the construction of homeliness, but set into finding a 'fundamental experience'. The next quotation illustrates and contextualises this:

PK How do you feel are the best ways to help a seven year old child develop in the best directions...?

J The most multi-faceted way possible, you mentioned earlier art and movement and so on, and these, are considered to be the realms in which a young child lives. ... Ideally, in a Steiner School, a lot of subjects are taught, using movement. And, the rhythm of the school day is structured such that a child won't have to sit still at their desk, all day long, there are periods, when we get up...then we do some more, heavy, work again, writing or whatever, and then again there'd be movement physical activity but, to do with the subject you're working with. So, children learning the letters of the alphabet, again at the age of seven, not before. They might spend part of the morning playing different games with straight lines in them, and then you're running 
in curves. And out of that come letters of the alphabet. Then we'd have stories about the letter $b$ and the friendly letter $b$ who's a big brown bear...little rhymes things like that, they would live the whole day with the letter $b$, the sound, and then the writing. So that it really lives within them as an idea, as a representation of the sound, in all its different ways. So there are as many approaches as you can get, as possible, to a fundamental experience... (Teacher, female, five years)

The buildings are drawn into this educative ideal in particular ways, not explicit to this teacher's argument, but embroiled in the changing fabric of a typical day. The knowing creation of atmospheres or rhythms gives discursive weight to some of the arguments I forwarded about the party in Vienna, in a more generalisable sense. The use of desks, spaces, materials and the differential moods activities such as drawing, sitting, running and listening are carefully planned to produce particular situations, but which are also set within the general schemata of Stockmeyer's curriculum. These rhythms, so crucial to Steiner education, are always created through readings of the curriculum, which are then worked through available materials, classrooms, the weather (for outside activities), the lighting, the teacher's abilities and the children's agencies. The idea of 'home' loses weight here, as children 'come out' of the Kindergarten world at age seven, yet we still retain a sense of a 'fundamental experience', and how this is produced. We must also not forget that the sense of a 'rosy' time that $S$ mentions above applies to the school as a whole, so that certain facets of a comfortable or comforting schooling are folded into these everyday practices.

As I have suggested, it is in the Kindergarten that the idea of homeliness is most apparent (as $\mathrm{J}$ stresses, the age boundary for reading/writing is age seven, when the children leave). It is instructive to hear how, through the buildings, a typical day is constructed there - elements worth quoting at length:

PK I was wondering if you could tell me a bit about the sorts of activities that you do in the Kindergarten.

F Do you want me to run through a typical day?

PK Yes, please.

F Well, we follow the same kind of pattern, each day, but the activities we do vary, but they're fairly constant weekly. On Monday, we start with an activity, and both groups do baking, the children all join in. Then, as they 
finish, they go off and play, they probably have an hour, of free creative play, where...they're free to do, what they want with things, they quite often use the big furniture like tables and chairs, put chairs on top of the tables, then it's a space rocket, or, they make houses or dens...

PK So did they put these sort of shelf things here, to make a little den?

Well, yeah. They can re-arrange things however they want... . Some mornings it needs a bit of help, there's always a bit of kind of intervention that needs to happen as well. But this group actually this year's been pretty harmonious, so if it's really working well, then l'll quite often just sit somewhere and get on with, something. I think it is quite good for them too, I mean that's in a way the ideal, you know, that, the adult is busy with whatever they're doing, and the children play! So, then about half past ten ummm we tidy up, try and encourage, that's supposed to be a communal thing. ...They're supposed to, do it by imitation (laughs quite long, loud)! And we vary it depending on what time of year, or how the groups are, or what's happening. ...So we set it all up, laying the tables. And the children actually help prepare the food. On Monday they bake, on Tuesday we have apple crumble, an, my children chop the apples, and Anita's group do painting that morning, but then they make the crumble part, and put it all together... . And then after we've eaten...we have outside time, until, about the last quarter of an hour, when we have a story. For outdoor play, we either go up to the school, where there's more space, or up to the forest.

PK For example for the children's free play, are there particular toys or objects that you think are particularly important?

F Well I think it's really important that, it's natural materials. Because I think, the feeling behind that, it's a kind of truth in a way, it's something real, as they would find in the natural world. ...And also simple, things that, the simpler they are the better, because they use their imagination then....And different groups are different. (Female, teacher, parent)

What becomes clearer through this extract is how specific rhythms are produced, how these are both repetitive, yet particular to certain groups or favourite games, and how this is bound into Steiner theory and the general ideals/difference of the school. The use of particular objects, initially chosen with care by the founding parents and teachers as they furnished the buildings, represents an interpretation of the Steiner education through a system of objects and built spaces - 'a kind of truth', as F says, like other teachers. This system is also designed to produce a warm, cosy space, a 'haven for childhood'. Here, smells of cooking, story time, and imaginative play are designed to $s(t)$ imulate a home environment which protects the children from the excesses of the 'outside world', providing a truer space within which childhood can be performed (unrecorded discussion with Kindergarten teacher during observation, 06/2003). As I 
mentioned above, 'free play' in particular is strongly associated with the other elements of a Steiner education (performance, art, homeliness), and ties together many of the important elements of that education which render it at least in its ideal state (as $\mathrm{F}$ notes), an example of organic, imaginative, harmonious play through which children learn 'life skills' like co-operation and communication (Bruce, 2003). This is a strongly utopian position in various ways: through the importance of education ${ }^{3}$ to the production of a utopian society, and utopian themes such as inclusiveness in that education; through the part this plays in the general atmosphere and aims of the school; through the relationship between a 'right' childhood, play and home; and in relation to euphoric moments of memory (for $\mathrm{M}$, above, and $\mathrm{N}$, in section 10.5) The ways that the children interact with this process is the topic of the next section.

\subsection{Children's use of the school}

The school system is entered into by children who, although their activities are structured by the curriculum and teachers, are allowed to use and re-use objects and spaces, creating imagined shops, homes, space rockets and so forth in the Kindergarten. As I observed at the Kindergarten, these activities are highly repetitive but are of course un-scripted, games with no particular outcome, with no real aim, yet which children can silently agree on, in the production of a space or atmosphere somewhere in between the individual and collective body. The natural materials they use draw them into creative games based around role-play and the imagination, resulting in highly unstable situations as in a sudden moment a shop becomes a space rocket, a child falls over and starts crying, another leaves one game and joins another group, or one child takes a wooden block from one game into another so that it becomes a completely different imaginary-yet-real object. A couple of examples of 'building-assemblage events' from my notebooks hint at this:

\footnotetext{
${ }^{3}$ In a recent paper Sargent (2004) argued that education was crucial to utopia. This conclusion emerges from this chapter in many ways, as well as that an ideal education can in itself be a utopian good or experience in various ways.
} 
There are only five children in the class but it is difficult to follow everything that is happening as it is going on so fast. Do I follow an individual child or one of the groups? There are different games which cut across each other. I hear various commands and conversations at the same time: "You can be a shopkeeper": "We're going to be late": "He's coming in to our house - I don't want to let him in" and so on. One of the alcoves has become a house, where there is going to be a birthday party with food made out of wooden bricks and fir cones, another boy is hiding under two upturned chairs with a curtain over them.

[In the room with the older class] $X$ sets up two standalone, non-backed bookshelves. He gets out cones, bricks, books, pots (for the lucky dip) and so on, which are chocolates and sweets. He sets them out carefully, letting me help. "It's been his game this week. I think he got the idea from the festival last week, and his parents are helping out at Glastonbury. He spends ages setting out the shelves like this every day and only has about 5 minutes to play at the end!" the teacher tells me. Behind the shelves he puts up a curtain, so that the alcove becomes the back of his shop. Then we have to make money for the shop, so we and another girl chop up bits of paper and scribble numbers on them. Then I buy various sweets from him, putting them in a basket he has got for me...

Two children are making a home in an alcove. At the same time, $X$ is sitting on the tables in the middle of the room whizzing round and round. Suddenly, two 'tigers' come running around the tables, roaring, looking for their den. As I watch them, I hear banging behind me and the table in the centre of 
the room has turned into a space rocket, with chairs for seats, and the alcove that was a home is now their base, the children are all shouting and pretending to make the rocket take off, and the echoes in the room [the acoustics are quite poor in certain spots due to the domed ceiling] fill the space with a deafening, high-pitched imitation of a rocket engine and the children get down from their chairs and run round and round the room as if traveling at high speed...

These excerpts tend to deaden and simplify the movement and atmosphere that the children created. Their creative use of objects is at times quite bewildering for adult eyes. Likewise, the speed (and lack of discussion) with which games, spaces and objects can be determined and agreed upon by a group, and then changed only moments later, is quite confusing. The ways that different objects become centres for attention as quickly as they are forgotten, as well as how an object can instantly change use tacking together a silent but strong agreement between children as to the focus of a game, attest to the power of the relationship between the imagination and material objects in children's construction of their own atmospheres, and the part these play in the general aims of the school day and Nant-y-Cwm's education. These games are quite different from the apple-chopping and story-times that make up other aspects of their days, with a different feel, and are part of the days which are punctuated by different rhythms, so that each activity is bound by the last and the next: "[T] he way you teach, in a rhythmic way, working with the children's rhythms... . The first things when the children come to school is to have an activity where they can breathe out, they can go out....So let them go out, they have free play. ...And then, when that's exhausted itself, which it will, you bring them back in again...to something more focused. ... And do that for a while, and then out again...we'd do this rhythm about seven or eith times in a morning, and you get the children working with you..." (teacher, male). These generic and specific rhythms are a crucial part of the children's formative years, and seen as truer to what children 'really need' by most of the parents and teachers. The children's free play in particular (as a crucial part of the curriculum), however, and their lightning fast use of space, 
highlighted to me how situations, atmospheres, meanings and consensus are contingently constructed through a conflation of subjectivities and materialities. As children prepare themselves for the world 'outside', and learn to negotiate the spaces, issues and activities which we as adults see as more serious, 'real world' concerns, we can see more explicitly through such openly changing situations how we construct our uses of buildings and the rhythms we make with them. These are similarly contingent upon the unsettling realities we construct out of them. These children's play, and the skillful if raw way they create situations as their realities - important to them - is highly suggestive of the ways that people are continuously dwelling in and out of buildings and how other atmospheres (such as a birthday party) are created. I think more critical geographies of children's use of architectural spaces could take on these concerns more broadly than my time-frame enabled me to do, yet these insights and those below begin to illuminate the ways in which children performatively co-produce the rhythms of a school day. They are enabled to take part in this homely atmosphere in and through the performance of play and learning: but whether this makes a difference to them it is perhaps impossible to represent. In the context of this thesis, the children's part in preparing apple crumble, taking part in story-time and in 'free' play, contribute to the performative geographies of the school, in particular as an idea(l). They also illustrate the ways in which homeliness is negotiated between teachers, parents and pupils, and how this was then translated and explained to me in interviews.

At the main school, I was able to observe children's free time in the playground, as well as the flow of their lessons. As parents and teachers stressed, older children's lessons are highly structured. For instance, at the beginning of each lesson, the children are asked to calm down and concentrate their energies on the task at hand. I used paintings in lessons with different classes to instigate conversations about what I had observed, as well as explore children's general attitudes to the school. As with the Kindergarten, these were often far from utopian, but a couple of examples illustrate the powerful, euphoric and nostalgic connections the children forged with the school, comparable with some of the feelings evoked in section 9.5. 
The first example is Daniel ${ }^{4}$ (age 13). Although I do not take the children's paintings to be representative of their feelings about the school (as they were merely asked to paint or draw 'my school'), I would like to re-produce Daniel's drawing below (Figure 9.1) to indicate that which incited our conversations. The image itself is relatively unsual in that it shows the view from the school onto the playground and perimeter wall rather than children's more usual choice of the front of the school itself. Yet Daniel's reasons for choosing this place were more than chance, or aesthetic judgement of what might make a 'good' picture.

For him, the wall either side of the gate was a key place in his school life $e^{5}$ :

PK So you're doing the front of the school? (He nods). What's this bit here?

D It's the wall outside the school.

PK Why've you done that and just the bottom of the school?

D It's very important. I sit there every morning before school, when I'm waiting, and watch people. I always sit there. It's my favourite place really.

\footnotetext{
${ }^{4}$ Children's names have been changed to protect their identities.

${ }^{5}$ To keep conversations informal, none of them were recorded. However, I took notes from them, and edited versions of these are included here.
} 


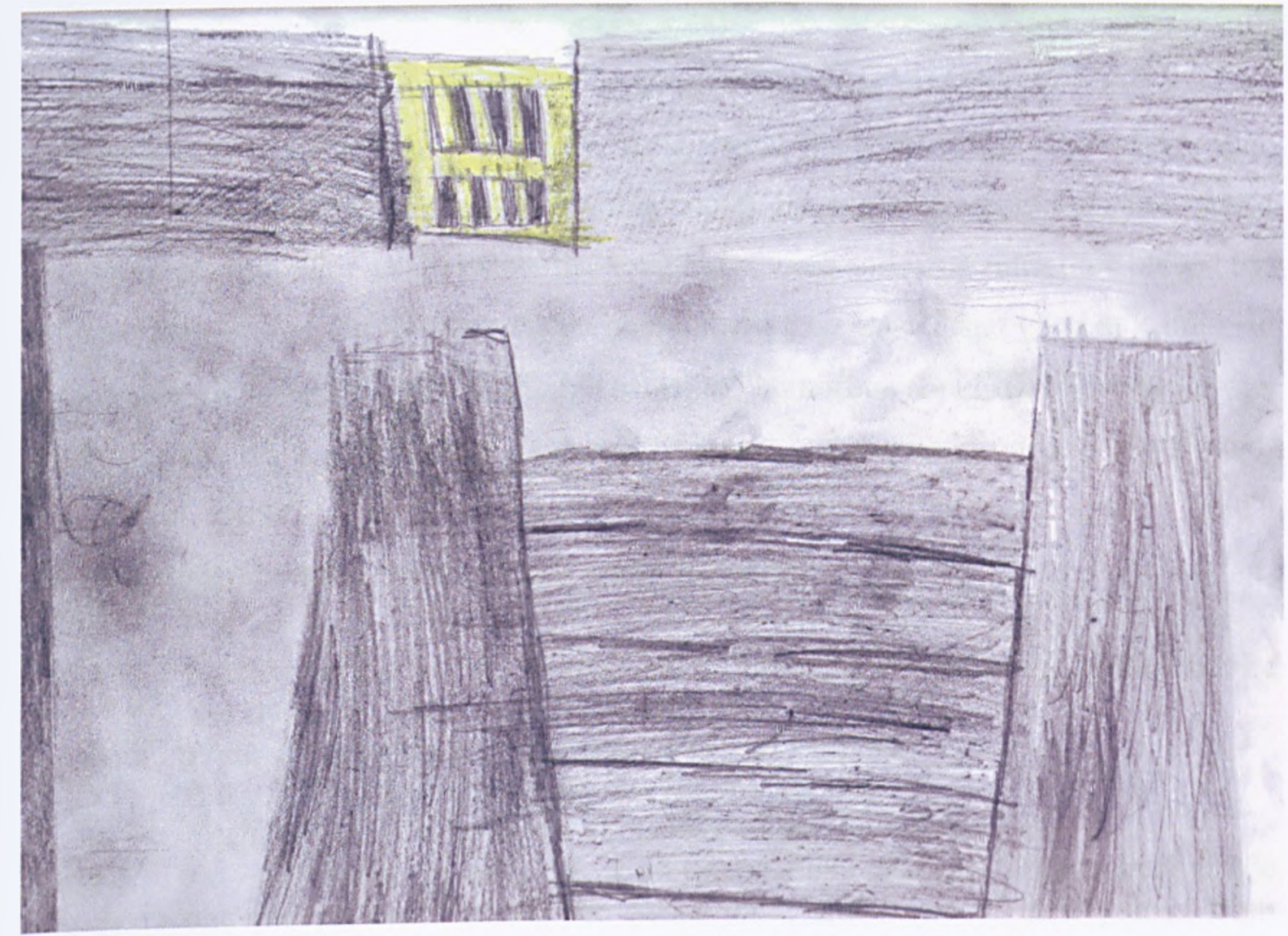

Plate 10.1 Daniel's sketch of the steps and wall at the front of the school (from the main school's doorway)

Daniel went on to discuss who he sat there with, and the importance of that wall in structuring his day at school. The fact that he has a good view for watching people is also crucial to him. He likes to be involved with everything that is going on at busy times, such as first thing in the morning. Yet he himself is not always involved in all the games the children play, so uses the wall and its vantage point as a way of becoming involved without active participation. It is both an object or structuring division in his experience of the school(day), and a point from which to see without always being seen, as well as a phenomenological symbol of his (repetitive) attachment to certain times of the day when he can sit and observe the varied movements of parents, teachers and children. Repetition is also a key element of performativity (Szerszynski et al., 2003), as much as that of newness - and is a key aspect of dwelling at a place (literally returning to the same site), however much new situations are co-produced in forever-changing assemblages, collections and encounters of spaces and other actants. 
Later, we talked more about some of the games I saw them play during breaktimes, as well as about Daniel's future hopes (including what his ideal house would look like, replete with crazy lifts, slides and swimming pools). He explains one of the games I had seen them playing with a ball, where the boundaries were and what rules they played by. He was often one of the first out of that game, feeling he wasn't that good at it but also that he was victimised slightly (although remained humorous about it). However, it was in his description of the football field that followed our discussion of the playground, that Daniel showed a yet more intense engagement with a particular space ('field') whose boundaries and meaning he defined as we spoke:

D I still want to draw the football pitch (not another view of the school that he had been advised to draw by the teacher).

PK Well, it's not as interesting as the building I suppose.

D But it is. We play there every day in the summer.

PK Yeah, but it's hard to draw. It's just a patch of grass - all green.

D No - it's not all green. Look at all the bare bits of earth. I know every single one [he proceeds to tell me about them and some of their games from memory in great detail].

PK So there's more to it than a patch of grass?

$\mathrm{D}$ Yeah, where we play every day. And people get kicked in the shins.

PK How come?

D Errr - that's usually me. I don't do it on purpose...

Why he remembered the field in such detail, I am unsure. Still, it is the deep attachment he holds with the place, through performative acts as simple as kicking people in the shins that mean the place, collections of various memories, and his relationship to the other children that are all combined in the sense of nostalgia and the massive details he conveyed through our discussion. From activity centred about the buildings, and his repetitive use of the wall, we have come away to the football pitch (which is a field also used for other activites). In our conversation at least, the wall and pitch are linked together as two of the most important elements in his own network of school spaces. Additionally, he will appear at the wall and pitch again tomorrow and the day after they are also continuous materials and spaces within which our conversation was located, and both of which we could see from where we were sitting. They are thus also 
the locus for hopes and desires for the next football match - interacting with the ground and kicking shins - or the next quiet time, sitting on the wall, just watching.

A second example came from Joanna (age 12). She was drawing the wooded garden area outside her classroom, focusing on some of the building projects (a bread oven, a barbeque) that children had constructed during their earlier years there. We talked about her drawing:

PK So how come you're doing the fireplace?

M I'm drawing the garden. We made that (wall-like structure) in our building main lesson. But I used to play here when I was younger, all the time. We used to like coming under the trees, away from the rest of the playground, there are some bits where no-one can see you or hear you.

Like Daniel, she reasons that she chose to draw this as a result of her previous memories of the school. In fact, on a few occasions, I had seen many of the younger girls playing there whilst the boys played ball games on the playground (although this changed quickly, and there was no real split between the sexes), the girls engaged in 'secret' play or conversations. Here was a place that the younger children go, to hide away or be in private, but which Joanna no longer used. Clearly, certain places seem better at certain ages, as well as they are seen to be used for and by certain groups. Additionally, the importance of various building projects as a centre for memories of those times, as well as of the activities that went on there, highlight again the place of such small objects in the embellishment of memories and engagements with places (somewhat like shells in Bachelard, 1988). 


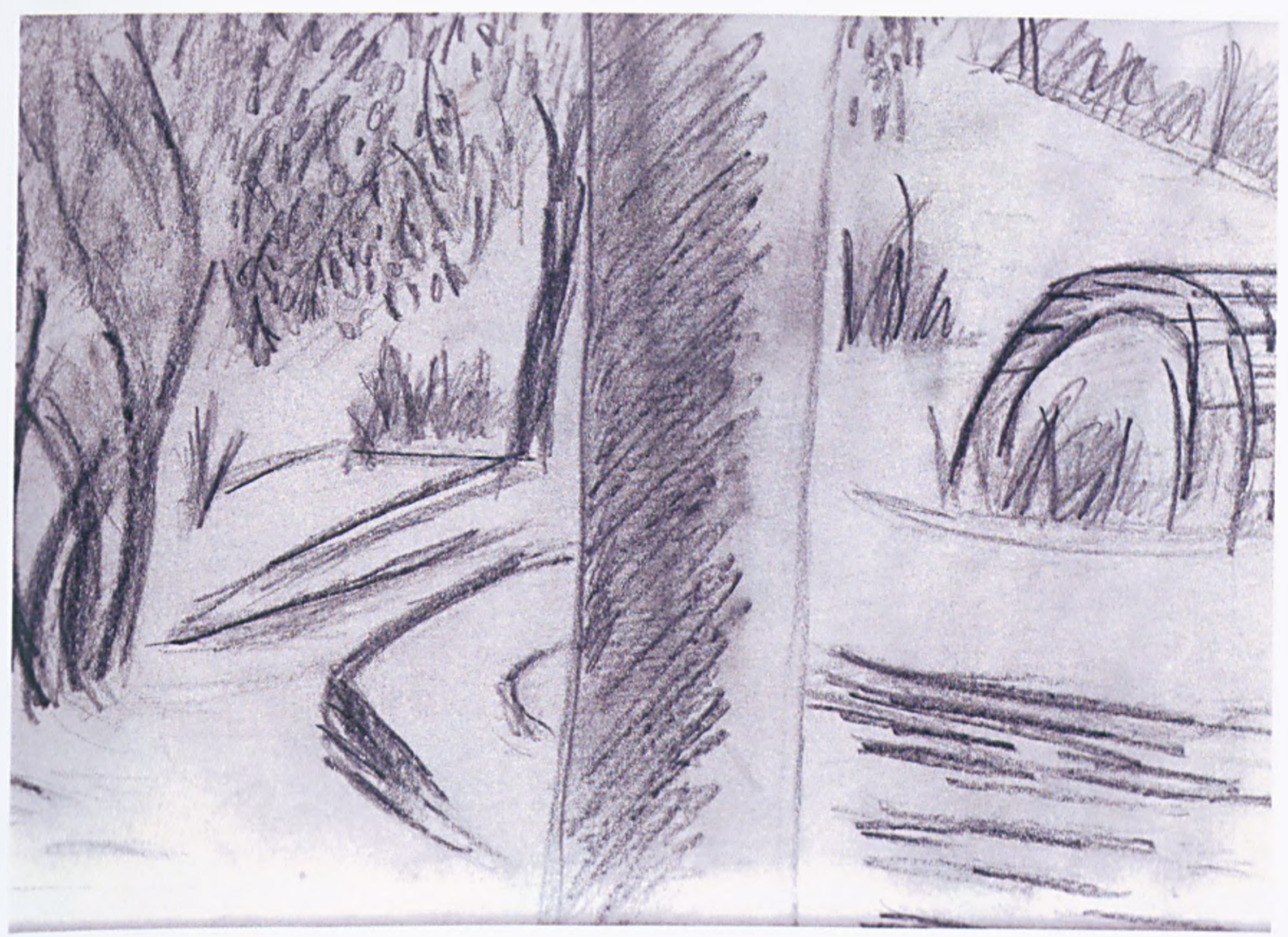

Plate 10.2 Joanna's drawing of the woodland area, with trees in the fore- and background, and a bread oven to the right.

Finally, the painting project with the youngest class we worked with (ages 8-9) initiated a fascinating debate between several girls about their time at the Kindergarten and certain particular events. I could not follow the conversation in detail, as it was not taperecorded, but the general gist is below, following one example of the paintings of the Kindergarten they had been asked to do. 


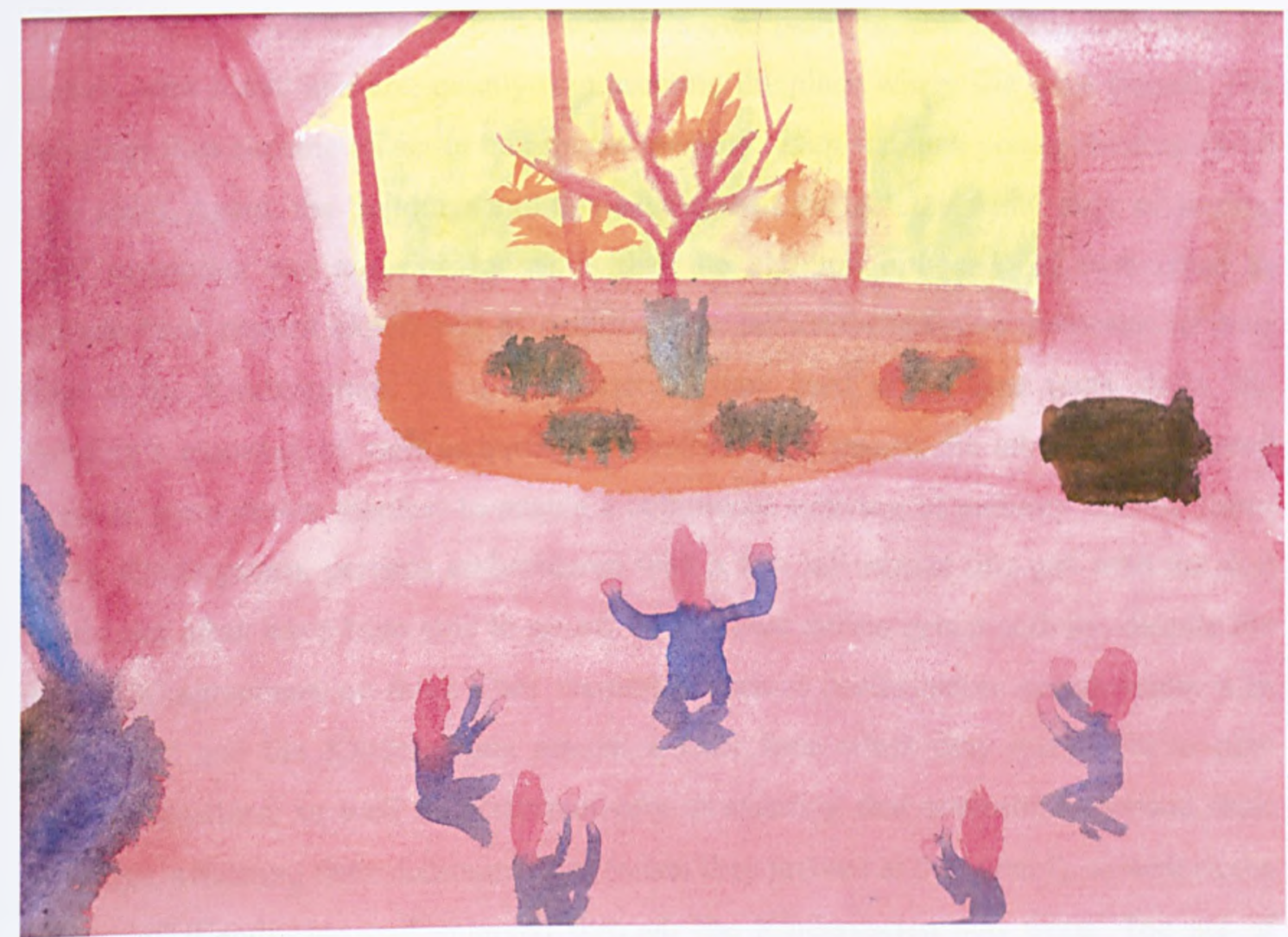

Plate 10.3 An example of one of the paintings of the Kindergarten by class $2 / 3$. Each of them copied the basic background from the teacher, but then added their own activities and materials (flowers, plates, people), all from memory.

I did not take part in the conversation, or instigate it, but merely came over to listen while they talked about events from two or three years previously. Like adults reminiscing, they huddled around together whilst painting, recounting stories of, in particular, when they were free to choose their own activities. Interstingly, then, the free, creative play which is a key part of the early years education was obviously enjoyable and memorable to them There were various stories. There was a story of where one had dragged another around the room. Two of the others re-played the conversation of when they had first met in the Kindergarten. They then tried to work out who was the oldest or the first there (so that a couple of the boys then join in the competition!). They talked about how they had sat in circles, playing memory games, singing, or having stories (and then transferred that into the picture above). Another mentioned how one of them often went off and did not take part in lessons, depicting her in another picture sitting in one of 
the alcoves, playing with a doll. In the latter's own painting, she showed herself, in an alcove, with a doll in a cot, quietly re-presenting the place where she once played. The paintings thus became an act of communal memory, even for such young children (8-10 year olds). Again, the buildings and this activity had instigated a wide range of stories, brief memories and amusing moments that the children bounced off each other to enliven their present experience of painting, and personal-collective memories of their time at the Kindergarten. Thus, the materials they used at the time (cots, dolls, the building's alcoves), as well as during this activity (the paints, the table they clustered around), were drawn together to enable a communal weaving of memory of their times at the Kindergarten, perhaps embroidered with a few tall stories (the girl with the doll would not often have been able to go off on her own during group activity, despite the two girls' agreement on this). They recounted various performative engagements with each other and the Kindergarten, almost a freer time when they were able to play without structure, as well as performatively re-enacting that community around their paintings, affirming their commonalities (when they arrived at the school), as well as the groups of friends that had emerged through the Kindergarten and since. The act of remembrance through such materials and performances drew them together, on that day in 2003, in that classroom. This again highlighted both children's phenomenological attachments to the Kindergarten through the specific and generic combinations of building spaces, materials, activities and other people, as well as their construction of memory, commonality and friendship through the materials they are provided with, and their own creative appropriation of a situation.

I do not wish to make any more of these situations than necessary. However, the act of memory, of commonality, and activities done and explained through the buildings, other artifacts, and other people, all hint at the ways in which the school is constructed and interpreted in an on-going sense by the children, in what I found to be often intense ways. This can only ever be done in relation to the ideals of the school, and the ways these are enacted through the parents and teachers who built and continuously enact those ideals. At times, these might be subverted, twisted, followed obediently, but those ideals are always constructed in and through such power relations and performative 
rhythms. Although the general aim might be to construct an ideal education with the children, they may not always be on side, however 'true' that education might be to their needs. At the same time, every effort is made to accommodate the tensions that arise in between the structure of the Steiner curriculum and its and children's own freedoms, so that a continual process of negotiation allows those ideals to become part of, not necessarily and end goal for, the everyday performances of which I provided examples above.

Wandering around the school at break-time, I witnessed fast-paced games, children rushing through an open door, chasing each other through the doorway as I held the door open, as they shouted after each other, feet stomping on the wooden boards. I watched a fight break out, someone cheat at a game, and a basketball game stuttering, as the children quietly awaited permission to retrieve a ball from the road. I meandered around outside the school as members of the oldest class sat in different positions outside, drawing the school, and stopped at different points to talk with them as they sat quietly, or suddenly ran off as either myself or the teacher disappeared, to throw bits of paper in through a window, only to stop as we returned. However, many of them produced excellent drawings, still working hard and producing fascinating insights into their lives there. The building was thus a focus for their attention (as well as a protection from mine and the teacher's) and a perimeter wall around which I walked to observe and talk with the children at various points. Through what I observed, and was told, and my own engagements with life and teaching at the Kindergarten and school, it became apparent that the ways children encounter and perform the rhythms of a day, or the ideals of an education, are often messy as Lees (2001) suggests. Yet they are also structured by those ideals, by parents and teachers, and by their own concerns, such that the buildings themselves are not only messy, but tools in more coherent memories, evocations of past times, used in fast-paced games, or in the enactment of a friendship group through concentrating on the buildings, their meanings and their past/present/future use. In terms of a critical geography of architecture, the buildings are thus settings, part of rhythmic performances, instigators of artistic and discursive conversation, tools or materials within memories, and/within spaces-in-formation, in-memory, and in-the-future. They 
are points for a collection of activity or memory, but evocative of other memories (being in the Kindergarten), or elements within fields of memory related to detailed observations and engagements with particular bits of them (as for Daniel). They are also elements within wider collective ideas about what the Kindergarten was like, free play, where one played as a youngster, and millions more, making their way into teachers', parents' and ex-pupils' depictions of the school and education. They and their ongoing use by children are part of the wider ideals of the school and its community, as well as those ideals themselves become embroiled back into children's ongoing use, memory and hopes of the school. These are perhaps quite generic moments, no different from any other schools (especially Steiner Schools), yet in the enactment and negotiation of an education by the children, specific, rooted memories are produced through 'memorable' performances at the school.

Finally, I would not suggest that any of these moments are in themselves utopian, or specifically related to the idea of 'home' (apart from perhaps the last example). They do highlight moments of euphoria, worry, and nostalgia, and that 'even' children can experience those moments both individually and collectively, buildings and spaces being inherent (but only as they were/are enlivened by action) to those moments. They may well be looked back upon in later life as utopian, nostalgic memories, but to predict this would be foolish. Similarly, however, it would also be dangerous to assert that children do not feel strongly enough about places, about their everyday enactment of those places with others, or about their hopes/fears for those places. They are by no means incapable of feeling utopian emotions that are anything other than momentary fantasies (like Daniel's ideal house might appear). For, if we examine M's quotation in section 10.2, stronger memories related to dwelling and home are apparent, even if the specific idea of home did not emerge strongly (if at all) in this section. Despite this disjuncture, it is also through parents' and teachers' joy at experiencing their children's time at the school through these instances, that almost doubly nostalgic emotions are experienced. This brings us to specifically utopian moments that emerge from particular foldings-together of homeliness with children's actions, and the general setting of the school. 


\subsection{From constructions of an ideal to ideal constructions: utopian moments}

The construction of the school as 'school-like', 'homely' or 'Steiner-like' is thus bound up in complex bundles of changing and conflicting discourses, practices, materials and emotions. Often these are highly problematic and quite far from ideal or homely, let alone evoking utopian practices or imaginations. However, there are three ways in which ideal or utopian situations are constructed out of the specific combination of materials at the school (through the way it was built), which tally with the party and marriage-time in Vienna. The first is that in the search for solutions to problems at the school, many make a nostalgic appeal to the past, and in particular the community spirit that grew up at the time and the material fruits of that in door-handles and windows (Chapter 12). The second is that although they are not utopian in themselves, children's play activities unsettle in themselves (explicitly displaying contingency and unknowability yet an almost telepathic compliance) and are bound into the larger-scale rhythms and 'breaths' of a day, week or year, and the notion of childhood this determines. They occur in an environment constructed for them (designed as harmonious) to carry out those actions, but whose meaning and performance is also perpetuated and questioned by these actions. Perhaps the whole experience affects a visitor who comes to see at first hand what goes on there, as did a couple of prospective parents when I was there: they were suitably impressed.

The third way, which I wish to briefly focus on here, also relates to people's early experiences of the school, and the ways that the particular assemblage of forces combined there to create a powerful and often identifiably utopian experience. These display aspects of the pain and uncanniness of the utopian unsettling, and in some ways represent 'honeymoon' periods, as at the Hundertwasser-Haus. Rather than the general meanings encountered earlier, it is specific instances or collective individuations that concern me. We must remember, however, that it is through these, as well as readings of the Steiner curriculum and more general conceptions of a comfortable, homely, childhood, that ethical versions of a 'good education' (section 10.2) emerge. Rather than 
analyse each one separately, and also rather than letting each simply speak for themselves, I make some brief general points after presenting the excerpts.

PK So what were your, first impressions of the School?

C I thought it was fantastic, I mean it's magical, you know. I thought wow! Just, the whole thing is beautiful. And I came in the spring, when it's lovely. And, the Kindergarten was just so brilliant, and going down to the river. ...It just wowed me really, just the whole setting. And I loved the fact that the School is an old-fashioned stone School is really nice. And it's just lovely the way there's, flowers everywhere, and the paintings on the wall up the stairs. And, it all seems really, so different to anything. The styling of the inside, you know the rounded corners and everything, was just so different, it was brilliant, I thought it was fantastic. (Parent of five years, female)

PK What were your first impressions when you came to this School?

J I was visiting a friend, and it was almost painful [my emphasis], because I liked it so much. I was living in Scotland, and I thought, I'd really like to send my children, but I don't suppose it'll ever happen. It was all quite painful (laughs quite long, quite loud)! It just looked very idyllic to me, very green and, slightly scruffy. Homely. Nothing clinical. Which a lot of School have got a clinical air. Yet still, ordered. Everything runs on time. Actually I'm sure it's not like that if you talk to the teachers. (Female, parent, helper)

$\mathrm{N}$ The other day we were talking about playing, And I thought, the best morning I had in the Kindergarten, was a rainy morning. And, we said, let's play hospitals. And the whole group, found each one could play a part. They turned the tables upside down and they put cloth in there, to make the beds. And, we had the hospital shop. Then, there had to be the ambulances, and the patients, of course, and the nurses and the doctors, and the visitors. And, it was like magic. They all found their place within it. That happens very rarely. You know. And then you think, oh, what a wonderful thing. Because the children, they were themselves, and yet, totally committed to what they were doing together. And then you think, well that's the most healthy, thing that can happen, for a child. That is one. At other times they quarrel. Other times they are disturbed. Other times, you know, one child can make it difficult for the other. But, that was such a happy, a happy morning. And they were all together. And it kind of evolved. You call that creative play. What else? We've had lovely, festivals. Also with the Maypole dancing. That was joyful. You know, colorful, joyful. (Female, founder, ex-teacher - left over ten years ago)

Apart from the third, these quotations deal with people's intial reactions to the school and in particular the Kindergarten. All of the excerpts do have certain things in common. The use of language, in particular words like 'joyful', 'fantastic' and 'painful', draws on 
a strongly emotive vocabulary which again struggles to come to terms with the atmosphere, feeling and materiality of the situations themselves and their replaying through memory and dwelling. Another commonality is that the initial reactions of children are hard to tease out here. This is partly as most have no experience of any other school, and partly as many of those I did talk to who had moved schools, had no real memory of specific experiences in the Kindergarten, let alone the first few days. However, as I have been stressing, the children are a key part of the constructions of joy, phenomenological pain and the 'wow' factor of an initial visit, or of a chosen memory of one of many moments in the classroom from over ten years in the past. Such specific events, rendered idyllic or nostalgically memorialised as euphoric, are particular configurations of the school's ideals, the children's rhythmic and often repetitive days, their particular creativities on that day, and the materials made available to them. Interestingly, their work, in paintings, texts, songs, dance and festivals, is a constant source of emotive force for proud parents and teachers, as well as a symbol of what the school as a whole means (however incoherent that is). These too represent and perform for teachers and parents the ideals of the school, as well as material and active events which remain in the memory as moments of happiness, nostalgic pain, or even an almost carnivalesque euphoria.

Other elements of these quotations are similarly prominent. In the first and second, there is a complex evocation of homeliness, scruffiness and order, all of which come together to produce an initial image which is magical and fantastic. Crucially, this is also 'different' from anything $C$ had experienced, so that again, the homely and difference intersect at the meeting of architecture, practice and environment in a profoundly utopian sense. This sense, although contingent on the specific collections of actors involved, and although contained within a lived moment rather than ideal plan (and hence unsettled), is I think more traditionally utopian in terms of comfort, order and homeliness. This demonstrates the inter-play between the utopian unsettling and more 'traditional' versions of utopia. In the final excerpt, the ideas of magic, happiness and joyousness recur specifically through the crossing of children's play with the ideals of free play. These again relate to enduring concerns in utopias and in relation to social 
harmony, which the children literally played out: total commitment, all with their own place, togetherness. All of these are qualified in relation to other instances of play (quarreling), against which such ideals are measured and through which events, and ethical 'goods' are encountered and emergent.

Additionally, these events both make space and draw on the particular combinations of spaces and materials at the school (as with the married couple in Vienna). Had these been slightly different, they may not have been experienced with the same affectual potency (something troubling in itself - could events have happened better?). Neither the creative force of what could have been (Harrison, 2000), nor traditional utopias themselves, as what could have been, or as expressions of lack or longing, grasp the evocative power of these moments, as they happened. They are contained within the fabric of everyday life rather than outside it, constructed out of particular situations, felt as floods of delight so strong that they are painful, and remembered with the same joyous force, glazed eyes and lost expression as certain events at the HundertwasserHaus.

\subsection{Conclusion}

From section 10.4 in particular, it becomes apparent through children's play that the idea of home is not the only concern that underlines the performance of a 'right' or good education at the school. However, they, like their parents and teachers, hold fond memories of other times at the school, and the Kindergarten in particular. These are held within an embodied, enduring sense of $d w e l l i n g$ and homeliness at the school.

Perhaps most uncannily, the school is not a home. Yet, specifically for younger children, but also in terms of the school as a 'haven' against the seeming excesses of modern life (compared with a 'rosy' time), the idea of homeliness within this local version of Steiner education is prevalent. There is an interesting comparison between two versions of the safety/risk that emerge at the school: the unsettling (for one parent at least) coldness of Health \& Safety versions of children's health, versus the worrying (for Health \& Safety 
proponents) freedom with which children should be treated at the school. Each holds their vision of the 'good', the latter perhaps comparable with Jacques' (2002) cryptoutopia in rendering other visions so awful or laughable that their own utopianism is hidden (although children's safety is, of course, no laughing matter). But this reminds us of two points that I discussed in Chapter 3. Firstly, to think about where we 'draw the line' with visions of utopia that seem tasteless, violent or unsettling enough to bring out emergent ethics which at least contingently inform everyday practice. Secondly, a complication of versions of the utopian unsettling: although each viewpoint is unsettling to the other (one version), each is simultaneously comforting and unsettling, depending on one's viewpoint (a second version), and each unsettles the other when they directly confront each other through individual practices. The question is, of course, what next for the school? ${ }^{7}$

Apart from this debate, I have shown how the 'messy geographies' through which the school is constituted, are constantly changing bundles of longer-term generalised educative goals, structured and un-structured practices, and materials and spaces. A key 'good' has been the idea of home or comfort which, in the final section, was combined with various bits of these bundles, to produce contingent moments which were experienced and defined as ideal (or utopian). Yet again, this demonstrates the unsettling contingency of everyday moments of utopian affect. It also highlights the emergent ethics that are actualised through them and in collections of these moments - especially in interviews - in relation to other, more 'negative' events. Moreover, we see how various concerns and stories are folded through the different chapters of this thesis, and even throughout this chapter alone. Nevertheless, although this is complex, we must not lose sight of the fact that, again, practical considerations (safety, learning, reading, playing) are at the heart of constructions of home/school, however much these can be connected with different ideas about utopia. Critical geographies of architecture might importantly allow us to expose the messiness and complexity of utopian ideas about home at this school - which render the whole effect quite uncanny. At the same time,

\footnotetext{
${ }^{6}$ See also Law and Mol, 2002.

${ }^{7}$ Some possible answers to this are presented in Chapters 8 and 12.
} 
although 'everyday' goings-on are equally messy and folded together, this complexity is lost - un-representable and un-represented - as people go about their business not always aware of or interested in notions of the 'good', the homely, or utopia.

\subsection{General conclusion to chapters $9 \& 10$}

Both chapters have attempted to present the importance of home and the homely to utopian moments, designs and emergent or longer-term ethics which are associated with them. They also exemplify my argument that the utopian unsettling does not replace previous ideas regarding utopia, but merely questions them, complements them, and adds to our understanding of the ways in which utopia is experienced. It has done this through an enduring facet of utopias - the notion of home. Although I argued that the Freudian and Heideggerian un/hemilich is a key element of the utopian unsettling (which I stand by), the idea of home has in fact been connected (and not connected) to that of utopia in many and complex ways through my geographies of the Hundertwasser-Haus and Nant-y-Cwm. However, the un/homely emerges in two ways in these two chapters. Firstly, in that one of my key arguments is that concerns and events from each thematic chapter flow and are collected into others. Thus, notions of difference - particularly at the house - are crossed with the homely to produce a variety of uncanny effects (for tourists, for example, and then collected into the experience of the married couple). Secondly, in that various other versions of the unsettling which are connected to the un/homely have emerged in these chapters - for instance, nostalgia, lack, contingency/materiality, and the crossing of utopian 'goods'.

The school and house contrast and complement each other in fascinating ways, and these are becoming clearer as we follow the flows that weave through these thematic chapters. At both, the idea of home - in various guises - is an axial point in interview material. The same is true for this thesis, although this logically leads into a re-collection of home and difference into ideas about community in the next two chapterswhen following the course of interview material. Broadly speaking, at the house, more identity-related concerns were apparent, largely through attempts to normalise the experiences of 
difference we had discussed earlier. There, however, more evental, euphoric utopian moments were also apparent, rather than any longer-term notions of the 'good'. At the school, perhaps as an aggregated result of the people and actions there, and the seeming need for an underlying 'vision', longer-term notions of 'homeliness', 'truth' and 'childhood' became important considerations. These were more 'ethical', longer-term notions of the good, yet still emerged through people's actions and specific memorialised collections thereof (perhaps this expands Badiou's [2003] version of ethics in order to contextualise evental truths through the biographies, becomings and linkages of which they are necessarily a part). At both buildings, practical, sometimes deliberately 'normal', concerns contextualised the (utopian) geographies that I encountered, illustrating how these were set within everyday life, and that we must be careful not to label all activities as utopian. Moreover, certain similarities did emerge: the importance of contingency and emergent ethics to almost all of these versions of utopia; the inter-play of 'traditional' and unsettling in the construction of the utopian un/homely; the fundamental role of 'difference' (and making a difference); the importance of community. Much of this is summarised by the simple tension between difference and 'fitting in' that ecological architects struggle with. Yet the situations we have encountered are far more complex than this dualism, enabling the emergence of many versions of utopia, which I have demonstrated in the inter-weaving of difference and homely (the un/homely) in the last four chapters. It is nonetheless this last similarity - community - which concerns me in the final two empirical chapters. 


\section{Chapter 11 Constructing community spaces: The Hundertwasser-Haus}

\subsection{Introduction to Chapters $11 \& 12$}

Utopias have always been linked with imagined notions of community, as well as community experiments (Hardy, 2000; Coates, 2001). Moreover, imagined communities - whether national, regional or local - have often been linked with idyllic pasts or a collective, politically stabilised and culturally coherent future (Jeans, 1990; Matless, 1998). Thus both the image and practice of 'community' are crucial to traditional conceptions of various kinds of utopia. I question various notions of community in the following two chapters, especially through a consideration of the material, architectural geographies that are necessarily incorporated into the performance of community. First, though, I expand upon and crystallise some of the key debates on community as I interpret them.

Community discourse is of course varied, ranging from 'Homezones' ('reclaiming' streets from car use for local residents) to international, fluid communities defined less by place and more by activity or political affiliation (Bauman, 2000). Communities are interpreted in at least two fundamental ways. They are either depicted as protective, homely arenas which preserve a common interest and provide a space for public discourse, or described as divisive, bounded spaces which, as a result of such protection, exclude various individuals, groups or interests (Young, 1990). Communities are identified, as I noted above, with ideal pasts or idyllic images of rurality, at the same time as they are current within concerns regarding sociality, subjectivity and ethics, following post-structuralist critiques (Silk, 1999; Popke, 2003). A key problem has been the dualistic sense in which 'liberal' and 'communitarian' views of community are opposed (D. Smith, 1999). Liberals suggest that the individual has the power to enter or leave a community at any time, so that communities are neither pre-given, nor essential: individual rights are thus the ultimate 'good'. Communitarians argue that communities are the essential way in which humans experience their identities and worlds, placing the

\footnotetext{
${ }^{1}$ For more information, see
}

(site accessed 14/08/2004). 
'common good' above individual rights. Therefore the loss of any sense of community is lamentable (Smith, 1999; Silk, 1999). Various syntheses and attempts to escape the problems of this dialectic have focused on the variety of forms that community should or can take. For example, some have promoted communities based around an ethic of care (D. Smith, 1999), whilst others discuss how they emerge around contingent, ephemeral and interest-based activities (Bauman, 2000).

Such debates have led to a critique of communities that are bounded by delimited spaces or fields of action (for example, in recent 'gated communities'), but has not meant the total disconnection of utopian political considerations from the idea(l) of community. For instance, Young's (1990) deconstruction of community is followed by an attempt to evade the dialectic of 'individual versus community' through multiplicitous actions and structures, and an ideal (urban) vision that valorises the unplanned and incongruous. This tallies with Sennett's $(1978,1996)$ vision of public space and human interaction (again, urban) where the pain of interaction with strangers promotes more authentic, 'adult' socialities. These relationships should provide a more radical, but more inclusive, community realm (see Chapter 3 ). This is tied into debates over public space which are beyond the realm of this thesis, but equally important to the intersection of community and architecture, and the ways in which spaces are produced, subverted and idealised (D. Mitchell, 1995; Lees, 1997, 1998).

Moreover, community spaces are also fundamental concerns (and abstract 'aims') of architecture and planning, as the traditional link between place-making or imagining and utopianism often shows (Fishman, 1984). This has concerned utopians and architects from More and Campanella to Morris, Howard, and even the Disney Corporation (Barricelli, 1999; Morris, 1993; Fishman, 1999; Frantz and Collins, 1999). Moreover, as the much-heralded 'urban renaissance', and various imageries evoke both so-called traditional community forms and promote various futures based around public art, festivals and consumption spaces, the utopian imagery implicit (and sometimes explicit) in such futures is questioned (Till, 1993; Miles, 1997; Hannigan, 1998). Moreover, the 'pioneering' and revanchist discourses which surround gentrification (Smith, 1996) and 
the new urbanism are triply implicated in critiques as to their exclusivity, in utopian images of comfort and safety, and, interestingly, can be connected with the somewhat different 'pioneering spirit' so pervasive in the early life of Nant-y-Cwm. Crucially, the exclusions that such images and designs enact - often deliberately - are seen as both socially divisive and further evidence of the loss of 'true' community values, social integration and benevolence (Davis, 1990; Ellin, 2001: see chapters $2 \& 3$ for more).

Community spaces are also important to ecologists and ecological architects, and the importance of community has already been briefly depicted in various ways at both the house and school (Day, 1990b; Restany, 2001). An appeal to de-centralised forms of democracy and responsibility has been a key tenet of (radical) ecological thought, and the local community a key way through which those ideals can be enacted (Martell, 1994). Most authors on this topic are aware of and warn against the problems and contingencies of community (Dobson, 1995). Yet they still promote the homely, utopian qualities of community as part of a way in which our essential needs - grounded in sustainable practice - can be met (Plant, 1989). Various anarchist, socialist and communitarian models for environmental sustainability have been followed by experimental practices, with varying degrees of success (Pepper, 1984). Perhaps the most popular today are 'alternative communities' geared around varying conceptions of sustainability and ecological 'best' practice (see Diggers \& Dreamers, 2001). Interestingly, at the school in particular, although the buildings and educational practices are rooted in particular, usually holistic, versions of ecology, other community-related concerns were far more important to interviewees. Nevertheless, some of the school community's difference stems from these ecological ideas, and they are folded into some of the practices that are geared around other ideals ${ }^{2}$, as we see in Chapter 12.

The following two chapters engage with these concerns and the notions of community space as they are felt at the house and school. I will attempt to negotiate the performative and discursive construction of the house and particularly the school - where the notion of

\footnotetext{
${ }^{2}$ For instance, the parents' roles in designing and constructing the school - which of course followed certain ecological strictures, as read through Steiner's outlines for school buildings and his curriculum, and the local and contemporary constraints and opportunities that presented themselves at the time.
} 
community was far more prevalent in interviews - as an effort of community-building, as well as a community building. The metaphor of construction which forms part of the title for this thesis is thus particularly relevant here. I will seek to show how communities are constructed with and around arrays of material objects, and follow the deliberate positioning and production of a community through sets of relations with other practices, and in relation to difference and the homely. At the house and school, I demonstrate how - although the action occurs in specific architectural spaces, bounded in particular at the house - it is the contingency and materiality of constructions of community which evade completely 'traditional', bounded notions of community. At both buildings, we see how communities of interest present specific but changing, perfomative collections of ideas, spaces and materials which produce (at the school) many emergent ethics and utopian 'goods'. This highlights how communities can be viewed as a 'good' themselves, as much as the means to or an element for another 'good' (especially the homely). Therefore, at the same time as we see relatively traditional versions of community (still relevant to the people involved), in relatively 'set' spaces, we see how contingent, messy and conflicting notions of community are performed through, and emergent from, collecting/dispersing arrays of actors (for example, friends or activities 'outside' the community) and ideas from geographically and socially disparate locations, into and involving either building. The 'field' of study and of community is thus defined through those practices - not given in advance - and specific and located versions of community defined more through collection into an idea or space rather than the boundaries thereabout. Both chapters re-site a discussion of community away from the public, urban realm which has troubled most theorists, although I am aware of the exclusivity of access to both buildings in terms of the specific number of people who can possibly live at the house, and the fees and partial attraction of the school. These new sites are the internal spaces of the house, and the rural (in other words, 'traditional' and idyllic) setting of the school. 


\subsection{Introduction: Hundertwasser-Haus}

Certain authors suggest that the community at the house has been particularly strong in light of what some see as invasions of the house by tourists. For example, Restany (2001: 46) notes that "Each dwelling is individualised by its own colour and by the exterior treatment of the windows, fitting like a piece in a jigsaw puzzle into the built fabric as a whole. ... The inhabitants of the house are conscious of belonging to a group apart. They live differently to, and better than, their neighbours. They are proud to have been able to influence their quality of life themselves." He directly folds some of Hundertwasser's (different, homely) design features - such as the window right and the lack of door locks - into this sense of community. These were introduced to increase sociality both inside the house and in relation to its 'outside', although Restany characterises this as a community of difference through this very fact, and a comparative vision of 'good living' that emerges through this. I question this separation and singular community spirit in this chapter, particularly where the importance of these elements was evoked in varying degrees by residents.

During my time at the house, the residents indicated three inter-relating facets to community (Gemeinschaft): the original community, geared around the newness of the house and various communal events; the openness of the house in general in promoting interaction from communal events to the family scale; and the importance of personal friendships and spontaneous communal events amongst other concerns and within their daily lives. Many of these were not as strongly nostalgic or utopian as at Nant-y-Cwm or some of the discussion in section 11.1, but provide a fascinating counter-point to the complexity and emotion involved in practices at the school, as well as a (short) critical investigation as to the ways in which the material spaces in the house were involved in various communal practices and meanings. 


\subsection{The original community}

Nostalgia played a key part in long-term residents' memory of the 'original' community, but presented perhaps an only weakly utopian element within our discussions about community. They remembered that community in particular by stressing changes in the house since then:

R Living here, the community? It was a great feeling, ... in the house, yeah. We were all trying hard...we all spoke to each other, made plans, and - events [Feste].

PK What types of events?

R Carnival [Fasching] events, New Year parties...//

J Birthdays. Or about the state of the house ${ }^{3}$...

PK And are there still events and so forth?

J There are...but this community circle [Gemeinschaftskreis] has receded a bit. The people who moved in at the beginning, they were all interested? And, with time, a few moved out... . And there's still just about a core [Kern] and, they care about it still. (Male and female, 1986)

There was a feeling here of an 'authentic' sense of community - partly a result of the newness of the house, and partly of its faults - that also required effort. A core of people is left from that time but as the early memories of the house are still fresh, the events and effort involved as they all moved in at once are still memorable, through the work and 'ordinary' concerns that they had. Now that such a mass of residents simultaneously moving in is impossible, and that the house changes in a more piecemeal fashion, this couple are suggesting that the atmosphere that was built up then is difficult to re-gain without those who 'care' about the house. Nostalgia is fairly evident here: but for me, the importance of work and care for this early community signals the joy and perhaps utopian nostalgia that emerged with the building. In fact, it was some of the house's material problems which have become - through the refractory lens of memory powerful elements in discussion about community. As I have suggested, hard work is a crucial way in which utopian ideals and moments come to be enacted, in addition to the utopian tones that are attached to that work itself. This is more evident in the

\footnotetext{
${ }^{3}$ There were a few problems with the house initially, some of which continue today. Some of the floors in the flats, for example became uneven, which was not intended there (M, 1989, personal communication). Other problems with the house and its function as an artwork are discussed in Chapter 8.
} 
construction of community at Nant-y-Cwm; nevertheless, this is weakly apparent in statements from $\mathrm{R}, \mathrm{J}$ and other residents. The notion of community being propounded here is one at once engaged with a sense of loss in the present, but also one that was created in relation to various elements of the building folded into these and later experiences (such as its newness, difference, faults and their experience thereof), rather than directly against it, enclosed by it, or determined by it.

The sense of work, loss of community and personal effort overlap considerably:

PK Do you meet up with other residents much?

J Some, yeah. Earlier on, I tried to get the residents together, I was really cheeky, I always went and knocked on their doors, and I said, what does your flat look like?, do you want to see mine?... I tried to get together carnival parties, and they went well...but then I said OK, now some of the others can do it, but when there's no motor there, nothing happens. (Female, 1986)

The dynamics of groups and inter-personal relations are naturally important here, apart from any direct influence from the house. These are better explained by psychologists, however what interests me is again the work that was involved here, and the difference between the pre-given notion of community from the first excerpt (although still worked), and the more active procurement of that community, highlighted through the act of door-knocking. Thus the house becomes drafted back into the story, as, for example, each flat is different. $J$ used this difference as a means through which her idea of community - and then the more general 'feeling' from the first quotation - could be enacted. Thus the house was a starting point, something to discuss, as with its faults. Its newness, linked with the swathe of new residents who moved in at first, and an associated community that then arose, all aroused weak but identifiable emotions of nostalgia about an ideal (and also quite uncertain) time. The capacity of the house to act in this way is seen to have diminished with time, as well as and in connection with the particular group of residents who live there now. Moreover, the changing energies of residents who have lived in the house since its completion have also affected the role of community at the house, wherein no 'motor' has been available to organise events in which that community is evoked/enacted. 


\subsection{The house's openness}

The house's 'openness' is also a key material and symbolic factor in the production of community there. But this too is a function of - and worked through changes in occupants, ideals and events:

S Earlier there were events, carnivals etcetera. But for example, my birthday [the party I attended], then only those who wanted to, came: it's not divided as such, there's not as much distance. I think, through these community rooms ${ }^{4}$, anyone can come down if they want, and that's super. But in your flat, then there's more distance...perhaps it's the feeling/atmosphere [Stimmung] that the house spreads/scatters [ausstreut]... . Or the children, naturally, we come together every day [because of them] (Female, 1995).

The house is seen to be an open, inclusive space through its community rooms, where anyone can join an event, should they have the will and energy. This inclusiveness is not merely structured by the legal status of these rooms, or even the general agreement amongst residents and the City Council about their function, but is enacted in different and changing ways. For example, the diminished number of events in these rooms points to changes in organisation and personal effort (above), as well as the ways that effort and choice - whether to attend a party - can continually re-constitute the ways a space is seen as open and inclusive, in connection to the changing 'community' with whom it is defined. And, as with the space outside the house, this is cut across by the invocation of other 'structural' concerns - such as the creation of a birthday atmosphere, or friendliness towards a stranger who has come to research daily life at the house. I am also drawn to the use of the word 'ausstreuen' (spreads, scatters) to signify that the house disseminates a particular feeling through(out) its design and structure. This is not a pure matter or dispersal outwards from a point, but a feeling that must be actively called upon as an interpretative strategy for assessing how community-orientated activities and interactions are forged through the house and its material spaces (building on Gieryn's 2002

\footnotetext{
4 'Gemeinschaftsraeume' - Wintergarden, playrooms.
} 
structurationist approach). Clearly, the house is seen as a key (and determining) actor as the feeling it spreads is permeated (in an active sense) through the use of its spaces. But this scattering-throughout is done with the house and through collections and layerings of past, present and future uses and ideals.

A notion of inclusiveness also permeated our discussions about the house:

PK Is it different from other social houses?

C Well, like I said, I didn't live in a social housing block before...but I would assume that it's pretty extraordinary. You see, the communication [between residents] in that sense, is very positive, and some gardens are also split in two - and that works too, yeah?

PK So is that because of the house [or] the particular people?

C Yeah - you learn it ${ }^{5}-I$ think because there are such different career groups here in the house, and - it's interesting - it works very well.

PK So you have to learn to live here then?

C No[!], I don't think you must learn to live here. If human have got enough space, then....one tolerates life with others much more, than when you're in a confined space, you'd get irritated, no? ...The respect exists [ist vorhanden]. One is more positive about others, than in a confined space, where you don't want any contact with anyone... and I think that people are much more communicative here. Now perhaps, it's not quite as simple, but it was there. (Female, 1986)

This woman ${ }^{6}$ uses similar language ('tolerates', 'others', 'respect') to those who debate communal life and living with difference at a more abstract level (for example, Young, 1990; Harvey, 1996; Silk, 1999). Implicit in this statement is a politics that begins with a spatial notion of encountering others. When $\mathrm{C}$ mentions 'space' I do not think she means purely the amount of physical space each person is allowed, rather that spaces are instituted ('public' spaces?) in which people are allowed space to interact and to be 'more positive with others'. In many ways this is a Rawlsian, liberal sense of individuals' toleration of each other where certain general freedoms (like spatial freedoms) lead to a better community (Silk, 1999). Hence certain aspects of the house's structure and its accompanying use (like split terraces) are seen to work together with the agency of the

\footnotetext{
S 'Man hat schon gelernt' - there is a passive sense here: literally, 'one has learned it'.

${ }^{6}$ This is the same woman who discussed the relationship between the Hundertwasser-Haus and other architectural trends, and clearly has thought about the house in more general, moral terms.
} 
residents to actualise an inclusive community. It is fascinating to hear both $\mathrm{C}$ and $\mathrm{S}$ talk in such terms about the process of producing a community through the material realities of the house. Additionally, taking into account this woman's knowledge of Hundertwasser, I would note that his quite liberal views and individualistic approach to architecture inhere in some of these processes and the ways that they are conceptualised here. For Hundertwasser, a community might be an end result of such a house, but the aim was an architecture more attuned to individualistic artistic needs. In both cases, however, we can loosely connect certain themes - through the 'scattering' and 'space' the house and its ongoing, co-relational performance enacts - into the utopian undertones of community discourse (inclusiveness in particular). Taken together, these fold together into euphoric moments which collect many discourses and other experiences into emergent, ethical notions of quasi-utopian inclusiveness, at the same time as these notions are collected into other euphoric moments - the excitement of first visiting the house, for example. Thus, as I have suggested, collecting/dispersing are not simple or dualistic processes, as here, as elsewhere, events cut across and are temporarily defined through contingent discursive moments, but whose collection evoke/provoke specific affectual and ethical notions.

We should not exaggerate the utopianism of these quotations, however much they are folded into other concerns, or evocative of utopian communitarian debate. Most residents were concerned, like $S$ and $C$, with the ways in which such an open community existed, and that they 'liked' that. How far the utopian extends into likes or dislikes, or weaker versions of what is 'good', it is not always clear from utopian literature, and therefore I think this rests on the particular framing of discussions of community that we had, and hence the connections with other themes and events they forged (see section 11.5). Either way, it was felt that the house itself encourages an (inter)active community at a variety of scales, but whether this is pre-given or a post-hoc result of individual freedoms begins to become unclear as we learn more about the materialities and performativities involved in the construction/encountering of community/ies at the house:

PK Can you remember the first few days here? 
L Well, what we liked, and what we always tell people, is that there was really open communication that predominated, with different neighbours? Not with all the residents, but its definitely more open than the house we were in before that.

PK Why was that?

L Well, I think if you live in such a house, then you know that it's something a bit different, and you walk around a bit differently, with certain things. And this difference, has also brought people together [Zusammengeholt], more than in other buildings perhaps. And that affects communication with each other. But there are as many people who don't want anything to do with their neighbours... (Female, 1989).

For $\mathrm{L}$, this is more a version of what she likes (and suits her identity - like her teacups earlier on) than any strongly utopian 'good' or atmosphere. However, it is interesting to note that both $\mathrm{C}$ and $\mathrm{L}$ began talking about 'communication' and 'community' without prompting, and as if communication and a pre-requisite space for it were the key grounds or 'goods' upon which community could be built - emergent, evental and performative ethics (perhaps only utopian for $\mathrm{C}$ ). Engagement with the community is, as we have heard, a fairly individualistic matter of personal interest, energy and preference. But again we are introduced to the agency of the building - this time as 'different' - which has 'brought people together', as Restany argues above. Interestingly, the somewhat abstract notion of the house as different leaves a degree of space between a more concrete goal around which people can rally (such as the politics of a 'public' park), and an initiatory and accompanying line of affect or interpretation from which a community can then be constructed. Nevertheless, the house has acted in different ways within ideas about community, and in communities of materials, people and actions, often collected into events such as birthday parties. Crucially, unlike Restany, we see how this is produced with the house in various contingent, material ways, and that this does not always involve the same people - as L suggests, some people are just (sometimes) not interested!

Others sought to illustrate how specific design features of the house encouraged sociality:

E Thank God it was that Hundertwasser's ideas were different. I don't know if you realise, that this house is an open house. It's open to every person - there are no bells on the doors, for example, at the entrances. Because every door 
should be open for every neighbour, and I think it's an idea that people can live together...you see there are so many characters, everyone's a bit different.

PK But it works here?

E Well, in the house itself... what should I say, it's more open. I suppose you haven't got this guilty feeling when you knock on someone's door, if you need something, or if you just want to talk, and when I was in another block thank God [I'm here] - open it was not...you only saw people when you went downstairs to go shopping, and you greeted them, but more than that nothing (Female, 1997).

With more of a depth of feeling than other residents, and despite her arrival at the house in 1997, the importance of a general community spirit, and the specific materials through which this is performed, are paramount to E. Again, this more broadly contextualises the house as 'different', although many of these activities are in fact quite mundane ("if you need something"). Even though people still have to knock, removing the formal barrier of the door bell - an idea of Hundertwasser's - signifies that everyone's door is open. This I think contributes to the 'homeliness' of the community for those who wish to take part. Yet, as this suggests, this is usually partial, and such generalised notions of community spirit predicated upon collected memories of contingent performances, whose spirit and hope at the same time encourages those actions to go on in whatever virtual forms they might take. This is a community enacted through such actions and materials, rather than pre-given by either Hundertwasser or the house. There are divisions within the house - families, friendship groups, chance meetings - which render any one community spirit, or overall view, essentially impossible to (re)present. Yet residents (and especially $\mathrm{C}$, who often spoke 'for' the house in more general terms) do identify variously defined community spirits, from their experience and stories they have heard. Overall, I think these interactions indicate the usefulness of critical geographies of architecture in teasing out the complexities of community-construction with the materialities of a building. The quotations and my interpretations thereof partially evade the communitarian-liberal debate through stressing the co-relational and performative manner in which experiences and definitions of 'community' emerge. We can make connections with utopia, again unsettling through the very contingency of these experiences and ethics, and refer back to my other utopian themes of difference and 
home, in particular where a couple of quotations are placed in the context of other discussions we had had, and notions of inclusiveness and togetherness. However, as much or more than this, residents were also concerned with the ways in which this was framed by concerns they would not define as utopian - such as chatting to friends, or borrowing some bread. In the next section, I deepen this discussion a little by focusing on such friendship networks, and the utopian moments with which these were at times identified.

\subsection{Personal friendships}

The importance of a community of friends around each resident was a crucial element in life at the house, and the ways in which one coped and made oneself 'at home' there. Again, the influence of the house upon these friendship groups - which could be seen as a function of choice rather than an inclusive community - are not merely encountered but also worked upon, through the house:

C Naturally, yeah I'm still, through time, friendly with people in the house naturally more intensively than other houses. (Female, 1986)

D The children play together, with cars, not always in the flat but probing outside too? And another family's children come down too - that wouldn't happen if the building hadn't been built with community in mind [gemeinschaftlich gebaut]. And we use the play rooms in winter very intensively, and naturally we're out in the gardens more in the summer. I actually think that for children, it's a paradise in Vienna. (Female, 1999)

Again the influence of the house on the forging and continuation of friendships is discussed as a profound factor in both structuring and providing a resource for different types of friendship. Whether 'intensive', or a 'paradise' for children in Vienna, the house is an important element in the ongoing relationships between adults and children. With the house, a community is built up which produces another version of childhood from within these friendship groups (I interviewed three couples whose children play with 
each other). In this, the house joins with the attitudes and friendships of this group of parents to facilitate versions of childhood where free play, minimal supervision and communal play are ideals. These are often meant less as organised play sessions so that here, the ideals of community are produced in spontaneous play, and the ideals of play, in spontaneous community events. As with many parties and other events, most are simply chance encounters or off-the-cuff decisions, based on 'who's around' rather than a deliberate enactment of community in the first place. Specifically though (as at Nant-yCwm and more broadly), free play is identified through community as ways in which the house is performed as a 'paradise for children in Vienna'. Hence, through difference from other buildings, utopian discourse is evoked in the depiction of the house as built with 'community in mind', a homely, comforting feeling in relation to notions of family, childhood and play ${ }^{7}$. Yet importantly, these meanings emerge only as a result of work, and of the contingencies of chance encounters and versions of 'free play' that are acted out by the children. Such elements help produce a homely notion of paradise, but that is dis-ordered, and relates directly to facets of the utopian unsettling.

In certain collective individuations, people have been able to make qualitative judgments about (for example) difference and community, play, home and even utopia, which refer to elements and events which weave throughout the themes, and which I have separated (quite arbitrarily at times) in this thesis. We can see this in particular as such communities of friends and materials are not just constituted by such events. These communities also form elements of other specific events, constitutive of as well as outcomes from utopian potentialities. Hence we can move from likes and dislikes or weak versions of the 'good', to weave these into more identifiably utopian concerns. Nowhere is this more evident than in the continuation of my discussion with the newly married-couple, which turned to community and friends ${ }^{8}$. Both quotations follow on from those in Chapter 9:

\footnotetext{
${ }^{7}$ See Chapter 10, where these ideas were more fully explored with the richer empirical material derived from Nant-y-Cwm.

${ }^{8}$ We should, as I have been making clear throughout the thesis, thus be aware of the multitude of concerns that relate to these moments, and cut across boundaries of community - such as references to work (another community) and tourists.
} 
D $\quad$....and, it was paradise.

PK Was it a distraction form work?

D Yeah, that was miles away, the topic of work was completely - no it was just another world, yeah.

PK And the people you met, are you still friends with them?

D From the house? Yeah - very good actually. You find that is what's great about the house, you encounter it often, because there are so many communal rooms. And that's simply really nice, because you're always somehow obliged/indebted [pflichten] again, more than in a normal house where you just meet people when you're getting the post (Female, 1999).

J ...It was really grand. And I should add, we had like a second garden, that was shared with our neighbours and we helped develop that a bit more. I think $I$ had contact with $X$ in the garden, and she had contacts with the other neighbour, and that was a new contact that we procured [verschafft]... and I think it was closer than in other houses.

PK I spoke to $\mathrm{S}$ yesterday, she said that it's easier with children, because everyone gets together more.

J Super, yeah - exactly, we've got loads of contact with them, also in the Wintergarden, we eat there with them - but there are also lots of people you never see. And I must say, I get the feeling it's changed a bit since the house was completed, I think they had lots more events. And lots of people are a bit worn out from that time. But I think now it's not so true any more. It's renewed a bit though, the communal rooms are used (Male, 1999).

I think these quotations highlight five considerations. Firstly, that - as $\mathrm{C}$ suggested above - the split gardens and other design features of the house are crucial material elements in the ways in which communities are constructed and spatialised. These ideas and materials are therefore also drawn into this ever-complicating whirlwind of a strongly utopian affect that has already been characterised as both homely and (hence) unsettling in a number of ways. Secondly and related, from a different viewpoint this time, we see how the contingent production and memory of utopian moments is part of a collection of heterogeneous elements, one of which was a version of community centred around the responsibilities, 'obligations', and 'procurement' of friendships. Thus an ANT version of communities of interest, materials and people is salient in a discussion of communities. We see the place of communities within wider idealistic and material relations, but simultaneously the place of ideas about utopia within ideas about community. Moral and emotive overtones are attached to the notion of community through the evocation of the idea in this particular (but also generic) context. 
Thirdly, here, the process of becoming-community - entering the Hundertwasser-Haus and parts thereof becoming one's identity - is etched out in the above quotations. From the utopian encountering of the house and the particular timing, to the process of 'procuring' friends, and then everyday, spontaneous meals, the ways this couple have become a part of the house, and it them until they feel they can talk about the 'community', are a crucial part of their coming to terms with the house-as-home (literally, in the naming of 'community'). Fourthly, the nature of relations between friends (and where friendships become community) is bound up in terms of 'indebtedness'. There is also a feeling that what might be seen as authentic versions of the original community at the house may have been lost, but that new versions are being created all the time. Thus various communities of obligation, friendship and everyday life are instituted, taking in the full complement of people, events, discourses, doorbells, birthday meals and terraces of which we have already heard. Thus communities are obliquely structured by and within different sets of concerns, rendering them somewhere in between complete and incomplete. Relating back to ideas of home, nostalgia or the 'good' inherent within the notion of community, this begs more research and discussion as to the performativities and materialities of the construction of rights, obligations and morals in those ideas (home, etcetera). This is a key direction in which critical geographies of architecture, performativity, materiality, utopia and community could all travel. Finally, the building returns as a key player in this community in many ways: with/in and housing the communities at the Hundertwasser-Haus; as purely a 'new' house where encounters with new residents are possible; as a 'different' house which in itself symbolises possibilities for different versions of life, providing something around which common concerns can be debated; and finally housing sets of spaces and places, sets of ideas and materials, through which changing notions of community and changing communities of interest, whether nostalgic, new, 'mundane' and/or utopian, can be lived.

\subsection{Conclusion}


This chapter has demonstrated a number of ways in which experiences and ethical discourses around community were encountered in co-relation with the house. More specifically, it has explored the particular design features or spacings that were critical elements therein. In all, I suggested that we could contextualise certain utopian moments through these discourses, and connect these with debates from community studies, which are often strongly utopian in character. However, at the same time, in themselves, many of the concerns I heard about could not be characterised as utopian in either traditional or unsettling terms - there is no sense that we have here a 'utopian house' or 'utopian community'. I discuss this crucial element in the conclusion to the thesis.

In this chapter, I have identified inter-relating facets of the construction of community with the Hundertwasser-Haus. I began by discussing the 'original' community, and the notions of nostalgia and work with which stories about that time are imbued. These, I argued, presented weak versions of the utopian unsettling, many of which were (or at least were seemingly) not related to utopia at all. The 'difference' of the house and community is, as Restany (2001) suggests, an important element of the house's atmosphere. I agree, however this occurred in a variety of ways (most usually in comparing the way the house was built with other houses), but was also of minimal concern in certain excerpts. I therefore then explored how the house 'scatters' or promotes an open, communal and inclusive atmosphere through its spaces and the ways they are experienced and produced, and through specific design features, such as the lack of doorbells. This took on a utopian character at times, although related to specific 'mundane' concerns and the general, complex uses of space that the residents undertake. I suggested that these insights might provide room for highly useful crossings of material and critical geographies of architecture with community-orientated practices. Finally, I illustrated how friendship groups were paramount in residents' experience of the house, which took in elements of how they made themselves feel 'at home' through their involvement with others, and specifically through children's play. A continuation of two quotations from a newly-married couple (D \& J) equally demonstrated how community and (an unsettling) utopia were entwined in the moments they presented in the weeks after their wedding, in the context of tourists, their jobs, previous houses and other 
relations outside the house, that were and were not detailed in their stories. These quotations, and the chapter, exemplified how utopian moments - and I think in this case, ethics - emerge in context. These moments present themselves as actualised events, with many (often not immediately 'utopian') practices gathered into them as they come to be experienced, tenuously defined, and remembered. These utopian moments complicate further (and thus unsettle) any neat definition or representation of 'paradisiacal', homely events, as once again they are experienced through the material contingencies of life in and outside the house. The themes of difference and home flowed through this chapter once more, allowing us to forge specific utopian connections and networks of events and ideas in context. I have also illustrated the inter-relation of events with more generalised 'ethics' of community, so that as I suggest in Chapter 3, ethics utopian or otherwise emerge through the contingencies and experience of events - again, rendering any utopian, community ethic profoundly unsettled. 


\section{Chapter 12}

\section{Constructing community spaces: Nant-y-Cwm}

School

\subsection{Introduction}

At Nant-y-Cwm, the fundamental importance of the 'community' (talked about in both abstract and concrete terms) was explicit in interviews and in time I spent at the school. Ideas regarding community pervaded stories about the school from its inception, to its present struggles and uncertain future. In particular, the stories about the school's founding - although based around particular personalities - draw on notions of a collective 'spirit' and togetherness, yet are replaced for some members by a sense of lethargy or loss of that spirit in recent times. Interestingly, the themes relating to community, and its enactment and representation at each building were very different, as this introduction has already hinted. However, in an ANT sense, the materialities of each building, and the importance of often unsettling themes such as nostalgia and work, are crucial elements in constructions of community at both buildings, as I began to demonstrate in the last chapter. These concerns also underscore many of the arguments in this chapter.

Based largely on interview material, this chapter will indicate how various notions of utopia and the 'good' were constructed at different interstices throughout the school's history, and how these notions were intimately connected with a community that is forever re-negotiating its attachment to different ideas and practices. As an example of an 'alternative community', in connection with the particular version of childhood the school attempts to construct, the meanings and emotions connected to the community at the school are very strong, and lived through notions of alterity and home. Although life there is also organised around other concerns, of which the community and its functioning are constituent parts, for many it is a normative version of community which pervades the experience of life at Nant-y-Cwm. Those different concerns, activities and agendas have been attached to or played out within and outside that community. These question what 'the' community (or communities) around the school is (or are). Such 
varied practices affect which normative version/vision of community is being described, how 'boundaries' are produced, and how these collect back into ideas about the 'right' education. I will show how, through such notions as work, money and education, various images of the community were produced and have been perpetuated, changed, or even lost. Ultimately, I will suggest that certain previous conceptualisations of community in particular normative versions, but also purely representational depictions and explanations of existing communities - cannot adequately come to terms with the intensity, complexity and materiality of the experiences of community at the school. This intensity, the effort of work, and the painful joy and anxiety attached to it, will themselves form the final examples of the performative, utopian unsettling I wish to present. This also works with and questions simple conflations of community with traditional and contemporary versions of utopia, based around comfort, homeliness, the 'good' and social justice; although these also appear in this chapter.

This section will follow a broadly chronological order from the construction of the school, to its ongoing use towards the present and debates about its future. However, each element of this is confused by the inter-mixing of time periods necessary for each person to make particular arguments, and to try to make sense of their experiences at the school through this problematic term.

\subsection{A 'pioneering spirit'}

The process of building that Christopher Day advocates - 'Consensus Design' involves a phenomenological desire to 'listen' to a place, its context, and the demands of the builders and future users of a building that will emerge there. This process is worth repeating here. As well as building a physical form, people's desires and intentions are collected in a kind of synthesis - not of unanimity but where each member is at least satisfied and can agree. Day's design is meant to be with, not for the intended users, a collection of ideas that creates a kind of unity. Drawing on Steiner- and Goethe-inspired theory and practice, he argues: 
"If democracy is not seen as equal opportunity for personal indulgence, but as the recognition of the value of every individual for his [sic.] own specifically individual contribution, then neither 'doing one's own thing' nor giving orders has a place. ...Such a meeting cannot demand conformity with the original idea, nor the right to depart freely from it. What is shared is the consistent principle, the ideal, the vision. If this is genuinely shared, the individual variations that arise will all be within the context of a unifying theme. ... In doing so, ideas form within the group which arise out of the meeting of thought-intentions... and actual situation. Individuals need to meet not as proponents of certain ideas, formed separately, but as listeners, already attuned in their minds to the subject. ...As Yes-No reactions and advocacy or defence blind us to what can come into being, such a conversation is quite opposite to a debate. From it can arise ideas as living realities, inspired commitment and wise decisions. ... If we work in this way we have become aware that we are listening to something that is developing all the time. The building is, as it were, a thought-form incarnating into matter. But it is a thought-form which is alive, is born of the idealised needs and real situation. It is not something it is possible to rigidly circumscribe at an early stage by a fixed design. This leaves no room for life. ...Ultimately the right decisions are not made by one person or even by one group. They arise out of the situation. ... Something new, intangible, but very real has been born - that which, beyond the individual contributors, comes to life in conversation" (Day, 1990b: 137-143).

The consensus element of this process can be summarised as a 'gathering argument' between a group where "[A]t some point a decision is self-evident" (Estes, 1989: 236). For Estes, this often needs a 'facilitator' to speed up the consensual process - in the case of a building project, this would be the architect who would not dictate, but would, rather, structure the conversation. This incites various debates. Firstly, some of what Day has to say bears a resemblance to Deleuze and Guattari's (1987) actual/virtual version of newness and creativity. This similarity is particularly evident, for instance, in the way that agreement, and form 'arise' (also phenomenlogically) out of a place almost magically in between intention and chance, as "a thought form which is alive," rather than leaving no room for life. Perhaps this is a somewhat simple comparison, as the process here itself is stabilised (through three stages in Day, 2002, Chapter 5), and the intentions of Deleuze and Guattari, and Day are somewhat different - the latter also searching for the 'authentic' version of a place rather than a type of more unbounded creativity. Either way, the 'arising' of a form and agreement, somewhere between the individual and collective, is uncannily similar to work on performativity which draws on Deleuze and Guattari (in particular, Harrison, 2000 on 'collective individuation'). 
Secondly, the kind of process that is being idealised here produces normative yet performative versions of community, space, place and creativity that are entwined to magically produce (or enable) a sudden agreement of which communitarians would be envious - and which borders on the utopian. Thus the linking of this actualisation or arising of form with such an idealised process which ultimately uncovers/constructs a shared 'Spirit of place' is highly utopian in a spatio-temporal sense quite different from Harvey's (2000; but is more similar to Grosz, 2001). The reliance on Goethe and Steiner also points to a somewhat spiritual, religious and transcendental philosophy, yet firmly rooted in an earth-bound, ecological, contingent and performative envisioning and enactment of the future.

Thirdly, Estes (1989) and Day argue that some sort of facilitator is necessary, around which to organise a community and particular decisions. I would argue that as much as a person, this can be a design and a building, or its constituent parts. The ways that the intentions, desires and memories of the early community at the school are nostalgically idealised around the school building point again to the importance of matter in the construction of communities. For instance, the surrounding landscape and the particular materials involved were all part of the collection through which buildings (and communities) were constructed. Clearly, dispersing and particularly active modes of collecting are being undertaken here in order to contingently forge the ideal and physical extent of the school. Finally, this design process has itself emerged from Day's experiences, in particular at the school, and is thus one idealised and abstracted version of that time. Since 1990, this has been modified in a variety of contexts in Wales and beyond. However, when the school and the Kindergarten were built, the process also evolved out of necessity, and the ideals that are firmed up in Day's later work were in their nascent, experimental stages. Yet I think, through the performativities, biographies and a version of the actual/virtual, and moving on from it, the experiences of those involved point to various notions of utopia.

At many times, I was introduced to the 'pioneering spirit' of particularly the late-1970s when the school was begun. The stories and information I was told took in hour-long 
descriptions of how the first few interested parents got together, to the health-giving effects of working on the building (see Day, 1990b), to specific events, to what were seen as structuring or enabling factors at the time. With the slightly rose-tinted lens of memory - and with the undoubted emotional attachment that interviewees had with the school as a result of their work there - we see that the building of a school and community was largely positive.

G We were a tight-knit little community.

S It was very different from now. I mean it was the time as well, I think. People were still full with this sort of exciting, pioneering spirit...you never thought about money, we just thought about ideas, and how to make them come true. So we sit around now in our fifties, sort of harking back to the good old days when, you know, it was possible to do that sort of thing. And it was great.

G Just the like the students of the Sixties, wanting to do something, positive, without the money! In the way of material things, everybody was happy to hand down old clothes, and old cars which were barely moving. Yeah, it was, really...a wonderful time....

S People were very generous with their time and energy, because they were inspired... . My feeling is that, really, the younger generation of people have been damaged, during the Thatcher years, by this tense materialism. And [instead] we were fighting for ideals still. ... It created a different kind of atmosphere, where it was easier to think of, a group or community, rather than just yourself. ...It's changed. The younger generation of people came along and, they found it a little bit more difficult to be sort of, totally giving. And of course, the time's changed (Male, female, founders, ex-parents, teacher).

A I guess I've seen it when it's been more in it's heyday.

PK What was it like then?

A Well there were more children and families. It seemed, I may be wrong, but there was sort of a more errr inspired, parent group. At the moment, people don't seem to quite so inspired. And there was more, maybe it's because there were more people who didn't have jobs, more hippie types if you like. There were also more, anthroposophical people. And now it seems to have gone through, a wave of shrinkage if you like.

PK What particular memories of the School have you got, sort of when first arrived here? Or the first few weeks.

A Oh it was grea-, it was sort of joyous, I suppose. And, everything seemed beautiful, you know (laughs through last phrase), because it was just great for the kids. And there was a lovely communal feeling amongst the parents. You know. It was like a little haven, to have found it really. (Female, longterm parent) 
PK So how did you get involved with building the School?

S Well, all the parents in those days, we had a working day on Thursday, most of the parents seemed to be pretty involved. We went along, I was pregnant, a lot of people seemed to be pregnant at that point. I remember learning to plaster. ...We were building with this pioneering spirit!

PK Did it help bring people together as well then?

J Yes, it did actually.

S Yeah I think there was a much stronger feeling then.

J People pioneering.

S Yeah. Because, if we didn't do it, the School wouldn't have existed. Whereas now, people arrive in a very different spirit I think. It's already created. And, a different energy

J Also you could give your building, labour, where we couldn't give money as well.

S Yeah. Partly. A lot of us were unemployed... And yes, it was a way of contributing to the school....

J But that pioneering style,that did pull everybody together. And you felt a sort of solidarity with all the other parents (Female and male, founders, long-term parents).

All of these excerpts have a common thread in discussing the 'pioneering spirit' with which the school was founded and built. Moreover, the fact that the community was 'tight-knit' was alluded to in a couple of places, a determining factor in the success of the school. Nevertheless, the long story one of the founders told me about its founding (not reproduced here) - detailed descriptions of who was involved, stories leading up to those meetings - in addition to those above, show how the community was something that had to be worked upon. It was not given in advance. There is a clear nostalgia for the way that the community was built up, as people were pulled in and taught to build by friends, and as the pervading spirit of the age (experiment, unemployment but hope) was evoked as a key energy in the construction of the community (see Osmond and Graham, 1984). Similarly here, as elsewhere, there was a community of interest where different backgrounds ('hippies', the unemployed, pregnant women) and concerns (anthroposophy, alternative religions) seemed to quite unquestioningly coincide in the production of a common denominator - a school for all - as Day suggests above. Hence the community and school are built through each other in the co-performativity of material build-ing. The difference between then and now is evident. A community is now in place which must be encountered rather than constructed, a community which 
has become fractured for the different reasons people now come, and the very reason that less work is necessary to become a part of that community. Thus, contra Ingold (2000), for those at the school, effort - embodied literally and metaphorically in the task of building - is equally as important as dwelling in the flow of practices from past through to future, the push to go on (see F's quotation, below). I will explain this slightly further. Harrison (2000), drawing on Ingold, argues that building is a representational practice, embedded in a (masculinist) separation of the world and its perception which entails the a priori construction of the world before it is lived in (cf. the actual/virtual and the problems of Euclidean space). Dwelling, on the other hand, is the 'homeland' of thinking, where we can only think of the world as we dwell in it (not before it) (Harrison, 2000). I am not so interested in the etymological separation of ideal terms here, yet in the very fact that building requires embodiment as well as cognitive thought, and that more importantly, at the school, 'building' is both imbued with a sense of $\mathrm{dwelling}$, and the principal means through which to go on, perhaps even after anything is 'built' - in working. Clearly, this requires a sense of the 'good' (building towards) and of the performative, as each emerges through the other and is in any case always contingent (hence, unsettled). Whether Harrison intends such a strong distinction I doubt - yet I hope to have clarified my own thoughts on this through this example and some of the quotations that follow.

Finally, I have re-printed part of a quotation which appeared in Chapter 10: that at the end of A's excerpt. This shows again the folding of different themes (this encounter was after the school was built, but only shortly) into utopian moments and ideas. There are in fact various versions of utopia in these quotations, from hope, excitement, work, community, inclusiveness and a sense of difference from the present (an avowedly nonconsumerist yet homely utopia), all of which combine in the sense of building a schoolcommunity together.

Moreover, the crucial place of 'the school' - both conceptually as a common 'good' to aim for, and materially in the sense of its physical construction - leads me to suggest that in this at least double form the school acted as a 'facilitator' itself. As it was worked 
on, its emergence from many fields of potentialities collected these energies together, both a node and a changing actor within the community-in-formation, as collection(s) of building-assemblage-events. The importance of manual and emotional work is already evident in particularly the last quotation above, but also:

V Well, Chris was the architect, and he was in charge of the volunteer building. I remember going in and saying, I'm not very good at flat plastering. He said, oh good, that's what we want. And so, we learned to work the render, just putting a rubber glove on our hands and, using the sort of heel of your hand, to create the shapes. And it was very tactile and enjoyable. ...And, it was a much richer experience, especially for children, seeing their parents working. And then, parents see their children's reactions when the water first came down to the pond and things like that. So, it did help a great deal in, building an identity of the children and parents of the School together. ...So, the builders decided a lot, as they went along. And, the children copying got involved too. And we tried to incorporate their ideas, and their bits of building where possible. In the grounds, in the playtime was where that happened most. I mean, when you were building steps then they'd come and join in. I mean, it wasn't formal. Not when I was around anyway.

PK What do you think you gained from it?

V Oh, a great deal. Not only building skills, but the confidence. ... But it's also very nice to create a home or a building. It gives you a very different relationship to that place. And, it keeps you fit, and also it's fun, working with a group. I remember the builder, when I then went on to help with other building jobs occasionally, the buildings, the Steiner-influenced buildings, the first thing they built, was the place where they'd have their tea, which was a fire. A shelter, so that their social theme was set up. And then, the conversations at break time used to be very philosophical, or funny, or, profound, or, political or whatever. And I think, physical work makes you feel good. And sort of makes your brain work well too. So, that was great, it was very worthwhile (Female, long-term parent).

F There were difficulties at different points along the way, which there are bound to be. [For example] somebody built the wall outside, and it wasn't in the right place, so it had to be taken down, and that caused quite a kind of... [argument]! It's amazing the amount of work that people put in, really, on a voluntary basis.

PK Do you think that's partially where the strong community 'round the school was built up?

F I think at that time, it did... . I think, we're struggling a little bit at the moment, to re-find something, that we had at that time, I mean the amount of work that people put in was, amazing really. And then also, I think part of the community at that time, apart from the building work, which really did draw people together, was also the fact that we did this, teacher's training I 
think. And there are maybe about fifteen people on the course, only, maybe, three or four actually taught, but I think it was such a valuable experience to do it, whether you ended up teaching from it or not, I think it was, you know. My feeling is we really need something like that again. How it's going to come, I'm not quite sure, except that we are in a bit of a crisis and, suddenly people are really, working towards something again. I think we've been through, maybe a period, where in a way you kind of fall asleep a bit... (Female, long-term parent, Kindergarten teacher).

P From having watched this school grow, using gift-labour, using it as a way of also bonding the community, and at the time, you sometimes think is it bonding the community, 'cos there's always arguments and things going on at the same time...but when I'm in the classroom, and you look at all the things in the school, that's been made, the beautifully-carved doorhandles, and, invariably, you would have a child saying, my Dad did that or, my Mum did that, and, as a result the children look at the school in a totally different way. I just think it's a fantastic example, educationally, for children to see adults say, we need this, we'll build it (Male, ex-parent).

The actual construction of the school has been assigned with a number of effects. Firstly, as Day (1990b) himself suggests, the health-giving qualities of moulding shapes and working with materials acts almost like a kind of therapy, as the performative engagement with various materials encourages the brain and body to work in unison, working the former in more complex ways than intellectual activity alone can provide. The creative effect of this work - from the deeper sense of meaning and attachment to whose parents did what in the last extract - has health-giving and social effects that both Day and Hundertwasser (1997: 46-48) and are keen to stress. This is also a fundamental tenet of Steiner education - the joining of 'body' and 'mind' in activities such as building projects, knitting and gardening (and hence a version of the human's place in the world). Secondly, and related, pervading all of the quotations so far is a note that work, physical and mental, as well as the community that that activity (e)merged with, gives a nostalgic attachment to the school and the community through memory, and as 'home', as V says. For Day (1990b), it is gift labour that can truly give work back its true meaning, and certainly it is from this benevolent attitude that some of the above opinions are delivered. At the same, time, I argue, the comforting image of the school, as well as the warm image projected of its construction, are underlain by hard effort, often non-utopian graft through rain and cold, arguments and mis-placed walls. It was not only 
the image of the school and its function for their children that drove on those volunteers, and that provided a utopian aim. It was also that the work itself that, although hard, was in itself rewarding, challenging and now seen as utopian in a quite different sense, as in F's quote - something which, in a Nietzschean sense, might wake them up a bit.

Thirdly, and again, the idea and identity of community is materialised and performed through ponds and doorhandles, children's play and moulding plaster, rather than merely an abstract categorisation of a group of people, bounded by an arbitrary line. Instead, particular networks, biographies and collections of objects and people are brought together with no knowing outside: these are collected into and towards the school, rather than encompassed by any exterior boundaries (but thus they could be inward-facing and exclusionary in that sense). This builds an identity of the school which folds into the education that is provided there. For now, such objects bear particular meanings which even for those who arrive today are apparent, engrained in the stories about and identities of the community at the school. We must also remember that this happened through other material performances, such as the teacher-training course that $F$ describes - a different community-within-a-community - which also built together a sense of solidarity and 'pioneering'. In both instances, our 'critical' geography of architecture has uncovered the importance of literal construction (in addition to ongoing use-asconstruction) in the production of meaning with buildings, which in this case are perhaps the most utopian of any at the school. Finally, how much the community was truly involved in the total planning and building of the school varies by person - most agree (unlike V) that to a great extent, Day was in charge. Some are quite ambivalent about their part in the process (like F), such that the utopianism and in particular nostalgia apparent here are very personal. For others, the level of their involvement did not matter so much as the conversations and togetherness that the building and its use as a building site allowed (end of V's quote). The difference between then and now is inherent in the 'proper' functioning of community, and the particular version or vision that is often agreed upon by longer-term members. This vision is one of the ideals, comfort and belonging achieved through hard work - involving the school buildings. 
We must remember that folded into this is a desire to build a 'right' education for these parents' children: parents were, as they suggest, trying to realise their 'ideals', something which for them makes the community special, different, and hence pioneering and utopian. An element of this is of course the homely atmosphere that persists at the school. Yet this mixture can have profoundly uncanny, unsettling and strongly utopian effect:

S But, funny things happen because, people come and I remember, one person talking to $X$, and $X$ was saying, how many years since he had worked on the Kindergarten. This person was nearly in tears, and saying, I'm so moved by this, because it's so, so amazing, this dedication, you don't find that sort of involvement, very often (Female and male, founders, ex-parents, teacher).

How one reacts to such an experience (some with a dose of cynicism, I suspect) varies according to the power one attaches to a story such as this to have such an effect. Nevertheless, the emotional involvement in this extract points to the ways that certain conversations or acts collect quite different elements (many utopian in themselves) to have such an uncanny impact. Once again, the joyous/painful feelings evoked through the effort that was involved, point to the utopian (and unsettling) importance of work to the school and its community, in relation to the atmosphere of the school today. Quite why the impact was so strong I did not find out, but I would suggest that much of this would remain non-representational in any case. Thus far, we have encountered various ways in which the school community was built, and how a material version of parents' vision(s) of the 'good' through hard work was constructed. Once again, these events, nostalgic memories, and their comparison with other situations, present qualified positions derived from an immersion in events themselves, not any abstracted discussion of pure 'ideals' or 'symbols'. These were then worked from in the course of building, and the whole process amalgamated and summarized in our interviews.

\subsection{Community today}

This leads into the meanings of Nant-y-Cwm's community today. From the interviews, various versions of community emerged, complicating the seemingly coherent goals of 
the 'pioneering' stage. Often, discussion strayed from that on community, as in particular the problems associated with the finances of the school and its future, or memories of particular communal events, pulled us into other themes. Four broad themes concerning the school's community became apparent: how ongoing (often unseen), 'non-teaching' work on the buildings and school perpetuated both the ideals of the school and people's changing attachments to it; how those ideals, specifically those of education and 'childhood' are enacted through specific versions of teacher-parentchild relationships; how the community is cut across by other concerns and communities, some of which are only tenuously related, if at all; and how the community is seen, through those ideals, to be inclusive of many beliefs and backgrounds.

Although caring for the upkeep of the building was only an element of volunteer work at the school, this was seen as representative of the general level of parental commitment that is required at Steiner Schools. Such a commitment is not just necessary for the upkeep of a community spirit, but in order that the school functions at all, and that its particular ideological principles are upheld. Thus an individual's commitment to the school is as much personal as it is connected to the community. This is a complex relationship:

PK Was that slightly strange to start off with when you saw this?

J No, because I knew Steiner Schools. Also because then the parents are in the school, they know what's going on. They hear everything, and they hear the lessons from the outside, when they're doing the cleaning or whatever. So, the parents are, in the school ideally, the children feel that the community of parents is around them, carrying the fabric of the school, essentially. It's happened to greater effect at Nant-y-Cwm I feel. So that's one, fundamental aspect that keeps the school going, that the parents are there, caring for the physical, everyday, ongoingness of the school. Then there's these fundraising activities that are also carried, chiefly by the parents (Female, parent, five years).

I am interested in the idea of the very presence of the parents - and their work at the school - giving a 'feel' of community for the children, so that there is an idea that they are 'carrying the fabric of the school'. Through this, the idea of 'home' is given further 
weight, as family life is crossed with that at the school through the appearance of parents. Clearly, the feeling of community is constructed through work on, and presence at, the physical buildings. This is nothing spectacular, usually cleaning the toilets, or maintenance, or in particular events held at the buildings or for the school, such as parents' evenings. Through this work, and these meetings, not only is the community around the school enacted, perpetuated, and crucially imagined, but that community is also a critical element in the construction of education at the school. As this parent highlights, it is not unusual for Steiner Schools to be organised in this way, so that the buildings, community and education are designed to performed as a unity. These are, however, not just ideals or enactments of a greater 'good', although they seem to partly be this, listening to parents and teachers. These community activities are also modes of doing the best possible, muddling through, and doing what is necessary. Like Law and Mol's (2002) signal-workers, these are often non-representational practices, hard to pin down under identifiable aims, and singular concerns - like getting the toilet clean. But, as I suggested in Chapter 11, we can see here how utopian ideals and moments are interspersed within some of these acts, entwined with the events, particularities and generalities (we hear in the last quotation about the general presence of adults, not one specific event) of days at school. We also see later how these acts - of those who put most work into the school - have been re-configured by some people as the new 'good' in terms of labour. These 'goods' are discussed in stark contrast with the more spectacular, but now seemingly less relevant, work of the 'pioneering' stage.

Additionally, where the school is essentially a private school, it relies on volunteer work in particular from those who cannot afford to pay full fees, and on pressure to raise funds in diverse ways:

PK Just coming back to the way the school's developed. What about the school community? Was there sort of a concerted attempt to, bring parents together all the time?

P Yeah, that's happened a lot, I think, and it still does. That's, one of the byproducts of not being funded by the State (laughs through last words). Everything within the school has to be paid for by the parent body. That goes right down to, you know, the biro we use in the office, there is an enormous pressure put on the parents, to provide, and, at the school we've developed 
various ways of raising money and supporting the school, which [means] all parents being involved (Male, ex-teacher).

The place of money at the school is in fact a contentious one - finances being at the heart of the current crisis there (see below). As parents are asked to contribute what they can afford (for stationery, etc.), much of the shortfall has been made up by other contributions, largely in the form of volunteer labour. One is almost compelled to work by a structural feeling that does not actively force people to work, but the power of unseen eyes watching people withdraw from a community of workers is quite strong. Money is of course a crucial part of utopia too. Most utopias either abolish money (as with many community schemes), democratise wages to near equality (one aspect of socialism) or provide an abundance of money (as in fairy stories like the Land of Cockaygne). Ultimately, (unequal access to) money is seen as a type of structuring evil. Escaping the vices and constraints of financial forces (towards security and comfort) is thus a key aim of utopias in connection with their political and liberatory potentials. This was dealt with at the school, initially, in a tremendous amount of volunteer work, along with the contributions of a few benefactors, so that the school cost just $13 \%$ of an ordinary project of similar proportions (Day, 1990b). Additionally, evoking the spirit of the time, those involved talk of how money was just a background concern, precisely backgrounded because of the pioneering spirit and inspiration they nostalgically draw on to describe that time (see previous section). This meant that the exact amount people had to pay was never set (nor was the amount of work that could replace that), so that there was often slippage between what different families paid, and between the amount of work they did and their financial contribution. Ultimately, of course, one cannot avoid the concern of money - this is a private school, despite the low income of some parents. The needs of the children and the buildings cannot all be provided for by volunteer labour, nor can teachers work unpaid. The 'enormous pressure' upon parents to provide is a harsh 'reality' compared with the enthusiasm and idealism of the 'pioneering stage' - another context for the versions of utopia I discuss here, and another outcome of the specific, conflicting geographies I encountered at Nant-y-Cwm. Crucially, however, this manifests itself in an interesting way at the school. The problem of money has always remained an element which should be 'removed' from the day-to-day performance of 
education at the school, as people work hard to keep the school functioning physically, as the type of education that its being produced demands a certain separation from such concerns. For some parents, this has meant that other parents as well as children have become separated from such 'practical' constraints through an at times dangerous and mis-placed ${ }^{1}$ idealism - hence some of the problems the school is currently experiencing.

The performance of a Steiner education at the school (also Chapter 10) is also carried out in a number of other ways. We become aware of how parents, teachers and children are also part of an 'educational' community too. There is no boundary or even definition of the general school community and the educational one - it is just that specific configurations of people and events are necessary to enact certain activities appropriate to the school:

J So, I feel there's a place and a time for far greater dialogue and communication between parents with teachers in a Steiner School, than parents in a State School...so it's very different here, and a community-run school.

PK So the meetings aren't just constructed formally, as in, a main parents' evening?

J There are those. But a typical parents' evening at a Steiner School would include, from a teacher, a presentation say on the term's work, coming up, which things with history and science and so on, how they were being addressed, and probably some artistic activity as well, that the parent really gets to experience what their child is participating in. And then there will probably be time at the end of that, or on a different day, for an individual one-to-one talk about the child (Female, teacher of five years).

P You were asking about, community, this is more than just practical things like cleaning the toilets. It is so important, that, the parents are, working with you on the education. I mean, if you've got kids going home, playing, computer games, up all night, blah blah blah, they come to school and they're frazzled. You've got a really difficult task, to work with them, and so the parents' evenings at school are, opportunities not to be missed. Yeah, but the important thing is you do it with them, you work with the children (Male, exteacher).

Thus the agency of the parents and the children themselves in creating 'proper' Steiner learning environments is key to the functioning of education at any level. Yet specific

\footnotetext{
' One woman argued this was almost 'child-like: see also N, below.
} 
types of performance, rhythm and comportment (see Chapter 10) are necessary for this education to become-specific to the ideals the community simultaneously holds and enacts, and which the buildings themselves are supposed to embody. In a swirling of elements, an almost abstract 'community' is both constitutive of and constituted by the education at the school. Moreover, the visioning of the school as a haven, a community which must be constantly involved and sensitive to the needs of the education, must also be worked on:

N It's always, this community-building 'round the School. It's an ongoing effort, a process. How can you help each other, how can you, keep in touch with each other, how can you support each other, parents and children? How can you make it so that people come, to the School? And, also get to know the education.

PK So, you say the School's not just there for the children, it's there for the parents as well?

$\mathrm{N}$ That's what I've always felt (she laughs quite long, quite loud, I do also)!

PK It is quite a haven away from everything else.

$\mathrm{N}$ Yes, that's right. But, also for the children's sake. So many young people, they are looking, they have lost their roots. It belongs to our time. But it also creates a lot of loneliness, and hardship, and suffering. Especially when relationships break down. It's all so disruptive and difficult. And the School, is the place that's there, for the child. It carries them through (Female, founder, ex-Kindergarten teacher).

This quotation highlights a number of themes. The school itself (the buildings as well as the idea) is seen as something around which the community can be built, a community which, moreover, should be built. It is thus an axial element in the construction of a community continually effected through networks of keeping in touch, support, and so forth. Moreover, the attachment to the school that I discussed in Chapter 10 comes through the place the school and the comfort of its community have for parents as well as children. Indeed, a couple of interviewees questioned whether the school's status as a 'haven' for children was not also for the parents. The questions of belonging, home and roots are all fundamental to particularly 'imagined communities' (Anderson, 1993), as those become projected within the future, present and past, as well as experienced as utopian, through partial subjective positionalities. Once again, this is an ongoing effort, as $\mathrm{N}$ suggests, which involves the buildings in complex ways - yet in simple tasks like 
cleaning, maintenance or decoration. The community is explicitly involved in the production of a homely education here, especially in relation to an 'outside' that is drawn by $\mathrm{N}$, against which children can be protected.

Community initiatives are also quite removed in many ways from the immediate localities and education at the school. They are, however, imbued with the financial concerns of the school, as well as cultural or identity-related similarities:

J The other thing I did for a while was with this organisation called Nutters. Which is, a, catering - it goes off catering, at festivals, like Glastonbury. It was set up in the early days, to help meet the shortfalls. It does make a lot of money. So I used to do that, it was really exhausting. ...It's a whole other, parallel existence with the School, that l've been through... (Female, longterm parent).

The effort of forging an education for the school - a haven - is thus implicated in various alternative funding sources. The presence of the 'Nutter's' café at Glastonbury is interesting for two reasons. Firstly, it connects together certain practices with those at the school in a network of broader practices that are (or at least used to be) labeled as 'hippie' or alternative. Thus the difference that we encountered earlier in the chapter is perpetuated by certain activities and materials (tents, foods, etc.) that are both paramount to the survival of the school and also incidental to its day-to-day functioning. This also normalises the school within certain 'communities' of people, beliefs and action. Secondly, this incidental existence - being 'parallel' to the school - but with it, suggests that those involved in the café are both engaged fully with the school at the same time as being engaged in something else. The functioning of the school is thus bound up in subsets of the community, attached to quite other tasks, people, materials and places. Whether they constitute communities themselves was unclear, as was whether they worked within broader, or almost separate, or cross-cutting, communities. Nevertheless, this purely illustrates the complexity of the intense work people do for Nant-y-Cwm. The constitution of 'difference' that the identification of the festival with the school gives, means the school is far from 'cut-off' from external practices, and 'fits in' with other communities that are not necessarily locationally proximate. Moreover, the 
identity of Nant-y-Cwm's community is enacted through particular bodies and materials, who also act elsewhere, mutating activities and ideals into a festival café, rather than a simpler extension of the school (perhaps through an advertisement or taking part in a local event). The identity of the school is thus effected through such linkages at the same time as that identity changes and creates new effects in its translation from West Wales to Somerset (Glastonbury). Other examples of Nant-y-Cwm's various linkages are the school's roles in the Steiner Schools 'network' - taking part in sports events with other schools, or staying for vocational weekends. The school, its identity, and 'community' not in a utopian sense now - are thus connected into varied and changing communities. There might appear to be boundaries around the school in terms of its problematic relationship with its 'outside', yet in sum there are various connections that are forged here: with other ecological buildings, people' personal interests and friends not at the school, families, Steiner Schools, Nutter's... .

This is cut across further by personal concerns - so that although there are many divisions within the school community in terms of its 'right' future, there are still more ways in which the community is not the 'centre' of attention, unsettling any privileged status it might hold, in dynamic, changing ways:

PK So what's you involvement with the school?

$\mathrm{C}$ Well, at the moment, I'm doing, the bookkeeping, and I do the wages. Last year I was the administrator. The year before, yes, I was teaching Welsh. ... I also teach IT, I work for a training organisation in X. Well, I work outreach actually, I take laptops out to the community. That's again work that is not just the hours I'm there with the students, it's also a lot of work at home, so it's quite difficult to, and the children too.

PK So how would you place the School in the context of your life then? Do you think it takes up most of your time?

C Ummm not now. This year, I actually feel it's a much healthier balance last year. Because, it was, I mean it was everything. It had, in the past, I mean, it seemed like the only thing I did, it was my job. ...And you also become the prime, where people say, can you help me with this and do you know about this? Which is good, I enjoyed that role, and I actually miss being a bit more involved (Female, parent, relatively recent). 
The place of the building in the last few extracts has been less clear. As the discussion moved from the school community to other concerns, naturally the buildings became less important. At the same time, however, some of the discussion about the community at the school was not centred on the buildings, but instead concerns of teaching or fundraising. Although the community is held together by the building as a focal point, once it has performed certain tasks, it is a forgotten facilitator for discussions and events far away - as communal activities become dispersed throughout local and even broader landscapes. For this woman - who mentions "the (local) community" - clearly the isolation of the school from that community is not felt in her own life. This illustrates again that not only is the school subject to varying demands and visions, but (not surprisingly), it plays a different and changing role in each person's life. At times, as C suggests, it can "take over", so that one's attachment to it is far from utopian. Moreover, the situation has changed since the pioneering days - there is now just a sense of going on, no need for total involvement, which is understandable given that the school appears as an 'achieved' state which can now be viewed as a service. However, for F, above, this has been part of the problem. For her, with the parents "falling asleep", a decrease in work (and vision) has led to some of the problems that the school has been experiencing. Apart from the utopian potential of work-in-itself, there is a fundamental aspect of utopianism here - that of the effort required to provide perpetual newness, energy and impetus, preferably through some sort of vision. In fact, without reference to work (a facet I think is important), many utopian commentators suggest this has been the key role for utopias - a constant source for change and impetus to go on - perhaps even a 'performative push' (Holloway, 1984; Rabkin, 1999; Thrift, 2000).

The final aspect of community life is the notion of inclusiveness. Much of the chapter on 'difference' highlighted how many of the practices at the school were part of often differing views, and that the school's inclusiveness encouraged people of many backgrounds to attend. However, the school's intake is far from representative, not only of 'minorities' defined by class, ability and race, but also of the local, Welsh-speaking community. The next quotation perhaps illustrates this tension (partially bound up in choice, and also in having the connections or beliefs to be interested in, or find out 
about, the school), before moving on to another different interpretation of the school's community:

D In terms of religion, it kind of encourages families who aren't comfortable, with the Christian education you might receive in mainstream Schools. I mean, we're pagans, but I don't mind the Steiner education, because it's so much broader. And although the rooms have got the mothers and child in the pictures, it includes all the other religions as well. But, that's the other thing with this particular School, is that, they're all white children, from, very similar backgrounds. But there are a lot of alternative families there. It is very inclusive, it's a really strange one. But they all seem to get on alright. My daughter gets on very well. And the children as well, because the ages are so sort of mixed up, they really do mix. There seems to be this real, family there. And because the teachers start with them at the age of six, and move through the School with them....

PK Is there a sort of larger, I don't know if you call it a community, of similar people around here?

D I think you can call it a community. Although I think one of the problems the School has been suffering is lack of community. The fact that the parents aren't necessarily socialising. Or, that they don't even know each other very well. I'll be honest, that when we first arrived, I was disappointed in the lack of welcome. I didn't mean I wanted a party for us, but I didn't feel like anybody was getting to know. And $I$ had to do the work, a bit. But there is a good community spirit now think. It's like anywhere, anywhere is politics, and, the School is the same as everywhere. You get human beings, you get politics (Male, new parent).

D presents a type of inclusiveness selective not so much along traditional categorisations or identities. Instead, he marks this out in terms of beliefs and the (lifestyle) choices that make up those identities, and can often cut across them. He highlights the few racial minorities at the school, but also the inclusiveness along religious grounds, despite the very Christian-orientated nature of teaching there. Yet this is far from a religion-based community or utopia (to the disappointment of some), as Steiner's curriculum is based on change and inclusiveness as well as an explicitly Christian-b(i)ased education. Yet despite this inclusiveness, $D$ received less than a warm welcome - which left his perception of encountering the community there both positive and negative. Thus one of the important aspects of a community - being made to feel welcome, at home - is not just inherent to an 'inclusive' community, but something perhaps contingent upon the time and the broader dynamic of events and materials available. Moreover, the change in 
community feeling since his arrival there - and the agency of the 'work' he had to do, as well as particular friendships forged (as at the house), have changed his perception of what community means at the school - and whether there is one at all.

I would add a cautionary note, that often many of the stories and events in this section have been far from concerned with ideas about utopia. They do tell us more about people's engagements with architecture, and about how a community is constructed through piecemeal engagements between human and non-human actors, through cleaning, building, maintenance, fund-raising and computers. There is a sense that people are working through everyday concerns and practical problems here, and that short-term goals are often key. However, in the holistic sense of the educational curriculum itself, and also the relations between what people told me and the broader ideals they espoused, larger-scale notions of the 'good' for children's education and qualitative judgments about the community at times verged onto utopian memories or visions. These were not necessarily unsettling (and were often comforting, or notions of inclusiveness), as in previous chapters. Nevertheless, a recognition of how these notions are constructed and given meaning, and the often unknowable, heavily-worked actions through which they are actualised, are unsettling in that 'stable' notions of the good can only ever be produced in and through those actions.

\subsection{The future of the school (community)}

Finally, I would like to take four extracts illustrative of the various ideas parents and teachers expressed to me during the interviews about how the school should develop in the future. As well as being contingent on the particular circumstances and content of the interview, and sometimes presenting normative or more traditionally utopian desires, they also point back to and illuminate people's opinions from the previous two sections regarding the school and the community that is constituted with it. 
As a result of the mass of energy that many people have put in for up to twenty years, some argue that many do not want to lose control of the school (naturally) and that they are too intensely involved with it.:

C You go to trusts, European Councils, partnerships, there are so many. And that's just off the top of my head.

D The trouble is, at the [School] Council, they're all knackered actually, exhausted of doing all the work.

C That's typical though. Why isn't anybody helping us? Because we don't want their help.

PK So they need lots of new people with lots of new ideas?

D Perhaps. Have you met X? ... And, X's very unpopular with the children. And $S$ represents, one aspect of Steiner education, which I think is best left behind. ...And a very bad representative of the School, I think. There's an exhausted Y, who's done everything for the School. They've all gone through it. And is now well worn out with the whole thing (Female and male, new parents).

Perhaps activity at Nant-y-Cwm has become a too personal and an abstract ideal of community thus fragmented into weary individuals' performance of everyday tasks, where being seen to continually invest energy. Perhaps even performing for certain people and materials, rather than an abstract totality, is of greatest concern. In the above quotation, the abstract notion of a community, and the work that is involved for it are anything but utopian - and the discussion turns to personalities rather than a totality. The question of help from outside is seen to be prefigured by a desire to draw limits around the community, where in fact the work they are undertaking may be less to do with the community than a sense of the (lost) ideals of the past. In fact, where some parents hold very different views of the school, the notion of a unity (already questioned through so many cross-cutting elements) is lost:

C I am quite happy with the School, the building. But I can tell you this. I am very very angry about the alternative educating, drug-taking, bollock-talking, crap, that I have an allergy to. It's all yap and no action. And it distresses me to see it in a School in such a nice place.

PK I suppose one of the troubles is that when they bring in the computers and the structure, some people say it takes out the spirit of the Steiner education.

C They can either have a School, or they can not have a School. And, Steiner, did his stuff at the beginning of the century. It's not a compromise though. If you want to live a the beginning of the Century, then go and join the Shakers. 
But Steiner wanted the best thing for the children. He couldn't foresee computers, but he would have embraced them. They're not antagonistic to a Steiner education.

D And the philosophy embraces change. Maybe some people take it too much as a bible (Female and male, new parents).

Interestingly, the changes that appear necessary for $\mathrm{C}$ are also simultaneously implied in the philosophies on which the school draws for its collective goals: "He [Steiner] couldn't foresee computers, but he would have embraced them." The general 'hippie' character of the community the woman in the last quotation identifies gives the latter a seemingly 'outside' view, defining the limits of what might be acceptable inside the school community and outside it. This version of difference highlights that the community at the school is neither solely made up of 'alternative' types or those that embrace a Steiner education, but a whole variety of beliefs, which render that community and its future complex and unstable.

Two final quotations illustrate quite different views about the future of the school. Again, perhaps, they attempt not to acknowledge some of the sources of funding (councils, trusts, charities) which might compromise the particular atmosphere of the school, despite the calls of the two people above:

PK So how do you think the School will be in the future?

A Well what I would like it to do is grow. I do find there's some people who are, not letting go of the past? Which, in a way, is inhibiting growth for the future. I mean I'm not into just getting rid of everything just for the sake of it, but it's, a very strong feeling I have, that things do have to change. Some of the teachers have to, become a little more modern maybe. And, address the times we're in now. This whole thing around the Kindergarten building has been quite an issue. Because, there's obviously, people who've been very upset, about the fact it might have to be sold. And it's bothered me slightly, because it's people who, you know, haven't had an understanding, or not been prepared to accept the reality of the crisis we've been in. And it's like, almost hanging on to something, for the sake of glorifying one individual [Christopher Day]. I mean I'm probably being a bit extreme here. But you know, when I think about, people have been saying, oh, you know, all the work that was put into it, and, Chris Day designing it and blah blah, and isn't it all wonderful blah blah. But actually, there are people who do unseen boring work, that have helped keep the School going as well (Female, longterm parent). 
PK How do you envisage the future of the School, in the next ten years?

J Well, I think that the School might have to, contract, a bit. But I think that anything is possible in the future. And certainly, all the Steiner Schools in England have got really long waiting lists. And I think that that will follow here eventually. As people, appreciate, how good Steiner education is for children.

PK So, is there more of a, concerted effort to, think about, why the School was set up in the first place, and, how you can sort of market it?

J Yes, there is a lot of that going on. People trying to, think of ways of marketing the School, better. Because, we've never, been, very aggressive, publicisers of the School.

PK And then, what sort of ideas have other people got, for the future of the School?

J Well, some people think we should move to ummm a bigger centre of population, that we're too isolated out here. Some people think it would be good to, you know have an Upper School as well, so that their older children could come here. You know, we could certainly develop, if we had enough, if we had older children here, then we could have lots more foreign students and things like that. We could, have a language School here in the Summer. If someone could organise it. And we could make use of the building in the Summer (Female, long-term parent).

These excerpts indicate various, conflicting, views about the future of the school. Firstly, A highlights the problem of attachment to place and nostalgia 'inhibiting' growth, as I discussed briefly above. In some ways, the deep phenomenological attachment people have to a place and community, have always been seen as indicative of attitudes which are neither progressive nor inclusive. With a post-structural deconstruction of Modern assumptions, of course, terms such as 'progress' have in turn also become questioned, so that the relationship between community, phenomenology, progress and change is more complex. Clearly, new approaches ${ }^{2}$ are called for in comprehending such processes. But here, competing versions of progress (using Steiner's philosophy to promote idolisation of the building and Chris Day, or to promote change) interact with certain versions of community (spectacular and mundane work), so that the difference between and performative production of each version is more complicated than the resolution of simple dualisms. Such nostalgia unsettles more 'rational' versions of how the school should develop, as well as providing another version of 'safety' and homeliness which

\footnotetext{
${ }^{2}$ For example, seeing a community as collection/dispersal, or through its material and performative elements rather than approaching them as pre-given entities or relationally constructed ideas.
} 
might be unsettling for some as a result of its apparently dis-ordered, ad hoc, and 'alternative' character. Similarly, those cosy images, of a 'rosy' time as we heard in Chapter 10, are themselves now disrupted as competing versions of the school's future challenge the authority of the work (with more 'unseen boring work') that went on then, and challenge that organisation as the hegemonic one at the school. This exposes a certain lack of coherence in the community as a whole. Moreover, this also evident in the varied assumptions of its members, and wherein the school buildings (with their competing financial, educational and memorial worth) are themselves problematic members of those communities.

Secondly, many of these suggestions would have to be carried out by a community of humans and non-humans. However, these ideas are not just ideas about that community, but specific assemblages designed for the school to go on at all, and attempt to mix its utopian past and ideals with a possibly more 'rational' future. There are still ideal or utopian 'goods' being proposed here, partly rooted in what 'we' as a community should do: however, these are located in very personal visions. Thus the concept of community, problematic as it already is, is rendered impotent at times where different groups of people rally around a particular concern in momentary discourses and actions. One event, such as a meeting about funding, does not necessarily constitute a community but agents drawn together in rough parallel to actualise sets of forces of which community intentions or considerations may be one (cf. Bauman, 2000). Thus, as with the previous chapters, each concern is internalised around the school and externalised into other situations. Thirdly, the materiality of the building recurs often only in my interpretation of events here. However, as the basis for discussion in interviews, it was strange to see how a joint notion of what the buildings were diffused conversations off in so many different directions, joining together massive generalisations (abstract ideas about the local Welsh community) or small elements (doorhandles) in heterogeneous ways. Again, we see how in the interview process itself, a critical geography of architecture hung on a mutable skeleton of collection/dispersal/cross-cutting (etcetera), had much to tell us. Fourthly, the school buildings make a cutting return in the recognition that all that work and homeliness might have to be sold off. This is of course profoundly unsettling, as too 
I suspect are the arguments of those who valorise more recent work over the 'pioneering' work done on the Kindergarten.

Finally, related, in comparison with section 12.2, we could question to what extent these differences and concerns are utopian. There are various answers to this difficulty. The first is that with the problems the school is undergoing, the key concern is survival, rather than the production of 'homely', euphoric or 'perfect' visions of the 'good'. However, there are four ways in which these visions bear elements of utopianism. Firstly, as Jacques (2002) argues, any vision can become utopian (or crypto-utopian) where it attempts to produce a particular mode of organisation or ordering in relation to other visions, just as these competing claims do. Secondly, we have the continual folding of other utopian themes: from difference and the homely, and in particular the school's past and the 'ideal' vision of childhood it promotes, which inform for example $A$ 's quotation in this section. Thirdly, in a sense of loss and almost desperation with the current situation, we fall back onto these 'better times', with a very painful sense of nostalgia. Finally, as I have argued, the unsettled future of the school has produced various visions. These might be crypto-utopian, but in the ways in which they are grounded in the material realities of the school and its history (not separate from those), they unsettle many of the previous visions and utopian moments at the school, expose their contingency, the performativity and ephemerality of a community, and the general utopian ethics that emerged from them. The school is not, and was never meant to be 'utopian', so this is not a case of the danger of failure. At the same time, the idea of community has been enduring in terms of the people involved and many of the ideas not all is constant flow and flux. Instead, we must bear in mind how the utopian elements that were and are involved in the school's construction are as unsettled yet persistent as the performances through which those elements were produced. The spaces of the school and the community were and are co-constructed along with these utopian elements, in processes of repetition and change.

\subsection{Conclusion: Nant-y-Cwm}


This chapter has shown the multitude of ways in which community is experienced at Nant-y-Cwm, and how this is connected into the themes of difference and the homely, and at times, to utopian moments or ethical positions. I began with Day's thoughts on Consensus Design, which emerged with the building of the school and provide one way to characterise the 'ideal' and utopian building process that occurred at the Main School and Kindergarten. This bears similarities with the actual/virtual distinction, and utopias related to that. I then encountered a series of utopian, and sometimes what I have termed 'unsettling', moments through the 'pioneering' stage of the school, the nostalgia for that time, the pain and tears associated with that, and the uncanny effect of hearing about that work at the school. These were rooted in euphoric moments (as at the HundertwasserHaus), but more broadly collected into general ethical concerns about what the community means and meant. Work was also associated with 'healthy' activity, and the opportunity to build an identity of the school together which could contribute to the education at Nant-y-Cwm very literally and also symbolically in later years - through door-handles and ponds. The buildings were a crucial part of this discussion for this time, but became less important (as did these versions of utopia) throughout the chapter. They were associated with the ongoing work necessary at the school - which for some replaced the more spectacular work done in the early period - and a new version of parents' 'good' practice. I also explored how the community had to be brought together by teachers (including parents and children in as many activities in- and outside the school as possible) to produce the 'correct' environment for a child to learn within a Steiner framework. These coherent versions of community were crossed with the plethora of ways in which the school, its buildings and various actors take part in various networks, from those of Steiner Schools to the festival scene - and the various discourses of alterity and normality they evoke through those connections. The notion of community was questioned further through a brief exploration of its 'inclusiveness', which emerged as a complex issue, contingent upon the performativity of certain situations. In the final section, we looked to the troubled future of the school, which at the time of writing is still by no means clear. We see that the notion of a community does pervade, but there are various, conflicting notions of the 'good', which appear utopian in some ways, but not in others. Which ever is the case, these cross with the 
many utopian, in some ways comforting images we have encountered throughout this thesis at the school, and unsettle those images through questioning their relationship to the present(s) and its futures, and the ways in which they were enacted. Here, the buildings effected a cutting return as the possibility of selling the Kindergarten (and all those associated actions, memories and discourses) looms as a solution to the school's financial crisis. Whatever eventually happens at the school will be an intensely complex mixture of all the elements that I have discussed so far, whose success is contingent upon the ways these are collected together and worked, and, possibly, the need for new visions to unsettle (yet not forget or break from) those of the past.

\subsection{General conclusion to chapters $11 \& 12$}

In a similar manner to Chapter 11, this chapter has argued for a performative understanding of community, for the role that community plays in utopian constructions, and the material importance of (bits of) buildings and other non-human actors in the enactment of communities. As with the Hundertwasser-Haus, the weaving of themes such as difference and home has brought us to a discussion of community rooted in a desire for alterity and normality, and for a 'right' way of conceiving the body's relationship to architecture (by 'making home').

I have attempted to show how the problem of interactions between people - community life - is a crucial element to discussions of utopia, in two sites that do not always receive much attention in conceptual discussions of community. However, although my conclusions were site-specific, the general importance of performativity, materiality and versions of the utopian unsettling specifically geared around work are, I would suggest, salient to various contexts and more general theoretical discussion. Additionally, by following the complex collecting/dispersing that constitutes communities ('scattering' and 'building together', in respondents' own words), I have shown how this particular version of a critical geography of architecture can produce complex but at least broadly identifiable meanings. These might be emergent ethics, practical considerations or utopian moments, yet this (and the buildings as key locational nodes or actors) helps us 
focus our attention on the contextual and thematically inter-woven construction of those moments in contingent 'fields' of action. These communities, although 'bounded' in some senses, were of course not in many others. At time these were very simply 'focussed' on the buildings themselves, as literal sites at which the co-production of ideas about difference, home (and community) could be enacted by communities of humans and non-humans together.

In total, we have seen how the processes of community-construction both differ and bear similarities at the Hundertwasser-Haus and Nant-y-Cwm. Yet again, the flow and contingency of utopia in relation to utopian ideas both unsettling and comforting has more profoundly unsettled the ways in which we conceive of utopia, its imagination and experience. To re-iterate, I view neither building as utopian, nor identify or connect all of the community practices in either chapter with utopianism: that would be a misrepresentation. I have shown, however, through a critical geography of architecture, that various instances are connected to utopian emotions and ethics, in particular where nostalgia and hard work are involved. Moreover, the idea of community is (still) at the heart of concerns that are both utopian and otherwise, whatever the complex relationship between 'utopia' and 'otherwise' might be in a specific building-assemblage-event. 


\section{Chapter 13 Conclusion}

\subsection{Unsettling utopia}

I began this thesis with a review of utopian studies and philosophy, especially from the nineteenth century onwards. I argued that most writers have been involved with the definition of utopia through its form, function or content, although 1 indicated that in most cases it was difficult to separate these descriptors. My discussion led through a variety of themes, including euphoria, the ideal or inclusive city, comfort, political or National visions, the ludic, communities, opulent consumption and luxury, perfection and process. I depicted a variety of approaches to utopia, from Marxism and socialist utopianism to feminism and post-structuralism. Through this, I demonstrated how my three key themes of difference, home/comfort and community were, to differing extents, crucial elements in such studies. It became clear in Chapter 2 that at least three areas were salient to much or all of this review, and also required further thought. First, and foremost, many commentators provide explorations (and visions) of utopia that discuss inclusiveness, community, comfort and economic stability. However, I argued throughout this work that there is an accompanying element or tone of the unhomely, uncanny, disruptive and even the despicable in traditional utopian thought, and in other visions of the 'good' or euphoric which can be re-theorised as utopian. In some instances it is possible to recognise that a degree of disruption is an obvious part of the effect utopians such as Marx, Le Corbusier, Barthes or Debord, desired. I believed that there was far more to be gained from this line of enquiry, theoretically, historically and in contemporary empirical terms: my conclusions from this are presented below. Second, recent work on utopia has investigated a range of debates of more general contemporary interest - such as the body, deconstruction, performativity and (very loosely), ANT (for example, Young, 1990; Levitas, 1990; Sargisson, 1996; Sandercock, 1998; Grosz, 2001). This situated utopia, and my own work, within a further exploration of these 
debates, incorporating as it does my third main thesis aim (p. 7). Furthermore, I also interpreted the contingency of many of these works (for example, Grosz' use of Deleuze and Guattari) as a crucial element of the utopian unsettling which is already recognised as fundamental to post-structuralist re-theorisations of utopia. My discussion hence began to situate utopia within (the virtuality of) everyday practices rather than in some isolated State or state, a move I sought to develop in this thesis. This also meant a turn to euphoric, utopian moments, as well as ethical or political visions of the 'good'. Third, I identified the problematic importance of space, and particularly architecture, to utopia (Harvey, 2000; Bauman, 2003). Where 'escape' was spatialised - and 'realised' - we encountered the problems of exclusion, and human and non-human physical limitation. In other words, the 'impossiblity' of utopia became apparent (and hence the turn to the contingent and virtual/actual in recent work). Nevertheless, the form of the ideal building or city pervades many texts that are concerned with politics or euphoric escape, one of the key sites at which utopia has been located, and in fact a utopian art itself (Kumar, 1991; Fishman, 1999). This set the scene for a more empirical investigation of utopia through contemporary architectural practices (Aim 2).

In Chapter 3, I fleshed out the main argument of this thesis (addressing Aim 1): that utopias are very often associated with the unsettling of social relations, thought and desire. Moreover, this unsettling, with a diverse array of forms and functions, might be a utopian dream itself, or the underlying characteristic of a utopian moment. The unsettling is not opposed to what I termed for clarity 'traditional' versions of utopias, nor is it designed to replace them. Instead, the arguments I presented in that chapter unsettle, and perhaps deconstruct, the problematic separation of utopia and dystopia, and utopia and reality. They also attest to fundamental energies and effects that are found in many utopias, which create a (sometimes painful, even violent) spine-tingling effect, as well as being geared around inclusiveness, comfort, or community. This required a performative sense of the affectual capacities of utopias, yet also demanded the 
beginnings of a rigorous re-thinking of the utopian 'good' - the ethical dimension that cannot escape any discussion of the 'good place'.

This general line of thinking hinged around eight, inter-related versions of the unsettling, and hinted towards many more. There is not space to discuss each in turn here, but I list them and make some general points. These were: revolution; hard work; the un/homely; ruination; sacrifice and the terrifying; Romanticism; risk and public space; and the performative - and emergent - evental ethical. One or many of these are contained within numerous (I would not arrogantly suggest all) visions or versions of utopia, from at least the nineteenth century onwards, and some appeared in my discussion of the Hundertwasser-Haus and Nant-y-Cwm School. Again, this does not mean that such visions cannot at the same time be homely, comforting or excessively luxuriant. Indeed, in the case of sacrifice, I wondered whether an extended/distended notion of excess might not be terrifyingly utopian. Additionally, it opens up a range of other visions as containing utopian characteristics, and attempts to account for the unsettled and unsettling ways in which utopias were constructed, and were set to work in society. There are three further points I should make in summarising this argument that relate to those regarding Chapter 2, above. Firstly, that my three main themes (difference, the homely and community) again emerged throughout this discussion, for instance in the utopic pain of encountering the other in more inclusive public or community spaces. These themes could also be seen in the hard work that was involved and very much desired in constructing - not necessarily just dwelling or living 'in' - utopias. Secondly, and more pointedly, much of this account, and indeed the whole thesis, revolved around the dismantling of any dualism between the homely and unhomely (which hence became the un/homely). In many cases, this required an invocation of matters architectural, through ruination, the Romantic, work, public and urban space, and materiality/performativity (see point 3 for the latter). Re-reading the rather different yet connected arguments of Freud and Heidegger, and then Vidler (1992) and Krell (1997), I 
argued that if the homely can become un-homely, and the utopian is attached to the homely, then the unhomely is not merely dystopian but also utopian. In other words, not only can each become the other (as Freud and Heidegger suggest), but if we fully deconstruct the coupling, and watch empirically how they are given meaning, each is contained within the other as well as emerges in connection with various other notions besides. Such a mutual production of utopia/dystopia might seem dialectical, but is not meant to be. For, by un-homely I mean discomforting and uncanny also (using this seeming dialectic to stress the un-homely of utopia), as I am interested in the ways in which the homely or un-homely come into being - or are performed. An interest in the un/homely not only necessitated an architectural way of thinking, but also, I think, an empirical re-engagement with architectural practices and geographies. This led to the third important argument of Chapter 3. I attempted to set the performative notions of utopia discussed in the previous chapter into the context of the utopian unsettling. I also explored the utopian potential in current geographies of performativity. I extended this into the related, but historically under-researched capacity of ANT and studies of materiality, to contribute to previously 'abstract' studies of utopia - in particular architecture. I was not only able to forge another connection with my discussion of architecture (and critical geographies, in Chapter 4), but highlighted the contingency and performativity of even representational, large-scale, perfectionist utopian 'visions'. More pointedly, and as a framework for researching utopia, I demonstrated how utopian moments - whether short, affectual experiences of euphoric intensity or 'hope' (Anderson, 2003), or longer-term notions of the 'good' - are only experienced in the context and matter-realities of 'everyday' life. I did not advocate a Romanticisation of the everyday - rather, an acknowledgment that all utopian experiences are emergent practices, contingent, actualised, and could have been (slightly) other. I also argued that the very fact that this occurred unsettled both utopia, and our definitions of the 'everyday' as that of the mundane, repetitive and purely practical. Moreover, that nonhuman agents (nature, bricks, door-handles, mould) were fully implicated, in a 
processual sense, in experiences and collective individuations which became-utopian, is also fundamentally unsettling.

Some of the above insights also drew directly for their inspiration and examples from the house and school, which are discussed below. These included Hundertwasser's valorisation of ruination, Day's of (community) work, and the processual contingency of human/non-human performativities, discussed to some extent by both architects. I incorporated the uncanny effect of both house and school, the importance of materiality in emergent utopias in both buildings, and the crucial recognition that these were always partial, inter-connected and contingent (even where desired-for), so that neither building was always, or in only one sense, 'utopia'. This point led to the final contribution of Chapter 3. At various instances throughout the chapter, and the thesis, I have questioned, where utopia is connected to the 'good' (and often 'extremely good'), how far we can extend that concept, and whether any powerfully ethical decision must always fall back on dualistic conceptions of good/bad. We must beware, as so many theorists have indicated, of the problem of creating or appropriating this and similar dualisms, for the exclusion and sometimes naturalised oppression of the 'losing' term (bad, female, poor, nature...) (Young, 1990, following Derrida). However, for example, how do we differentiate between good and bad sacrifice or war, or good or bad ruination - do we need to? From evidence at the house and school, both of which presented visions of good and bad practices relating to children's safety, I would conclude that, yes, perhaps we do. Yet I think, from my argument in Chapter 3, this is not a simple matter of defining the good and bad as if they were static material objects. Rather, we need to think through the performativity and materiality of the practices through which good and bad become emergent categories - and a discussion of utopia is one that is well placed to help with this (and could be in the future). Drawing on Badiou (2003), who theorises that ethical positions, even 'universals', come through the subject's encounter with an event - I suggested that we not only follow how utopian events come to be actualised. 
We should also watch how such moments are contextualised and aggregated into individual or, more commonly, communal notions of the good/bad/ugly/silly etcetera. These were always unsettled and unsettling - always contingent, as my empirical chapters demonstrated. Nevertheless, it was through memory, through contextualisation and flows of practices, through combinations and collections of actions, thoughts, materials and whatever else, that temporary and sometimes seemingly more permanent ethical, even utopian, positions were created. The utopian, and the utopian unsettling (and this is not an attempt to define), thus become associated with practices whereby euphoria, happiness, nostalgia, even pain, and wider appeals to notions of difference, the homely, community and other 'utopian' themes, are collected in the construction of avowedly 'good' spaces, times or practices.

\subsection{A critical geography of architecture}

The second aim of the thesis was to discuss ideas and practices relating to utopia through the lens of architecture. If utopias are co-relationally, contingently produced, these must be some-where (even if that is No-Where) - and, as I have argued, a key empirical and conceptual site for utopias has been the practice of architecture. In Chapter 4, I explored how more 'critical' geographies of architecture (Lees, 2001) could enable us to approach many of the above themes through empirical and theoretical research. Lees' position is that we should not only interpret buildings as symbolic texts, waiting to be read. We also need to use ethnographic methods, along with iconographic and other textual approaches, to construct a sense of the varied and 'messy' meanings that a multitude of different agents produces through their inhabitation of buildings (Lees, 2001). This would help us to investigate, for example, how the utopian elements of Hundertwasser's and Day's design philosophies interact with the changing, everyday meanings that tenants, parents, teachers, children, tourists and journalists make at each building, and the very different utopian experiences that are felt there, but many of which are still 
related to those initial practices.

I then stressed that we could incorporate other elements into our own critical geographies. These would be contingent upon the specific building under consideration, and I think the differences between my own and Lees' geographies are, naturally, a result of these contingencies. Nevertheless, I co-opted certain elements of performativity and ANT, many of which had also appeared in Chapter 3, into my work - stressing, for example, rhythm, materiality, collective individuations, the sensual and anxiety. This led into my ethnographic approach, derived very much through my work at the house and school, an effort of translation summarised by the notion and motion of collecting/dispersing. I argued that the ways buildings themselves collect and disperse, and are entrained in relations of collecting/dispersing, is a key way through which their lives are constituted and experienced in a conjoined textual-material-performative sense (as buildings always are experienced as such). Such collecting/dispersing occurred at the Hundertwasser-Haus, for example, in its inter-textual construction as an 'alternative' building and tourist attraction, and at the school in the contingent 'gathering' of ideas, materials and practices into the Kindergarten building, and Day's 'growing' of a place (Day, 1990a and b). I theorised buildings and practices as 'building-assemblage-events', a somewhat awkward term designed to evoke the complex geographies through which buildings are encountered, and how these became evident to me in interviews and participant observation. It is these practices, moreover, in their complexity and specific emergence and contextualisation, which at times become utopian or are attached to utopian strands of practices or ethics. These enabled an integrated (but not 'total') exploration of the ways in which each building's spaces were lived, 'inside' and 'outside', and hence an escape from any pure and problematic discussion of either form, function or content with regard to utopia.

This was not, of course, the only way in which these buildings could be theorised and 
practiced. In fact the thesis as a whole shows that collecting/dispersing evokes and is cut across by many other experiences and movements - of circulation, stasis, repetition, becoming, and so forth. Nevertheless, this provided a useful and practical way in which to approach both buildings, and attempt more critical geographies of the ways in which they were constructed and lived.

\subsection{The Hundertwasser-Haus and Nant-y-Cwm}

Many of the arguments thus far have been conceptual, but a number have been rooted in the empirical insights I gained from the house and school - some of which I have already demonstrated in this chapter. I will briefly attempt to summarise the arguments of Chapter 6, before drawing together those of the couplets (7-12) regarding difference, the homely and community. Some of these appealed to 'traditional' notions of utopia; others directly to the utopian 'unsettling'; many referred to the inter-weaving and coemergence of the two; still more provoked new and other versions of the utopian, often very specific and local.

Chapter 6 dealt with the 'initial' construction of both buildings, contextualising them within Hundertwasser's and Day's writings and the many and varied influences upon them. Neither building, nor architect, nor any of their texts, can be classified as 'utopian', and we should be aware of this caveat when discussing their many and varied ideas relating to health, ecology, creativity or Modern architecture. Yet we can tease out certain utopian themes in relation to Aim 1 of the thesis, many of which relate to health, ecology and so forth, and connect with those of difference, home and community. Both Day and Hundertwasser are fascinated by architectural process. This is one of the key ways in which ideal or utopian forms emerge, through contingent, loose or un-known designs, and the 'freer' practices of those involved in working on them. There is in both a valorisation of work, and a clear statement that more creative practices, ideally 
involving the future inhabitants of a building in deep connection with an holistically conceived 'nature', can 'make a difference', and overcome what Hundertwasser terms the 'tyranny' of the straight line. They both provide a vision of health geared around architectural creativity and the concentric (collecting?) relationship between the human body and environment (the human 'skins'). Once again, they elucidate utopian senses in which the body may dwell and be at home in a more sensitive architecture. Their focus on health and creativity (and education) can be related to a long tradition of utopian architects who have also theorised the importance of bodily-social health in relation to quite other conceptions of this relationship (Crouch, 1996; Fishman, 1999; Worpole, 2000). For both, the production of healthy bodies emerged in quite different attempts to 'fit in' or 'make a difference', as the façade of each building - and later discussion suggested. Hundertwasser was fascinated by the process of ruination, and the unsettling yet aesthetically and performatively pleasing effects that 'natural' processes could impart on a building. His philosophy partly influenced my own discussion of ruination in Chapter 3, and again points to the inter-relationship of good and bad, light and dark, dystopia and utopia in the experience of the utopian unsettling. Day, as we saw in later chapters, is equally interested in the importance of community to buildings. He depicts how neither 'community' nor 'building' are pre-given entities, but emerge in-formation through his ideal construction process. In terms of press coverage, the house is much better-known, and more controversial. Quite simple and sarcastic utopian descriptions were applied - 'fairy tale castle', for instance - which set the house into the land of make believe, as a (criticised) consumer fantasy, or even child-like (ironic, in relation to the school), in a negative sense. I also began to show in Chapter 6 how the collecting/dispersing of elements around both buildings was a crucial way in which these utopian facets emerged.

The following chapters were largely based around interviews and ethnographic material, and indicated above all the unsettling contingency of utopian situations, the ways these 
were constituted by flows between events as well as chapters, and the ways they were 'contextualised' and informed by 'non'-utopian practices. As with earlier discussion, I argued that the notion of the 'homely' was perhaps the key axis of these chapters, as ideas about difference and community fed into and from that of home, and that it was from the construction of the 'homely' that uncanny crossings of difference/normal, or community work/comfort, emerged. For each couplet, I indicate here the utopian elements that emerged - in context - from my critical geography of each building. In addition, I highlight any other important concerns that presented themselves, reminding the reader that each theme has been of recent or near-recent importance in social theory as well as utopian theory.

Chapters 7 and 8 dealt with 'difference'. Difference was a complex issue, often connected to that of home. However, I demonstrated how various versions of difference were felt at and through the materialities and performances of each building. At the house, I argued that an enormous and sometimes utopian part of its attraction to tourists was the crossing of difference with normality or homeliness (as social housing; also cf. Koller, 1996). The uncanny effect of this crossing drew on Hundertwasser's ideas (for example, ruination and ecology), and press attention so that many Hundertwasser'pilgrims' were drawn there. The actions of tourists were then folded into quite other utopian experiences - for example, feeling constantly on holiday, or as part of a postwedding holiday. We also heard more positive evocations of press descriptions of the house - fairy-tale castle, and 'paradise'. At the school, the issue of difference was felt in quite other ways - in part, as a result of its almost 'opposing' aesthetic 'fit' into the landscape - and was thus an interesting comparison as well as a case in its own right. There were fewer utopian elements there, as these were associated with broader depictions of the importance of an alternative education, folded into more utopian versions of the 'good' in later chapters. However, such alterity has been an uncanny element of the school's effect, as well as the nostalgic pain and loss associated between 
memory of the past, the school's isolation, and other versions of childhood 'safety', which now unsettle the pioneering, and more 'fitting' visions of the 1970s. I also acknowledged debate regarding the 'inclusiveness' of the school, which fed into later thoughts on community. Material from both buildings illustrated how difference was a result of the specific collection and dispersal of specific symbolic and performative acts. For instance, the act of putting pots and pans on the windowsill, or the artistic work produced by the children, were attractive in different ways. However, these were not always utopian, and highlighted instead the many ways in which difference was constructed, through the buildings, in a material sense. I argued that although we had already seen the beginnings of various versions of utopia - both unsettling and traditional - we would need to wait and see how the buildings made a difference in other utopian terms.

Chapters 9 and 10 provided related, but also very different, versions of utopia, through the notion of 'home' - uncanny at both buildings for the house which has become artwork and tourist attraction, and the school which is, well, not a house. In summary, at both buildings, much of the work that occurred, and especially in interviews, did not only attempt to construct images of homeliness or comfort, but to stress how life at each building was very normal (of course, the home is an important site for the experience of the 'mundane'). Ironically, when comparing such visions of comfort, it is in fact the school which, through its vision of childhood, is most comforting, whereas at the house, more practical concerns were evident. We must place this notion of comfort at the school in relation to the broader ideals of Steiner education (see Chapter 10 for more), yet it is the creation, with the buildings, of a homely atmosphere, which is a key part of this, and was grounded there in nostalgic, again painful, memories and hopes from childhood. At both buildings, we encountered moments of euphoria, especially in the initial experience of each building, and the specific collections of events and objects (building-assemblage-events) that were involved. This was not purely deterministic, as 
this was entrained in those particular events, and the changing work done at the buildings since then, as well as any abstract conceptual architectural principles. In a honey-moon period or first visit to the school, for example, we see the recurrence of euphoria, moments of the 'good', 'joyous' and 'strange', rather than abstract visions or ethico-political abstractions. Here, we saw many versions of utopia, many of which were unsettling: excitement and strangeness, and overcoming these to feel 'at home'; comfort and paradise; the loss of these moments and contextualisation through memory; a rural or childhood idyll - a 'right' way to educate children; the folding in of other utopian effect - difference, tourism, and so forth; the very fact that these situations were contingent and emergent, in many ways un-planned. It is, I think, quite uncanny to acknowledge that even 'comfort' is contingent, and an effect of work. However, in the school in particular, these moments were collected together, with other images and ideals, to produce a more coherent vision of education though homeliness. Although more consistent, such visions were still partially contingent on the events that flowed into them, and the ways in which these ideals were constantly negotiated through practice and in interviews, and were thus 'evental', in Badiou's (2003) sense. Nonetheless, through these aggregations and memories, the visions and judgments that interviewees made also presented what Jacques (2002) terms 'crypto-utopias', or what we might more broadly term visions of the 'good' which compete directly with others. In other words, the difference the school offers comes only through its homeliness, and to some extent, vice-versa. It would, at both buildings, be unfair to categorise all of the inhabitants' lives as about making-the-homely. We should not forget our other two themes, nor the practical considerations of going on, and just 'being', nor the other concerns and spaces (jobs, friends, pubs, shops) with which each person is also occupied. Yet I argued that, whether this is utopian or not, most people, through the spatialised events of which they are a part, at least some of the time, do what they think is 'good'. 
In the final two chapters, I discussed yet more versions of utopia, this time in relation to community and the strong tradition of (political) utopian thought associated with the form and function of communal life. I was particularly enthusiastic about the ways in which respondents helped me understand and theorise the ways in which buildings materially made a difference in the construction of communities, and how building and community were built together. At the school, our critical geography extended back into the performativities of plastering, making door-handles and hard work with what were rapidly becoming good friends. The sense of 'pioneering' - of hope, doing 'good', for one's children - was pervasive yet done through work with the buildings. We might not encounter the magical utopian 'spirit' of place that Day (1990a) depicts in full, yet in the memory at least, this presented a somewhat ideal time. In a sense, this attachment is also apparent at the house, as is the strong, nostalgic sense of loss associated with the 'original' community. This is, of course, a comforting homeliness that many people remember (if ever existed) in relation to community (Bauman, 2000), and whose exclusivity is a key critique of both communitarianism and utopia (Silk, 1999).

There are, however, other themes that relate to the more contemporary experience of community at both buildings, despite a sense of loss that is found in both - and where for both, interestingly, the necessity for work is apparent. First, the idea of community is once again folded into specific utopian moments, such as that of the newly married couple. Second, it is folded into the uncanny, tear-jerking experience of the school for one visitor - an unusual combination of hard work, community spirit, and the eventual outcome - a different, homely school. Third, the experience and working of community (whether through door-knocking or involving parents in lessons) is a key way in which new and long-term members can feel 'at home' and familiar with the places and situations they encounter. Fourth, and with little direct notion of utopia, material objects and spaces are seen to 'scatter' a feeling of community throughout the buildings in different ways - perhaps through something as simple as the lack of door-bells! Fifth, 
these spaces are constantly changing, are re-appropriated and combined, through events, so that the house does not present a 'community space' as such, but certain rooms might become community rooms through repetition as well as newness, through parties or a flat open to friends. Sixth, as these communities are not socio-spatially essential, the 'inside' and 'outside' thereof are constantly re-positioned through practice, such that the boundaries of each building are also constantly under construction (I made this point in Chapter 4, with reference to Kwinter, 2001). Different 'fields' of practice might involve, for example, other individual connections with other communities, the work that some do to take part, or the place of each building within wider communities. This was played out in taking part in the Glastonbury festival, working in the 'local community', the ecological buildings network, or the Steiner Schools community. Thus, neither difference nor community are merely spatially proximate. As I outlined in Chapters 7 and 8 , both buildings and practices there 'fit in' to other communities and practices in quite different ways from those that are immediately obvious. Finally, and in particular at the school, it was through the idea of community that the internal coherence that any 'pioneering' stage might have suggested was contested, and that the contingency of any notion of the 'good', attached to 'community', was exposed. Different versions of the future of the school unsettled each other, as competing claims to the school's past and present practices unsettled those past visions, perhaps valorising 'boring' work above the spectacular. These were perhaps not traditional visions of utopia, but neither were they just about 'survival', as matters of great nostalgic and idealistic importance were attached to these notions of the 'good'. Additionally, when the buildings seemed to be disappearing into the background of our conversations, they returned as the key confluence for debates between finance, childhood, memory and work. 


\subsection{Future work and closing comments}

There are many directions that future work on utopia might take, following this thesis. The many elements connected to the utopian unsettling require refinement and addition, through further research, both specifically on buildings and away from them. Greater historical work could be done, for example, on examining the role of the (utopian) unsettling in a far broader array of examples than I have had space to explore here. The notions of collecting/dispersing could also be further refined, although I hope they are useful to anyone researching or thinking about buildings. Further work could be done at other ecological buildings. The theme of 'ecology' was never particularly strong through the ethnographies I undertook, hence further 'post-structuralist' engagements and critical geographies are still warranted. Furthermore, there are many other buildings, sites and practices (perhaps outside Europe and North America), which could benefit from more critical geographies. Some of the insights from performativity and ANT I have collected here - for instance regarding materiality, rhythm, euphoria and utopian spacing - might also be developed in producing still more refined, sensitive geographies that can work through the complex processes that occur at and with buildings. Hence I hope to have increased the variety of ways in which we think about and research buildingassemblage-events, which I hope will be useful for future conceptual and empirical work. Another line of research might look further at critical geographies of children's use of architecture than I have been able to do here, and to theorise children's actions and childhood through performativity and an attention to embodied practices. This could similarly extend into (perhaps policy work) on the ways that educational practices produce atmospheres, ethical 'ideals' and spacings unique to specific schools, yet explore how these are inveigled in broader curricula and societal 'norms' and demands. Finally, in connection with utopia and broader ethical debates which again are too large to do justice to in this thesis, I imagine that future work in relation to nonrepresentational theory and elsewhere will continue to think through the ethics and 
politics of 'doing good'. Specifically, I think more work (especially empirical) on the relationship between Badiou's philosophy and recent geographical engagements with various strands of post-structuralism - and with utopia - might be fruitful.

In sum, then, I would not characterise either building as utopian, in any essential sense. Nor was either building designed to 'be' utopia. Nor is or was utopia (in fact, like the buildings,) always the key concern for inhabitants of either building. However, I have demonstrated how utopias, whether traditional or unsettling (and I have given many instances of the latter), and whether momentary or in longer-term conceptions of the 'good', have emerged contingently, through work, through materiality, and in the coproduction of performative spatialities. If there has been a stress on these, this has been to emphasis how they appear, in context, and to begin to think about why utopias are still relevant (Aim 1), even if this returns to some of the problems of representation. There has, moreover, not been space to describe all of the processes and concerns that are experienced at each building. Yet I think that the preceding chapters demonstrate how utopia is, in many guises, an enduring but often momentary element, folded into the ways in which these buildings are encountered, in context.

I think that many of my conclusions (utopian and otherwise) could, interestingly, apply to the ways in which people experience any building. For many of the people I interviewed would never agree they were living in utopia, or were necessarily any different. Moreover, it would be unfair to suggest that those who live in other buildings could not experience utopia in similar ways. Yet these will never be the same, of course, as each building is different, as is each person's relationship, their memories, capabilities, and experiences. What really makes the difference, then, are the specific foldings that these buildings offer, and the specific stories I have heard and told - the specific collections and dispersals we effect. Neither life, nor architecture, are of course just about collecting and dispersing; however these present useful ways to think about 
and do research with buildings, and have helped in the discussion of various utopian themes.

This thesis has accounted for and expanded upon my three main aims in many more ways than it has been possible to present in this conclusion. In all, I argue that a group of ideas collected under the idea of the 'utopian unsettling' can help us to re-think the impact and even relevance of utopia to both historical and contemporary times (and I would make no more spectacular claim than that). This has been undertaken, crucially, not only through thinking architecturally about difference, community and especially the un/homely, but through a critical geography of two buildings, and the themes that emerged there. I have expanded upon a growing interest in such critical geographies with my own here, and added theoretically and empirically to this debate with a focus on performativity, ANT and collecting/dispersing. This focus has enabled me to think through the contingency of utopia, and the material and performative spatialities that become-utopian. The contingency of utopia is in itself unsettling, as well as enabling me to demonstrate the importance of the un/homely to utopia. Finally, in discussing the themes of difference, the homely and community, and much else besides, I have demonstrated how the idea of utopia persists in its relevance to contemporary theory. Moreover, it can enable us to think about performativity, materiality, ethics and space in ways that are useful and relevant to various contexts - whether an inner-city social housing block in Vienna, or an alternative school in rural West Wales. 


\section{Appendix 1}

Interview schedule for Hundertwasser-Haus interviews. As with most in-depth interviews, this was used as a basis only, as interviewees often dictated the direction and pace of the conversation. English translation followed by original German version.

\begin{tabular}{|c|c|}
\hline Question & $\begin{array}{c}\text { Sub-questions } \\
\end{array}$ \\
\hline 1). How long have you lived here? & $\begin{array}{l}\text { - Do you live alone? } \\
\text { - How old are your children? } \\
\text { - What type of work do you do? } \\
\text { - Where did you live before? } \\
\text { - Was that social housing? } \\
\text { - What was that like? }\end{array}$ \\
\hline $\begin{array}{l}\text { 2). How did it happen, that you came to } \\
\text { live in the Hundertwasser-Haus? }\end{array}$ & $\begin{array}{l}\text { - Did you apply? } \\
\text { - Was there a waiting list? } \\
\text { - What were your first impressions of the } \\
\text { house when you saw it BEFORE moving } \\
\text { in? } \\
\text { - Had you soon pictures of the house, or } \\
\text { heard much about it? } \\
\text { - Tell me what you know about } \\
\text { Hundertwasser*. Which parts of his life } \\
\text { and work interest you the most? } \\
\text { - Did you know this before you moved in } \\
\text { (or only know now)? }\end{array}$ \\
\hline $\begin{array}{l}\text { 3). What was the experience like when } \\
\text { you first arrived here, and how much } \\
\text { contact did you have with the other } \\
\text { residents? }\end{array}$ & $\begin{array}{l}\text { - How did you feel? Was it daunting, or } \\
\text { exciting? } \\
\text { - Was it a distraction from work? }\end{array}$ \\
\hline
\end{tabular}




\begin{tabular}{|c|c|}
\hline & $\begin{array}{l}\text { - Were there any specific things you had to } \\
\text { do or agree to, to live here? } \\
\text { - Who did you meet during the first few } \\
\text { weeks? } \\
\text { - Are you still friends with them? }\end{array}$ \\
\hline $\begin{array}{l}\text { 4). Could you tell me about what } \\
\text { changes you have made to your home? } \\
\text { Do you know if all of the residents have } \\
\text { made changes? }\end{array}$ & $\begin{array}{l}\text { ****These things here are interesting - } \\
\text { why did you do this? Were these here } \\
\text { before?/ Could you show me what hae } \\
\text { done with this room - when and why?**** } \\
\text { - Was there much to do when you first } \\
\text { arrived? } \\
\text { - What was here in the way of furniture } \\
\text { and decoration? } \\
\text { - Do you know if all the flats were } \\
\text { originally the same? } \\
\text { - What changes have you made since? } \\
\text { - What personal touches do you think you } \\
\text { have brought to the house? } \\
\text { - Have you used your window rights? Why } \\
\text { (not)? } \\
\text { - Have others? } \\
\text { - Would you like to make more changes? } \\
\text { - Would you feel free to make whatever } \\
\text { changes you liked? }\end{array}$ \\
\hline $\begin{array}{l}\text { 5). If you had to move, for whatever } \\
\text { reason, what would you miss most about } \\
\text { living in the Hundertwasser-Haus? }\end{array}$ & $\begin{array}{l}\text { - Do you think your daily life would } \\
\text { change? } \\
\text { - Do you now live 'ecologically' and with } \\
\text { an interest in art? Or was this already the } \\
\text { case? Could you now easily live in a } \\
\text { 'normal' house with this in mind? }\end{array}$ \\
\hline
\end{tabular}




\begin{tabular}{|c|c|}
\hline & $\begin{array}{l}\text { - How much longer can you see yourself } \\
\text { living here? } \\
\text { - If you could move out - where would } \\
\text { you go - to another social housing house, } \\
\text { or what? }\end{array}$ \\
\hline $\begin{array}{l}\text { 6). How suitable is the house for } \\
\text { children? Is this a house built for } \\
\text { children? }\end{array}$ & $\begin{array}{l}\text { - If have children:- } \\
\text { - Do they play much in the house, and } \\
\text { what do they do? } \\
\text { - Where else do they go? } \\
\text { - Where are their favourite places? }\end{array}$ \\
\hline $\begin{array}{l}\text { 7). Do you have much contact with the } \\
\text { other residents in the house? }\end{array}$ & $\begin{array}{l}\text { - Do you often invite friends here - have } \\
\text { they similar interests? (Who here?) } \\
\text { - What do you do? } \\
\text { - Do you organize special events? } \\
\text { - Does the house enter the conversation } \\
\text { much? }\end{array}$ \\
\hline $\begin{array}{l}\text { 8). Is there much contact with the } \\
\text { KunstHaus, with Buero Harel, or with } \\
\text { the residents/users of any of } \\
\text { Hundertwasser's other projects? }\end{array}$ & \\
\hline $\begin{array}{l}\text { 9). What do you think about the tourists } \\
\text { who come to the house? } \\
\text { I have heard some have tried to get into } \\
\text { the house....!?!? }\end{array}$ & $\begin{array}{l}\text { - Has the tourism had any effect on your } \\
\text { daily life? Negative/positive? } \\
\text { - Do you have much contact with the } \\
\text { tourists? } \\
\text { - Does it make you think about the house } \\
\text { more? } \\
\text { - Do you think tourists expect someone } \\
\text { living in the house to act in a particular } \\
\text { way - and do you? }\end{array}$ \\
\hline
\end{tabular}




\begin{tabular}{|c|c|}
\hline $\begin{array}{l}\text { 10). Have you had any contact with the } \\
\text { press? }\end{array}$ & $\begin{array}{l}\text { - IF YES:- } \\
\text { - Can you be honest about your ideas } \\
\text { relating to the house, and Hundertwasser? } \\
\text { - What particular things do you feel you } \\
\text { have to say? } \\
\text { - Does anyone tell you what to say? } \\
\text { - Are you expected to be knowledgeable? } \\
\text { - IF YES OR NO:- } \\
\text { - How keen would you be to speak to the } \\
\text { press? } \\
\text { - What do you think of the coverage of the } \\
\text { house and Hundertwasser? } \\
\text { - How much interest is there in the house } \\
\text { at the moment? }\end{array}$ \\
\hline $\begin{array}{l}\text { 11). Do you talk about the building } \\
\text { much with friends and relatives? }\end{array}$ & $\begin{array}{l}\text { - How do they feel about you living here? } \\
\text { - Interested? } \\
\text { - Jealous? }\end{array}$ \\
\hline $\begin{array}{l}\text { 12). Do you think the house fits in in } \\
\text { Vienna? Which other buildings do you } \\
\text { like here and around the world? }\end{array}$ & \\
\hline $\begin{array}{l}\text { 13). If I asked you to see the house as an } \\
\text { 'outsider', someone who didn't live here, } \\
\text { or a tourist, what do you think would be } \\
\text { the most important elements of the } \\
\text { building? }\end{array}$ & \\
\hline $\begin{array}{l}\text { 14). If you were the architect for a new } \\
\text { social housing project in Vienna, what } \\
\text { would the house be like? }\end{array}$ & $\begin{array}{l}\text { - Aesthetically, community, children, } \\
\text { greenery.... } \\
\text { - Would employ Hundertwasser or } \\
\text { use features of buildings? }\end{array}$ \\
\hline
\end{tabular}


German version of schedule (used in all interviews)

\begin{tabular}{|c|c|}
\hline $\begin{array}{c}\text { Frage } \\
\end{array}$ & $\begin{array}{l}\text { Extra-fragen } \\
\end{array}$ \\
\hline $\begin{array}{l}\text { 1). Seit wann wohnen Sie hier im } \\
\text { Hundertwasser-Haus }\end{array}$ & $\begin{array}{l}\text { - Haben Sie eine Familie, oder wohnen Sie } \\
\text { alleine? } \\
\text { - Wie alt sind Ihre Kinder? } \\
\text { - Wie is Ihr Beruf? } \\
\text {-Wo wohnten Sie vor dem Hundertwasser- } \\
\text { Haus? } \\
\text { - War das ein Gemeindebau? } \\
\text {-Wie war Ihre Meinung dazu? }\end{array}$ \\
\hline $\begin{array}{l}\text { 2). Koennten Sie mir erzaehlen, wie sind } \\
\text { Sie draufgekommen, hier zu wohnen? }\end{array}$ & $\begin{array}{l}\text { - Haben Sie sich gemeldet, hier zu } \\
\text { wohnen? } \\
\text { - Gabe es eine Warteliste? } \\
\text { - Wie war Ihr Eindruck vom Haus, als Sie } \\
\text { das am ersten Mal sah? } \\
\text { - Hatten Sie Bilder vom Haus gesehen, } \\
\text { oder viel davon gehoert, BEVOR Sie } \\
\text { eingezogen sind? } \\
\text { - Koennten Sie mir ein bisschen ueber } \\
\text { Hundertwasser sagen - ueber seine } \\
\text { Theorien, Leben - und lhre Meinungen zu } \\
\text { Hundertwasser?* } \\
\text { - Wussten Sie soviel vor dem Einziehen - } \\
\text { und hat dass eine Wirkung auf Ihre Wahl? }\end{array}$ \\
\hline $\begin{array}{l}\text { 3). Koennten Sie sich die ersten paar } \\
\text { Tagen, und die ersten paar Wochen hier } \\
\text { erinnern - die Zeit kurz nach Sie hier } \\
\text { eingezogen sind? Wie war das Haus, } \\
\text { und wieviel Kontakt gab es mit anderen } \\
\text { Bewohnern? }\end{array}$ & $\begin{array}{l}\text { - Wie fuehlten Sie sich? War es } \\
\text { entmutigend, oder spannend, hier } \\
\text { einzuziehen? } \\
\text { - War es eine Zerstreuung von der Arbeit? }\end{array}$ \\
\hline
\end{tabular}




\begin{tabular}{|c|c|}
\hline & $\begin{array}{l}\text { - Gab es besondere Sachen, dem Sie } \\
\text { stimmen muessen - Regeln, Rechte, usw.? } \\
\text { - Waehrend der ersten paar Wochen, mit } \\
\text { wem - welche andere Bewohner - haben } \\
\text { Sie gesprochen? } \\
\text { - Sind die Leute noch Ihre Freunde? }\end{array}$ \\
\hline $\begin{array}{l}\text { 4). Ich moechte wissen, wie Sie Ihre } \\
\text { Wohnung geaendert oder umgestaltet } \\
\text { haben. Was haben Sie da gemacht? } \\
\text { Wissen Sie, ob alle die Bewohner viel } \\
\text { gemacht haben? }\end{array}$ & $\begin{array}{l}\text { ****Diese Dinge hier sind interessant - } \\
\text { warum haben Sie dass gemacht?/ Waren } \\
\text { die hier vorher?/ Koennten Sie mir zeigen, } \\
\text { was Sie mit diese Zimmer gemacht haben } \\
\text { - wann und warum?**** } \\
\text { - Gab es viel zu tun, als Sie erst hier } \\
\text { eingezogen sind? } \\
\text { - Was fuer Moebel und Dekoration war } \\
\text { hier? } \\
\text { - Wissen Sie, ob jede Wohnung ganz } \\
\text { gleich gestaltet war, nach der Bauende im } \\
\text { Jahr } 1985 ? \\
\text { - Koennten Sie sagen, welche } \\
\text { Aenderungen sind ganz praktisch, und } \\
\text { welche sind persoenlich, sozusagen? } \\
\text { - Haben Sie Ihre Fensterrecht verwendet? } \\
\text { Warum/nicht? Haben andere Bewohner? } \\
\text { - Moechten Sie weitere Aenderungen } \\
\text { machen? Ist es leicht, und sind Sie 'frei', } \\
\text { jede Aenderung zu machen? }\end{array}$ \\
\hline $\begin{array}{l}\text { 5). Wenn Sie vom Hundertwasser-Haus } \\
\text { ausziehen muessten, was wuerden Sie } \\
\text { am meisten vermissen? }\end{array}$ & $\begin{array}{l}\text { - Wuerde sich das Alltag veraendern? } \\
\text { - Leben Sie jetzt 'Oekologisch', und mit } \\
\text { eine Interesse fuers Kunst? Oder kam das } \\
\text { vorher? Koennten Sie sich vorstellen, ob } \\
\text { das so leicht in einem 'normalem' Haus } \\
\text { wuerde? } \\
\text { - Noch wie lang moechten Sie da wohnen? }\end{array}$ \\
\hline
\end{tabular}




\begin{tabular}{|c|c|}
\hline & $\begin{array}{l}\text { - Wenn Sie ausziehen koennten - wo } \\
\text { wuerden Sie gehen - zu einen andere } \\
\text { Gemeindebau oder? } \\
\text { - Was wuerden Sie sagen, wenn ich Ihnen } \\
\text { diese Frage stellte - wie ist es, in einem } \\
\text { 'Hundertwasser-Haus' zu wohnen? }\end{array}$ \\
\hline $\begin{array}{l}\text { 6). Wie ist das Haus fuer Kinder? Ist es } \\
\text { ein Haus gebaut fuer Kinder? }\end{array}$ & $\begin{array}{l}\text { Wenn er/sie Kinder hat:- } \\
\text { - Spielen die Kinder viel im Haus, und was } \\
\text { machen sie? } \\
\text { - Wo sonst [?] spielen sie? } \\
\text { - Spielen die Kinder im allgemeinem } \\
\text { anders als in anderen Haueser? } \\
\text { - Wo sind da ihre Lieblingsecke oder } \\
\text { Lieblingsspielplaetze? }\end{array}$ \\
\hline $\begin{array}{l}\text { 7). Treffen Sie oft mit den anderen } \\
\text { Bewohnern des Haeuses? }\end{array}$ & $\begin{array}{l}\text { - Wer sind hier Ihre Freunde? } \\
\text { - Was machen Sie - besondere } \\
\text { Aktivitaeten? } \\
\text { - Organisieren Sie hier Festen, } \\
\text { Sonderevents, usw.? } \\
\text { - Sprechen Sie viel ueber das Haus? }\end{array}$ \\
\hline $\begin{array}{l}\text { 8). Gibt es viel Kontakt mit dem } \\
\text { KunstHaus, Buero Harel, oder die } \\
\text { Bewohner/Kunde von Hundertwasser's } \\
\text { anderen Projekten? }\end{array}$ & \\
\hline $\begin{array}{l}\text { 9). Wie ist Ihre Meinung ueber die } \\
\text { Touristenmasse, die zum Haus kommen, } \\
\text { das Haus anzuschauen? } \\
\text { Ich habe irgendwo gehoert, dass einige } \\
\text { Touristen probiert haben, im } \\
\text { Hundertwasser-Haus einzugehen....!?!? }\end{array}$ & $\begin{array}{l}\text { - Hat der Tourismus eine grosse Wirkung } \\
\text { auf Ihrem Alltagleben? Negativ/positiv? } \\
\text { - Haben Sie viel Kontakt mit den } \\
\text { Touristen? } \\
\text { - Denken Sie mehr [?] ueber das Haus, } \\
\text { wegen der Touristen? }\end{array}$ \\
\hline
\end{tabular}




\begin{tabular}{|c|c|}
\hline & $\begin{array}{l}\text { - Glauben Sie, dass die Touristen es } \\
\text { erwarten, dass Bewohner des Haeuses eine } \\
\text { Stereotyp erfuellen mueesen? Wie ist das? } \\
\text { Fuehlen Sie, dass Sie so sein muessen? }\end{array}$ \\
\hline $\begin{array}{l}\text { 10). Hatten Sie oder haben Sie viel } \\
\text { Kontakt mit Journalisten und die } \\
\text { Presse? }\end{array}$ & $\begin{array}{l}\text { - Wenn ja:- } \\
\text { - Koennten Sie ehrlich Ihre Meinungen } \\
\text { zum Haus und Hundertwasser sagen? } \\
\text { - Welche besondere Dinge fuehlen Sie, Sie } \\
\text { muessen sagen? } \\
\text { - Sagt jemand was Sie sagen sollten? } \\
\text { - Ist es erwartet, dass Sie viel ueber dass } \\
\text { Haus wissen? } \\
\text { - Wenn ja oder nein:- } \\
\text { - Freut es Ihnen, mit Journalisten zu } \\
\text { sprechen? } \\
\text { - Was ist Ihre Meinung zur Presseartikeln, } \\
\text { Fernsehprogrammen, usw.. ueber das Haus } \\
\text { und Hundertwasser? }\end{array}$ \\
\hline $\begin{array}{l}\text { 11). Sprechen Sie oft ueber das Haus mit } \\
\text { Familie oder Freunden? }\end{array}$ & $\begin{array}{l}\text { - Was ist Ihrer Meinung darueber, dass Sie } \\
\text { hier wohnen? } \\
\text { - Sind sie Interessiert? } \\
\text { - Haben sie Eifersucht? }\end{array}$ \\
\hline $\begin{array}{l}\text { 12). Glauben Sie, dass das Haus wirklich } \\
\text { ein Teil dieses Bezirk ist? Ein Teil } \\
\text { Wiens? } \\
\text { Welche andere Gebaeude freuen sich - } \\
\text { in Wien, und Weltweit? }\end{array}$ & \\
\hline
\end{tabular}




\begin{tabular}{|l|l|}
\hline $\begin{array}{l}\text { 13). Wenn ich Ihnen fragte, das Haus als } \\
\text { nicht-Bewohner zu vorstellen, oder als } \\
\text { ein(e) Tourist(in), welche Dinge } \\
\text { (Baueme, Mauer, Farben, Ideen) } \\
\text { wuerden fuer Sie am wichtigsten sein, } \\
\text { glauben Sie? }\end{array}$ & \\
\hline $\begin{array}{l}\text { 14). Wenn Sie der/die Architekt(in) fuer } \\
\text { einen neue Gemeindebau in Wien } \\
\text { waren, wie wuerde diese Haus sein? }\end{array}$ & $\begin{array}{l}\text { - Aestetisch, Gemeinschaftlich, Kinderlich, } \\
\text { Oekologisch....? }\end{array}$ \\
& $\begin{array}{l}\text { - Wuerden Sie Hundertwasser fragen, zum } \\
\text { Beispiel, oder vielleicht einige } \\
\text { Eigenschaften von seinen Gebaeuden } \\
\text { benutzen? }\end{array}$ \\
\hline
\end{tabular}




\section{Appendix 2}

Interview schedule for Nant-y-Cwm interviews. Again, as with most in-depth interviews, this was used as a basis only, as interviewees often dictated the direction and pace of the conversation, and as respondents had varying relationships with the school (from ex-pupils to founders, very recent parents to long-term teachers).

\begin{tabular}{|c|c|}
\hline Main question & $\begin{array}{c}\text { Sub-question } \\
\end{array}$ \\
\hline $\begin{array}{l}\text { 1). Firstly, if I were an interested parent, } \\
\text { for example in London, chatting to you } \\
\text { about the school - how would you } \\
\text { describe it to me? }\end{array}$ & $\begin{array}{l}\text { - Also - the place itself - could you } \\
\text { describe it? }\end{array}$ \\
\hline $\begin{array}{l}\text { 2). What, in your mind, are the driving } \\
\text { principles behind the school? }\end{array}$ & $\begin{array}{l}\text { - Welsh? Links with local community? } \\
\text { Nature? A wonderful place? } \\
\text { - Could you tell me a little about Steiner } \\
\text { education, as you interpret it? } \\
\text { - How do you think this is translated into } \\
\text { the school building? }\end{array}$ \\
\hline $\begin{array}{l}\text { 3). Would it be possible to give me a bit } \\
\text { of information on your own background } \\
\text { please? }\end{array}$ & $\begin{array}{l}\text { - Do you work? } \\
\text { - How many children do you have? } \\
\text { - Where are you from originally? } \\
\text { - What types of school did you go to? } \\
\text { - What other activities involved with? }\end{array}$ \\
\hline $\begin{array}{l}\text { 4). I was wondering if you could tell me } \\
\text { a little about how you found the school, } \\
\text { and why you decided to send your } \\
\text { child(ren) there/teach there/become } \\
\text { involved in setting it up? }\end{array}$ & $\begin{array}{l}\text { - Why did you choose this school as the } \\
\text { suitable one for your children? } \\
\text { - Had they been in 'mainstream' schools } \\
\text { beforehand? } \\
\text { - Are you local? }\end{array}$ \\
\hline
\end{tabular}




\begin{tabular}{|c|c|}
\hline & $\begin{array}{l}\text { - If no, why did you come to this area? } \\
\text { - If yes, how does it fit into the local } \\
\text { community and landscape? }\end{array}$ \\
\hline $\begin{array}{l}\text { 5). Could you tell me a bit about the first } \\
\text { few weeks of your own, and your } \\
\text { child(ren)'s lives at the school? }\end{array}$ & $\begin{array}{l}\text { - What was you first impression when you } \\
\text { saw the school? } \\
\text { - After you had visited, what did you } \\
\text { think? } \\
\text { - What are you lasting memories of the } \\
\text { first few weeks? } \\
\text { - How did your child(ren) react to the } \\
\text { school then - any stories? } \\
\text { - Were there any particular elements of the } \\
\text { school that impressed your children, or that } \\
\text { they talked about? } \\
\text { - If I asked you in ten years' time what } \\
\text { your strongest memories of the school } \\
\text { were, what do you thin you would say? }\end{array}$ \\
\hline $\begin{array}{l}\text { 6). What about now, in the last few } \\
\text { months for example? What particular } \\
\text { elements of their education and life at } \\
\text { the school are most important for you - } \\
\text { and for them? }\end{array}$ & $\begin{array}{l}\text { - What activities do they do at the school, } \\
\text { that remain with you? } \\
\text { - What the most important elements of the } \\
\text { school for the children's education, and for } \\
\text { their lives were and are? } \\
\text { - What elements do you think are different } \\
\text { from a 'normal' education? } \\
\text { - Is this difference important? }\end{array}$ \\
\hline $\begin{array}{l}\text { 7). How important is it to you, and was } \\
\text { it to you when you joined, that the } \\
\text { school, as a whole was 'different' from } \\
\text { mainstream schools?* }\end{array}$ & $\begin{array}{l}\text { - What elements are different? } \\
\text { - Is it a 'haven' away from everything? Is } \\
\text { this important? }\end{array}$ \\
\hline
\end{tabular}




\begin{tabular}{|c|c|}
\hline & $\begin{array}{l}\text { - In what ways is it a special place? } \\
\text { - What does Nant-y-Cwm have to offer } \\
\text { schools and children's education and lives } \\
\text { in general? Or, is it important to you that it } \\
\text { is unique? } \\
\text { - Does it give you the sense that } \\
\text { you/children are 'different'? }\end{array}$ \\
\hline $\begin{array}{l}\text { 8). What is your impression of the } \\
\text { buildings at Nant-y-Cwm? }\end{array}$ & $\begin{array}{l}\text { - When you \& children first saw? } \\
\text { - Now? } \\
\text { - Important? } \\
\text { - A part of education/lives there? } \\
\text { - Do you know any of the background to } \\
\text { them? } \\
\text { - Anyone talk about them? }\end{array}$ \\
\hline $\begin{array}{l}\text { 9). Could you tell me about the } \\
\text { community at the school?* }\end{array}$ & $\begin{array}{l}\text { - Events? } \\
\text { - Much interaction with teachers? } \\
\text { - Take part in educational activities - at } \\
\text { home or at school? What do you do? } \\
\text { - What else could do? } \\
\end{array}$ \\
\hline $\begin{array}{l}\text { 10). What is your involvement at the } \\
\text { school? }\end{array}$ & $\begin{array}{l}\text { - Work? } \\
\text { - Help? } \\
\text { - How much time and energy does the } \\
\text { school take up, in the context of the other } \\
\text { activities we discussed above? } \\
\text { - How much is it a part of home life? } \\
\text { - How important is it to you? }\end{array}$ \\
\hline $\begin{array}{l}\text { 11). I understand the school, and } \\
\text { particularly the Kindergarten, is } \\
\text { undergoing some difficulties. Could you }\end{array}$ & \\
\hline
\end{tabular}




\begin{tabular}{|c|c|}
\hline $\begin{array}{l}\text { tell me a little about this please, and } \\
\text { your involvement with this?* }\end{array}$ & \\
\hline $\begin{array}{l}\text { 12). I would like to talk a little bit about } \\
\text { the school in the context of the wider } \\
\text { community, and in the Steiner school } \\
\text { network. What is its function within } \\
\text { each of these? }\end{array}$ & $\begin{array}{l}\text { - How important is it? } \\
\text { - What links are there? } \\
\text { - Which parts of the school (building, } \\
\text { education, people, things made there) are } \\
\text { most important outside the school } \\
\text { community? } \\
\text { - Is it difficult for new parents to adjust to } \\
\text { life there? }\end{array}$ \\
\hline $\begin{array}{l}\text { 13). 'Nature' is a difficult concept for us } \\
\text { all to grasp. What do you think it means } \\
\text { at Nant-y-Cwm? }\end{array}$ & $\begin{array}{l}\text {-For education and activities? } \\
\text { - For your child(ren)? }\end{array}$ \\
\hline $\begin{array}{l}\text { 14). If you could design a school, what } \\
\text { would this look like? }\end{array}$ & $\begin{array}{l}\text { - Think school could be changed? How? } \\
\text { Why? } \\
\text { - In what ways has the school made you } \\
\text { think about buildings? } \\
\text { - Did you before? } \\
\text { - If could design own house, what would } \\
\text { be like? } \\
\text { - How feel about? }\end{array}$ \\
\hline $\begin{array}{l}\text { 15). Do you know how much publicity } \\
\text { there has been of the school in the press, } \\
\text { or in advertising done by the school. } \\
\text { What is your opinion of this? }\end{array}$ & \\
\hline $\begin{array}{l}\text { 16). Is there anything else that you'd } \\
\text { like to add, about your own opinions, } \\
\text { experiences or ideas, and your } \\
\text { child(ren)'s? }\end{array}$ & \\
\hline
\end{tabular}

*Indicates question added after initial interviews/observations 


\section{Appendix 3}

List of interviews, times and dates at the Hundertwasser-Haus. All names have been changed to protect respondents' anonymity.

\section{Interview A}

Interview with Joanne

Conducted by Peter Kraftl

Date:- 22/03/2003

Time:- 9:15pm - 10:30pm

Location:- Joanne's flat, Hundertwasser-Haus, Wien

Others present:- None

\section{Interview B}

Interview with Claire

Conducted by Peter Kraftl

Date:- 22/03/2003

Time:- 10:30pm-12:00pm

Location:- Claire's flat, Hundertwasser-Haus, Wien

Others present:- None

\section{Interview C}

Interview with Sarah

Conducted by Peter Kraftl

Date:- 24/03/2003 
Time:- 10:00am-11:45am

Location:- Sarah's flat, Hundertwasser-Haus, Wien

Others present:- None

\section{Interview D}

Interview with Emma and Tim

Conducted by Peter Kraftl

Date:- $25 / 02 / 2003$

Time:- 19:30-21:10

Location:- Emma's flat, Hundertwasser-Haus, Wien

Others present:- None

\section{Interview $\mathbf{E}$}

Interview with Jenny and Robert, husband and wife

Conducted by Peter Kraftl

Date:- $26 / 02 / 2003$

Time:- 21:00-22:00

Location:- Jenny and Robert's flat, Hundertwasser-Haus, Wien

Others present:- Their children at times, mainly near the beginning

\section{Interview $\mathbf{F}$}

Interview with John

Conducted by Peter Kraftl

Date:- 27/02/2003

Time:- 18:30-19:30 
Location:- John's flat, Hundertwasser-Haus, Wien

Others present:- None

\section{Interview $\mathbf{G}$}

Interview with Rachel

Conducted by Peter Kraftl

Date:- 01/03/2003

Time:- 15:00-15:20

Location:- Rachel's flat, Hundertwasser-Haus, Wien

Others present:- A few members of family, who remain silent

\section{Interview $\mathbf{H}$}

Interview with Danielle

Conducted by Peter Kraftl

Date:- 03/03/2003

Time:- 14:00-15:15

Location:- Danielle's flat, Hundertwasser-Haus, Wien

Others present:- Her young son, at times (also upstairs)

\section{Interview I}

Interview with Lara

Conducted by Peter Kraftl

Date:- 03/03/2003

Time:- 18:00-19:05 
Location:- Lara's flat, Hundertwasser-Haus, Wien

Others present:- None

\section{Interview with art-café owner, Hundertwasser-Haus}

Conducted by Peter Kraftl

Date:- 01/03/2003

Time:- 16:00-17:00

Location: Art-café, under Hundertwasser-Haus

Other present: a few customers

Interview NOT recorded 


\section{Appendix 4}

List of interviews, times and dates at Nant-y-Cwm School. All names have been changed to protect respondents' anonymity.

\section{Interview 1}

Interview with Paul

Conducted by Peter Kraftl

Date:- 10/03/2003

Time:- 11:00-13:00

Location:- Paul's house, Pembrokeshire

Others present:- None

\section{Interview 2}

Interview with Joanne

Conducted by Peter Kraftl

Date:- 01/04/2003

Time:- 10:30-12:00

Location:- Joanne's house, Pembrokeshire

Others present:- None

\section{Interview 3}

Interview with Fleur

Conducted by Peter Kraftl

Date:- 02/04/2003

Time:- 14:00-15:30 
Location:- Nant-y-Cwm School Kindergarten, Pembrokeshire

Others present:- None

\section{Interview 4}

Interview with Anna

Conducted by Peter Kraftl

Date:- 03/04/2003

Time:- 11:00-13:15

Location:- Anna's house, Carmarthen

Others present:- None

\section{Interview 5}

Interview with George \& Susanne

Conducted by Peter Kraftl

Date:- 03/04/2003

Time:- 14:00-17:00

Location:- George \& Susanne's house, above the Gwaun Valley, Pembrokeshire Others present:- None

\section{Interview 6}

Interview with Christine

Conducted by Peter Kraftl

Date:- 02/05/2003

Time:- 13:30-15:30 
Location:- Christine, Pembrokeshire

Others present:- None

\section{Interview 7}

Interview with Joan

Conducted by Peter Kraftl

Date:- 07/05/2003

Time:- 11:00-12:00

Location:- Nant-y-Cwm School, Pembrokeshire

Others present:- Children \& teachers in playground

\section{Interview 8}

Interview with Andrea

Conducted by Peter Kraftl

Date:- 08/05/2003

Time:- 10:30-12:30

Location:- Andrea's house, Llanycefn, Pembrokeshire

Others present:- Young daughter then friend (parent at School?) later - not really on tape

\section{Interview 9}

Interview with Janet

Conducted by Peter Kraftl

Date:- $12 / 05 / 2003$

Time:- 13:00-14:00 
Location:- Field, Nant-y-Cwm School, Pembrokeshire

Others present:- Another lady's young baby, in her arms; and children playing football nearby

\section{Interview 10}

Interview with John and Sadie

Conducted by Peter Kraftl

Date:- 27/05/2003

Time:- 10:30-12:30

Location:- John and Sadie's house, Pembrokeshire

Others present:- $12 / 13$ year old son; friend

\section{Interview 11}

Interview with Violet and Ronald

Conducted by Peter Kraftl

Date:- 28/05/2003

Time:- 15:00-17:00

Location:- Violet and Ronald's house, Pembrokeshire

Others present:- Family, friends and builders in background

\section{Interview 12}

Interview with Nina

Conducted by Peter Kraftl

Date:- 29/05/2003

Time:- 11:00-12:00 
Location:- Nim's house, Pembrokeshire

Others present:- Family, friends and farming/language exchange students in background

Interview 13

Interview with Roberta

Conducted by Peter Kraftl

Date:- 29/05/2003

Time:- 14:00-15:30

Location:- Nant-y-Cwm School, Pembrokeshire

Others present:- None

\section{Interview 14}

Interview with Roger

Conducted by Peter Kraftl

Date:-30/05/2003

Time:- 12:00-13:00

Location:- Roger's house near Bryberian, Pembrokeshire

Others present:- None

\section{Interview 15}

Interview with Daniel and Candy

Conducted by Peter Kraftl

Date:-03/06/2003

Time:- 10:30-12:00 
Location:- Daniel's house near Llanycefn, Pembrokeshire

Others present:- Daniel's young son

\section{Interview 16}

Interview with Mandy

Conducted by Peter Kraftl

Date:-03/06/2003

Time:- 13:30-14:30

Location:- Mandy's house, Narberth, Pembrokeshire

Others present:- Mandy's young daughter

\section{Interview 17}

Conducted by Peter Kraftl

Interview with Violet and Ronald

Date:- 28/05/2003

Time:- 15:00-17:00

Location:- Violet and Ronald's house, Pembrokeshire

Others present:- Family, friends and builders in background 


\section{Bibliography}

Note: references marked with an asterisk* are incomplete as these were photocopies provided by the Hundertwasser archive, where it had not been possible to keep full bibliographic details in all cases.

Abbayard, N. (2000) "The cinematic city: Between modernist utopia and postmodernist dystopia," Built Environment. 26(4): 268-281

Ackroyd, (2002) "Utopia or ideology: Karl Mannheim and the place of theory," in Parker, M. (ed.) Utopia and organization. Blackwell: Oxford: 40-58

Adam, H. (1994) "Inflation des schoenen Scheins: Die Hundertwaser-Well," Neue Zuercher Zeitung. 22/03/1994: no pagination*

Aitken, S. (1997) "Analysis of texts: Armchair theory and couch-potato geography," in Flowerdew, R. and Martin, D. (eds.) Methods in human geography: A guide for students doing a research project. Harlow: Pearson Education Limited, Ch. 12: 197-212

Aitken, S. (2001) "Playing with children: Immediacy was their cry," The Geographical Review. 91(1-2): 496-508

Alexander, P. and Gill, A. (1984) Utopias. London: Duckworth.

Al-Hindi, K.F. and Stadder, C. (1997) "The hidden histories and geographies of neotraditional town planning: The case of seaside, Florida," Environment and Planning D: Society and Space. 15(3): 349-372

Allen, J.L. (1992) "Horizons of the Sublime: The invention of the Romantic West," Journal of Historical Geography. 18(1): 27-40

Amit, V. (ed.) (2000) Constructing the field: Ethnographic fieldwork in the contemporary world. London: Routledge

Anderson, Benedict (1993) Imagined communities: Reflections on the origin and spread of nationalism. London: Verso

Anderson, Ben. (2002) "A principle of hope: Recorded music, listening practices and the immanence of utopia," Geografiska Annaler. 84B: 211-227

Andrews, J. and Taylor, J. (1982) Architecture: A performing art. Guildford: Lutterworth Press

Bachelard, G. (1994[1964]) The poetics of space. Trans. Maria Jolas. Boston: Beacon 

Badiou, A. (2000) Deleuze: The clamour of being. Trans. L. Burchill. Minneapolis: The
University of Minnesota Press

Badiou, A. (2003) Infinite thought: Truth and the return of philosophy. London:

Continuum

Baeten, G. (2002a) "The spaces of utopia and dystopia: Introduction" Geografiska Annaler Series B. 84(3-4): 141.

Baeten, G. (2002b) "Western utopianism/dystopianism and the political mediocrity of critical urban research," Geografiska Annaler Series B. 84(3-4): 143-152

Bahro, R. (1991) "Communes", in Dobson, A. (ed.) The Green Reader. London: Baker-Smith, D. and Barfoot, C. (1987) Between Dream and Nature: Essays on Utopia
and Dystopia. Amsterdam: Rodopi

Ballard, J.G. (1999[1962]) The drowned world. London: Millennium

Bann, S. (2003) "Arcadia as utopia in contemporary landscape design: The work of Bernard Lassus," History of the Human Sciences. 16(1): 109-121

Barad, K. (2003) "Posthumanist performativity: Toward an understanding of how matter comes to matter," Signs. 28(1): 801-831

Barricelli, J.P. (1999) "Practical hallucinations: Campanella's La Citta Del Sole," in Slusser, G., Allen, P., Gaillard, R. and Chatelain, D. (eds.) Transformations of utopia:

Changing visions of the perfect society. NY: AMS Press, Inc.: 3-16

Barnes, T. and Duncan, J. (eds.) (1992) Writing worlds: Discourse, text and metaphor in the representation of landscape. London: Routledge

Barnett, C. (1993) "Stuck in the post: An unsympathetic critique of Andrew Sayer's "Postmodernist thought in Geography: A realist view"," Antipode. 25(4): 365-368 Bataille, G. (1985) Visions of excess: Selected writings 1927-1938. Minneapolis:
University of Minnesota Press

Bataille, G. (1988) The accursed share. NY: Zone

Bataille, G. (1997) The Bataille reader. Botting, F. and Wilson, W. (eds.) Oxford: Blackwell

Baudrillard, J. (1988) America. Trans. C. Turner. London: Verso 
Baudrillard, J. (1996) The system of objects. Trans. J. Benedict. London: Verso

Baudrillard, J. (1998) Paroxysm: Interviews with Phillippe Petit. Lonodn: Verso

Baudrillard, J. (2001) The uncollected Baudrillard. London: SAGE Bauman, Z. (1987) Legislators and Interpreters: On Modernity. Post-Modernity, and
Intellectuals. Cambridge: Polity

Bauman, Z. (1992) "Survival as a social construct", Theory, Culture and Society. 9: 1-26

Bauman, Z. (2003) "Utopia with no topos", History of the Human Sciences. 16(1) 11-25

Baxter, J. and Eyles, J. (1999) "Prescription for research practice? Grounded theory in qualitative evaluation," Area. 31(2): 179-181

Baydar, G. (2003) "Spectral returns of domesticity," Environment and Planning D;

Society and Space. $21: 27-45$

Bayer, H., Gropius, W and Gropius, I. (1959) Bauhaus, 1919-1928. Branford: Bailey \& Swinfen

Bell, D. (1997) "Anti-idyll," in Cloke, P. and Little, J. (eds.) Contested countryside cultures: Otherness, marginalization and rurality. London: Routledge

Bell, V. (ed.) (1999) Performativity and belonging. London: SAGE

Benjamin, A. (1988) "Deconstruction and art/the art of deconstruction," in Norris, C. and Benjamin, A. (ed.) What is deconstruction? London@ Academy Editions: 33-54

Benjamin, W. (1985) One way street and other writings. London: Verso

Benjamin, W. (2002) The arcades project. Cambridge, Massachusetts: Harvard University Press

Bingham, N. (1996) "Object-ions: From technological determinism to geographies of relations," Environment and Planning D: Society and Space. 14(6): 635-657

Bishop, P. (1992) "Rhetoric, memory and power: Depth psychology and postmodern geography," Environment and Planning D: Society and Space. 10(1): 5-22

Blau, E. (1999) The architecture of Red Vienna. Cambridge, Massachusetts: The MIT Press

Bloch, E. (1995) The principle of hope. Trans. N. Plaice, S. Plaice and P. Knight. Cambridge, Massachusetts: The MIT Press 
Blum, V. and Nast, H. (1996) "Where's the difference? The heterosexualization of alterity in Henri Lefebvre," Environment and Planning D: Society and Space. 14(5):
559-580

Boesky, A. (1999) "Club Med as utopias: Antedating the idyll," in Slusser, G., Allen, P., Gaillard, R. and Chatelain, D. (eds.) Transformations of utopia: Changing visions of the perfect society. NY: AMS Press, Inc.: 117-126

Bonnett, A. (1992) "Art, ideology and everyday space: Subversive tendencies from Dada to postmodernism," Environment and Planning D: Society and Space. 10(1): 69-86

Borden, I., and McCreevy, S. (2001) "Critique of lines," Architectural design. 71(3): 6-7

Bourdieu, P. (1986) Distinction: A social critique of the judgement of taste. Trans. R. Nice. London: Routledge

Botto, M.I.D. (2004) "Redesigning utopia for the $21^{\text {st }}$ century? Some reflections on current projects of urban regeneration in the United Kingdom," paper presented to the $5^{\text {th }}$ International Conference of the Utopian Studies Society, 8-10 July, 2004

Bradley, F. (ed.) (1996) Rachel Whiteread: Shedding life. London: Tate Gallery Publishing Ltd

Bramhas, E. (1987) Der Wiener Gemeindebau: Von Karl-Marx Hof zum Hundertwasserhaus. Basel: Birkhaeuser Bramwell, A. (1985) Blood and soil: Richard Walther Darre and Hitler's Green Party.
Bourne End: Kensal Press Brown, E.J. (1976) Brave New World, 1984 and We: An Essay on Anti-Utopia. Ann
Arbor: Ardis

Bruce, T. (1991) Time to play in early childhood education. London: Hodder \& Stoughton Educational

Bruce, T. (2003) "Series editor's introduction," in Orr, R. My right to play: A child with complex needs. Maidenhead: Open University Press

'Building futures' web page (07/2003): $16 / 10 / 2003$ , accessed

Burdett, C. (2003) "Italian fascism and utopia," History of the Human Sciences. 16(1):
93-108 
Burgess, J. and Wood, P. (1988) "Decoding docklands: Place advertising and the decision-making strategies of the small firm," in Eyles, J. and Smith, D.M. (eds.) Qualitative methods in human geography. Cambridge: Polity Press, Ch.6: 94-117

Burrell, G. and Dale, K. (2002) "Utopiary: Utopias, gardens and organization," in Parker, M. (ed.) Utopia and organization. Blackwell: Oxford: 106-127

Cache, B. (1995) Earth moves: The furnishing of territories. Ed. M. Speaks. Massachusetts: The MIT Press

Callenbach, E. (1990) Ecotopia: The Notebooks and Reports of William Weston. London: Bantam.

Cant, S. and Sharma, U. (1998) "Reflexivity, ethnography and the professions (complimentary medicine): Watching you watching me watching you (and writing about both of us)", The Sociological Review. 46(2): 245-263

Carey, J. (1999) The Faber book of utopias. London: Faber

Caygill, H. (1998) Walter Benjamin: The colour of experience. Lonodn: Routledge

Christensen, P. and James, A. (eds.) (2000) Research with children: Perspectives and practices. London: Falmer

Christoph, H. (1980) "Neuschwanstein fuer Gemeindemieter," Profil. 41: 61-64

Christoph, H. (1985) "Zwiebelturm statt Humusklo," Profil. 25: 72

Clark, N. (2002) "The demon-seed: Bioinvasion as the unsettling of environmental cosmopolitanism," Theory, Culture and Society. 19(1-2): 101-125

Clark, N. (2003) "Feral ecologies: Performing life on the colonial periphery," in Szerszynski, B., Heim, W. and Waterton, C. (eds.) Nature performed: Environment, culture and performance Oxford: Blackwell, 163-182

Clarke, D.B. and Doel, M.A. (1994) "The perfection of geography as an aesthetic of disappearance," Ecumene. 1(4): 317-323

Clifford, J. (1997) Routes: Travel and translation in the late Twentieth Century. Cambridge, Massachusetts: Harvard University Press

Cloke, P. (2002) "Deliver us from evil? Prospects for living ethically and acting politically in human geography," Progress in Human Geography. 26(5): 587-604 
Cloke, P., Goodwin, M. and Milbourne, P. (1997) Rural Wales: Community and marginalization. Cardiff: University of Wales Press

Cloke, P. and Jones, O. (2001) "Dwelling, place, and landscape: An orchard in Somerset," Environment and Planning A. 33: 649-666

Coates, C. (2001) Utopia Britannica: British Utopian Experiments: 1325-1945. London: Diggers \& Dreamers Publications.

Coffey, A. (2002) "Ethnography and self: Reflections and representations," in May, T. (ed.) Qualitative research in action. London: SAGE, Ch. 15: 313-331

Cook, I. (1997) "Participant observation," in Flowerdew, R. and Martin, D. (eds.) Methods in human geography: A guide for students doing a research project. Harlow: Pearson Education Limited, Ch. 8: 127-149

Cooper, D. (2004) "Negotiating public, private and community: The place of property in a free school," paper presented to the $5^{\text {th }}$ International Conference of the Utopian Studies Society, 8-10 July, 2004

Cooper-Marcus, C. (1993) "Designing for a commitment to place: Lessons from the alternative community Findhorn," Seamon, D. (ed.) Dwelling, seeing and designing: Toward a phenomenological ecology. Albany: SUNY Press, Ch. 13: 299-330

Cosgrove, D. (1982) "The myth and stones of Venice: An historical geography of a symbolic landscape," Journal of Historical Geography. 8(2): 145-169

Cosgrove, D. (1990) "Environmental thought and action: Pre-modern and post-modern," Transactions of the Institute of British Geographers. 15: 344-358

Cosgrove, D. (1998) Social formation and symbolic landscape. Madison: University of Wisconsin Press

Cosgrove, D. and Daniels, S. (eds.) (1988) The iconography of landscape. Cambridge: CUP

Cosgrove, D., Roscoe, B., and Rycroft, S. (1996) "Landscape and identity at Ladybower Reservoir and Rutland Water," Transactions of the Institute of British Geographers. 21(3): 534-550

Cosgrove, D. and Thornes, J. (1982) "The truth of clouds: John Ruskin and moral order in the landscape," in Pocock, D. (ed.) Humanistic geography and literature. London: Croom Helm, 239-253

Coyle, F. (2004) "'Safe space' as counter-space: Women, environmental illness and 'corporeal chaos'," The Canadian Geographer. 48(1): 62-75 
Crang, M. (1998) "Places of practice and the practice of science," Environment and Planning A. 30: 1971-1974

Crang, M. (2002) “Qualitative methods: The new orthodoxy?" Progress in Human Geography. 26(5): 647-655

Crang, P. (1998) Cultural geography. London: Routledge

Cronon, W. (1991) Nature's metropolis: Chicago and the great west. London: Norton

Crook, S. (2000) "Utopia and dystopia," in Browning, G., Halchi, A. and Webster, F. (eds.) Understanding contemporary society: Theories of the present. London: SAGE, Ch.15: 205-218

Crossley, C. (1999) "Utopia and the French Romantic imagination," in Slusser, G., Allen, P., Gaillard, R. and Chatelain, D. (eds.) Transformations of utopia: Changing visions of the perfect society. NY: AMS Press, Inc.: 31-38

Crouch, C. (1999) Modernism: In art, design and architecture. Hampshire: Macmillan Press Ltd.

Crouch, D. (2001) "Spatialities and the feeling of doing," Social and cultural geography. 2(1): $61-75$

Curry, M.R. (2000) "Wittgenstein and the fabric of everyday life," in Crang, M. and Thrift, N. (eds.) Thinking space. London: Routledge, Ch.4: 89-113

Daniel, P. and Ivatts, J. (1998) Children and social policy. Basingstoke: PALGRAVE

Daniels, S. (1993) Fields of visions: Landscape imagery and national identity in England and the United States. London: Polity Day, C. (1990a) Places of the soul: Architecture and environmental design as a healing
art. Wellingborough: The Aquarian Press

Day, C. (1990b) Building with heart: A practical approach to self and community building. Hartland, Devon: Green Books

Day, C. (with Sillett, J. and Hannay, P.) (1991) "Look and learn," The Architects' Journal. 193(20): 32-51

Day, C. (1998) A haven for childhood: The building of a Steiner Kindergarten.

Clunderwen, Carmarthenshire: Starborn Books 
Day, C. (2002) Spirit and place: Healing our environment, healing environment. Oxford: Architectural Press

Davis, J.C. (1984) "The history of utopia: The chronology of Nowhere," in Alexander, P. and Gill, A. (eds.) Utopias. London: Gerald Duckworth \& Co. Ltd., Ch.1: 1-18

Davis, M. (1990) City of quartz: Excavating the future in Los Angeles. London: Verso

Dearling, A. (with G. Meltzer) (2003) Another kind of space: Creating ecological dwellings and environments. Lyme Regis: Enabler Publications

Debord, G. (1967) The society of the spectacle. Detroit: Black and Red

DeCerteau, M. (1984) The practice of everyday life. Berkeley: University of California Press

Deleuze, G. and Guattari, F. (1983) On the line. NYC: Semiotext(e)

Deleuze, G. and Guattari, F. (1987) A thousand plateaus: Capitalism and schizophrenia. Minneapolis: The University of Minnesota Press

Deleuze, G. and Guattari, F. (1994) What is philosophy?. London: Verso

DeLyser, D. and Starrs, P.F. (2001) "Doing fieldwork: Editors' introduction," The Geographical Review. 91(1-2): iv-viii

'Demolition Detectives', (28/10/2002), Channel 4 Television, 8pm-9pm

Denscombe, M. (1998) The good research guide for small-scale social research projects. Buckingham: Open University Press

Derrida, J. (1974) Of grammatology. Trans. G.C. Spivak. Baltimore: The John Hopkins University Press

Derrida, J. (1978) Writing and difference. Trans. A. Bass. London: Routledge and Kegan Paul

Derrida, J. (1988) "Letter to a Japanese friend," Trans. D. Wood and A. Benjamin. in Wood, D. and Bernasconi, R. (eds.) Derrida and difference. Evanston, IL: Northwestern University Press, 7-12

Derrida, J. (1990) Limited Inc. Evanston: Northwestern University Press

Derrida, J. (1991) Derrida reader between the blinds. Ed. P. Kamuf. NY: Columbia University Press 
Dewsbury, J.-D. (2000) "Performativity and the event: Enacting a philosophy of difference," Environment and Planning D: Society and Space. 18(4): 473-496

Dewsbury, JD, Harrison, P. and Rose, M. (2002) "Enacting geographies: Introduction," Geoforum. 33(4): 437-440

Dewsbury, JD and Naylor, S. (2002) "Practising geographical knowledge: Fields, bodies and dissemination," Area. 34(3): 253-260

DfES (2003) Every child matters., Governmental Green Paper. Accessed at , 07/2004.

Diggers and Dreamers: The guide to communal living. (2003) London: Diggers and Dreamers Publications

Drexler, A. and Hines, T.S. (1982) The architecture of Richard Neutra: From International Style to California Modern. New York: The Museum of Modern Art

Diprose, R and Ferrell, R. (1991) "Introduction," in Diprose, R. and Ferrell, R. (eds.) Cartographies: Poststructuralism and the mapping of bodies and spaces. St. Leonards, Australia: Allen and Unwin: vii-ix

Dobson, A. (1995) Green Political Thought. London: Routledge.

Doel, M.A. (1992) "In stalling deconstruction: Striking out the postmodern," Environment and Planning D: Society and Space. 10(2): 163-179

Doel, M.A. (1996) "A hundred thousand lines of flight: A machinic introduction to the nomad thought and scrumpled geography of Gilles Deleuze and Felix Guattari," Environment and Planning D: Society and Space. 14(4): $421-439$

Doel, M.A. (2003) "Gunnar Olsson's transformers: The art and politics of rendering the co-relation of society and space in monochrome and technicolour," Antipode. 35(1): 140-167

Dovey, K. (1999) Framing places: Mediating power in built form. London: Routledge Driver, F. (2000) "Editorial: Field-work in geography," Transactions of the Institute of
British Geographers. 25: 267-268

Driver, F. and Gilbert, D. (eds.). (1999) Imperial cities: landscape, display and identity. Manchester: Manchester University Press

Du Gay, P., Hall, S., Jones, L., Mackay, H. and Negus, K. (1997) Doing cultural studies: The story of the Sony Walkman. London: SAGE 
Duncan, J. and Ley, D. (eds.) (1993) Place/culture/representation. London: Routledge

Edwards, B. (2001) "Sustainablity: The search for an earthly paradise," Architectural Design. 71(4): 7

Edwards, B. and du Plessis, C. (2001) "Snakes in utopia: A brief history of sustainability," Architectural Design. 71(4): 9-19

Ellin, N. (2001) "Thresholds of fear: Embracing the urban shadow," Urban Studies. 38(5-6): 869-883

Estes, C. (1989) "Consensus and community," in Plant, J. (ed.) Healing the wounds: The promise of ecofeminism. London: Green Print, 226-233

Fannin, M. (2003) "Domesticating birth in the hospital: "Family-centred" birth and the emergence of "Homelike" birthing rooms," Antipode. 35(3): 513-535

Feltham, O. and Clemens, J. (2003) "Editors' preface," in Badiou, A. Infinite thought: Truth and the return of philosophy. London: Continuum

Ferch, C. (1985) “Kunst statt Kalk," Bunte. 28/02/1985: 152

'Fflic' (u.d.) Short youth programme in Welsh for S4C, Welsh-language channel.

Fine, G.A. and Sandstrom, K.L. (1988) Knowing children: Participant observation with minors. London: SAGE

Fishman, R. (1984) "Utopia in three dimensions: The ideal city and the origins of modern design," in Alexander, P. and Gill, A. (eds.) Utopias. London: Gerald Duckworth \& Co. Ltd., Ch. 9: 95-107

Fishman, R. (1999) Urban Utopias in the Twentieth Century: Ebenezer Howard, Frank Llloyd Wright, Le Corbusier. Cambridge, Massachusetts: The MIT Press

Flatscher, A. (1991) "Wien im Hundertwasser-Boom: Der Meister baut und baut...," Salzburger Nachrichten. 05/05/1991: no pagination*

Forrester, M.A. (2002) "Appropriating cultural conceptions of childhood: Participation in conversation," Childhood. 9(3): 255-276

Forsey, H. (1989) "Community - meeting our deepest needs," in Plant, J. (ed.) Healing the wounds: The promise of ecofeminism. London: Green Print, Ch.24: 227-234

Fortier, A.-M. (1999) "Re-membering places and the performance of belongings," in Bell, V. (ed.) Performativity and beonging. London: SAGE, 41-64 
Foucault, M. (1986) "Of other spaces," Diacritics: A review of contemporary criticism. 16(1): $22-27$

Fournier, V. (2002) "Utopianism and the cultivation of grassroots possibilities:

Grassroots movements of hope," in Parker, M. (ed.) Utopia and organization. Blackwell: Oxford: 189-216

Frampton, K. (2000) Modern architecture: A critical history. London: Thames \& Hudson

Franck, K. (2000) "Yes, we wear buildings," Architectural Design. 70(6): 93-96

Frantz, D. and Collins, C. (1999) Celebration, USA: Living in Disney's brave new town. New York: Harry Holt and Company, LLC

Frazer, J. (1998) "The co-operative evolution of buildings and cities," in Streitz, N.A. Konomi, S. and Burkhardt, M.-J. (eds.) Cooperative buildings: Integrating information, organization, and architecture. Berlin: Springer-Verlag, 130-141

Frayling, C. (1995) Things to come. London: The British Film Institute

Freud, S. (1955) The complete psychological works of Sigmund Freud, Volume 17. London: The Hogarth Press Ltd.

Friedman, M. (1982) De Stijl: 1917-1931: Visions of Utopia. Oxford: Phaidon.

Fyfe, N. and Bannister, J. (1996) "City watching: Closed circuit television surveillance in public spaces," Area. 28(1): 37-46

Gade, D.W. (2001) "The languages of foreign fieldwork," The Geographical Review. 91(1-2): $370-379$

Gage, J. (1987) J.M.W. Turner: A wonderful range of mind. New Haven: Yale University Press

Garvey, C. (1977) Play. London: Fontana

Giddens, A. (1984) The constitution of society: Outline of the theory of structuration. Cambridge: Polity Press

Gieryn, F. (2002) "What buildings do," Theory and Society: Renewal and Critique in Social Theory. 31(1): 35-74

Gilbert, M. (1994) "The politics of location: Doing feminist research at "Home"," Professional Geographer. 46(1): 90-96 
Glancey, J. (2000) Twentieth-Century architecture: The structures that shaped the Twentieth Century. London: Carlton Books Limited

Gold, J.R. (1997) The experience of modernism: Modern architects and the future city. London: E \& FN Spon

Golomshtock, I. (1990) Totalitarian art. London: Harper Collins

Goment, E. and Harrion, A. (1999) "A sociology of attachment: Music amateurs, drug users," in Law, J. and Hassard, J. (eds.) Actor network theory and after. Blackwell: Oxford: $220-247$

Goss, J. (1988) "The built environment and social theory: Towards and architectural geography," Professional Geographer. 40(4): 392-403

Goss, J. (1993) "The "Magic of the Mall": An analysis of form, function, and meaning in the contemporary retail built environment," Annals of the Association of American Geographers. 83: 18-47

Gregory, D. (2000) "Edward Said's imaginative geographies," in Crang, M. and Thrift, N. (eds.) Thinking Space. London: Routledge, Ch.14: 302-348

Grey, C. and Garsten, C. (2002) "Organised and disorganized utopias: An essay on presumption," in Parker, M. (ed.) Utopia and organization. Blackwell: Oxford: 9-23

Grosz, E. (1992) “Bodies-cities," in Colomina, B. (ed.) Sexuality and space. NY: Princeton Architectural Press: 241-253

Grosz, E. (1995) Space, time, and perversion: Essays on the politics of bodies. London: Routledge

Grosz, E. (2001) Architecture from the outside: Essays on virtual and real space. Cambridge, Massachusetts: The MIT Press

Gruffudd, P. (1995) “'Propaganda for seemliness': Clough Williams-Ellis and Portmeirion, 1918-1950," Ecumene. 2(4): 399-422

Gruffudd, P. (1996) "The countryside as educator: Schools, rurality and citizenship in inter-war Wales," Journal of Historical Geography. 22(4): 412-423

Guy, S. (2002) "Sustainable buildings: Meanings, processes, users," Built environment. 28(1): $5-10$

Halfacree, K. (1996) "Out of place in the country: Travellers and the "rural idyll"," Antipode. 28(1): 42-72 
Hall, P. (1984) "Utopian thought: A framework for social, economic and physical planning," in Alexander, P. and Gill, A. (eds.) Utopias. London: Gerald Duckworth \& Co. Ltd., Ch.16: 189-195

Hall, P. and Ward, C. (1998) Sociable Cities: The legacy of Ebenezer Howard.

Chichester: Wiley.

Hannah, M. (1993) "Foucault on theorizing specificity," Environment and Planning D: Society and Space. 11:349-363

Hannay, P. (1991) "Comparing the two," The Architects' Journal. 193(20): 42-45 [contained within "Building feature: Look and learn," p.32-51

Hannigan, J. (1998) Fantasy city: Pleasure and profit in the postmodern metropolis. London: Routledge

'Happy architecture' (18/11/2002), BBC 4, 7:30pm-8pm

Haraway, D.J. (1997) Modest Witness@ @econd_Millennium. FemaleMan@ Meets_OncoMouse ${ }^{\mathrm{TM}}$. London: Routledge

Hardy, D. (1979) Alternative Communities in Nineteenth Century England. London: Longman

Hardy, D. (2000) Utopian England: Community experiments 1900-1945. London: E \& FN Spon

Harre, R. (2002) "Material objects in social worlds," Theory, Culture and Society. $19(5 / 6): 23-33$

Harries, K. (1993) "Thoughts on a non-arbitrary architecture," in Seamon, D. (ed.) Dwelling, seeing and designing: Toward a phenomenological ecology. Albany: SUNY Press, Ch.3: 41-59

Harris, C. (2001) "Archival fieldwork," The Geographical Review. 91(1-2): 328-334

Harrison, J.F.C. (1984) "Millennium and utopia," in Alexander, P. and Gill, A. (eds.) Utopias. London: Gerald Duckworth \& Co. Ltd., Ch.6: 61-66

Harrison, P. (2000) "Making sense: Embodiment and the sensibilities of the everyday," Environment and Planning D: Society and Space. 18(4): 497-517

Harrison, P. (2002) "The caesura: Remarks on Wittgenstein's interruption of theory, or, why practices elude explanation," Geoforum. 33(4): 487-503 
Harvey, D. (1989) The condition of postmodernity : an enquiry into the origins of cultural change. Oxford: Blackwell

Harvey, D. (1996) Justice, nature and the geography of difference. Oxford: Blackwell

Harvey, D. (2000) Spaces of Hope. Edinburgh: Edinburgh University Press.

Harvey, D. (2003) "Can we build an urban utopia?" The Times Higher Education Supplement. 14/02, accessed at , $02 / 2003$

Hazel, N. (2003) "Elicitation techniques with young people," Social research update, University of Surrey. 12: 1-6

Heidegger, M. (1962) Being and Time. Oxford: Blackwell

Heidegger, M. (1988) Martin Heidegger: Basic writings. Ed. D.F. Krell. London: Routledge Hetherington, K. (1997) The badlands of modernity: Heterotopia and social ordering.
London: Routledge

Hetherington, K. (1999) "From blindness to blindness: Museums, heterogeneity and the subject," in Law, J. and Hassard, J. (eds.) Actor network theory and after. Blackwell:

Hetherington, K. (2002) "The unsightly: Touching the Parthenon Frieze," Theory, Culture and Society. 19(5/6): 187-205

Hetherington, K and Law, J. (2000) "Guest editorial: After networks," Environment and Planning D: Society and Space. 18: 127-132 Hetherington, K. and Lee, N. (2000) "Social order and the blank figure," Environment
and Planning D: Society and Space. 18(2): 169-184

Hillis, K. (1994) "The virtue of becoming a no-body," Ecumene. 1(2): 177-196

Hinchliffe, S. (2000) "Entangled humans: Specifying powers and their spatialities," in Sharp, J.P., Routledge, P., Philo, C. and Paddison, R. (eds.) Entanglements of power: Geographies of domination/resistance. Routledge: London: 219-237

Holloway, L. and Hubbard, P. (2001) People and place: The extraordinary geographies of everyday life. Harlow: Pearson Education Limited

Holloway, M. (1984) "The necessity of utopia," in Alexander, P. and Gill, A. (eds.)

Utopias. London: Gerald Duckworth \& Co. Ltd., Ch.15: 179-188 
Holloway, S.L. (2003) "Outsiders in rural society? Constructions of rurality and naturesociety relations in the racialisation of English gypsy-travellers, 1869-1934,"

Environment and Planning D: Society and Space. 21(6): 695-715

Honour, H. (1981) Romanticism. Harmandsworth: Penguin

Horvarth, M. (u.d.) "Der Prinz und der Meister oder die verbaute Zukunft," Buchkultur. p.28-29*

Howard, E. (1965) Garden cities of to-morrow. GB: Alden \& Mowbray Ltd.

Howard, P. (1985) "Painters' preferred places," Journal of Historical Geography. 11(2): $138-154$

Howell, P. (2000) "Prostitution and racialised sexuality: The regulation of prostitution in Britain and the British empire before the Contagious Diseases Act," Environment and Planning D: Society and Space. 18(3): 321-329

Hughes, J. and Sadler, S. (eds.) (2000) Non-plan: Essays on freedom, participation and change in modern architecture and urbanism. Oxford: Architectural Press

Hundertwasser, F. (1983) Schoene Wege: Gedanken ueber Kunst und Leben. Ed. W. Schurian. Muenchen: Deutscher Taschenbuch Verlag

Hundertwasser, F. (1997) Hundertwasser architecture: For a more human architecture in harmony with nature. Koeln: Taschen

Hussey, C. (1967) The Picturesque. London: Frank Cass

Huxley, A. (1972) Island. London: Chatto \& Windus

Huxley, A. (1994) Brave New World. London: Flamingo

Hyams, H. (2003) "Adolescent bodyspaces: Making homegirls, homebodies and homeplaces," Antipode. 35(3): 536-558

Hyndman, J. (2001) "The field as here and now, not there and then," The Geographical Review. 91(1-2): 262-272

Imrie, R. (2003) "Architects' conceptions of the human body," Environment and Planning D: Society and Space. 21: 47-65

Ingold, T. (2000) The perception of the environment: Essays in livelihood, dwelling and skill. London: Routledge 
Jacques, R.S. (2002) "What is a crypto-utopia and why does it matter?" in Parker, M. (ed.) Utopia and organization. Blackwell: Oxford: 24-39

Jacoby, R. (1999) The end of utopia: Politics and culture in an age of apathy. NY: Basic Books

Jameson, F. (1991) Postmodernism, or, the cultural logic of late capitalism. London: Verso

Jeans, D.N. (1990) "Planning and the myth of the English countryside in the Interwar Period," Rural History. 1(2): 249-264

Jencks, C., Quotrup, J., Rizzini, I. and Thorne, B. (2000) "Editorial: Children's places and spaces in the world," Childhood. 7(1): 5-9

Jones, H.M. (1974) Revolution and Romanticism. New Have: Yale UP

Josselson, R. (1993) The narrative study of lives: Volume 1. London: SAGE

Katz, C. (1994) "Playing the field: Questions of fieldwork in geography," Professional Geographer. 46(1): 67-72

Kearney, R. (1998) Poetics of imagining: Modern to pos-modern. Edinburgh: Edinburgh University Press

Keohane, K. (2002) "The Revitalisation of the City and the Demise of Joyce's Utopian Modern Subject", Theory, Culture and Society. 19(3): 29-49.

Khittl, K. (1985) "Wohnen im Pflanz," Wochenpresse. 20(14): no pagination*

Knight, D. (1997) Barthes and utopia: Space, travel and writing. Oxford: OUP

Kockel, U. (2001) "Heimat als Widerstaendigkeit: Ueberlegungen zu einem Europa freischwebender Regionen," in Goettsch, S. and Koehle-Hezinger, C. (eds.) Komplexe Welt: Kulturelle Ordnungssyteme als Orientierung. Muenster: Waxmann, 167-176

Koller, K.H. (1996) Hundertwasserhaus Wien. Wien: Museums Betriebs Gesellschaft $\mathrm{MBH}$

Kolnai, A. (1995) The utopian mind and other papers. Ed. F. Dunlop. London: The Athlone Press

Kraftl, P. (forthcoming) "Geography, environmental education and ecological architecture," (article in two parts), National Association of Environmental Education, journal. 
Krause, G. (1981) “Ein Prestigeprojekt wird langsam faul," Kurier. 14/08/1991: 19

Krell, D.F. (1997) Archeticture: Ecstasies of space, time and the human body. Albany: SUNY Press

Kumar, K. (1987) Utopia and Anti-Utopia in Modern Times. Oxford: Blackwell.

Kumar, K. (1991) Utopianism. Milton Keynes: Open University Press.

Kumar, K. (2003) "Aspects of the western utopian tradition," History of the Human Sciences. 16(1): 63-77

Kwinter, S. (2001) Architectures of time: Toward a theory of the event in modernist culture. Cambridge, Massachusetts: The MIT Press

Lane, B.M. (1985) Architecture and politics in Germany 1918-45. Cambridge: Harvard UP

Lassman, P. (2003) "Political theory as utopia," History of the Human Sciences. 16(1): 49-62

'Latent utopias' exhibition and website. Exhibition: 01-03/2003, Graz, Austria: visited 02/2003. Website: unobtainable)

Latham, A. (1999) "Powers of engagement: On being engaged, being indifferent, and urban life," Area. 31(2): 161-168

Latour, B. (1993) We have never been modern. London: Harvester Wheatsheaf

Latour, B. (1999) "On recalling ANT," in Law, J. and Hassard, J. (eds.) Actor network theory and after. Blackwell: Oxford: 15-25

Latour, B. (2002) "Morality and technology: The end of means," Theory. Culture and Society. 19(5/6): 247-260

Law, J. (ed.) (1991) A sociology of monsters: Essays on power, technology and domination. London: Routledge

Law, J. (1999) "After ANT: Complexity, naming and topology," in Law, J. and Hassard, J. (eds.) Actor network theory and after. Oxford: Blackwell: 1-14

Law, J. (2002) "Objects and spaces," Theory, Culture and Society. 19(5/6): 91-105 
Law, J. and Bijker, W.E. (1992) "Postscript: Technology, stability and social theory," in Law, J. and Bijker, W.E. (eds.) Shaping technology/building society. Cambridge, Massachusetts: The MIT Press, Ch.11:290-308

Law, J. and Hassard, J. (eds.) (1999) Actor network theory and after. Oxford: Blackwell Law, J. and Mol, A. (2001) "Situating technoscience: An inquiry into spatialities," Environment and Planning D: Society and Space. 19:609-621

Law, J. and Mol, A. (2002) "Local entanglements or utopian moves: An inquiry into train accidents," in Parker, M. (ed.) Utopia and organization. Blackwell: Oxford: 82-105

Leach, N. (1997) Re-thinking Architecture: A Reader in Cultural Theory. London: Routledge

Leary, R. (1996) "Bright character's colourful work," Observer. 03/1996: 206

Le Corbusier (1971) The city of tomorrow. London: The Architectural Press Ltd

Lees, L. (1997) "Ageographia, heterotopia, and Vancouver's new public library," Environment and Planning D: Society and Space. 15(3): 321-347

Lees, L. (1998) "Urban renaissance and the street: Spaces of control and contestation," in Fyfe, N. (ed.) Images of the street: Planning, identity and control in public space. London: Routledge, Ch.16: 236-253

Lees, L. (2001) "Towards a critical geography of architecture: The case of an ersatz colosseum," Ecumene. 8(1): 51-86

Lees, L. (2002) “Rematerializing geography: The 'new' urban geography," Progress in Human Geography. 26(1): 101-112

Lefebvre, H. (1991) The production of space. Oxford: Basil Blackwell Ltd

Lefebvre, H. (1996) Writings on cities. Ed. and trans. E. Kofman and E. Lebas. Oxford: Blackwell

Leitner, B. (1976) The architecture of Ludwig Wittgenstein: A documentation. NY: NY University Press

Lerup, L. (1977) Building the unfinished: Architecture and human action. London: SAGE

Levitas, R. (1990) Concept of Utopia. Syracuse: Syracuse University Press 
Levitas, R. (1998) The inclusive society? Social exclusion and New Labour. Basingstoke: MacMillan Press Ltd.

Levitas, R. (2003) "Introduction: the elusive idea of utopia", History of the Human Sciences. $16(1): 1-10$.

Ley, D. (1993) "Co-operative housing as a moral landscape," in Duncan, J. and Ley, D. (eds.) Place/culture/representation. London: Routledge, Ch.8: 128-148

Lightfoot, G. and Lilley, S. (2002) "Writing utopia," in Parker, M. (ed.) Utopia and organization. Blackwell: Oxford: 155-168

Little, J. and Leyshon, M. (2003) "Embodied rural geographies: Developing research agendas," Progress in Human Geography. 27(3): 257-272

Limb, M. and Dwyer, C. (eds.) (2001) Qualitative methodologies for geographers: Issues and debates. London: Arnold

Llewellyn, M. (2003) "Polyvocalism and the public: 'Doing' a critical geography of architecture," Area. 35(3): 264-270

Llewellyn, M. (2004) "'Urban village' or 'white house': Envisioned spaces, experienced places, and everyday life at Kensal House, London in the 1930s," Environment and Planning D: Society and Space. 22(2): 229-249

Longhurst, R. (2000) “'Corpogeographies' of pregnancy: bikini babes," Environment and Planning D: Society and Space. 18(4): 453-472

Loewenthal, D. (1991) "British National identity and the English landscape," Rural History. 2(2): 205-230

Loewy, M. (1998) "Consumed by night's fire: The dark romanticism of Guy Debord," Radical Philosophy. 87: 31-34

Lyotard, J-F. (1989) The Lyotard Reader. Ed. A. Benjamin. Oxford: Blackwell

Lynn, G. (1998) Folds, bodies and blobs: Collected essays. Belgium: La Lettre Volée

Lubelska, A. (ed.) (1993) Better play. London: National Children's Bureau

Lucas, J. (1988) "Places and dwellings: Wordsworth, Clare and the Anti-Picturesque," in Cosgrove, D. and Daniels, S. (eds.) The iconography of landscape. Cambridge: CUP

Lupton, D. 2004) Risk. London: Routledge 
MacLeod, G. and Ward, K. (2002) "Spaces of utopia and dystopia: Landscaping the contemporary city," Geografiska Annaler. 84B(3-4): 153-170

Macnaghten, P. and Urry, J. (1998) Contested natures. London: SAGE

Madenipour, A. (1996) "Urban design and dilemmas of space," Environment and Planning D: Society and Space. 14(3): 331-355

Madge, P. (1997) “Ecological design: A new critique," Design Issues. 13(2): 44-54

Mannheim, K. (1960[1936]) Ideology and utopia: An introduction to the sociology of knowledge. London: Routledge

Manuel, F.E. (1966) French utopias.

Manuel, F.E. and Manuel, F.P. (1979) Utopian thought in the Western world. Harvard: Harvard University Press

Marcuse, H.(1968) "Liberation from the affluent society," in Cooper, D. (ed.) The dialectics of liberation. Harmandsworth: Penguin: 175-192

Margolin, V. (1997) The Struggle for Utopia: Lissitzky, Rodchenko, Moholy-Nagy 1917-1946. Chicago: Chicago University Press.

Martell, L. (1994) Ecology and society: An introduction. Oxford: Blackwell

Marx, K. (1977) Selected writings. Ed. D. McLellan. Oxford: OUP

Marx, L. (1964) The machine in the garden: Technology and the pastoral ideal in America. Oxford: OUP

Mason, J. (2002) "Qualitative interviewing: Asking, listening and interpreting," in May, T. (ed.) Qualitative research in action. London: SAGE, Ch. 10: 225-241

Masschelein, A. (2002) "The concept as ghost: Conceptualization of the uncanny in latetwentieth-century theory," Mosaic: A journal for the interdisciplinary study of literature. 35(1): 53-68

Massey, D. (2000) "Entanglements of power: Reflections," in Sharp, J.P., Routledge, P., Philo, C. and Paddison, R. (eds.) Entanglements of power: Geographies of domination/resistance. Routledge: London: 279-286

Massumi, B. (2001) "Becoming-deleuzian," Environment and Planning D: Society and Space. 19(4): 395-406 
Matless, D. (1990) "Definitions of England: Presevation, Modernism and the nature of the Nation," Built Environment. 16(3): 145-167

Matless, D. (1998) Landscape and Englishness. London: Reaktion

Matless, D. and Revill, G. (1995) "A solo ecology: The erratic art of Andy

Goldsworthy," 2(4): 424-448

Matthews, H., Taylor, M., Sherwood, K., Tucker, F., and Limb, M. (2000) "Growing up in the countryside: Children and the rural idyll," Journal of rural studies. 16: 141-153

Matthews, H. (2002) "Children and regeneration: Setting an agenda for community participation and integration," Children and society. 17: 264-276

Matthews, H. (2003) "Inaugural editorial," Children's geographies. 1: 3-5

Maxey, I. (1999) "Playgrounds: From oppressive spaces to sustainable places," Built environment. 21(5): 18-24

May, T. (1993) Social research: Issues, methods and process. Buckingham: Open University Press

McCann, E.J. (1997) "Where do you draw the line? Landscape, texts, and the politics of planning," Environment and Planning D: Society and Space. 15(6): 641-661

McCann, E.J. (1997) "Collaborative visioning or urban planning as therapy? The politics of public-private policy making," The Professional Geographer. 53(2): 207-218

McCormack, D. (2002) "A paper with an interest in rhythm," Geoforum. 33(4): 469-485

McCormack, D. (2004) "Drawing out the lines of an event," Cultural Geographies. 11(2): $211-220$

McDowell, L. (2002) "Unsettling naturalisms," Signs. 27(3): 815-822

McFague, S. (1972) The Family, Communes, and Utopian Societies. NY: Harper and Row

McGreevy, P. (1987) "Imagining the future at Niagara Falls," Annals of the Association of American Geographers. 77(1): 48-62

McKendrick, J.M. (1999) "Playgrounds in the built environment," Built environment. 25(1): $5-10$

McNamee, S. (2000) "Foucault's heterotopia and children's everyday lives," Childhood. $7(4): 479-492$ 
Mercer, D. (2002) "Future-histories of Hanford: The material and semiotic production of a landscape," Cultural geographies. 9(1): 35-67

Merrifield, A. (1995) "Lefebvre, anti-logos and Nietzsche: An alternative reading of The production of space," Antipode. 27(3): 294-303

Metcalfe, A. (2001) "Nothing: The hole, the holy, the whole," Ecumene. 8(3): 247-263

Miles, M. (1997) Art, space and the city: Public art and urban futures. London:

Routledge

Milbourne, P. (1997) Revealing rural 'others': Representation, power and identity in the British Countryside. London: Cassell

Mitchell, D. (1995) "The end of public space? People's park, definitions of the public, and democracy," Annals of the Association of American Geographers. 85(1): 108-133

Mitchell, D. (2000) Cultural geography: A critical introduction. Oxford: Blackwell

Mitchell, W.J. (1996) City of bits: Space, place and the Infobahn. Massachusetts: MIT

Molotch, H. (1993) "The space of Lefebvre," Theory and society. 22: 887-895

More, T. (1988 [1516]) Utopia. Ed. G.M. Logan and R.M. Adams. Cambridge:

Cambridge University Press

Morris, W. (1993 [1891]) News From Nowhere and Other Writings. London: Penguin

Morrow, V. and Richards, R. (1996) The ethics of social research with children: An overview," Children and Society. 10(2): 90-105

Moser, I. and Law, J. (1999) "Good passages, bad passages," in Law, J. and Hassard, J. (eds.) Actor network theory and after. Blackwell: Oxford: 196-219

Mugerauer, R. (1994) Interpretations on behalf of place: Environmental displacements and alternative responses. Albany SUNY Press

Mugerauer, R. (1995) Interpreting environments: Tradition, deconstruction, hermeneutics. Austin: University of Texas Press

Mumford, L. (1959 [1922]) The Story of Utopias. Gloucester, Massachusetts: Peter Smith. 
Murdoch, J. (1997) "Inhuman/nonhuman/human: Actor-network theory and the prospects for a nondualistic and symmetrical perspective on nature and society," Environment and Planning D: Society and Space. 15(6): 731-756

Murdoch, J. and Marsden, T. (1994) Reconstituting rurality. London: UCL Press

Myersen, G. (2003) "Utopia@second_Millennium. Daedalus meets Job" History of the Human Sciences. 16(1): 79-92

Nair, S. (1996) "Expressive countercultures and postmodern utopia: A Caribbean context," Research in African Literature. 27(4): 71-87

Nash, C. (2000) "Performativity in practice: Some recent work in cultural geography," Progress in Human Geography. 24(4): 653-664

Nast, H.J. (1994) "Opening remarks on "Women in the field"," Professional Geographer. 46(1): 54-66

Nast, H.J. (2001) "Climbing scale and place: Geological musings and social geographical method," The Geographical Review. 91(1-2): 185-191

Neville-Sington, P. and Sington, D. (1993) Paradise Dreamed: How Utopian Thinkers Have Changed the Modern World. London: Bloomsbury.

Nietzsche, F. (1976) The portable Nietzsche. (Ed. and trans. W. Kaufmann) London: Penguin

Nieuwenhuys, C. (2001[1964]) "New Babylon: An urbanism of the future," Architectural design. 71(3): 12-14

Norberg-Schulz, C. (1985) The concept of dwelling: On the way to a figurative architecture. NY: Rizzol International Publications, Inc.

Norris, C. and Armstrong, G. (1999) The maximum surveillance society: The rise of CCTV as social control. Oxford: Berg

Norris, C. and Benjamin, A. (1998) What is deconstruction?. London: Academy

Oc, T, and Tiesdell, S. (1998) "City centre management and safer city centres: Approaches in Coventry and Nottingham," Cities. 15(2): 85-103

Olalquiaga, C. (1992) Megalopolis: Contemporary cultural sensibilities. Minneapolis: University of Minnesota Press

Ole Jensen, J. (2002) "Green buildings as part of the infrastructure: Supporter, symbol or stranger," Built environment. 28(1): 22-32 
Olin, J.C. (1989) Interpreting Thomas More's Utopia. New York: Fordham University Press

ORF (2003) "Streit um Hundertwasser-Haus-Urheberschaft," 06/02/03, Kulturkritik. Accessed at , $02 / 2003$

Ormiston, G. (1988) "The economy of duplicity," in Wood, D. and Bernasconi, R. (eds.) Derrida and difference. Evanston, IL: Northwestern University Press, 41 -50

Orwell, G. (1964) Animal Farm: A Fairy Story. London: Longman.

Orwell, G. (1990 [1949]) Nineteen Eighty-Four. Harmandsworth: Penguin

Osborne, T. (2003) "Utopia, counter-utopia," History of the Human Sciences. 16(1): $123-136$

Osmond, J. and Graham, A. (1984) Alternatives: New approaches to health, education, the family and the Antiquarian Age. London: HarperCollins

Pallasmaa, J. (1996) The eyes of the skin: Architecture and the senses. London: Academy Editions

Papanek, V. (1995) The green imperative: Ecology and ethics in design and architecture. London: Thames and Hudson

Paperno, I. and Grossman J.D. (1994) Creating Life: The Aesthetic Utopia of Russian Modernism. Stanford: Stanford University Press

Parker, M. (2002a) "Utopia and the organizational imagination: Outopia," in Parker, M. (ed.) Utopia and organization. Blackwell: Oxford: 1-8

Parker, M. (2002b) "Utopia and the organizational imagination: Eutopia," in Parker, M. (ed.) Utopia and organization. Blackwell: Oxford: 217-224

Parr, H. (2001) "Feeling, reading and making bodies in space," The Geographical Review. 91(1-2): 158-167

Pawley, M. (1998) Terminal architecture. London: Reaktion Books Ltd.

Pawley, M. (2000) "Friedensreich Hundertwasser: Maverick architect building against the grain," The Guardian. 14/04/2000: no pagination. Accessed at , archive facility, 04/2002

Pels, D., Hetherington, K. and Vandenberghe, F. (2002) "The status of the object Performances, mediations, and techniques," Theory, Culture and Society. 19(5/6): 1-21 
Pepper, D. (1989) The roots of modern environmentalism. London: Routledge

Pepper, D. (1991) Communes and the Green Vision. London: Green Print

Pepper, D. (1996) Modern Environmentalism: An Introduction. London: Routledge

Perrella, S. (1998) "Hypersurface theory: Architecture><culture," Architectural Design. 68(5/6): $7-15$

Pfeiffer, B.B. (1997) Frank Lloyd Wright: Master builder. London: Thames and Hudson Ltd

Philo, C. (1987) "'Fit localities for an asylum: The historical geography of the 'mad business'," Journal of Historical Geography. 13: 398-415

Philo, C. (1992) "Foucault's geography," Environment and Planning D: Society and Space. 10(2): 137-161

Pile, S. (1993) "Human agency and human geography revisited: A critique of 'new models' of the self," Transactions of the Institute of British Geographers. 18(1): 122-139

Pile, S. and Rose, G. (1992) "All or nothing? Politics and critique in the modernismpostmodernism debate," Environment and Planning D: Society and Space. 10(2): 123136

Pinder, D. (2001) "Utopian transfiguration: The outer spaces of New Babylon," Architectural design. 71(3): 15-19

Pinder, D. (2002) "In defence of utopian urbanism: Imagining cities after the 'end of utopia'," Geografiska Annaler. 84 B (3-4): 229-241

Piper, J. (1940) "Decrepit glory: A tour of Hafod," Architectural Review. 87: 207-210

Piper, J. (1947) "Pleasing decay," Architectural Review. 102: 85-94

Pitzer, D.E. (1984) "Collectivism, community and commitment: America's religious communal utopias from the Shakers to Jonestown," in Alexander, P. and Gill, A. (eds.) Utopias. London: Gerald Duckworth \& Co. Ltd., Ch.11: 119-135

Plant, J. (ed.) (1989) Healing the wounds: The promise of ecofeminism. London: Green Print

Plener, D. (1992) “Kunst oder Kuriositaet," Die Presse. p.21 
Ploszajska, T. (1994) "Moral landscapes and manipulated space: Class, gender and space in Victorian reformatory schools," Journal of Historical Geography. 20(4): 413429

Popke, E.J. (2003) "Poststructuralist ethics: Subjectivity, responsibility and the space of community," Progress in Human Geography. 27(3): 298-316

Porter, P.W. and Lukermann, M. (1975) "The geography of utopia", in Lowenthal, D. and Bowden, M.J. (Eds.) Geographies of the Mind. Oxford: Oxford University Press

Porush, D. (1999) "From Talmud to Cyberspace: Transcendence at the interface," in Slusser, G., Allen, P., Gaillard, R. and Chatelain, D. (eds.) Transformations of utopia: Changing visions of the perfect society. NY: AMS Press, Inc.: 128-138

Powell, R.C. (2002) "The sirens' voices? Field practices and dialogue in geography," Area. $34(3):$ 261-272

Pratt, G. (1992) "Spatial metaphors and speaking positions," Environment and Planning D: Society and Space. 10: 241-244

Pratt, G. and Hanson, S. (1994) "Geography and the construction of difference," Gender, place and culture. 1: 5-29

Punch, S. (2002) "Interviewing strategies with young people: The 'Secret Box', stimulus material and task-based activities," Children and society. 16(1): 45-56

Rabkin, E. (1999) The utopian paradox: On the necessity of an impossible dream," in Slusser, G., Allen, P., Gaillard, R. and Chatelain, D. (eds.) Transformations of utopia: Changing visions of the perfect society. NY: AMS Press, Inc.: 305-315

Reed, J.D. (1985) “An old flasher's fantastical flats,” Time. 38: 60

Relph, E. (1976) Place and placelessness. London: Pion

Restany, P. (2001) The power of art: Hundertwasser, the painter-king with the five skins. Koeln: Taschen

Revill, G. (2004) "Performing French folk music: Dance, authenticity and nonrepresentational theory," Cultural Geographies. 11(2): 199-209

Robertson, I. and Richards (2003) Studying cultural landscapes. London: Arnold

Robinson, M. (1988) The American vision: Landscape painting of the United States.

London: Octopus 
Rollins, W.J. (1995) "Whose landscape - technology, fascism and environmentalism on the National Socialist Autobahn," Annals of the Association of American Geographers. 85(3): 494-520

Rose, G. (1993) Feminism and geography: The limits of geographical knowledge. Cambridge: Polity

Rose, G. (1997) "Performing inoperative community: The space and the resistance of some community arts projects," in Pile, S. and Keith, M. (eds.) Geographies of resistance. London: Routledge, Ch.9: 184-202

Ross, A. (2000) The Celebration chronicles. London: Verso

Rubin, H.J. and Rubin, I.S. (1995) Qualitative interviewing: The art of hearing data. London: SAGE

Rybcinski, W. (1987) Home: A short history of an idea. NY: Penguin Books

Sadler, S. (1998) The Situationist city. London: MIT Press

Sanchez-Janowski, M. (2002) "Representation, responsibility and reliability in participant-observation," in May, T. (ed.) Qualitative research in action. London: SAGE, Ch.6: 144-160

Sandercock, L. (1998) Towards cosmopolis. Chichester: John Wiley \& Sons Ltd Santner, I. (1984) “Sozusagen das achte Weltwunder," Die Weltwoche. 44(1): 63

Santner, I. (1991) "Friedensreich Hundertwasser architektelt gnadenlos weiter," source unkown*

Sargent, L.T. (1982) "Is there only one utopian tradition?" Journal of the History of Ideas. 43(4): 681-689

Sargent, L.T. (2004) "Living in utopia," paper presented to the $5^{\text {th }}$ International Conference of the Utopian Studies Society, 8-10 July, 2004

Sargisson, L. (1996) Contemporary feminist utopianism. London: Routledge

Sarup, M. (1993) An introductory guide to post-structuralism and postmodernism. Hemel Hempstead: Harvester Wheatsheaf

Sarup, M. (1996) Identity, culture and the postmodern world. Edinburgh: Edinburgh University Press 
Saunders, R.H. (2001) "Home and away: Bridging fieldwork and everyday life," The Geographical Review. 91(1-2): 88-94

Sayer, A. (1993) "Postmodernist thought in Geography: A realist view," Antipode. 25(4): 320-244

Sayer, A. (1993) “A reply to Clive Barnett," Antipode. 25(4): 369

Schamoni, P. (dir.) (1972) "Hundertwasser's rainy day," video recording. Screenplay: F. Hundertwasser and P. Schamoni

Schediwy, R. (1999) Hundertwassers Haeuser: Dokumente einer Kontroverse ueber zeitgemaesse Architektur. Wien: Edition Tusch

Schmied, W. (1997) "The mole - father of all architects. In Hundertwasser, F.

Hundertwasser architecture: For a more human architecture in harmony with nature.

Koeln: Taschen, 6-7

Schmied, W. and Fuerst, A. (2003) Hundertwasser complete works: Collector's edition. Koeln: Taschen

Schneider, S. (2001) "Vienna: A classic mix," accessed on website , on $09 / 10 / 203$

Schorske, C.E. (1998) Thinking with history: Explorations in the passage to modernism. Princeton: Princeton University Press

Seamon, D. (1993) "Dwelling, seeing and designing: An introduction," in Seamon, D. (ed.) Dwelling, seeing and designing: Toward a phenomenological ecology. Albany: SUNY Press, Ch.1: 1-21

Seigworth, G.J. (2000) "Banality for cultural studies," Cultural Studies. 14(2): 227-268

Sennett, R. (1978) The fall of public man. London: Faber \& Faber Limited

Sennett, R. (1996) Flesh and stone: The body and the city in Western civilization. NY: W.W. Norton \& Co.

Shand, J. (1984) "The Reichsautobahn: Symbol for the Third Reich," Journal of Contemporary History. 19(2): 189-200

Sharp, D. (1966) Modern architecture an Expressionism. London: Longmans, Green and Co Ltd

Sheail, J. (1975) "The concept of National Parks in Great Britain 1900-1950," Transactions of the Institute of British Geographers. 66: 41-56 
Shields, R. (1992a) "A truant proximity: Presence and absence in the space of modernity," Environment and Planning D: Society and Space. 10(2) 181-198

Shields, R. (1992b) Places on the Margin: Alternative Geographies of Modernity. London: Routledge.

Shoard, M. (1999) A right to roam. Oxford: OUP

Shookman, E. (1999) "Fantasies on the fringe: Romantic concepts of nationalism in utopias set at the edges of nineteenth-century Europe," in Slusser, G., Allen, P., Gaillard, R. and Chatelain, D. (eds.) Transformations of utopia: Changing visions of the perfect society. NY: AMS Press, Inc.: 39-51

Shurmer-Smith, P. (1994) "Cixous' spaces: Sensuous space in women's writing," Ecumene. 1(4): 349-362

Shurmer-Smith, P. (2000) "Helene Cixous," in Crang, M. and Thrift, N. (eds.) Thinking Space. London: Routledge, Ch. 7: 154-166

Shurmer-Smith, P., Hannem, K. (1994) Worlds of Desire, Realms of Power: A Cultural Geography. London: Edward Arnold.

Sibley, D. (1995) Geographies of exclusion: Society and difference in the West. London: Routledge

Sibley, D. (2000) "Placing anxieties," in Cook, I., Crouch, D., Naylor, S. and Ryan, J.R. (eds.) Cultural turns/geographical turns. Harlow: Pearson Education Limited: 359-369

Silk, J. (1999) "Guest editorial: The dynamics of community, place and identity," Environment and Planning A. 31(1): 5-17

Skeggs, B. (2002) "Techniques for telling the reflexive self," in May, T. (ed.) Qualitative research in action. London: SAGE, Ch.17: 349-374

Slater, D. (1997) "Spatialities of power and postmodern ethics - rethinking geopolitical encounters," Environment and Planning D: Society and Space. 15: 55-72

Slusser, G. (1999) "Souls on ice: Cryonics and the bodily utopia," in Slusser, G., Allen, P., Gaillard, R. and Chatelain, D. (eds.) Transformations of utopia: Changing visions of the perfect society. NY: AMS Press, Inc.: 139-151

Smith, D.M. (1988) "Towards an interpretative human geography," in Eyles, J. and Smith, D.M. (eds.) Qualitative methods in human geography. Cambridge: Polity Press, Ch. 14: 255-268 
Smith, D.M. (1997) "Back to the good life: Towards and enlarged conception of social justice," Environment and Planning D: Society and Space. 15(1): 19-35

Smith, D.M. (1999) "Geography, community, and morality," Environment and Planning A. 31(1): 19-35

Smith, F. and Barker, J. (2001) "Commodifying the countryside: The impact of out-ofschool-care on rural landscapes of children's play," Area. 33(2): 169-176

Smith, F.M. (1996) "Problematising language: Limitations and possibilities in "foreign language research," Area. 28(2): 106-166

Smith, N. (1996) The new urban frontier: Gentrification and the revanchist city. London: Routledge

Smith, R. (1999) "The death drive does not think," in McQuillan, M., MacDonald, G., Purves, R. and Thomson, S. (eds.) Post-theory: New directions in criticism. Edinburgh: Edinburgh University Press, Ch. 10: 161-175

Smith, R.G. (1997) "The end of geography and radical politics in Baudrillard's philosophy," Environment and Planning D: Society and Space. 15(3): 305-320

Soja, E. (1990) "Heteropologies: A remberance of other spaces in the Citadel-LA", Strategies. 3: 6-39.

Soja, E. (2000) Postmetropolis: Critical studies of cities and regions. Oxford: Blackwell Sorel, G. (1969[1908]) The illusions of progress. Berkeley: University of California Press

Sotriffer, K. (1985) “Aus dem Buch des Gartenzwergs,” Die Presse. 12/08/1985: 4

Spradley, J.P. (1980) Participant observation. London: Holt, Rinehart \& Winston, Inc.

Staehli, L.A. and Lawson, V.A. (1994) "A discussion of "Women in the Field": The politics of feminist fieldwork," Professional Geographer. 46(1): 96-102

Stallybrass, P. and White, A. (1986) The politics and poetics of transgression. London: Methuen

Steiner, R. (1909) The education of the child in the light of anthroposophy. Accessed at , 12/06/2003

Steiner, R. (1919) An introduction to Waldorf education. Accessed at , 12/06/2003 
Stewart, L. (1995) "Bodies, visions, and spatial practices: A review essay on Henri Lefeabvre's The production of space," Environment and Planning D: Society and Space. 13: 609-618

Streitz, N.A. Konomi, S. and Burkhardt, M.-J. (eds.) (1998) Cooperative buildings: Integrating information, organization, and architecture. Berlin: Springer-Verlag

Szerszynski, B., Heim, W. and Waterton, C. (eds.) (2003) Nature performed: Environment, culture and performance Oxford: Blackwell

Taylor, P. (1999a) "Places, spaces and Macy's: Place-space tensions in the political geography of modernities," Progress in Human Geography. 23(1): 7-26

Taylor, P. (1999b) Modernities: A geohistorical interpretation. Cambridge: Polity Press

Thomas, K. (2001) "Lines in practice: Thinking architectural representation through feminist critiques of geometry," Geography research forum. 21:57-76

ThomsDon. D. (2000) "Friedensreich Hundertwasser," accessed at $.08 / 2004$

Thrift, N. (1997) "The still point: Resistance, expressive embodiment and dance," in Pile, S. and Keith, M. (eds.) Geographies of resistance. London: Routledge, Ch.6: 124 151

Thrift, N. (1999) "The place of complexity," Theory. Culture and Society. 16(3): 31-70

Thrift, N. (2000a) "Afterwords," Environment and Planning D: Society and Space. 18: 213-255

Thrift, N. (2000b) "Entanglements of power: Shadows?" in Sharp, J.P., Routledge, P., Philo, C. and Paddison, R. (eds.) Entanglements of power: Geographies of domination/resistance. Routledge: London: 261-278

Thrift, N. (2000c) "With child to see anything strange: Everyday life in the city," in Bridge, G. and Watson, S. (eds.) A companion to the city. Oxford: Blackwell, Ch.34: 398-409

Thrift, N. and Dewsbury, J.-D. (2000) "Dead geographies - and how to make them live," Environment and Planning D: Society and Space. 18(4): $411-432$

Till, K. (1993) "Neotraditional towns and urban villages: The cultural production of a geography of 'otherness'," Environment and Planning D: Society and Space. 11(6): 709732 
Till, K.E. (2001) "Returning home and to the field," The Geographical Review. 91(1-2): 46-56

Tschumi, B. (1994) Architecture and disjunction. Cambridge, Massachusetts: The MIT Press

Tuan, Y.-F. (1974) Topophilia: A study of environmental perception, attitudes and values. London: Prentice Hall

Turnbull, D. (2002) "Performance and narrative, bodies and movement in the construction of places and objects, spaces and knowledges: The case of the Maltese Megaliths," Theory, Culture and Society. 19(5/6): 125-143

Turner, C. (2003) "Mannheim's utopia today", History of the Human Sciences. 16(1): 27-47

Urry, J. (1990) The tourist gaze: London: SAGE

Valentine, G. (1989) “The geography of women's fear," Area. 21(4): 385-390

Valentine, G. (1997) "Tell me about...: Using interviews as a research methodology,"," in Flowerdew, R. and Martin, D. (eds.) Methods in human geography: A guide for students doing a research project. Harlow: Pearson Education Limited, Ch. 7: 110-126

Valentine, G. (1999) "Doing household research: Interviewing couples together and apart," Area. 31(1): 67-74

Valentine, G. (2001) Social geographies: Space and society. Harlow: Pearson Education

Valentine, G. and McKendrick, J. (1997) “Children's outdoor play: Exploring parental concerns about children's safety and the changing nature of childhood," Geoforum. 28(2): 219-235

Vandenberghe, F. (2002) "Reconstructing humants: A humanist critique of actornetwork theory," Theory, Culture and Society. 19(5/6): 51-67

Venturi, R., Scott Brown, D. and Izenour, S. (1972) Learning from Las Vegas: The forgotten symbolism of architectural form. London: The MIT Press

Verstraeten, G. (2002) "Railroading America. Towards a material study of the nation," Theory, Culture and Society. 19(5/6): 145-159

Vidler, A. (1992) The architectural uncanny: Essays in the modern unhomely.

Cambridge, Massachusetts: The MIT Press 
Waksler, F.C. (1986) "Studying children: Phenomenological insights," Human Studies. 9: 71-82

Walker, R. (1995) "Landscape and city life: Four ecologies of residence in the San Francisco Bay Area," Ecumene. 2(1): 33-64

Walkerdine, V., Lucey, H. and Melody, J. (2002) "Subjectivity and qualitative method," in May, T. (ed.) Qualitative research in action. London: SAGE, Ch. 8: 179-196

Walkowitz, J.R. (1992) City of dreadful delight: Narrative of sexual danger in LateVictorian London. London: Virago

Walther, S.D. (1981) The railroad in the American landscape 1850-1950. Wellesley: Wellesley College

Ward, C. (1974) Utopia. Harmandsworth: Penguin.

Ward, C. (1995) "Walter Segal: Community architect," in Cates, C., How, J., Jones, L., Morris W. and Wood, A. (eds.) Diggers and Dreamers. Wislow: Diggers and Dreamers Publications: $90-97$

Wates, N. and Knevitt, C. (1987) Community architecture: How people are creating their own environment. London: Penguin

Whatmore, S. (1998) "Editorial: Nature's revenge? Rethinking rural environments," Environment and Planning A. 30: 1149.1150

Wigley, M. (2001) "The great urbanism game," Architectural design. 71(3): 8-11

Williams, R. (1973) The country and the city. London: Chatto \& Windus

Wilson, F. (1979) The joy of building: Restoring the connection between architect and builder. NY Van Nostrand Rheinhold Company

Wilson, E. (1995) "The invisible flâneur," New Left Review. 191: 90-1 10

Wines, J. (2000) Green architecture. Taschen: Koeln

Wisneki, C., Ishii, H., Dahley, A., Gorbet, M., Brave, S., Ullmer, B. and Yarin, P. (1998) "Ambient designs: Turning architectural space into an interface between people and digital information," in Streitz, N.A. Konomi, S. and Burkhardt, M.-J. (eds.)

Cooperative buildings: Integrating information, organization, and architecture. Berlin: Springer-Verlag, 22-32

Wood, D. (1988) "Différance and the problem of strategy," in Wood, D. and Bernasconi, R. (eds.) Derrida and difference. Evanston, IL: Northwestern University Press, 63-70 
Woods, L. (1993) War and architecture. Trans. A. Wagner. Pamphlet Architecture 15, NY: Princeton Architectural Press

Woodward, C. (2002) In ruins. London: Vintage

Woolgar, S. (2002) "After word? - On some dynamics of duality interrogation: Or: Why bonfires are not enough," Theory, Culture and Society. 19(5/6): 261-270

Worpole, K. (2000) Here comes the sun: Architecture and public space in TwentiethCentury European culture. London: Reaktion Books

Wright, P. (1985) On living in an old country. London: Verso

Wylie, J. (2002) "An essay on ascending Glastonbury Tor," Geoforum. 33(4): 441-454

Yacobi, H. (2002) "The architecture of ethnic logic: Exploring the meaning of the built environment in the 'mixed' city of Lod - Israel," Geografiska Annaler Series B. 84(3-4): $171-187$

Young, I.M. (1990) "The ideal of community and the politics of difference," in

Nicholson, L.J. (ed.) Feminism/postmodernism. London: Routledge, Ch.12: 300-323

Zamiatin, E.I. (1993) We. NY: Penguin 